\title{
THE SALT NORM: A Quantitative Chemical-Mineralogical Characterization of Natural Waters
}

\author{
M.W. Bodine, Jr. and Blair F. Jones
}


UNITED STATES DEPARTMENT OF THE INTERIOR

DONALD P. HODEL, Secretary

GEOLOGICAL SURVEY

Dallas L. Peck, Director

For additional information write to:

Project Chief

U.S. Geological Survey

MS 432, National Center

Reston, Virginia 22092
Copies of this report can be purchased from:

Open-File Services Section

Distribution Branch

U.S. Geologica1 Survey

Box 25425, Federal Center

Denver, Colorado 80225 


\section{CONTENTS}

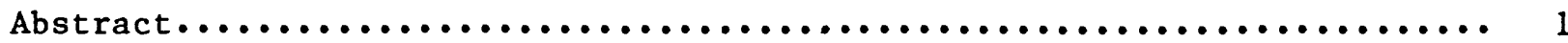

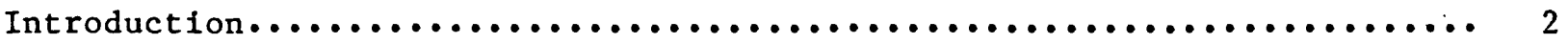

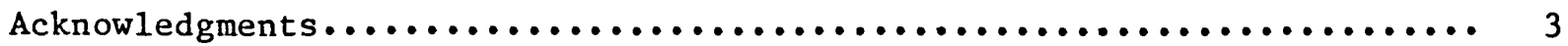

The SNORM Program......................................... 3

Solutes............................................. 4

Carbonate-Bicarbonate Modifications........................ 6

Carbonate fraction in analyzed (bi) carbonate alkalinity ......... 6

Carbonate-bicarbonate assignment to normative salts........... 8

Boron Modifications................................... 9

Cation-Anion Charge Balance................................ 9

Normative Salts...................................... 11

0ccurrence as Salt Minerals............................. 11

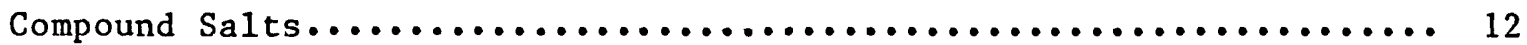

Salt Stability Criteria................................ 13

Salt Composition Modifications............................ 19

Normative Salt Assemblages................................. 20

Eligible Salts........................................ 20

Number of Salts in the Assemblage.......................... 22

Prohibited Salt Associations.............................. 23

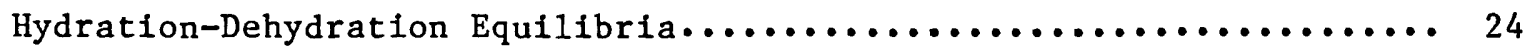

Simple Salt Assemblages.................................... 25

Interpretation of Salt Norms............................... 27

Meteoric Norms........................................ 38

Marine Norms............................................ 39

Diagenetic Norms....................................... 45

Summary.............................................. 47

References............................................. 48

Appendix I: Source Codes.................................. 53

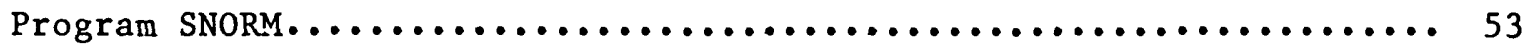

Subroutine PREP.................................. 58

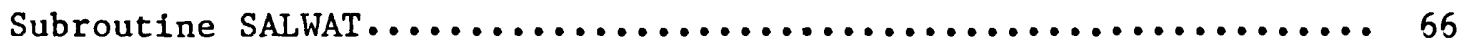

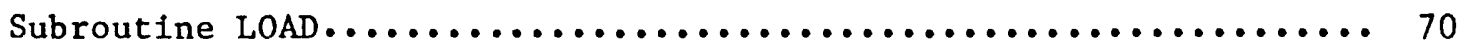

Subroutine JOIN.................................. 75

Subroutine PICK.................................... 81

Subroutines ARRAY, CONVT, and DGELG................... 83

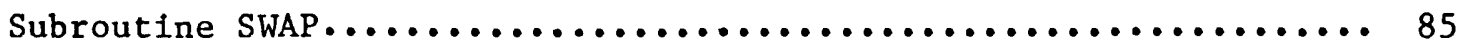

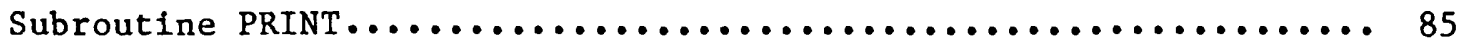

NEODAT (data file of constants for SNORM) $\ldots \ldots \ldots \ldots \ldots \ldots \ldots \ldots \ldots \ldots$

Appendix II: Structure of SNORM............................. 98 
Appendix III: User Procedures and Options........................ 106

Designating and creating input file........................ 106

Designating output devices.............................. 108

Designating character of output........................... 109

Designating solute modifications...........................11

Appendix IV: Examples of SNORM Output..................... In pocket

Standard format................................ In pocket

Short line-length format............................ In pocket Appendix V: Phase Relations among Normative Salts.................. 112

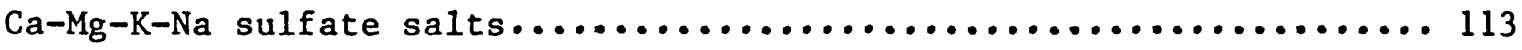

$\mathrm{Ca}-\mathrm{Mg}-\mathrm{Na}$ borate salts.................................. 121

$\mathrm{Ca}-\mathrm{Mg}-\mathrm{Na}$ phosphate and fluoride salts..................... 127

Equilibria involving three anions........................ 129

FIGURES

Dlagrams showing:

1. Calculated stability relations among $\mathrm{Na}_{2} \mathrm{CO}_{3}-\mathrm{NaHCO}_{3}-\mathrm{H}_{2} \mathrm{O}$ salts $\ldots . .16$

2. Hydroxyapatite-whitlockite stability relations.............. 18

3. Relative proportions of calcium, carbonate species, and sulfate in natural waters and character of preclpitated salts.......... 29

4. Diagnostic chart for normative salts.................. 37

$\mathrm{V}-1$. Calculated phase relations in the $\mathrm{CaCO}_{3}-\mathrm{MgCO}_{3}-\mathrm{Na}_{2}\left(2 \mathrm{HCO}_{3}, \mathrm{CO}_{3}\right)-\mathrm{H}_{2} \mathrm{O}$

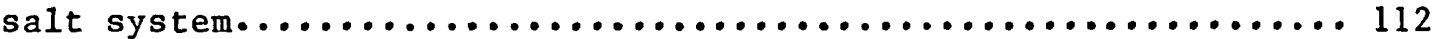

$\mathrm{V}-2$. Calculated phase relations in the $\mathrm{CaSO}_{4}-\mathrm{MgSO}_{4}-\mathrm{K}_{2} \mathrm{SO}_{4}-\mathrm{Na}_{2} \mathrm{SO}_{4}-\mathrm{H}_{2} \mathrm{O}$ salt system within the 0.726-0.665 water activity interval...... 118

$\mathrm{V}-3$. Calculated phase relations in the $\mathrm{CaSO}_{4}-\mathrm{MgSO}_{4}-\mathrm{K}_{2} \mathrm{SO}_{4}-\mathrm{Na}_{2} \mathrm{SO}_{4}-\mathrm{H}_{2} \mathrm{O}$ salt system within the 0845-0.811 water activity interval....... 119

$\mathrm{V}-4$. Calculated phase relations among (b1)carbonate and sulfate nor-

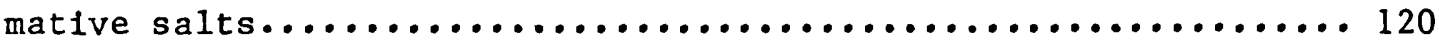

$\mathrm{V}-5$. Calculated relations among (bi)carbonate and sulfate simple-salt components of normative salts.......................... 121

V-6. Calculated phase relations in the $\mathrm{CaCl}_{2}-\mathrm{MgCl}_{2}-\mathrm{K}_{2} \mathrm{Cl}_{2}-\mathrm{Na}_{2} \mathrm{Cl}_{2}-\mathrm{H}_{2} \mathrm{O}$ salt system..................................... 122

$\mathrm{V}-7$. Calculated phase relations in the $\mathrm{Ca}-\mathrm{Mg}-\mathrm{Cl}_{2}-\mathrm{CO}_{3}-\mathrm{H}_{2} \mathrm{O}$ salt system.. 122

V-8. Calculated phase relations among sulfate and chloride salts..... 123

V-9. Calculated relations of chloride with (bi)carbonate and sulfate

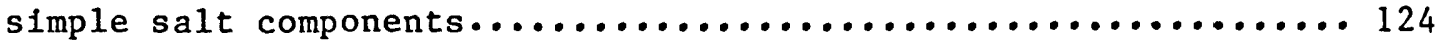

$\mathrm{V}-10$. Calculated phase relations in the $\mathrm{Ca}-\mathrm{Mg}-\mathrm{K}-\mathrm{Cl}-\mathrm{NO}_{3}-\mathrm{H}_{2} \mathrm{O}$ salt system. 125

V-11. Calculated relations of nitrate among (bi)carbonate, sulfate, and chloride simple salt components..................... 126 
$\mathrm{V}-12$. Suggested phase relations in the $\mathrm{Ca}-\mathrm{Mg}-\mathrm{PO}_{4}-\mathrm{F}-\mathrm{H}_{2} \mathrm{O}$ salt system.... 127

V-13. Calculated phase relations among $\mathrm{Ca}-\mathrm{Mg}$ fluoride salts and coexisting carbonate, sulfate, and chloride salts........... 128

\section{TABLES}

1. Solutes in water analyses that SNORM recasts into the normative salt assemblage.................................... 4

2. Abbreviations of normative salts in SNORM and their chemical formulae..........................................

3. Normative borate salts, their chemical formula with anion charge per formula unit and per boron; and their modified chemical formula with anion anton charge per formula unit and per boron that ylelds 1dentical borate charge per boron for each............. 10

4. Standard chemical potential values and sources............... 14

5. Salts excluded from assemblages in SNORM as a function of charge ratios of selected cation and anion groups of solutes..... 21

6. Prohibited associations in normative salt assemblages....... In pocket

7. Water activities $\left(\mathrm{a}_{\mathrm{H}_{2} \mathrm{O}}\right)$ and indicator salts for hydration-

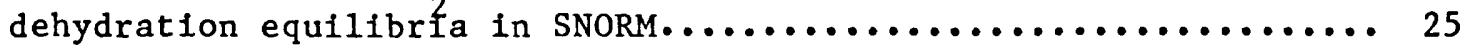

8. Major solute concentrations and major-ion normative salts for mean compositions of seawater and world river waters........... 30

9. Salt norms of representative water samples................ 32

10. Salinity, major anfon concentration, and salt norms for hypersaline marine liquors from surface evaporation ponds.......... 41

11. Salt norms for selected analyses of groundwaters from the salt lake areas of the Yilgarn Block, Western Australia........... 42

12. Salt norms for representative brines from sabkhas south of the Bardawil Lagoon, north Sinai......................... 46

II-1. Subprograms in SNORM and their major operational features....... 99

II-2. Solutes and salt components in SNORM data file (NEODAT)........ 103

II-3. Salts in SNORM data file (NEODAT) and their chemical formulae.... 104

II-4. "Base salts" excluded from trial "base salt assemblages" in SNORM as a function of charge ratios of selected cation and

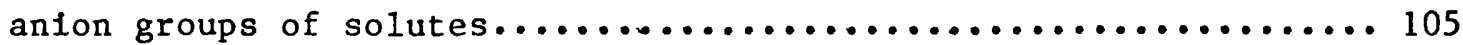

II-5. Prohibited "base salt" assoclations in SNORM's base-salt

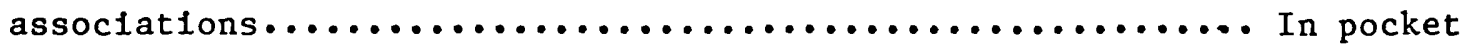

III-1. Default concentration units in SNORM output................ 110

$\mathrm{V}-1$. Calculated water activities for equilibria in the $\mathrm{CaSO}_{4}-\mathrm{MgSO}_{4}-$

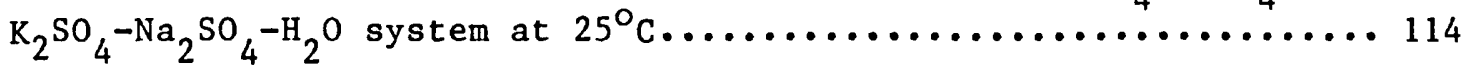

$\mathrm{V}-2$. Stable four-salt sulfate and coexisting chloride salt assem-

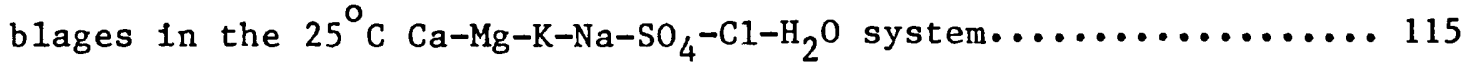




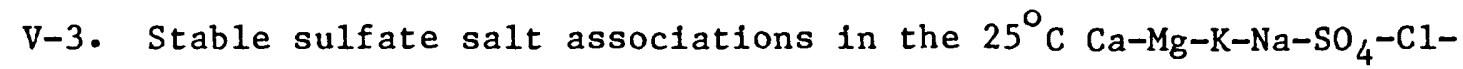
$\mathrm{H}_{2} \mathrm{O}$ system in assemblages with two or more chloride salts....... 116

$\mathrm{V}-4$. Stable four-salt sulfate assemblages in the $\mathrm{CaSO}_{4}-\mathrm{MgSO}_{4}-\mathrm{K}_{2} \mathrm{SO}_{4}-$

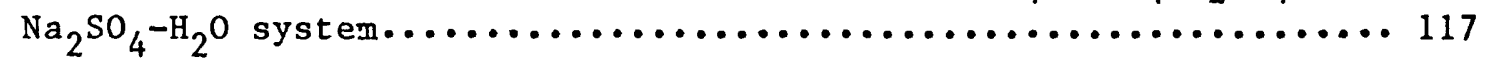

$\mathrm{V}-5$. Prohibited salt associations involving three or more anions and their permissable isochemical equivalents................... 129 


\section{ABSTRACT}

The new computer program SNORM calculates the salt norm from the chemical composition of a natural water. The salt norm is the quantitative ideal equilibrium assemblage that would crystallize if the water evaporated to dryness at $25^{\circ} \mathrm{C}$ and 1 bar pressure under atmospheric partial pressure of $\mathrm{CO}_{2}$. SNORM proportions solute concentrations to achieve charge balance. It quantitatively distributes the 18 acceptable solutes into normative salts that are assigned from 63 possible normative salts to allow only stable associations based on the Gibbs Phase Rule, available free energy values, and observed low-temperature mineral associations.

Although most natural water compositions represent multiple solute origins, results from SNORM identify three major categories: meteoric or weathering waters that are characterized by normative alkali-bearing sulfate and carbonate salts; connate marine-like waters that are chloride-rich with a halite-bischofite-carnallite-kieserite-anhydrite association; and diagenetic waters that are frequently of marine origin but yield normative salts, such as Ca-bearing chlorides (antarcticite and tachyhydrite) and sylvite, which suggest solute alteration by secondary mineral reactions. The solute source or reaction process within each of the above categories is commonly indicated by the presence or absence of diagnostic normative salts and their relative abundance in the normative salt assemblage. For example, salt norms (1) may identify lithologic source; (2) may identify the relative roles of carbonic and sulfuric acid hydrolysis in the evolution of weathering waters; (3) may identify the origin of connate waters from normal marine, hypersaline, or evaporite salt resolution processes; and (4) may distinguish between dolomitization and silicate hydrolysis or exchange for the origin of diagenetic waters. 


\section{INTRODUCTION}

Chemical composition plays a central role in the classification of natural waters and interpretation of their source and evolution. In this paper we offer a quantitative chemical-mineralogical method of characterizing natural waters that desribes the solutes as an idealized $25^{\circ} \mathrm{C}$ equilibrium assemblage of mineral salts. We suggest that characterization of a water's composition as an assemblage of salts leads to a more detalled chemical classification of natural waters and hopefully provides indications of solute source and subsequent interactions.

Dissolved constituents in natural waters expressed as salt abundances are not new. In the nineteenth century, it was a common practice to report water compositions in terms of abundances of simple salts. As Hem (1970) points out, this practice predated the acceptence of the Arrhenius concept of dissociated ions, and, although it attempted to express water composition in terms of the salts produced upon evaporation, it was actually more closely related to the classical gravimetric analytical procedures than to the natural occurrence of mineral salts. Such schemes relled chiefly on forming simple salts with little regard to salt association. It is not surprising then that this form of expressing water compositions diminished in the twentieth century with only occasional use in the more recent literature (see, for example, Rankama and Sahama, 1950, p. 318; Lambert, 1978).

Comparison and study of both marine and non-marine evaporite deposits have demonstrated some striking differences in the associated salt mineral assemblage (Stewart, 1963; Brattsch, 1971; Jones, 1970; Eugster, 1980; Sonnenfeld, 1984), that commonly are indicative of both lithologic origin and subsequent geochemical evolution of the dissolved constituents (Hardie and Eugster, 1970; Eugster and Hardie, 1978; Eugster and Jones, 1979; Eugster and others, 1980). Thus, it might be informative to attempt reconstruction of the solute content of a natural water into the equilibrium salt assemblage expected were the solution evaporated to dryness under earth surface conditions.

This salt assemblage is analagous to the CIPW norm (Cross and others, 1902), which is an idealized equilibrium assemblage of igneous minerals calculated from the rock's chemical composition. The CIPW norm has proven useful in igneous petrology for characterizing and classifying igneous rocks and providing quantitative data for interpretation of the origin and evolution of an igneous complex. We suggest a parallel application of the idealized equilibrium salt assemblage--the salt norm, which is calculated from a water's chemical composition. Indeed, its simflar construction and association permits the general classification of natural solutions based on saline 
mineral assemblages. Such classifications are more detailed and suggestive of solute origin and subsequent interaction than major cation-anion predominance currently, the most commonly used system of hydrochemical classification.

Transformation of a standard water analysis into the normative salt assemblage is performed by the new computer program SNORM. Preliminary results from SNORM for a wide variety of water compositions suggest that, for example, a few key normative salts are diagnostic of source, such as meteoric as opposed to connate marine waters, and the relative abundance of selected normative salts is indicative of the character of water-rock interaction in subsurface environments, such as silicate hydrolysis in a crystalline host as opposed to dolomitization in a carbonate matrix. Examples of salt norms and their interpretation will be presented and discussed following a description of SNORM.

\section{Acknowledgments}

We wish to thank our many colleagues for help and encouragement to the work, particularly B. A. Kimball, S. L. Rettig, R. J. Spencer, W. D. Grundy, G. Van Trump and S. E. Schneider. We are especially grateful for the continuing inspiration of $\mathrm{H}$. P. Eugster in pursuing all aspects of mineralfluid interaction.

\section{THE SNORM PROGRAM}

SNORM is a computer program written specifically to compute the normative salt assemblage from the solute concentration data in a conventional water analysis. Although the salt norm can be visualized as the solid residuum that coexists with the small, last vestige of solution upon evaporation at $25^{\circ} \mathrm{C}$, the normative assemblage is computed directly from solute concentrations without proceeding along an evaporation path with its myriad succession of brine-solid interactions. Neither brine evolution nor character of the vestigial brine are considered; SNORM only distributes the solutes into the appropriate liquid-free salt assemblage. The program transforms 18 solutes (table 1) into a normative salt assemblage from a listing of 63 possible salts (table 2).

The program is written in FORTRAN IV (Appendix I). The structure of SNORM and a description of the computational procedures are given in Appendix II, user procedures and options in Appendix III, and sample print-outs in Appendix IV. SNORM performs three major tasks: (1) it reads solute concentration values from a conventional water analysis into the program, recasts these values into other appropriate concentration units, and adjusts the solute concentrations to yield cation-anion charge balance; (2) it determines the equilibrium normative salt assemblage based on the principles 
Table 1. Solutes in water analyses that SNORM recasts into the normative salt assemblage

CATIONS

ANIONS

Major

$\begin{array}{llll}\mathrm{Mg}^{2+} & \mathrm{Na}^{+} & \mathrm{Cl}^{-} & \mathrm{HCO}_{3}^{-} \\ \mathrm{Ca}^{2+} & \mathrm{K}^{+} & \mathrm{SO}_{4}^{2-} & \mathrm{CO}_{3}^{2-}\end{array}$

Minor

$\begin{array}{llll}\mathrm{Li}^{+} & \mathrm{Sr}^{2+} & \mathrm{F}^{-} & \mathrm{NO}_{3}^{-} \\ \mathrm{NH}_{4}^{+} & \mathrm{Ba}^{2+} & \mathrm{Br}^{-} & \mathrm{B}^{*} \\ & & \mathrm{I}^{-} & \mathrm{PO}_{4}^{3-}\end{array}$

* Boron assigned as borate with a charge of $-7 / 12$ $(-0.583)$ per boron or the charge per boron that is appropriate for the borate stoichiometry of the normative salt in the assemblage.

of phase equilibria, and assigns quantitatively all solutes into the salts of the assemblage; and (3) quantitatively recasts the major-solute normative salts into their respective single cation-single anion simple salts for graphic-classification purposes.

Our approach to accomplish the transition from the first task to the second requires exact cation-anion charge balance among the solutes for distribution into the electrically neutral normative salt assemblage. If an unbalanced population of cation and anion charges were to be distributed, excess charge would remain unassigned or salt compositions would have to be adjusted to form charged salts to compensate for the charge imbalance among the solutes. Both alternatives are undesirable; the former would require deleting the excess residue, and the latter would require each normative salt to contain excess cation or anion to compensate for the charge imbalance among the solutes.

\section{Solutes}

The solutes (table 1) that SNORM distributes into normative salts (table 2) were selected to comply with two criteria: (1) The solute, at least occasionally, occurs in natural waters in more than negligible (trace) concentrations; and (2) the solute forms its normative salt(s) through direct 


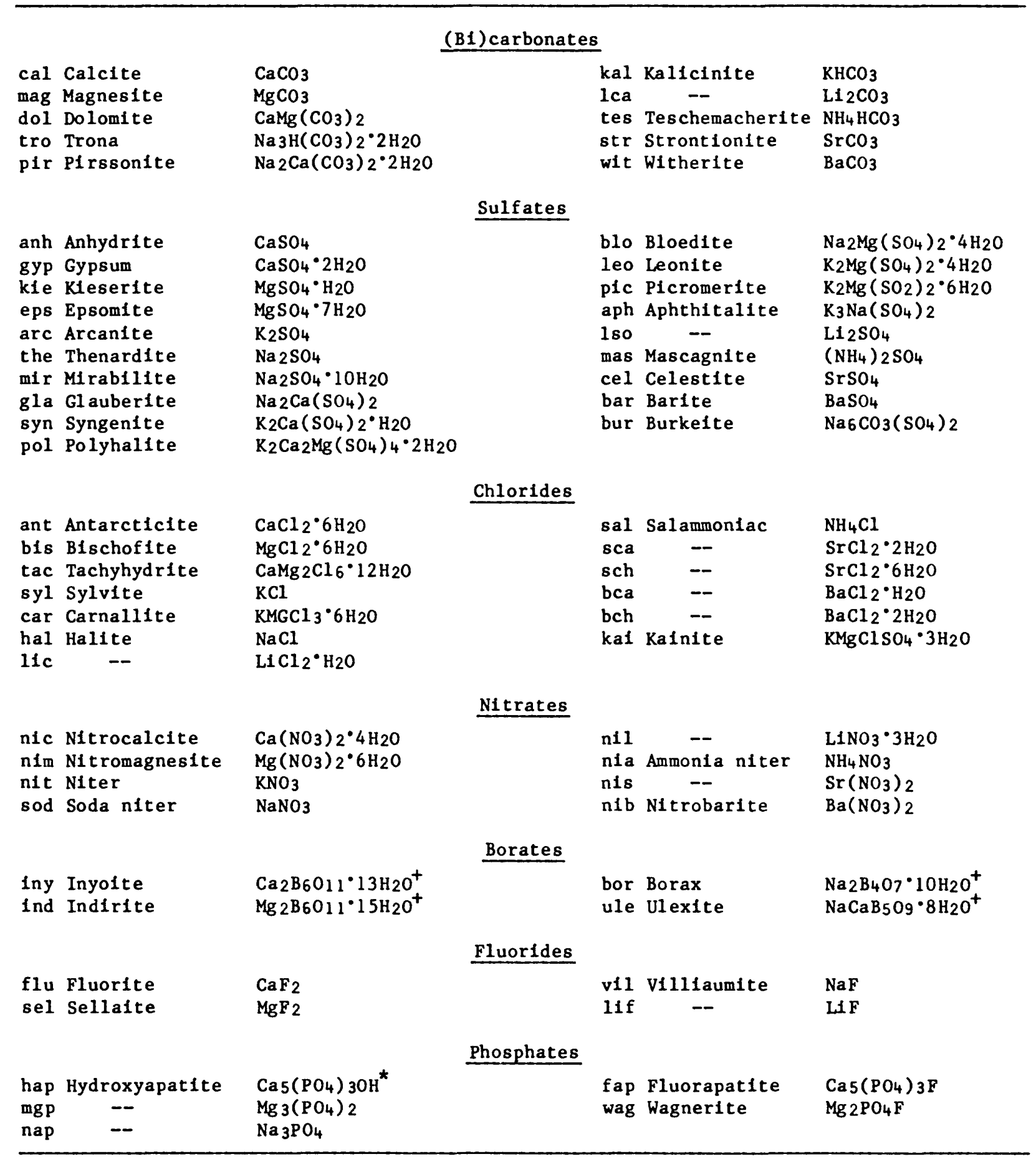

\footnotetext{
* Normative hydroxyapatite calculated as ${ }^{\circ} \mathrm{Ca}_{4} .75\left(\mathrm{PO}_{4}\right)_{3.17}$.

${ }^{+}$If calculated with average borate charge of $-7 / 12$ per boron; mineral compositions

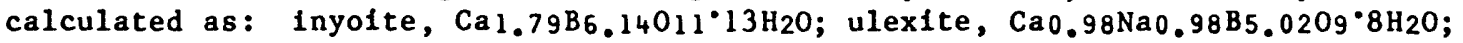
indirite, $\mathrm{Mg} 1.79 \mathrm{~B}_{6} .14 \mathrm{O}_{1} 1^{\circ} 15 \mathrm{H}_{2} \mathrm{O}$, and borax, $\mathrm{Na}_{2} .28 \mathrm{~B}_{3} .9107^{\circ} 1 \mathrm{OH}_{2} \mathrm{O}$.
} 
combination with other solutes in the sample without interacting with the aqueous environment or requiring any chemical or charge modification. This latter criterion was adopted to exclude solutes that require interaction with water (hydrolysis, a $\mathrm{pH}$ effect; or $\mathrm{H}_{2} \mathrm{O}$ dissociation, a redox effect), or a chemical and charge modification, because the character of the solute in the analysis differs form its character in the resultant solid phase. Thus, nelther $\mathrm{pH}$ nor redox conditions enter directly into SNORM computations and cation-anion charge balance of the adjusted solute concentrations is preserved in the normative salt assemblage.

Fortunately, the solutes that were rejected from the normative calculation on the basis of the second criterion characteristically occur in no more than trace amounts. Uncommon exceptions are dissolved silica and alumina; iron, manganese, certain base metals, and transition elements; and reduced carbon and sulfur species. In waters where these constituents are present in significant amounts, the application of the normative calculation may be inappropriate.

Of the solutes that are distributed into normative salts (table 1) boron and the bicarbonate-carbonate pair, hereinafter referred to collectively as (bi)carbonate, are too widely distributed in natural waters to be excluded although they do not conform fully to the second criterion. Bicarbonate and carbonate are important constituents in most waters, and in most surficial or dilute waters and alkaline-saline lake waters they are the dominant anions. Boron, although not as abundant as (bi)carbonate, is a significant minor solute in many waters and reaches substantial concentrations in some continental evaporite waters. Assignment of (bi)carbonate to normative salts, however, requires additional manipulation of their concentrations to form the normative assemblage, and modification of normative borate salt compositions is sometimes required to maintain solute charge balance.

Carbonate-Bicarbonate Modifications

The concentrations of (bi)carbonate may require one or two modifications for assignment to normative salts. The first, if necessary, determines the fraction of carbonate in the total carbonate-bicarbonate concentration if total (bi)carbonate is expressed as bicarbonate. The second modification allows partitioning between carbonate and bicarbonate for assignmemt into the designated normative (bi)carbonate salts.

\section{Carbonate fraction in total analyzed (bi)carbonate alkalinity}

The first modification, is determined prior to adjusting solute concentrations to achieve cation-anion charge balance, and is made only if $\mathrm{pH}$ of the sample is recorded and total dissolved inorganic carbon (DIC) 
concentration is reported as bicarbonate, that is, no value for carbonate concentration is given. Under these circumstances the mole fraction of carbonate in the total analyzed DIC can be calculated. If, on the other hand, sample $\mathrm{pH}$ is not given, or carbonate concentration is reported, this calculation is omitted.

The carbonate-bicarbonate concentration ratio is calculated from the carbonate-bicarbonate equation,

$$
\mathrm{HCO}_{3(\mathrm{aq})}^{-}=\mathrm{CO}_{3(\mathrm{aq})}^{2-}+\mathrm{H}^{+}(\mathrm{aq})
$$

that defines the $25^{\circ} \mathrm{C}$ equilibrium

$$
\mathrm{K}_{\mathrm{eq}}=\frac{\left(\mathrm{a}_{\left.\mathrm{CO}_{3}^{2-}\right)\left(\mathrm{a}_{\mathrm{H}}{ }^{+}\right)}\right.}{\left(\mathrm{a}_{\left.\mathrm{HCO}_{3}^{-}\right)}\right.}=10^{-10.329}
$$

in which a is the individual ion activity for each of the designated solutes and $K_{e q}$ is the equilibrium constant that has been assigned the value from Plummer and others (1976).

After activities are written in terms of molality, $\mathrm{m}_{1}$,

$$
a_{i}=\gamma_{1} m_{i}
$$

with $\gamma_{1}$ designating the individual ion activity coefficient of the ith ion, molalities are substituted for activities into equation (1), which is rearranged to

$$
\frac{\mathrm{m}_{\mathrm{CO}_{3}^{2-}}}{m_{\mathrm{HCO}_{3}^{-}}}=\frac{\left(\gamma_{\mathrm{HCO}_{3}^{-}}\right)^{\mathrm{K}} \mathrm{eq}}{\left(\gamma_{\left.\mathrm{CO}_{3}^{2-}\right)\left(\mathrm{a}_{\mathrm{H}}+\right)}\right.}
$$

and defines the carbonate-bicarbonate concentration ratio.

The term that remains to be evaluated before equation (2) can be solved is the ratio of ion activity coefficients, $\gamma_{\mathrm{HCO}_{3}^{-1}} \mathrm{CO}_{3}^{2-}$. Each coefficient is calculated following procedures in WATEQ using the Debye-Hückel expression (Truesdell and Jones, 1974; Plummer and others, 1976). Use as a ratio of 
activity coefficients in equation (2) tends to cancel out systematic error in each of the individual values. The significance of error in these coefficients at high ionic strengths (alkaline-earth chloride-rich waters with very low (bi)carbonate concentrations) is further reduced and becomes negligible.

One source of error in solving equation (2) that may occasionally arise is if the analytical data are expressed in "per liter" units and water density is not reported. Molarity (moles per liter) is not equivalent to molality (moles per kflogram water), and the latter units cannot be directly calculated from the former without a density determination. Yet, definition of the ionic strength in the Debye-Huckel expression requires molalities. For such cases in which only molarities are known, we use a highly generalized empirical conversion,

$$
m_{1}=M_{i}\left(1+0.022 \sum e_{\text {cation }}\right)
$$

In which $m_{1}$ is the molality, $M_{i}$ is the molarity, and $\sum \mathrm{eq}_{\text {cation }}$ is the sum of the cation equivalents per liter in the analysis.

The result from equation (2), the carbonate-bicarbonate concentration ratio, is converted to the mole fraction of carbonate in the analyzed DIC. If the carbonate mole fraction exceeds 0.001 , the fraction is used to calculate the carbonate and bicarbonate concentrations from the analytical bicarbonate value for use in further SNORM computations. Alternatively, if the carbonate mole fraction is less than 0.001 , the entire calculation is abandoned, and the original analytical value of (bi)carbonate (DIC) is retained as bicarbonate concentration; the low carbonate mole fraction is considered insignificant and below the level of analytical error for the DIC determination.

\section{Carbonate-bicarbonate assignment to normative salts}

The reversible transition between adjusted carbonate and bicarbonate concentrations is required without effecting charge neutrality of the system. We have adopted the relationship

$$
2 \mathrm{HCO}_{3}^{-} \text {(aq) }=\mathrm{CO}_{3}^{2-}(\mathrm{aq})+\mathrm{H}_{2} \mathrm{O} \text { (1iq) }+\mathrm{CO}_{2} \text { (gas) }
$$

that permits assignment of (bi)carbonate species into any (bi)carbonate salt(s) in the normative assemblage, yet conserves the total (b1)carbonate charge (only production or consumption of neutral carbon dioxide and water accompanies the transformation). 


\section{Boron Modifications}

Boron assignment into normative salts presents a second problem. Boron is expressed as elemental boron in conventional water analyses but occurs as the borate radical in boron-bearing normative salts. Furthermore, each normative borate salt has one of three different boron-oxygen ratios in its respective borate radical with each exhibiting a different borate charge per boron (table 3 ). Thus, not only must boron in the analysis be recast as negatively charged borate to permit calculating a comprehensive cation-anion charge balance, but borate charge per boron for the recast solute is dependent on which borate salt(s) occur in the normative assemblage.

The stoichiometries of the four borate salts can be modified as shown in table 3, so that each contains a hypothetical borate radical of intermediate composition with a common charge per boron $(-0.583)$. This permits recasting boron in the analysis to borate with the same charge per boron as in the modified borate salts. After adjusting solute concentrations to yleld cationanion charge balance, the boron can be assigned as borate to any of the modified borate salt stoichiometries. This produces a normative salt assemblage that adheres to the adjusted solute concentrations but contains borate salt(s) with slightly altered but balanced stolchiometry.

A norm that contains only a single borate salt (or the indirite-inyoite pair with identical borate stoichiometries) is recalculated with correct borate stolchiometry for the borate salt. Boron is again recast as a borate, but with the charge per boron mandated by the salt's correct stoichiometry. After readjusting solute concentrations to yield charge balance, the norm is recomputed with the normative borate salt reassigned to its correct stoichiometry. If, on the other hand, the norm does contain two or more borate salts (other than the indirite-inyoite pair), the initially computed norm is retained and the use of modified borate salt compositions (table 3 ) is specified in the output.

\section{Cation-Anion Charge Balance}

Charge neutrality among the solutes to be distributed into normative salts, already stressed as an important calculation in SNORM, is accomplished by summing the equivalency of cations ( $\left.\mathrm{Leq}_{\mathrm{cation}}\right)$ and anions ( $\mathrm{eq}_{\mathrm{anion}}$ ) and determining their deviation from neutrality $\left(\sum_{\mathrm{eq}}\right.$ cation $\left./ \mathrm{eq}_{\text {anion }}=1.0\right)$. In this calculation boron is summed as the borate anion with an assigned borate charge per boron. Because the cause of deviation from cation-anion charge balance cannot be uniquely diagnosed, SNORM distributes the charge imbalance throughout all solutes. Those cation or anion concentrations with total excess charge are decreased proportionally, and the oppositely charged solute 


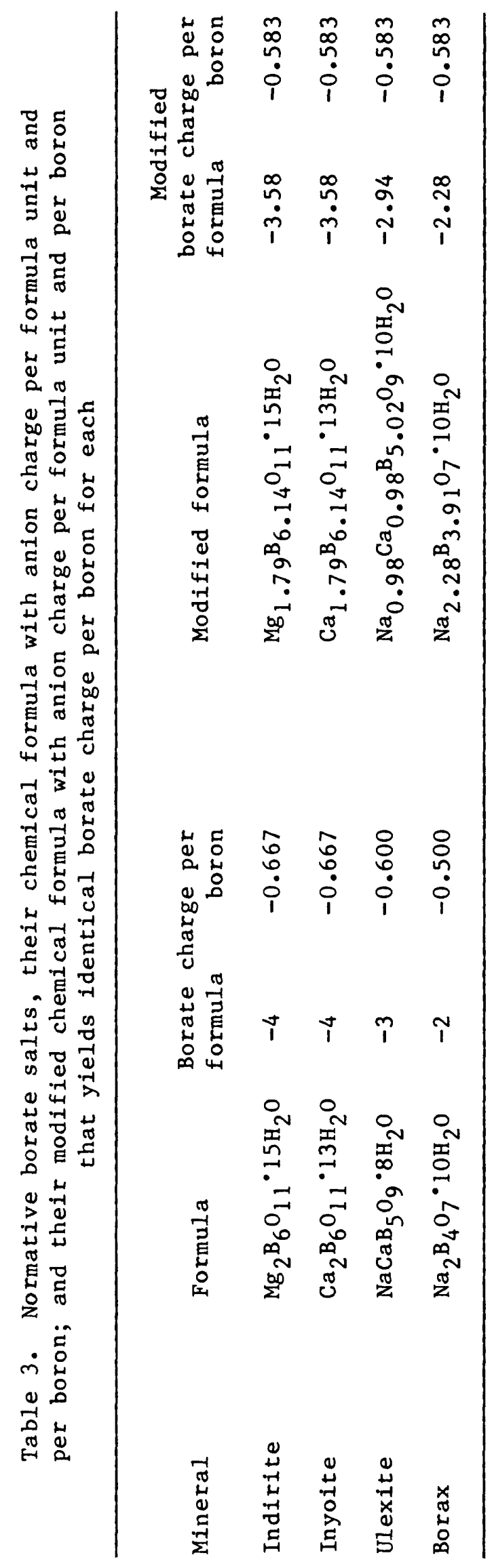


concentrations are correspondingly increased. Thus, the effect of the omission of one important solute from the analysis, or the faulty analysis of one solute, becomes distributed throughout all the solutes.

\section{Normative Salts}

SNORM assembles the salt norm for each water analysis from a list of 63 normative salts (table 2). The list contains the necessary array of salts to permit representation of the composition of any known natural water by an idealized equilibrium assemblage. The succeeding discussion reviews the features of the normative salt listing and the criteria that we adopted to formulate the list.

\section{Occurrence as Salt Minerals}

Whenever possible, the normative salts have been assigned compositions that occur naturally as minerals. However, several of the salts in table 2 do not occur naturally but only as normative salts because SNORM allows no interaction with host-rock salts, allows no consumption of solutes through authigenesis of clays and other silicates, allows no solid solution in the normative salts except for bromide and lodide in chlorides, and, unlike the natural process, "evaporates" the water to total dryness in a single step.

The largest group of these are the lithium salts; none occur as minerals. The lithium salts are moderately-to-highly soluble and, at the same time, lithium is never a dominant solute in natural waters. Its concentration rarely exceeds a few ppm except in a few playa evaporite waters associated with volcanics (Ericksen and others, 1976; Rettig and others, 1980), geothermal systems, and some deep basin "oll fleld" brines (Livingston, 1963; White and others, 1963) in which 1ithium concentrations reach several hundred ppm or more. Lithium substitutes readily for magnesium and ferrous iron in coexisting clay minerals and, to a lesser extent, in other minerals. Therefore, lithium never reaches a sufficiently high concentration for its salts to precipitate in natural systems--even from the saline evaporite brines that are noticeably enriched in lithium.

Similarly, the chloride and nitrate salts of barium and strontium, not known as minerals except for nitrobarite, are vastly more soluble than their respective sulfates and carbonates; thus, barium and strontium concentrations in natural waters characteristically remain low because of their direct precipitation as sulfates or carbonates, their substitution for calcium in carbonate (particularly strontium in aragonite) and sulfate minerals, and their replacement as carbonates and sulfates of preexisting carbonate and sulfate minerals in the host rock. Normative barium and strontium chlorides and nitrates occur in assemblages for concentrated waters drastically depleted 
in (bi)carbonate and sulfate, that is, waters containing normative calcium and magnesium chloride salts; they only occur in norms because no interaction with host rocks is permitted. In addition, the barfum and strontium-bearing waters characteristically occur as deep basin (oil-field) brines that almost never reach the surface and undergo significant evaporative concentration and salt precipitation.

Sodium phosphate is Included as a normative salt to accomodate those few waters in which phosphate remains after forming the normative calcium and magnesium phosphate salts. Magnesium phosphate, a salt that is unknown as a mineral, occurs in normative assemblages only if insufficient fluoride is present to form the magnesium fluorophosphate wagnerite.

Finally, the solutes bromide and lodide do not occur naturally as discrete bromide and iodide salts in sedimentary environments, but rather as solid solution components in chloride salts. We treat them similarly in SNORM; their adjusted concentrations are summed with that of chloride, and the total is assigned to the normative chloride salts in the assemblage.

\section{Compound Salts}

A wide variety of compound (double) salts are present in evaporite and other low-temperature environments; these salts range in abundance from the common dolomite, fluorapatite, and carnallite, to the rare tachyhydrite, kalistrontite, and pirssonite. The occurrence, genesis, and stability of many compound salts are well documented (see, for example, Braftsch, 1971; Eugster, 1980; Eugster and others, 1980; Harvie and others, 1984) and these must be included when forming the normative assemblage. Therefore, we have included all identifiably stable compound salt minerals that are composed solely of major solutes, that is--compound salts in the $\mathrm{Ca}-\mathrm{Mg}-\mathrm{K}-\mathrm{Na}-\mathrm{Cl}-\mathrm{SO}_{4}-\mathrm{HCO}_{3}-\mathrm{CO}_{3}-\mathrm{H}_{2} \mathrm{O}$ system, as well as several of the common compound-salt minerals, fluorapatite, wagnerite, and ulexite, that contain minor solutes. of this latter group, wagnerite and the two apatites are SNORM's only normative calclum and magnesium phosphate minerals.

We have, however, excluded all compound salts that are not found as minerals, and most compound salt minerals that contain a minor solute, such as

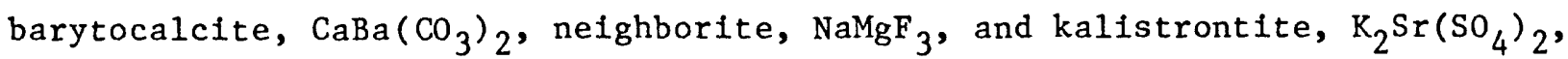
among others. This is done partially to reduce the number of phases in the listing of normative salts, but more importantly, to eliminate uncertainties about the stabilities and permissable mineral assoclation of these rare minerals. Furthermore, standard chemical potentials of many compound salts are unknown. A principal reason for referring to the salt norm as an idealized equilibrium assemblage of salts is because these compound salts were 
omitted from the listing; some of these salts are undoubtedly stable at surface conditions.

\section{Salt Stability Criteria}

Each normative salt (table 2) is identified as the salt that is stable at $25^{\circ} \mathrm{C}$ and 1 bar pressure under the atmospheric partial pressure of carbon dioxide $\left(10^{-3.5}\right.$ bars) within the water activity range of its occurrence in normative assemblages. The water activity, in turn, is determined by the composition of the terminal brine coexisting (saturated) with the full complement of salts in the normative assemblage and will be discussed more fully in the succeeding section. Most individual salt stabilities under the above constraints were determined from calculations using their standard chemical potentials at $25^{\circ} \mathrm{C}$ and 1 bar ( $10^{5}$ pascals) as listed in table 4. These calculations only recently became possible for a large number of the salts, particularly the compound major-cation sulfate and chloride salts of marine and continental evaporite deposits, when standard chemical potentials became available through the work of Harvie and Weare (1980), and Harvie and others $(1982,1984)$.

The total array of calculations using table 4 to identify the stable salts that constitute table 2 need not be reviewed; the calculations identifying the normative sodium (bi)carbonate salt will illustrate our procedure and the data in table 4 will permit the reader to pursue other examples.

Five candidates exist among the sodium (bi)carbonate salts: nahcolite, $\mathrm{NaHCO}_{3}$; trona, $\mathrm{Na}_{3} \mathrm{H}\left(\mathrm{CO}_{3}\right)_{2} \cdot 2 \mathrm{H}_{2} \mathrm{O}$; natron, $\mathrm{Na}_{2} \mathrm{CO}_{3} \cdot 10 \mathrm{H}_{2} \mathrm{O}$; sodium carbonate heptahydrate, $\mathrm{Na}_{2} \mathrm{CO}_{3} \cdot 7 \mathrm{H}_{2} \mathrm{O}$; and thermonatrite, $\mathrm{Na}_{2} \mathrm{CO}_{3} \cdot \mathrm{H}_{2} \mathrm{O}$. Using the chemical potentials in table 4, phase equilibria can be calculated and plotted (fig. 1) as water activity $\left(\mathrm{a}_{\mathrm{H}_{2}} \mathrm{O}\right)$ versus partial pressure of carbon dioxide $\left(\mathrm{p}_{\mathrm{CO}_{2}}\right)$. Thermonatrite and the heptahydrate are only stable below atmospheric partial pressure of carbon dioxide $\left(10^{-3.5}\right.$ bars, fig. 1) and are unacceptable as normative salts. Of the remaining three, natron is stable at water activities above $0.88\left(\log a_{\mathrm{H}_{2} \mathrm{O}}=-0.055\right)$, nahcolite is stable at water activities below $0.15\left(\log a_{\mathrm{H}_{2} \mathrm{O}}=-0.815\right)$, and trona is stable in the water activity interval between 0.15 and 0.88 . Water activities as low as 0.15 in natural waters are approached only in saturated $\mathrm{CaCl}_{2}$ brines (Harvie and others, 1984) in which no alkali (bi)carbonate salts are stable; therefore nahcolite as a normative salt is unacceptable. On the other hand, water activities are less than 0.8 in solutions saturated with sodium (bi)carbonate (Harvie and others, 1984), and natron is unstable. Only trona remains as the sodium (bi)carbonate salt in normative assemblages. 
Table 4. Standard chemical potential values and sources

\begin{tabular}{|c|c|c|c|}
\hline Volatile & Chemical formula & $\mu^{\circ} / \mathrm{RT}$ & Source \\
\hline $\begin{array}{l}\text { Water (1iquid) } \\
\text { Carbon dioxide (gas) } \\
\text { Salt }\end{array}$ & $\begin{array}{l}\mathrm{H}_{2} \mathrm{O} \\
\mathrm{CO}_{2}\end{array}$ & $\begin{array}{l}-95.6635 \\
-159.092\end{array}$ & $\begin{array}{l}1 \\
1\end{array}$ \\
\hline $\begin{array}{l}\text { Ammonia niter } \\
\text { Anhydrite } \\
\text { Antarcticite } \\
\text { Aphthitalite } \\
\text { Aragonite }\end{array}$ & $\begin{array}{l}\mathrm{NH}_{4} \mathrm{NO}_{3} \\
\mathrm{CaSO}_{4} \\
\mathrm{CaCl}_{2} \cdot 6 \mathrm{H}_{2} \mathrm{O} \\
\left.\mathrm{K}_{3} \mathrm{Na}_{2} \mathrm{SO}_{4}\right)_{2} \\
\mathrm{CaCO}_{3}\end{array}$ & $\begin{array}{l}-74.146 \\
-533.73 \\
-893.65 \\
-1057.05 \\
-455.17\end{array}$ & $\begin{array}{l}2 \\
1 \\
1 \\
1 \\
1\end{array}$ \\
\hline $\begin{array}{l}\text { Arcanite } \\
\text { Barite } \\
\text { Barium chloride } \\
\text { Barium chloride hydrate } \\
\text { Barium chloride dihydrate }\end{array}$ & \begin{tabular}{l|}
$\mathrm{K}_{2} \mathrm{SO}_{4}$ \\
$\mathrm{BaSO}_{4}$ \\
$\mathrm{BaCl}_{2}$ \\
$\mathrm{BaCl}_{2} \cdot \mathrm{H}_{2} \mathrm{O}$ \\
$\mathrm{BaCl}_{2} \cdot 2 \mathrm{H}_{2} \mathrm{O}$
\end{tabular} & $\begin{array}{l}-532.39 \\
-549.51 \\
-326.94 \\
-425.88 \\
-522.99\end{array}$ & $\begin{array}{l}1 \\
2 \\
3 b \\
3 b \\
3 b\end{array}$ \\
\hline $\begin{array}{l}\text { Bischofite } \\
\text { Bloedite } \\
\text { Borax } \\
\text { Burkeite } \\
\text { Calcite }\end{array}$ & $\begin{array}{l}\mathrm{MgCl}_{2} \cdot 6 \mathrm{H}_{2} \mathrm{O} \\
\mathrm{Na}_{2} \mathrm{Mg}\left(\mathrm{SO}_{4}\right)_{2} \cdot 4 \mathrm{H}_{2} \mathrm{O} \\
\mathrm{Na}_{2} \mathrm{~B}_{4} \mathrm{O}_{7} \cdot 10 \mathrm{H}_{2} \mathrm{O} \\
\mathrm{Na}_{6} \mathrm{CO}_{3}\left(\mathrm{SO}_{4}\right)_{2} \\
\mathrm{CaCO}_{3}\end{array}$ & $\begin{array}{l}-853.1 \\
-1383.6 \\
-590.95 \\
-1499.4 \\
-455.6\end{array}$ & $\begin{array}{l}1 \\
1 \\
3 c \\
1 \\
1\end{array}$ \\
\hline $\begin{array}{l}\text { Calcium chloride tetrahydrate } \\
\text { Carnallite } \\
\text { Celestite } \\
\text { Dolomite } \\
\text { Epsomite }\end{array}$ & $\begin{array}{l}\mathrm{CaCl}_{2} \cdot 4 \mathrm{H}_{2} \mathrm{O} \\
\mathrm{KMgCl}_{3} \cdot 6 \mathrm{H}_{2} \mathrm{O} \\
\mathrm{SrSO}_{4} \\
\mathrm{CaMg}\left(\mathrm{CO}_{3}\right)_{2} \\
\mathrm{MgSO}_{4} \cdot 7 \mathrm{H}_{2} \mathrm{O}\end{array}$ & $\begin{array}{l}-698.7 \\
-1020.3 \\
-540.95 \\
-871.99 \\
-1157.83\end{array}$ & $\begin{array}{l}1 \\
1 \\
2 \\
1 \\
1\end{array}$ \\
\hline $\begin{array}{l}\text { Fluorapatite } \\
\text { Fluorite } \\
\text { Gaylussite } \\
\text { Glauberite } \\
\text { Gypsum }\end{array}$ & $\begin{array}{l}\mathrm{Ca}_{5}\left(\mathrm{PO}_{4}\right)_{3} \mathrm{~F} \\
\mathrm{CaF}_{2} \\
\mathrm{Na}_{2} \mathrm{Ca}\left(\mathrm{CO}_{3}\right)_{2} \cdot 5 \mathrm{H}_{2} \mathrm{O} \\
\mathrm{Na}_{2} \mathrm{Ca}\left(\mathrm{SO}_{4}\right)_{2} \\
\mathrm{CaSO}_{4} \cdot 2 \mathrm{H}_{2} \mathrm{O}\end{array}$ & $\begin{array}{l}-2604.3 \\
-474.77 \\
-1360.5 \\
-1047.45 \\
-725.56\end{array}$ & $\begin{array}{l}2 \\
2 \\
1 \\
1 \\
1\end{array}$ \\
\hline $\begin{array}{l}\text { Halite } \\
\text { Hexahydrite } \\
\text { Hydroxyapatite } \\
\text { Kainite } \\
\text { Kalicinite }\end{array}$ & $\begin{array}{l}\mathrm{NaCl} \\
\mathrm{MgSO}_{4} \cdot 6 \mathrm{H}_{2} \mathrm{O} \\
\mathrm{Ca}_{5}\left(\mathrm{PO}_{4}\right)_{3} \mathrm{OH} \\
\mathrm{KMgC}_{4} \mathrm{SO}_{4} \cdot 3 \mathrm{H}_{2} \mathrm{O} \\
\mathrm{KHCO}_{3}\end{array}$ & $\begin{array}{l}-154.99 \\
-1061.60 \\
-2535.8 \\
-938.2 \\
-350.06\end{array}$ & $\begin{array}{l}1 \\
1 \\
2 \\
1 \\
1\end{array}$ \\
\hline $\begin{array}{l}\text { Kieserite } \\
\text { Labile salt } \\
\text { Leonite } \\
\text { Lithium carbonate } \\
\text { Lithium chloride }\end{array}$ & $\begin{array}{l}\mathrm{MgSO}_{4} \cdot \mathrm{H}_{2} \mathrm{O} \\
\mathrm{Na}_{4} \mathrm{Ca}\left(\mathrm{SO}_{4}\right)_{3} \cdot 2 \mathrm{H}_{2} \mathrm{O} \\
\mathrm{K}_{2} \mathrm{Mg}\left(\mathrm{SO}_{4}\right)_{2} \cdot 4 \mathrm{H}_{2} \mathrm{O} \\
\mathrm{Li}_{2} \mathrm{CO}_{3} \\
\mathrm{LiCl}\end{array}$ & $\begin{array}{l}-579.8 \\
-1751.45 \\
-1403.97 \\
-456.7 \\
-155.06\end{array}$ & $\begin{array}{l}1 \\
1 \\
1 \\
3 c \\
3 c\end{array}$ \\
\hline $\begin{array}{l}\text { Lithium chloride hydrate } \\
\text { Lithium fluoride } \\
\text { Lithium nitrate } \\
\text { Lithium nitrate trihydrate } \\
\text { Lithium sulfate }\end{array}$ & $\begin{array}{l}\mathrm{LiCl} \cdot \mathrm{H}_{2} \mathrm{O} \\
\mathrm{LiF} \\
\mathrm{LiNO} 3 \\
\mathrm{LiNO}_{3} \cdot 3 \mathrm{H}_{2} \mathrm{O} \\
\mathrm{Li}_{2} \mathrm{SO}_{4}\end{array}$ & $\begin{array}{l}-254.88 \\
-237.09 \\
-153.76 \\
-455.25 \\
-533.2\end{array}$ & $\begin{array}{l}3 c \\
3 c \\
3 c \\
3 c \\
3 c\end{array}$ \\
\hline
\end{tabular}


Table 4 (continued).

\begin{tabular}{|c|c|c|c|}
\hline Salt & Chemical formula & $\mu^{\circ} / \mathrm{RT}$ & Source \\
\hline $\begin{array}{l}\text { Lithium sulfate hydrate } \\
\text { Magnesite } \\
\text { Mascagnite } \\
\text { Mirabilite } \\
\text { Nahcolite }\end{array}$ & $\begin{array}{l}\mathrm{Li}_{2} \mathrm{SO}_{4} \cdot \mathrm{H}_{2} \mathrm{O} \\
\mathrm{MgCO}_{3} \\
\left(\mathrm{NH}_{4}\right)_{2} \mathrm{SO}_{4} \\
\mathrm{Na}_{2} \mathrm{SO}_{4} \cdot 1 \mathrm{H}_{2} \mathrm{O} \\
\mathrm{NaHCO}_{3}\end{array}$ & $\begin{array}{r}-631.59 \\
-414.45 \\
-363.74 \\
-1471.15 \\
-343.33\end{array}$ & $\begin{array}{l}3 c \\
1 \\
2 \\
1 \\
1\end{array}$ \\
\hline $\begin{array}{l}\text { Natron } \\
\text { Nesquehonite } \\
\text { Niter } \\
\text { Nitrobarite } \\
\text { Nitrocalcite }\end{array}$ & $\begin{array}{l}\mathrm{Na}_{2} \mathrm{CO}_{3} \cdot 1 \mathrm{H}_{2} \mathrm{O} \\
\mathrm{MgCO}_{3} \cdot 3 \mathrm{H}_{2} \mathrm{O} \\
\mathrm{KNO}_{3} \\
\mathrm{Ba}\left(\mathrm{NO}_{3}\right)_{2} \\
\mathrm{Ca}\left(\mathrm{NO}_{3}\right)_{2} \cdot 4 \mathrm{H}_{2} \mathrm{O}\end{array}$ & $\begin{array}{l}-1382.78 \\
-695.3 \\
-159.16 \\
-321.34 \\
-691.22\end{array}$ & $\begin{array}{l}1 \\
1 \\
2 \\
2 \\
3 b\end{array}$ \\
\hline $\begin{array}{l}\text { Nitromagnesite } \\
\text { Picromerite } \\
\text { Pirssonite } \\
\text { Polyhalite } \\
\text { Potassium carbonate hydrate }\end{array}$ & $\begin{array}{l}\mathrm{Mg}\left(\mathrm{NO}_{3}\right)_{2} \cdot 6 \mathrm{H}_{2} \mathrm{O} \\
\mathrm{K} 2 \mathrm{Mg}\left(\mathrm{SO}_{4}\right)_{2} \cdot 6 \mathrm{H}_{2} \mathrm{O} \\
\mathrm{Na}_{2} \mathrm{Ca}\left(\mathrm{CO}_{3}\right)_{2} \cdot 2 \mathrm{H}_{2} \mathrm{O} \\
\mathrm{K}_{2} \mathrm{Ca}_{2} \mathrm{Mg}\left(\mathrm{SO}_{4}\right)_{4} \cdot 2 \mathrm{H}_{2} \mathrm{O} \\
\mathrm{K}_{2} \mathrm{CO}_{3} \cdot 3 / 2 \mathrm{H}_{2} \mathrm{O}\end{array}$ & $\begin{array}{l}-839.36 \\
-1596.1 \\
-1073.1 \\
-2282.5 \\
-577.37\end{array}$ & $\begin{array}{l}3 \mathrm{~b} \\
1 \\
1 \\
1 \\
1\end{array}$ \\
\hline $\begin{array}{l}\text { Potassium sesquicarbonate } \\
\text { Potassium sodium carbonate } \\
\text { Potassium trona } \\
\text { Salammoniac } \\
\text { Sellaite }\end{array}$ & $\begin{array}{l}\mathrm{K}_{8} \mathrm{H}_{4}\left(\mathrm{CO}_{3}\right)_{6} \cdot 3 \mathrm{H}_{2} \mathrm{O} \\
\mathrm{KNaCO}_{3} \cdot 6 \mathrm{H}_{2} \mathrm{O} \\
\mathrm{K}_{2} \mathrm{NaH}_{3}\left(\mathrm{CO}_{3}\right)_{2} \cdot 2 \mathrm{H}_{2} \mathrm{O} \\
\mathrm{NH}_{4} \mathrm{Cl} \\
\mathrm{MgF}_{2}\end{array}$ & $\begin{array}{r}-2555.4 \\
-1006.8 \\
-971.74 \\
-82.201 \\
-432.07\end{array}$ & $\begin{array}{l}1 \\
1 \\
1 \\
2 \\
2\end{array}$ \\
\hline $\begin{array}{l}\text { Soda niter } \\
\text { Sodium carbonate heptahydrate } \\
\text { Sodium phosphate } \\
\text { Strontionite } \\
\text { Strontium chloride }\end{array}$ & $\begin{array}{l}\mathrm{NaNO}_{3} \\
\mathrm{Na}_{2} \mathrm{CO}_{3} \cdot 7 \mathrm{H}_{2} \mathrm{O} \\
\mathrm{Na}_{3} \mathrm{PO}_{4} \\
\mathrm{SrCO}_{3} \\
\mathrm{SrCl}_{2}\end{array}$ & $\begin{array}{r}-148.11 \\
-1094.95 \\
-721.64 \\
-458.93 \\
-315.12\end{array}$ & $\begin{array}{l}2 \\
1 \\
3 c \\
2 \\
3 b\end{array}$ \\
\hline $\begin{array}{l}\text { Strontium chloride dihydrate } \\
\text { Strontium chloride hexahydrate } \\
\text { Strontium nitrate } \\
\text { Sylvite } \\
\text { Syngenite }\end{array}$ & $\begin{array}{l}\mathrm{SrCl}_{2} \cdot 2 \mathrm{H}_{2} \mathrm{O} \\
\mathrm{SrCl}_{2} \cdot 6 \mathrm{H}_{2} \mathrm{O} \\
\mathrm{Sr}\left(\mathrm{NO}_{3}\right)_{2} \\
\mathrm{KCl} \\
\mathrm{K} 2 \mathrm{Ca}\left(\mathrm{SO}_{4}\right)_{2} \cdot \mathrm{H}_{2} \mathrm{O}\end{array}$ & $\begin{array}{l}-517.15 \\
-904.13 \\
-314.29 \\
-164.84 \\
-1164.8\end{array}$ & $\begin{array}{l}3 \mathrm{~b} \\
3 \mathrm{~b} \\
3 \mathrm{~b} \\
1 \\
1\end{array}$ \\
\hline $\begin{array}{l}\text { Tachyhydrite } \\
\text { Teschemacherite } \\
\text { Thenardite } \\
\text { Thermonatrite } \\
\text { Trona }\end{array}$ & 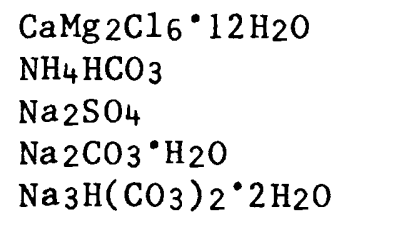 & $\begin{array}{l}-2015.9 \\
-268.7 \\
-512.35 \\
-512.8 \\
-960.38\end{array}$ & $\begin{array}{l}1 \\
3 \mathrm{a} \\
1 \\
1 \\
1\end{array}$ \\
\hline $\begin{array}{l}\text { Villiaumite } \\
\text { Witherite }\end{array}$ & $\begin{array}{l}\mathrm{NaF} \\
\mathrm{BaCO}_{3}\end{array}$ & $\begin{array}{l}-220.39 \\
-456.74\end{array}$ & $\begin{array}{l}2 \\
2\end{array}$ \\
\hline
\end{tabular}

\footnotetext{
Sources - 1. Harvie and others (1984).

2. Robie and others (1978).

3. NBS Technical Note 270: a. Wagman and others (1968); b. Parker and others (1971); c. Wagman and others (1981).
} 


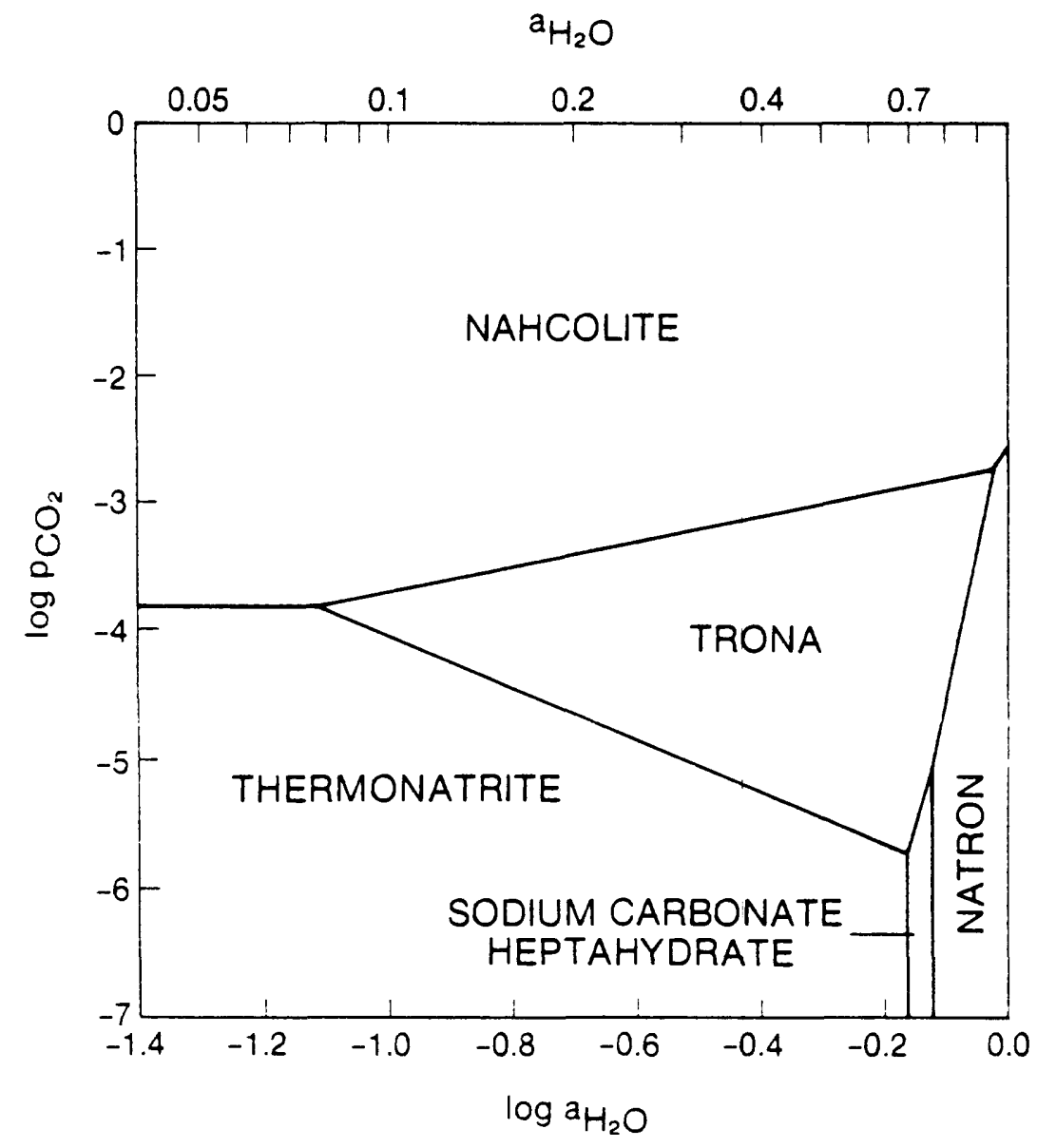

Figure 1. Calculated stability relations among the $\mathrm{Na}_{2} \mathrm{CO}_{3}-\mathrm{NaHCO}_{3}-\mathrm{H}_{2} \mathrm{O}$ salts at $25^{\circ} \mathrm{C}$ and 1 bar pressure as functions of water activity and fugacity of carbon dioxide in the coexisting aqueous phase.

Examples of results using paralle1, but generally less complex calculations include: designation of kalicinite as the normative salt, rather than a variety of potassium (bi)carbonate salts; elimination of any sodiumpotassium (bi)carbonate salts as normative salts; designation of pirssonite as the normative salt rather than gaylussite; and designation of kieserite and epsomite, leonite and picromerite, gypsum and anhydrite, thenardite and mirabilite, and the appropriate hydrates of $\mathrm{BaCl}_{2}, \mathrm{SrCl}_{2}, \mathrm{LiCl}_{2} \mathrm{Li}_{2} \mathrm{SO}_{4}$, and $\mathrm{LiNO}_{3}$ in table 2 as permissable alternative hydrates. The designation of the normative $\mathrm{MgSO}_{4}$ hydrates, epsomite and kieserite, produced an unusual result. Hexahydrite, a not uncommon evaporite mineral with a hydration level between that of kieserite and epsomite (table 4), precipitates during 
progressive evaporation of seawater at $25^{\circ} \mathrm{C}$ (Braitsch, 1971; Harvie and others, 1982) but within an interval that is between the water activities in brines coexisting with alkaline-earth bearing chlorides and alkali-bearing sulfates.

In some instances aqueous ion activities also had to be considered along with the crystalline salts, water activity, and, in reactions involving (bi)carbonate salts, the partial pressure of carbon dioxide, to designate the normative salt. Hydroxyapatite, rather than whitlockite, $\mathrm{Ca}_{3}\left(\mathrm{PO}_{4}\right)_{2}$, as the stable calcium phosphate is an example. Hydroxyapatite is a common sedimentary mineral and whitlockite is relatively rare; the latter's occurrence as a sedimentary mineral appears to be restricted to modern insular guano deposits (Gulbrandsen, 1975). The equflibrium between hydroxyapatite and whitlockite,

$$
\begin{aligned}
& 2 \mathrm{Ca}_{5}\left(\mathrm{PO}_{4}\right)_{3} \mathrm{OH}+2 \mathrm{H}^{+}=3 \mathrm{Ca}_{3}\left(\mathrm{PO}_{4}\right)_{2}+\mathrm{Ca}^{2+}+2 \mathrm{H}_{2} \mathrm{O} \\
& \text { hydroxyapatite whitlockite }
\end{aligned}
$$

is plotted in terms of $\mathrm{pH}$ and the logarithm of the aqueous calcium ion activity to define hydroxyapatite and whitlockite stability fields for two extremes of water activity, $a_{\mathrm{H}_{2} \mathrm{O}}=1.0$ and 0.1 (fig. 2). Calcite saturation at atmospheric partial pressure of carbon dioxide at the same two water activities is also shown; calcite saturation lies well within the hydroxyapatite field at more than two orders of magnitude greater calcium ion activity than the hydroxyapatite-whitlockite equilibrium. Thus, with any calcium-bearing salt in the normative assemblage, hydroxyapatite, rather than whitlockite is the stable calclum phosphate salt. All Ca-bearing salts are nearly as soluble or more soluble than calcite except fluorite, and if fluorite occurs in the assemblage, fluorapatite, not hydroxyapatite, is the stable phosphate. These results parallel Gulbandsen's observation that whitlockite appears to be a metastable intermediate in the transition from guano to apatite.

In those cases in which standard chemical potentials of one or more related salts were not avallable, evidence from geologic observations and experimental results was used. The unusual evaporite minerals chlorocalcite $\left(\mathrm{KCaCl}_{3} \cdot 6 \mathrm{H}_{2} \mathrm{O}\right)$ and georgeyite $\left(\mathrm{K}_{2} \mathrm{Ca}_{5}\left[\mathrm{SO}_{4}\right]_{6} \cdot \mathrm{H}_{2} \mathrm{O}\right)$, for example, were not designated as normative salts because their occurrence appears to be restricted to thermally metamorphosed salts (Braitsch, 1971). Bloedite was selected as the normative $\mathrm{Na}-\mathrm{Mg}$ sulfate, rather than vanthoffite or loewite, and leonite and picromerite as the normative $\mathrm{K}-\mathrm{Mg}$ sulfates, rather than langbeinite, based on experimental data and nature of their occurrence reported by Braitsch (1971). 


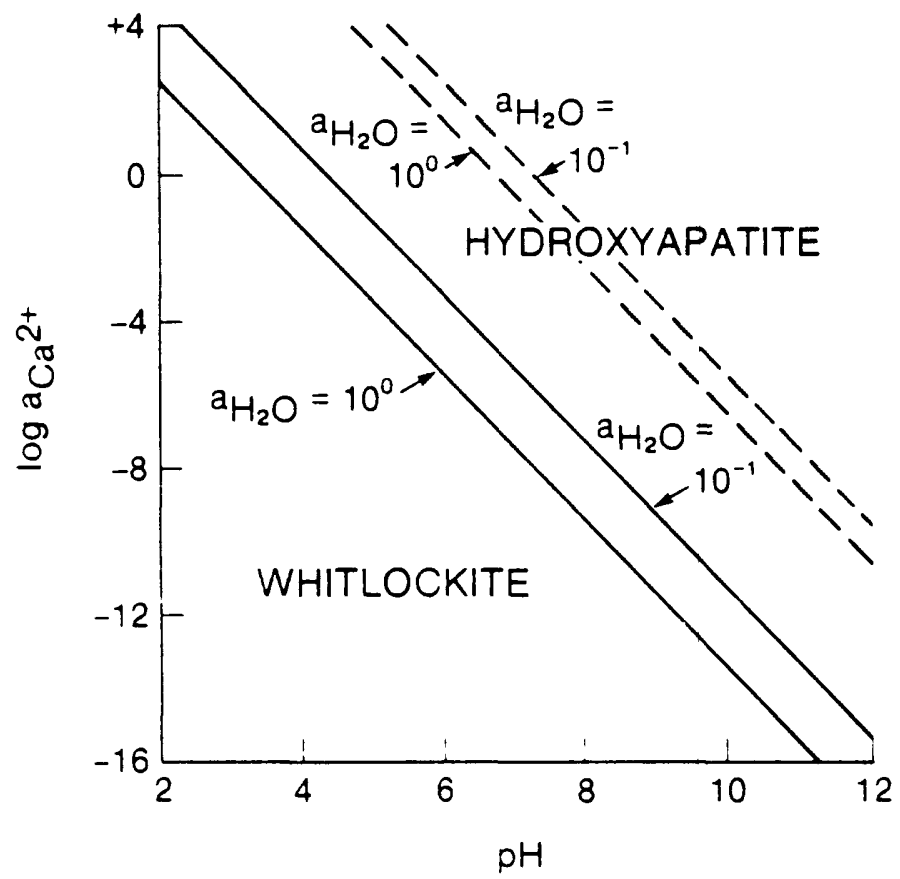

Figure 2. Hydroxyapatite-whitlockite stability relations (solid lines) at $25^{\circ} \mathrm{C}$ and 1 bar pressure as a function of the logarithm of calcium ion activity and $\mathrm{pH}$ in the coexisting aqueous fluid at two extreme water activities $\left(10^{0}\right.$ and $\left.10^{-1}\right)$; calcite saturation (dashed lines) at atmospheric partial presure of carbon dioxide $\left(10^{-3.5}\right.$ bars) plotted for the same two water activity extremes.

Designation of the normative borate salts cannot be rigorously resolved. Not only have a vast number of borate minerals, some with complex compositions, been identified from evaporite deposits (see, for example, Sonnenfeld, 1984, p. 470-471), but nearly all are lacking standard free energy values. Therefore, we have designated only four normative borates (table 2) that, from observations of natural occurrences, are representative of, rather than rigorously defined by the normative assemblage.

We have arbitrarily limited the normative borate salts to the quinary system, $\mathrm{CaO}-\mathrm{MgO}-\mathrm{Na}_{2} \mathrm{O}-\mathrm{B}_{2} \mathrm{O}_{3}-\mathrm{H}_{2} \mathrm{O}$. This excludes all double anion borates such as boracite, lueneburgite, heldenite, and the array of borosilicates; the rarely occurring potassium-bearing borates, kaliborate and santite; and all minor cation borates such as the various strontium-bearing borates infrequently encountered in the Zechstein salts (Braitsch, 1971). Except for ulexite, we 
have also excluded all double cation borates; ulexite has been included because of its frequent abundance in many playa and spring deposits (Muessig, 1959; Bowser and Dickson, 1966).

For each endmember borate composition we have designated its most abundant and frequently occurring anhydrous stoichiometry as the normative salt composition. The anhydrous stoichiometery $2 \mathrm{CaO}^{\circ} 3 \mathrm{~B}_{2} \mathrm{O}_{3}$ (the minerals inyoite, mayerhoffite, and colemanite). is far more abundant than other calcium borate stoichiometries. Although the magnesium borates ascherite and boracite are the most abundant borate minerals in marine evaporite rocks, there is convincing evidence that these minerals are secondary having formed in response to thermal metamorphism and postdepositional fluid transport and deposition (Kühn, 1968; Braftsch, 1971; Sonnenfeld, 1984). In recent playa and spring deposits, on the other hand, the anhydrous stolchiometry $2 \mathrm{MgO} \cdot 3 \mathrm{~B}_{2} \mathrm{O}_{3}$ (the minerals indirite and kurnakovite) is the most frequently occurring composition of the relatively rare magnesium borates (Muessig, 1959, 1966). The $\mathrm{Na}_{2} \mathrm{O}^{\circ} 2 \mathrm{~B}_{2} \mathrm{O}_{3}$ anhydrous stoichiometry (the minerals borax, tincalconite, and kernite) is unquestionably the most abundant of the sodium borate compositions in recent playa and spring deposits and is the major commercial source of boron (Muessig, 1959; Smith and Haines, 1964; Bowser and Dickson, 1966). These three anhydrous stoichiometries plus $\mathrm{Na}_{2} \mathrm{O}^{\cdot} 2 \mathrm{CaO} 0^{\circ} 5 \mathrm{~B}_{2} \mathrm{O}_{3}$ (the minerals ulexite and probertite) constitute the anhydrous stoichiometries of the normative borate salts.

Designation of the "stable" hydrate for each of the four borate stoichiometries is based on observations by Muessig (1959). He concluded that, based on sedimentological, textural, and other paragenetic criteria at playa evaporite deposits along with some experimental data, the most hydrated in each of the colemante, indirite, borax and ulexite hydration series is the primary borate salt; lesser hydration states are presumably secondary. We are not convinced his conclusions are valid throughout the range of water activities associated with normative salt assemblages. For example, the low water activity associated with normative $\mathrm{Mg}-\mathrm{Ca}$ chloride salt assemblages is far below that observed at playa occurrences and may well be in equilibrium with borate salts of lower hydration. Nevertheless, until more definitive data for the borate mineral stabilities become avallable, we have incorporated Muessig's conclusions into SNORM by designating inyoite, indirite, borax, and ulexite (table 2) as the normative hydration states of the four anhydrous stoichiometries.

\section{Salt Composition Modifications}

Hydroxyapatite (table 2) is the only normative salt, other than the borates, whose composition cannot be constructed solely from a combination of 
solutes; hydroxyapatite contains one hydroxide radical per formula unit. In order to preserve cation-anion charge balance in the system, hydroxyapatite's composition is modified to $\mathrm{Ca}_{4.75}\left(\mathrm{PO}_{4}\right)_{3.17}$ (the whitlockite composition) from $\mathrm{Ca}_{5}\left(\mathrm{PO}_{4}\right)_{3}(\mathrm{OH})$. This change is not large and apatite's abundance in salt norms is characteristically minor; thus, the modification has little effect. Furthermore, fluorapatite, which does retain its correct stoichiometry in normative assemblages, is the stable apatite in any sample which contains sufficient fluoride, and results in only infrequent occurrence of normative hydroxyapatite.

\section{Normative Salt Assemblages}

The salt norm for each sample consists of the equilibrium assemblage of normative salts from table 2, the abundances of which are quantitatively equivalent to the adjusted solute abundances (concentrations). Assignment of the correct salts to the norm occurs in three steps: (1) The group of salts from table 2 that are eligible candidates based on solute species in the analysis and gross solute concentration relationships is defined; (2) the Gibbs phase rule is applied to determine the number of salts that comprise the assemblage; and (3) the single assemblage of elgible salts that contains only permissable salt associations and is quantitatively equivalent to solute concentrations is identified.

\section{Eligible Salts}

Salts from table 2 are selected to form a group of eligible candidates for possible assignment to the salt norm for each analysis. In this manner a substantial number of the 63 salts in table 2 are eliminated from further consideration. Because equilibrium hydration levels are assigned later, only the less hydrated salt from each of seven pairs of salts with two potentially permissable hydration states is retained in the list of eligible salts; anhydrite, for example, is retained as an eligible salt but gypsum is deleted. Two criteria are then applied to each analysis to further reduce the number of eligible salts.

The first criterion is that each eligible salt must be composed exclusively of components that occur as solutes in the analysis. This eliminates any salt that is composed of one or more solutes that are not. represented in the analysis.

The second criterion is that each eligible salt is compatible with selected solute equivalency relations in each of four sets of solutes. Each relation compares a sum of solute equivalencies between a designated group of cations and a designated group of anions (table 5), and, if the specified relation is fulfilled, the group of salts ldentified with the relation are 
Table 5. Salts excluded from assemblages in SNORM as a function of charge ratios of selected cation and anion groups of solutes

\begin{tabular}{lll}
\hline I. & Leq $(\mathrm{Ca}+\mathrm{Mg}+\mathrm{Ba}+\mathrm{Sr}+\mathrm{Li})>\mathrm{Keq}\left(\mathrm{PO}_{4}+\mathrm{SO}_{4}+\mathrm{CO}_{3}+\mathrm{F}+\mathrm{B}^{*}\right)$ \\
Trona & Glauberite & Ammonia niter \\
Pirssonite & Syngenite & Ulexite \\
Kalicinite & Bloedite & Borax \\
Witherite & Leonite & Villiaumite \\
Teschemacherite & Aphthitalite & LiF \\
Thenardite & Mascagnite & Na3PO4 \\
Arcanite & Burkeite &
\end{tabular}
II. $\quad \mathrm{Seq}(\mathrm{Ca}+\mathrm{Mg}+\mathrm{Ba}+\mathrm{Sr}+\mathrm{Li})<\mathrm{Seq}\left(\mathrm{PO}_{4}+\mathrm{SO}_{4}+\mathrm{CO}_{3}+\mathrm{F}+\mathrm{B}^{*}\right)$
Antarcticite $\quad \mathrm{SrCl}_{2}{ }^{\circ} 2 \mathrm{H}_{2} \mathrm{O} \quad$ Nitromagnesite
Tachyhydrite $\quad \mathrm{BaCl}_{2}{ }^{\bullet} \mathrm{H}_{2} \mathrm{O} \quad \mathrm{Sr}\left(\mathrm{NO}_{3}\right)_{2}$
Bischofite Nitrocalcite Nitrobarite

$\begin{array}{lll}\text { III. } \operatorname{Leq}_{(\mathrm{Ca}+\mathrm{Mg}+\mathrm{Sr})}<\operatorname{\Sigma eq}_{\left(\mathrm{PO}_{4}+\mathrm{CO}_{3}\right)} & \\ \text { Anhydrite } & \text { Bloedite } & \text { Inyoite } \\ \text { Kieserite } & \text { Leonite } & \text { Ulexite } \\ \text { Glauberite } & \text { Celestite } & \text { Indirite } \\ \text { Syngenite } & \text { Carnallite } & \text { Fluorite } \\ \text { Polyhalite } & \text { Kainite } & \text { Sellaite }\end{array}$
IV. $\quad \operatorname{Leq}(\mathrm{Ca}+\mathrm{Mg})>\mathrm{Leq}_{\left(\mathrm{PO}_{4}+\mathrm{CO}_{3}+\mathrm{F}\right)}$

$\begin{array}{lll}\text { Trona } & \text { Witherite } & \text { Villiaumite } \\ \text { Pirssonite } & \text { Teschemacherite } & \text { LiF } \\ \text { Kalicinite } & \mathrm{Li}_{2} \mathrm{CO}_{3} & \mathrm{Na}_{3} \mathrm{PO}_{4} \\ \text { Strontionite } & \text { Brukeite } & \end{array}$

* Borate assigned an average charge of $-7 / 12$ per boron (see text).

deleted from the list of eligible candidates for that particular norm. These relations follow the major compositional "divides" that were defined by Hardie and Eugster (1970), and Eugster and Hardie (1978).

The first relation ( $I$ in table 5) defines an alkaline-earth chloride water in which the alkali-bearing (bi)carbonate and sulfate salts, among others, are unstable and not considered. The second relation (II) is the inverse of ( $I$ ) and defines a water in which the alkaline-earth chloride salts are not considered. The third and fourth relations define the two major varients of II; either an alkali (bi)carbonate water (III) in which the alkaline-earth bearing sulfate salts, among others, are not considered, or an alkali sulfate water in which the alkali-bearing (bi)carbonate and other salts are not considered. 
The procedures by which the four groups of ineligible salts were identified rely chiefly on the free energies of reaction at standard conditions calculated with standard chemical potentials (table 4). As an example, consider the two equilibria

$$
\begin{aligned}
& \mathrm{Na}_{2} \mathrm{Ca}\left(\mathrm{SO}_{4}\right)_{2}+\mathrm{CaCL}_{2} \cdot 6 \mathrm{H}_{2} \mathrm{O}=2 \mathrm{CaSO}_{4}+2 \mathrm{NaCl}+6 \mathrm{H}_{2} \mathrm{O} \\
& \text { glauberite antarcticite anhydrite halite }
\end{aligned}
$$

and

$$
\underset{\text { bloedite }}{\mathrm{Na}_{2} \mathrm{Mg}\left(\mathrm{SO}_{4}\right)_{2}}{ }_{4 \mathrm{H}_{2} \mathrm{O}}+\underset{\text { bischofite }}{\mathrm{MgCl}_{2}} 6 \mathrm{H}_{2} \mathrm{O}=\underset{\text { kieserite }}{2 \mathrm{MgSO}_{4} \mathrm{H}_{2} \mathrm{O}}+\underset{\text { halite }}{2 \mathrm{NaCl}}+8 \mathrm{H}_{2} \mathrm{O}
$$

that yield free energies of reaction of -25.6 and $4.5 \mathrm{kilojoules}$ respectively. These values are substituted into the equality defining the natural $\log$ of the equilibrium constant, 1 in $\mathrm{K}_{\mathrm{eq}}$, in terms of the free energy of reaction at standard conditions, $\Delta G_{r}^{\circ}$,

$$
\ln \mathrm{K}_{\mathrm{eq}}=-\mathrm{RT} \Delta \mathrm{G}_{\mathrm{r}}^{\mathrm{O}}
$$

with $R$, the gas constant, and $T$, the temperature in degrees Kelvin. The equilibrium constant, in turn, defines the activity of water in both equilibria, $\mathrm{K}_{\mathrm{eq}}=\left(\mathrm{a}_{\mathrm{H}_{2}}\right)^{6}$ and $\left(\mathrm{a}_{\mathrm{H}_{2} \mathrm{O}}\right)^{8}$, respectively. Water activities are 5.6 and 0.8 respectively for the two reactions at equilibrium. The high water activities (a maximum water activity at bischofite saturation is 0.34 ) at equilibrium preclude stablility of the glauberite-antarcticite and bloeditebischofite pairs, and contribute to the documentation that alkali-bearing sulfates are unstable in alkaline-earth chloride waters ( $I$ in table 5), and conversely, that alkaline-earth chlorides are unstable in alkali-bearing sulfate waters (II). Whenever possible, parallel equilibria were calculated to identify the ineligible salts for each of the four relations.

For those salts without standard chemical potential data, ineligiblities were arbitrarily assigned based on relations in other groups. For example, borax and ulexite were ruled ineligible in alkaline-earth chloride waters, and inyolte, ulexite, and indirite were ruled ineligible in alkali carbonate waters.

Number of Salts in the Assemblage

The number of salts in each normative assemblage is calculated through use of the Gibbs phase rule 


$$
P=C-F+2
$$

in which $P$ is the maximum number of phases in the assemblage, $C$ is the minimum number of components whose abundances are independent variables and collectively define the phases quantitatively, and $F$ is the number of degrees of freedom that can be independently imposed on the system.

Two degrees of freedom, temperature and pressure, are identified for the salt norm system. These are arbitrarily assigned $\left(25^{\circ} \mathrm{C}\right.$ and 1 bar) as independent variables and are not fixed by the character of the normative ass emblage.

The number of components in the salt norm system, in addition to water, may be initially envisioned as the number of solutes in the analysis. However, because of the character of the normative assemblage and some previously adopted conventions, the number of components in the phase rule calculation comply with the following stipulations.

Because the sum of adjusted concentrations of chloride, bromide, and lodide are distributed into the chloride salts as mutually indistinguishable solutes, their collective abundance represents a single component rather than three individual solute components. Similarly, because the adjusted concentrations of carbonate and bicarbonate can be mutually exchanged one with the other through equation (3) to conform to the stoichiometry of the designated (bi)carbonate salts, the collective abundance of carbonate and bicarbonate defines a single component. The number of remaining single ion solute components is then lowered by one for use in the phase rule because some one arbitrarily designated solute concentration can be considered as a dependent variable that establishes cation-anion charge balance. Finally, water is not considered a component in the phase rule calculation; because no free water coexists with the normative assemblage, water's abundance is a dependent variable that is defined solely by the number of hydration waters required to form the normative salts.

\section{Prohibited Salt Associations}

After determining which salts are eligible in an assemblage of a given initial composition (table 5) and the number of salts that constitutes the assemblage, only one assemblage can be formed that is qualitatively and quantitatively compatible with the adjusted solute concentrations, and that excludes all prohibited salt associations throughout the assemblage.

The criterion that the assemblage excludes all prohibited (unstable) salt associations in the assemblage is fulfilled if the assemblage contains none of the prohibited associations shown in table 6 . The table is a compendium of 
all salt associations that are prohibited, or assumed prohibited at $25^{\circ} \mathrm{C}$ and 1 bar pressure. Most of the unstable associations are salt pairs that are identified in the matrix of normative salts; a few are prohibited three-salt and four-salt associations that are listed outside the matrix. Alternative hydration states for those salts with more than one stable hydration state are not specified in table 6; designation of hydration states for these salts will be discussed subsequently.

Calculations producing table 6 follow the same general procedures discussed previously for the development of table 5. Whenever possible, the unstable associations in table 6 were calculated by determining the equilibrium with the standard chemical potential data from table 4; an unstable association has higher free energy in the appropriate chemical environment (water activity, carbon dioxide partial pressure) than its stable isochemical equivalent. For salts lacking standard chemical potential data, in particular, the borates and phosphates, unstable associations were identified by analogy with prohibited associations in other groups and relationships observed in low-temperature natural assemblages. Major features of the phase relations among the normative salts that result from these calculations or assumptions are given in Appendix $V$.

The compositional constraints for the assemblage require that all solutes are qualitatively represented in the collective composition of salts in the assemblage, and that salt abundances can be quantitatively calculated from the solute abundances. Only a single assemblage that contains no prohibited associations from table 6 will satisfy this latter constraint, and this assemblage, after assigning proper hydration levels to salts with more than one hydration state, becomes the normative assemblage.

\section{Hydration-Dehydation Equilibria}

The final step in defining the salt norm is assignment of the equilibrium hydrate for any of the six salt compositions that can occur in one of two possible hydration states (table 7). Each hydration-dehydration transformation in table 7 is defined by its equilibrium water activity; thus, the water activity in the most concentrated brine that coexists with and is saturated with the full normative assemblage determines the stable hydration level of each salt pair. However, SNORM neither considers brine evolution nor calculates the composition and thermochemical properties of the terminal brine; SNORM only considers initial water composition and distributes the solutes into the equilibrium salt assemblage. The stable hydration state for these salts must be assigned using criteria from the normative assemblage itself, rather than from unknown thermochemical and compositional properties of an undefined terminal brine. 


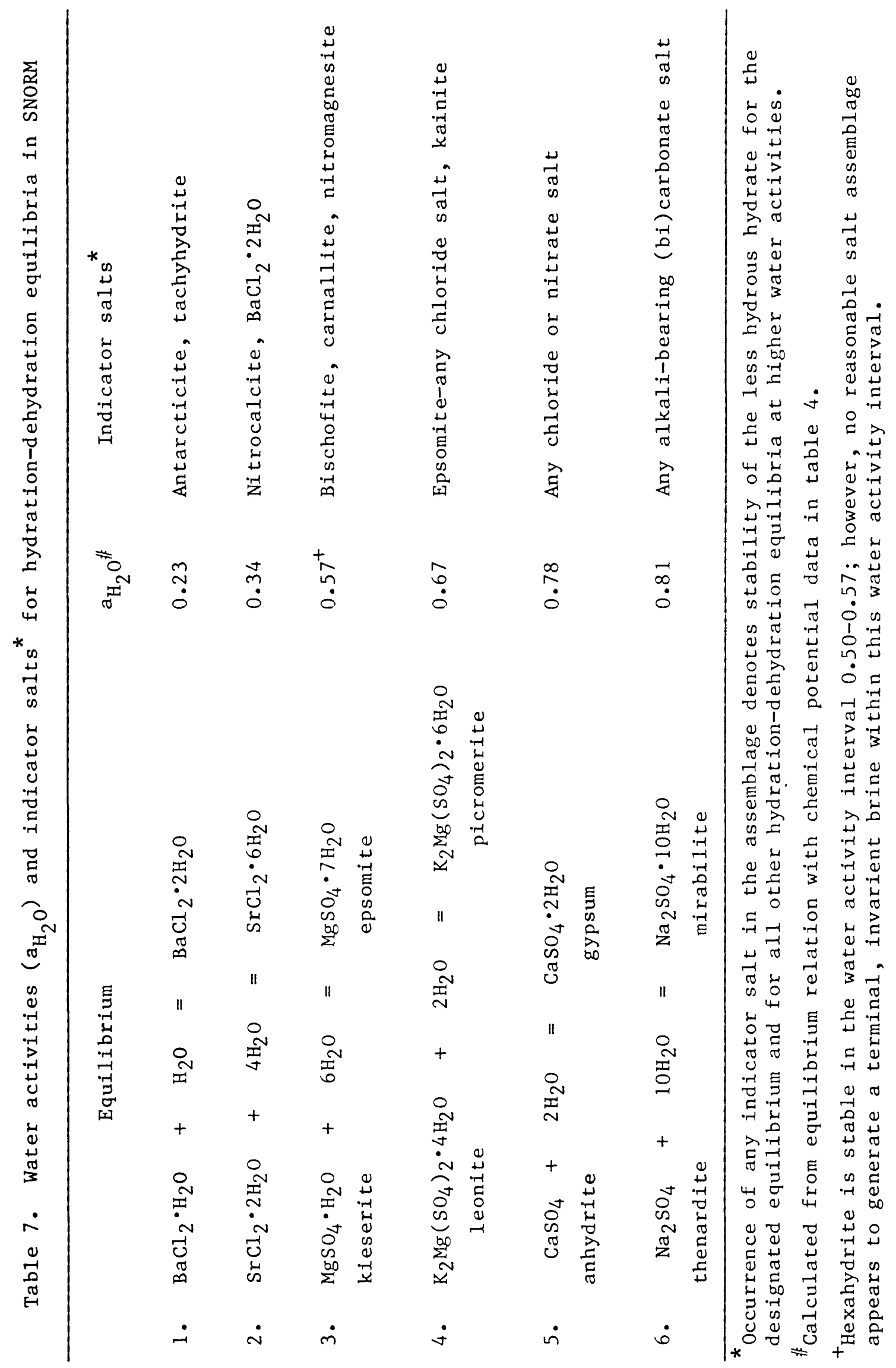


Water activity in a brine varies markedly as a function of brine composition, and a brine's invarient terminal composition, therefore its water activity, are fixed by the assemblage of coexisting salts. For example, a terminal brine coexisting with the antarcticite-tachyhydrite pair has a water activity $<0.2$; on the other hand, a terminal brine coexisting with a variety of sulfate salts and no chloride or nitrate salts in the assemblage has a water activity $>0.8$ (Harvie and others, 1982).

Thus, the array of salts constituting the assemblage defines the water activity in the terminal brine, and the presence or absence of selected "indicator" salts in the assemblage allows confident assignment of the stable hydration level to each of the six pairs of salts in table 7 . The presence of any indicator salt in the assemblage dictates stability of the lower hydration state for that hydration-dehydration pair and for each succeeding pair at higher equilibrium water activities in table 7; conversely, the absence of any indicator salt for that equilibrium and for any preceeding hydrationdehydration equilibrium at lower water activity dictates the stability of the higher hydration state in the normative assemblage.

\section{Simple Salt Assemblages}

The simple salt assemblage that is calculated by SNORM is recast from the normative salt assemblage and offers an abbreviated, simplified representation of the salt norm that may be useful in comparing waters or tracing their evolution. The simple salt assemblage is a quantitative listing of the constituent anhydrous simple salt components in those normative salts that are composed exclusively of major solutes. For example, a mole of normative polyhalite yields two moles of $\mathrm{CaSO}_{4}$ and one mole of each $\mathrm{MgSO}_{4}$ and $\mathrm{K}_{2} \mathrm{SO}_{4}$ that are assigned to the simple salt assemblage; a mole of normative borax, on the other hand, is ignored. Each simple salt is defined with an anion charge of -2 to maintain consistency throughout an array of simple salts; this results in molar units of the alkali chlorides being expressed as $\mathrm{Na}_{2} \mathrm{Cl}_{2}$ and $\mathrm{K}_{2} \mathrm{Cl}_{2}$. Twelve different simple salts are recognized: the carbonates (normative bicarbonate is expressed as carbonate in the simple salts), sulfates, and chlorides (chloride includes any bromide and iodide in solid solution) of each of calcium, magnestum, potassium, and sodium.

The advantages of the simple salt assemblage are twofold. First it offers a managable basis (12 different simple salts vs 63 different normative salts) for characterizing waters graphically for comparative and descriptive purposes, as well as a shorthand for describing a water-a $\mathrm{Na}_{2} \mathrm{CO}_{3}$ water or a $\mathrm{CaCl}_{2}$ water. Second, it offers to those lacking a mineralogic background a useful and understandable alternative to the compositional complexities and nomenclature of saline minerals. 
sulfate or carbonate, a spread in solute concentration of three orders of magnitude. Perhaps, the most profound consequence of this exercise will be the prediction of further evolution of solute composition out of contact with initial precipitates, particularly those containing more sparingly soluble constituents. However, interpretation becomes questionable for very dilute waters in which solute sources are dominated by aerosol dissolution, biologic degradation, or anthropogenic contaminants. Some effects of such initial contributions may remain despite extensive subsequent reaction in the normal weathering environment.

Hardie and Eugster (1970) have underscored the importance of the calcite and gypsum solubility "divides" in the subsequent solute evolution of concentrating waters. The required removal of $\mathrm{Ca}$ and carbonate or sulfate in equal proportions at the time of precipitation assures the continued dominance of whichever of the two constituents is most abundant at that point. As $\mathrm{Ca}$ must exceed both $\mathrm{CO}_{3}$ and $\mathrm{SO}_{4}$ to prevail at both junctures, it is easy to understand why calcium-dominated saline solutions are relatively uncommon. In fact, the excess of equivalent sulfate over calcium in seawater leads to its clear alkali-magnesium sulfo-chloride character with evaporative concentration. The importance of the two common, relatively insoluble calcium salts to the compositional evolution of natural waters is illustrated by a trilinear dfagram (fig. 3) taken from R. J. Spencer (Univ. of Calgary, personal commun. 1982). The plot of water compositions on this diagram will qualitatively predict the major-solute matrix of all saline waters. The calculation of salt norms permits these predictions to be made in a more quantitative way.

Readily discernible differences of genetic importance can be illustrated in the comparison of salt norms (table 8) for seawater and for the average world river compositions given by Livingstone (1963). The abundance of alkaline-earth carbonates, as represented by calcite and dolomite, the presence of alkali-bearing double sulfates glauberite and syngenite, and the relatively minor amount of halite as the sole chloride in the river-water norm differ markedly from the chloride-rich, carbonate-poor seawater assemblage. The contrast illustrates the fundamental difference in ultimate anionic source for reacting solutions $\left(\mathrm{H}_{2} \mathrm{CO}_{3} \mathrm{vs} . \mathrm{HCl}\right)$, and the more geochemically evolved state of the oceans as compared to most continental waters (Mackenzie and Garrels, 1966). It generally is agreed that the oceans achieved their present chloride concentration very early in earth history by degassing at $\mathrm{HCl} / \mathrm{H}_{2} \mathrm{O}$ ratios very close to present crustal values (Holland, 1984). Subsequent additions of primordal chloride to the hydrosphere compared to the mass of $\mathrm{Cl}$ in the oceans or sedimentary rocks can be considered negligible. 
At the same time there are two distinct disadvantages to exclusive use of the simple salt assemblage. First, any major solutes that are combined with minor solutes, such as sodium in normative borax or soda niter, are omfted from the simple salt assemblage. Second, the simple salt assemblage cannot be viewed as an equilibrium assemblage; recasting any normative compound salt into its simple salts immediately precludes an equilibrium association among the simple salts. Furthermore, the simple salt assemblage may well be an infraction of the Gibbs phase rule; the number of simple salts in the assemblage frequently exceeds the phase rule maximum. The simple salt assemblage should be considered as a useful supplement to, rather than a substitute for the salt norm.

\section{INTERPRETATION OF SALT NORMS}

Attempts to interpret the origin of the principal constituents dissolved in natural waters frequently have used fon ratios and graphical techniques. These considerations commonly rely on diagnostic relations between individual solutes, which remain relatively unaffected or follow known trends through subsequent geochemical evolution of the water mass. Such trends and relationships accompanying the extensive concentration of natural surface and subsurface waters have been generalized by Hardie and Eugster (1970), Eugster and Hardie (1978), Carpenter (1978), Eugster and Jones (1979), and Al Droubi and others (1980). These papers emphasize the control of major-element distribution in waters by precipitate mineral mass balances (particularly calcite, gypsum, and halite), and the potential of using constituents conserved in solution for tracing the geochemical history of any water.

The law of mass action requires that cations and anions be added or subtracted from solution in stoichiometric proportion by the congruent dissolution or precipitation of a mineral. Thus, molar proportions of ions in a given water reflect the composition of original simple salt minerals or the products of nonsalt mineral dissolution by natural acid (carbonic from the hydrolysis of $\mathrm{CO}_{2}$ or sulfuric from oxidation and hydrolysis of sulfides). The computational association of cations and anions into a salt norm, such as is done in SNORM, quantitatively projects an eventual disposition of the dissolved constituents according to the most stable salt assemblage at $25^{\circ} \mathrm{C}$ and one bar pressure.

Outside a system closed to all components except $\mathrm{H}_{2} \mathrm{O}$, the computation does not directly address the geochemical evolution of a natural water, but much may be inferred from some knowledge of relative solubility sequence, preclpitation kinetics, and geologic setting. Such interpretation must allow for the differences in environmental influences likely to accompany the range in solubility between alkaline-earth carbonate, calcium sulfate, and alkali 


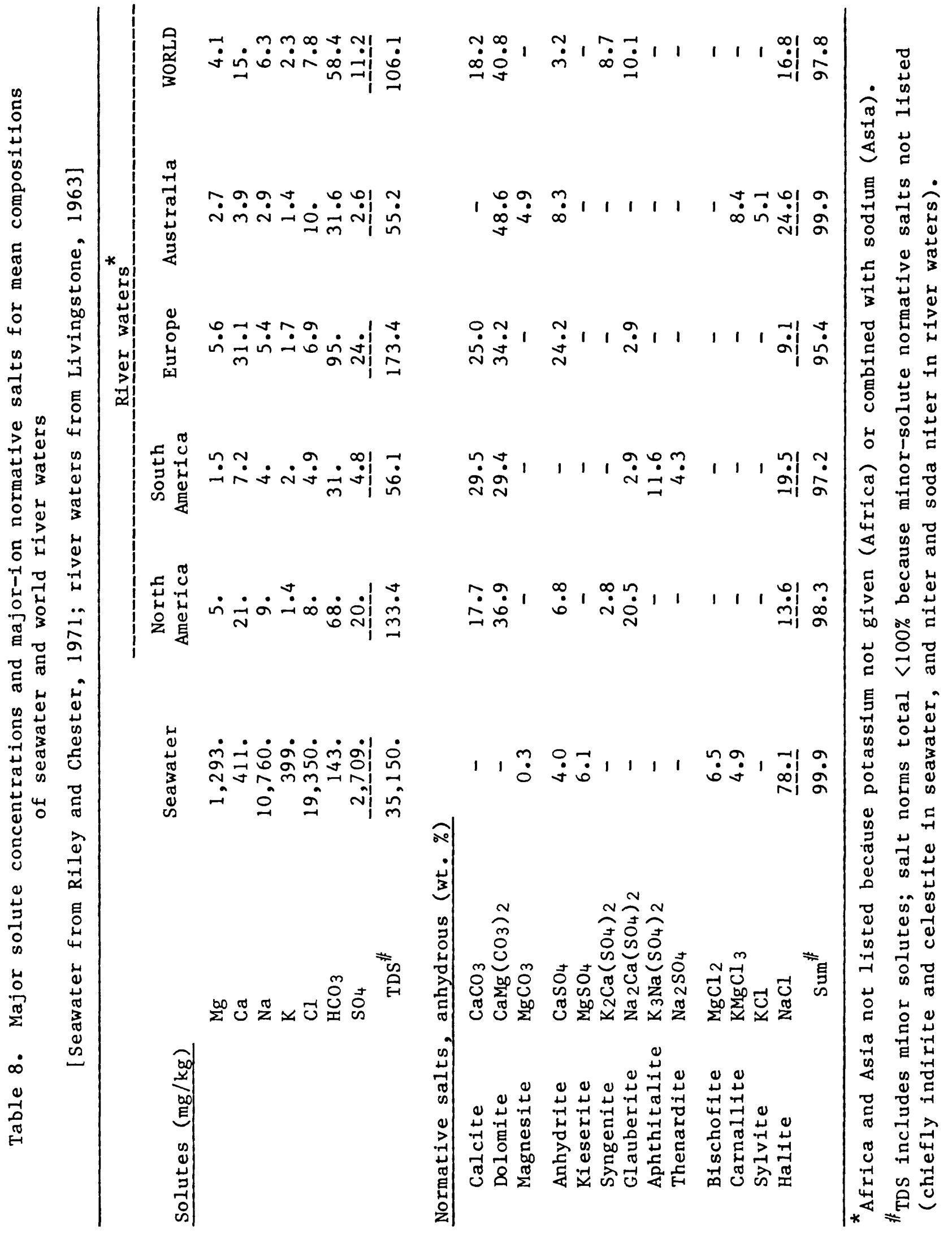




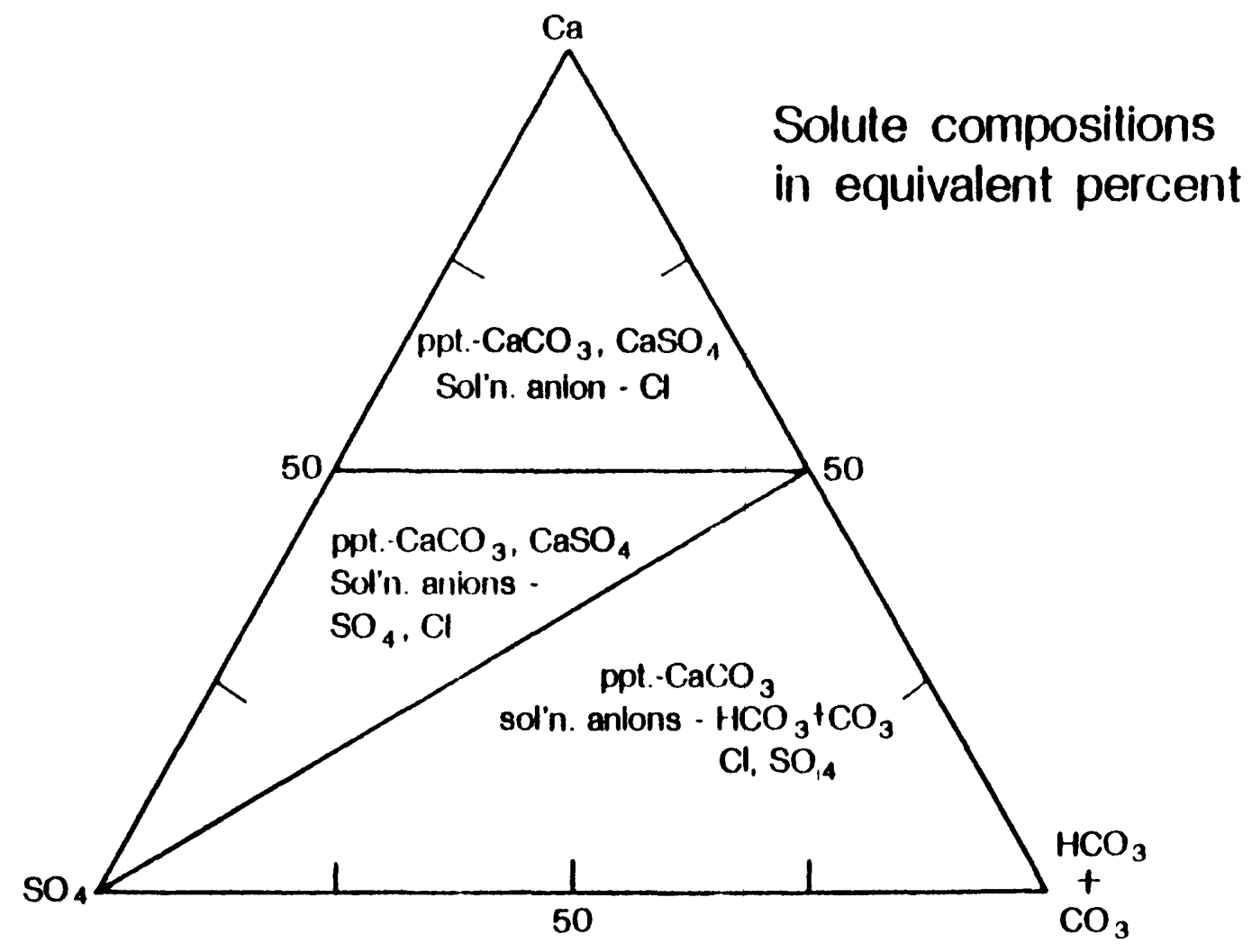

Figure 3. Trilinear diagram from R. J. Spencer differentiating the solute compositions of natural waters according to the relative proportions of calcium, carbonate species, and sulfate. The diagram illustrates the importance of the calcite and gypsum "divides" to evolving solution composition. The fields of the diagram are labeled with precipitates and dominant solution anions to be expected on further evaporation.

The extent of variance in salt norms for continental waters in table 8 can be seen through the differences in assemblage, as well as amounts, for the average river waters of some continents. Note the more sodic North American waters (led by the Mississippi River system) are characterized by abundant glauberite, the more potassic waters from South American (dominated by the Amazon) produce aphthitalite, and the more chloridic Australian waters (principally the River Murray) make normative sylvite. Despite a variance of 3 times in carbonate-species concentration, the four average river norms all contain between 50 and 60 weight percent carbonate minerals. All the river norms contain halite ( $<20$ percent) and only the South American average lacks anhydrite (all sulfates of this assemblage are alkali-bearing).

The contrast in salt norms between the average river waters and seawater but also between the river waters themselves, suggests the usefulness of the 


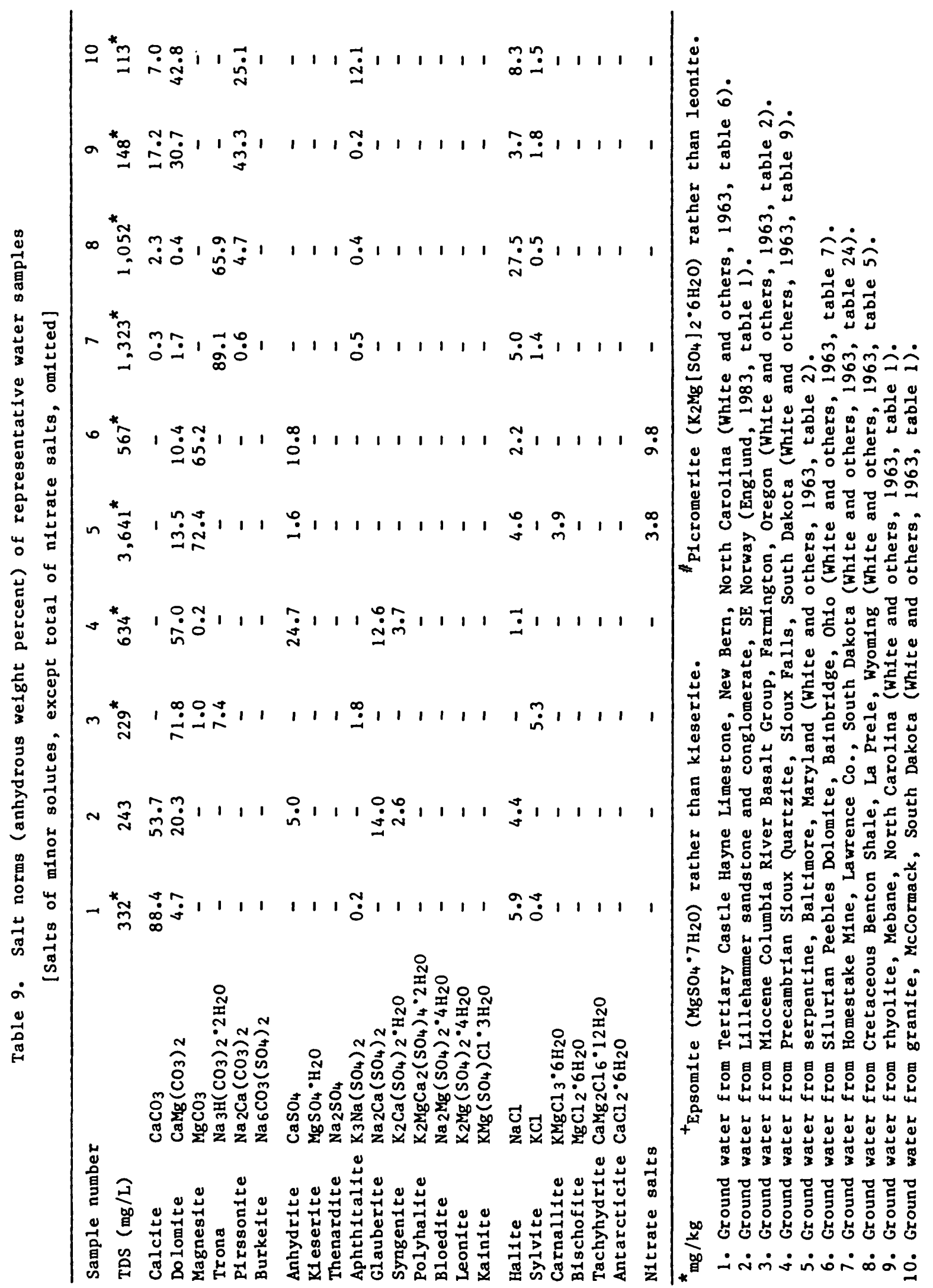


salt norm in identifing solute sources despite the lack of direct information on the geochemical evolution of the waters. Except for dilute waters deriving their principal solutes from surficial sources, major-solute categories can most readily be related to principal 1ithologies (Jones, 1966; Garrels, 1967; Hem, 1970; and Drever, 1982). Thus, for the major anions, carbonate waters are associated with the dissolution of limestones or silicate hydrolysis. Sulfate waters reflect the oxidation of reduced sulfur and/or the dissolution of gypsum. Chloride waters are most likely associated with an ultimate source in marine salts or hydrothermal systems, though they commonly are recycled and modified in continental basins, such as the Great Salt Lake (Spencer and others, 1985). At the same time, for the major cations, the alkalis are prominent in waters associated with siliceous crystalline rocks, pyroclastics, and the sediments derived therefrom; calcium is dominant in waters from carbonate or plagioclase-rich rocks; magnesium is characteristic of waters interacting with mafic rocks and marine muds; and all the major cations can be important in waters associated with mixed clastic lithologies. Such considerations, particularly for saline waters, can point to normative salt assemblages characteristic of genetic end members.

To test the interpretive value of the normative analysis and to establish the most diagnostic assemblages, we have computed salt norms for more than 500 analyses of fresh and saline waters from a wide variety of environments worldwide. From the final tabulations we have selected 50 examples (table 9) to illustrate a broad range of normative characteristics. Because solute derivation is most readily related to mineral reaction and tends to be of much interest in salinity problems, particular attention was given to various ground waters, seawater mixtures, and saline basin waters. In table 9, normative salt minerals are arranged according to major anion groups in order of carbonates, then sulfates, then chlorides, with mixed anion phases intermediate. Within each anion group, the sequence generally is from simple, single cation-anion phases to more complex double salts, with minor exceptions, this sytem corresponds to increasing single-phase aqueous solubility. Our attempt to reconcile increasing salt complexity with increasing solubility produces a different cation sequence for the chlorides than for the carbonates and sulfates.

We tried to choose sample salt norms for table 9 so as to have two examples with abundant amounts of each major-solute phase, some additional samples were taken from special 11 thologic environments or from unusual normative salt assemblages. From the results of all the salt-norm computations, a diagnostic chart has been derived (fig. 4). Although many natural waters reflect multiple solute origins, salt norms basically fall into three major categories: meteoric, marine, and diagenetic. These general 


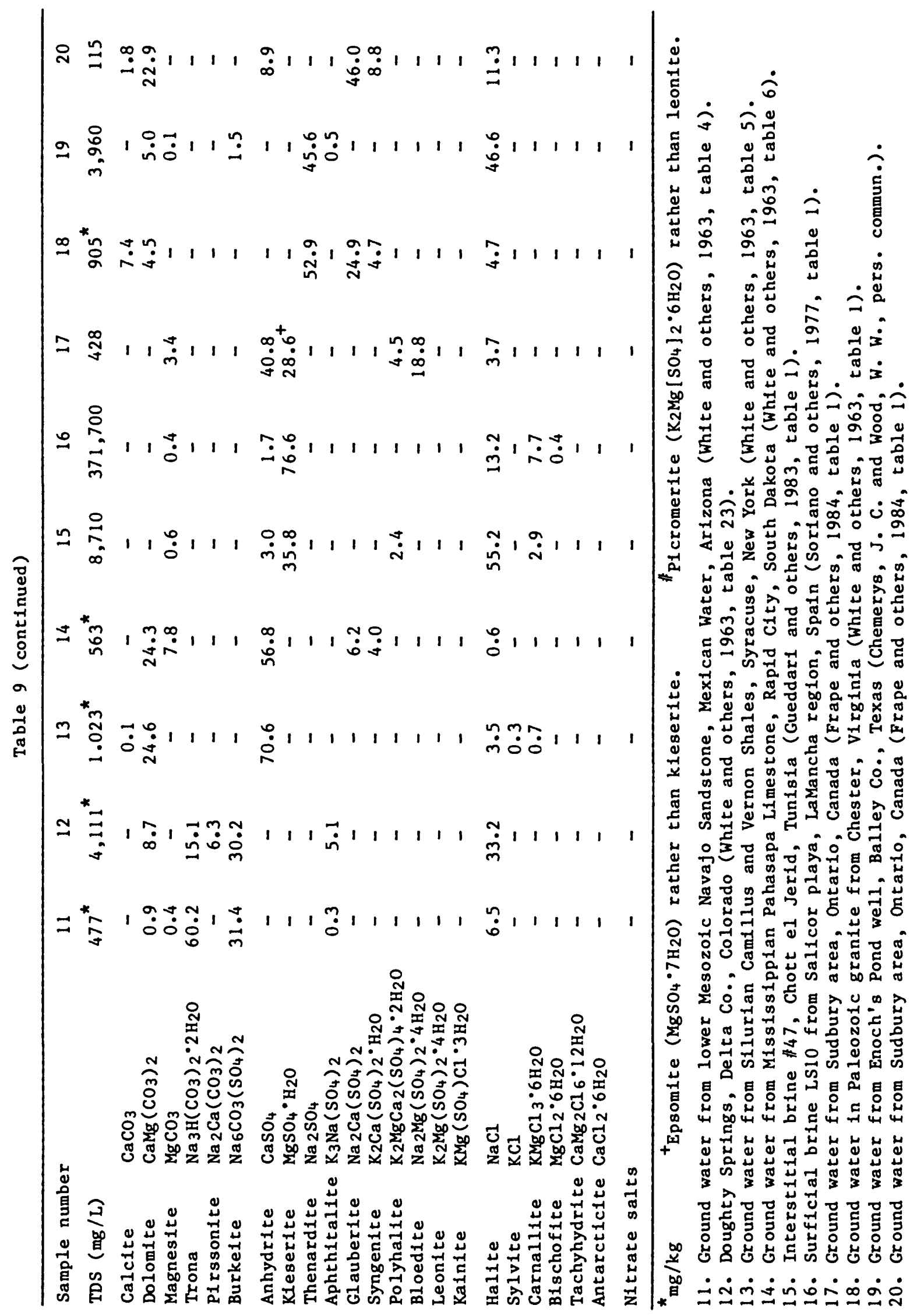




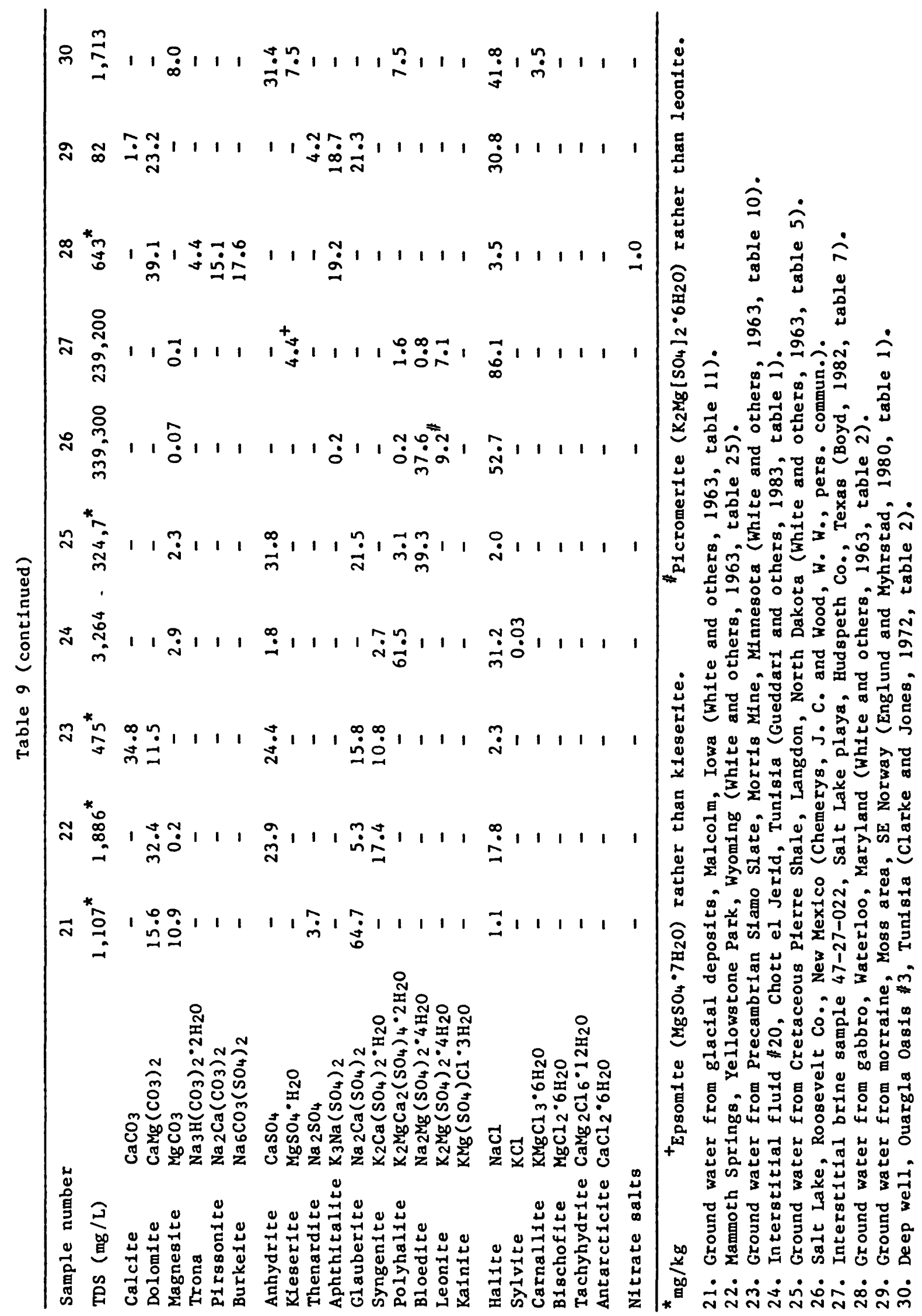




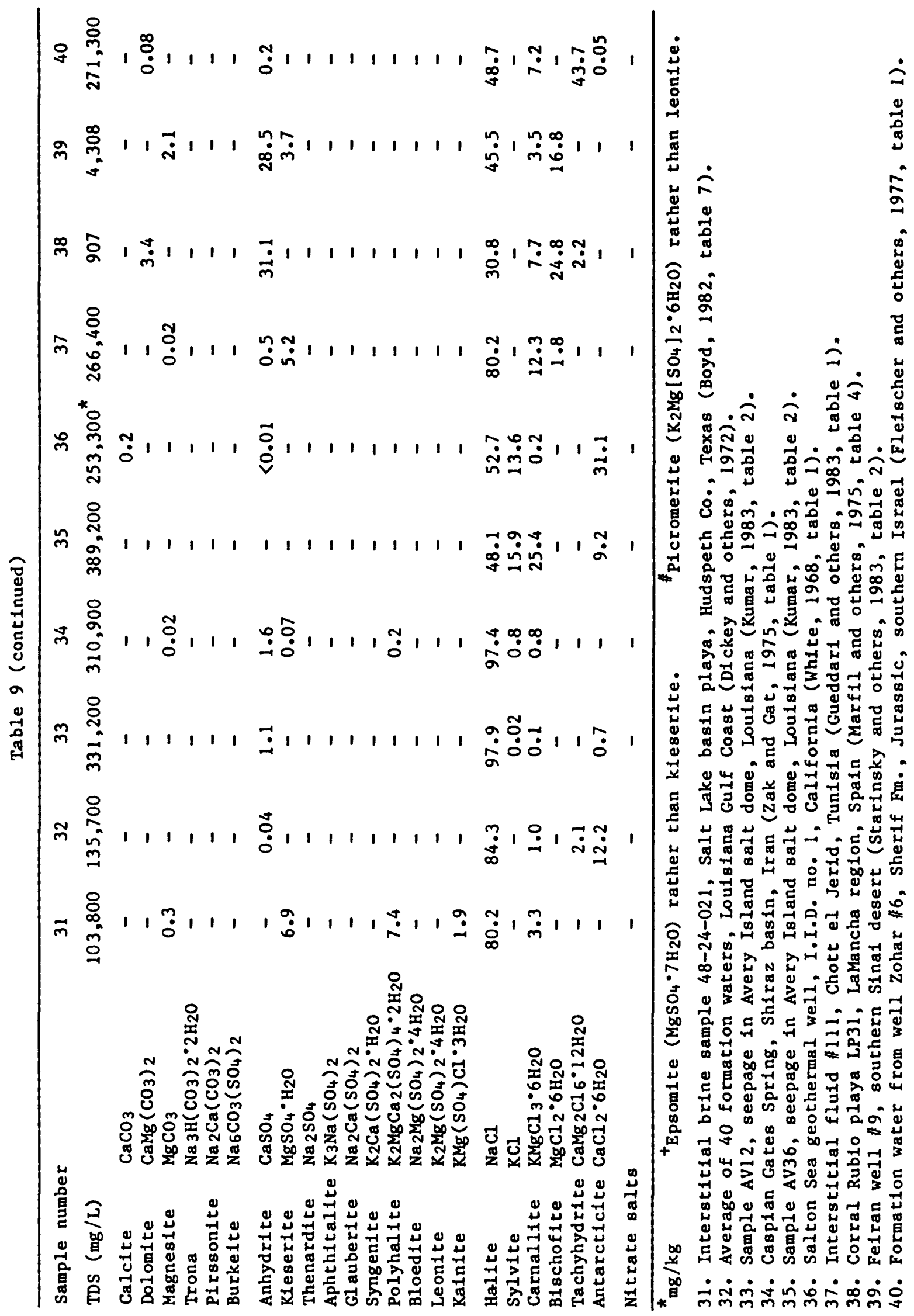




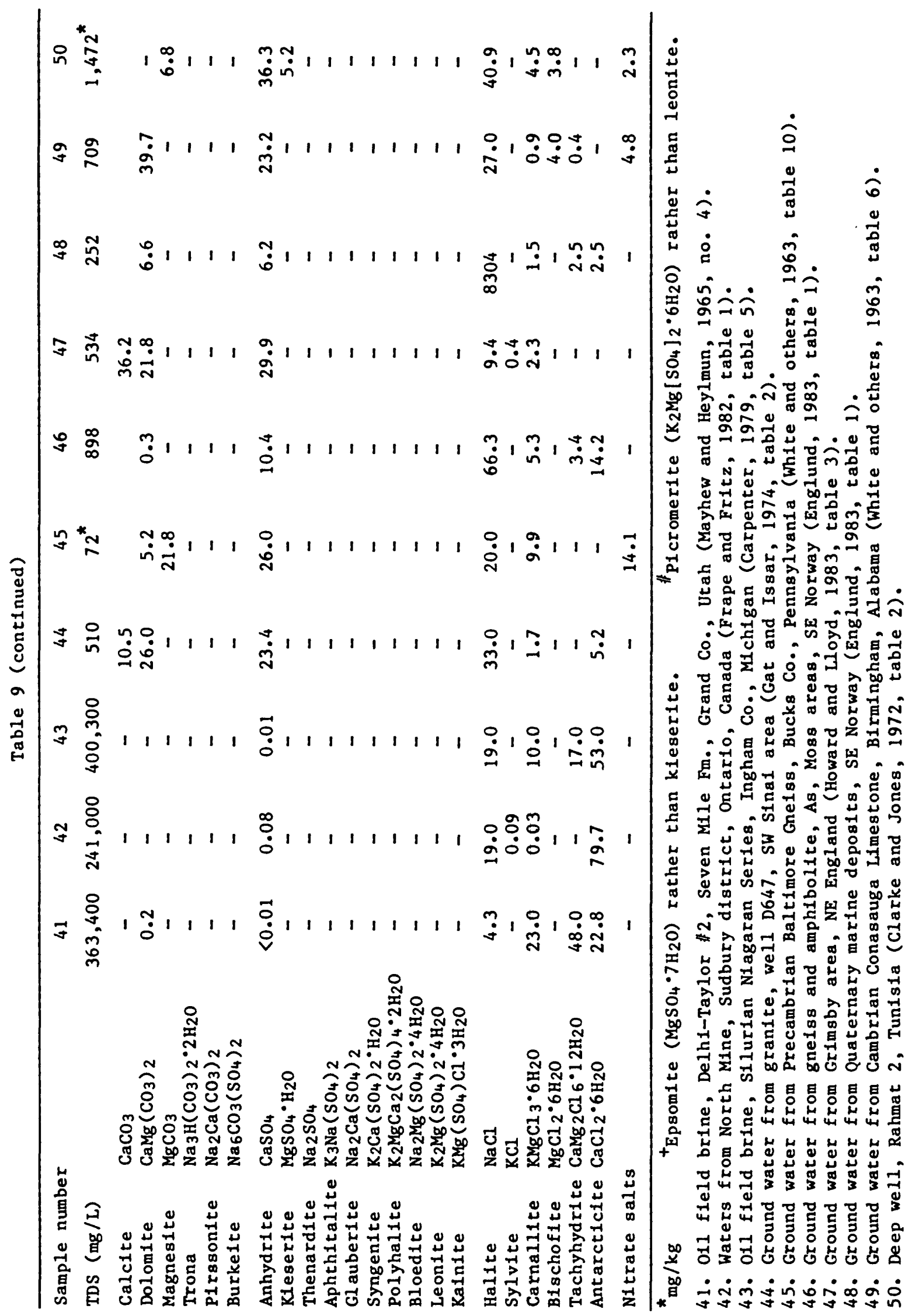



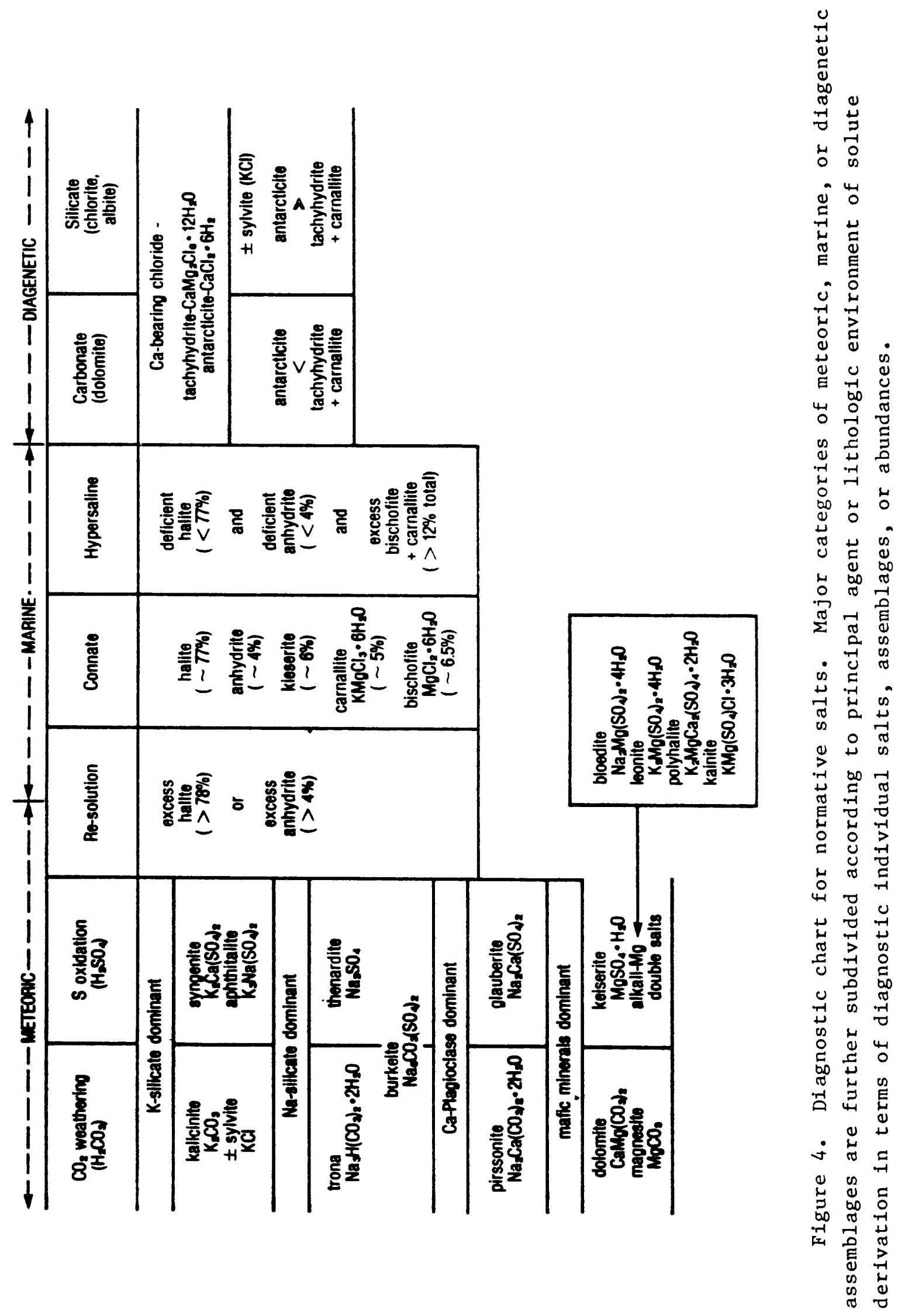
categories are based on qualitative similarity of complete normative assemblages rather than on detalled characteristics of the constituent phases.

\section{Meteoric Norms}

Salt norms for meteoric water deriving their solutes principally from rock weathering reflect the principal agent promoting dissolution in the pedogenic environment. In addition to direct aqueous dissolution of mineral salts, such as the carbonate minerals, carbonic acid and sulfuric acid in meteoric waters each generate their characteristic solute compositions. A distinctive feature of the normative assemblages from meteoric waters is the absence of the alkaline-earth-bearing chlorides.

Carbonic acid hydrolysis of rock-forming minerals produces a salt norm dominated by carbonate minerals (table 9). The very high calcite abundance in the norm from the Tertiary Castle Hayne Limestone (\#1) of North Carolina or the calcic Permian clastics of SE. Norway (\#2), and the abundant normative dolomite in waters from the Mississippian Pahapsa Limestone of South Dakota (非14) and the Cambrian Conasuaga Limestone of Alabama (非49) are examples of straight forward cabonate-rock dissolution. The occurrence of normative alkali carbonate phases (trona or kalicinite), on the other hand, is diagnostic of silicate hydrolysis. Examples of silicate hydrolysis are given in table 9 in the trona-bearing salt norms for ground waters from siliceous crystalline or clastic rocks, for example, the granite of the Black Hills, South Dakota (\#7), the Cretaceous Benton Shale of Wyoming (非), or the lower Mesozoic Navajo sandstone, Arizona (非1).

In the absence of carbonate rock dissolution, contrasts in amounts of trona, alkali alkaline-earth double carbonate (pirssonfte), and alkaline-earth carbonate in the norm reflect variations in the alkali/alkaline-earth ratios in silicate minerals (feldspar and pyroxene or amphibole) in the associated lithologies. Increased importance of Ca-plagioclase and/or mafic minerals is reflected in the norms for ground water from the granite of McCormack, South Carolina (table 9, 非10), or metamorphosed volcanic rocks at Mebane, North Carolina (table 9, 非). The norms for waters associated with normal carbonic acid weathering of mixed alkali-bearing silicate rocks commonly contain sylvite (table 9, $3,7,8,9,10)$. The lower solubility of the trona-sylvite pair compared to that of the kalicinite-halite pair under atmospheric conditions leaves potassium associated with chloride in the normative calculation. Normative kalicinite appears only in salt norms for ground waters where potash feldspar is the dominant solute source. Large amounts of normative dolomite can result from hydrolysis of mixed $\mathrm{Ca}-\mathrm{Mg}$ silicates, such as the plagfoclase-pyroxene mineralogy of basalt or gabbro (table 9 , \#3 and 28). Abundant normative magnesite, on the other hand, requires hydrolysis of 
dominantly magnesium silicate, such as serpentine (table 9, 非), biotite (table 9, 非5), or even Mg clays in carbonate rock (table 9,

Meteroic waters alded in weathering by sulfuric acid derived from the oxidation of sulfides (perhaps cycling through acid rain; table 9, 非 and 非29) produce salt norms characterized by sulfate minerals. Predominant anhydrite in the norm can, of course, simply reflect dissolution of original evaporitic $\mathrm{CaSO}_{4}$, such as in waters from the silurian gypsiferous red beds of central New York (table 9, 非13) and the gypsiferous Pahasapa Limestone of South Dakota (\#14). In addition, abundant normative potassium-magnesium-mixed sulfates can be characteristic of residual meteoric fluids following fractional precipitation of gypsum and/or carbonates (table 9, $\$ 27$ and $\# 31$ ).

The presence of either of the pure alkali sulfates, thenardite $\left(\mathrm{Na}_{2} \mathrm{SO}_{4}\right)$ and aphthitalite $\left(\mathrm{K}_{3} \mathrm{Na}\left(\mathrm{SO}_{4}\right)_{2}\right)$, or of the alkall sulfo-carbonate, burkelte $\left(\mathrm{Na}_{6} \mathrm{CO}_{3}\left(\mathrm{SO}_{4}\right)_{2}\right)$, or of the alkali-calcium double salts, glauberite $\left(\mathrm{Na}_{2} \mathrm{Ca}\left(\mathrm{SO}_{4}\right)_{2}\right)$ and syngentie $\left(\mathrm{K}_{2} \mathrm{Ca}\left(\mathrm{SO}_{4}\right)_{2}{ }^{\circ} 2 \mathrm{H}_{2} \mathrm{O}\right)$ can be considered diagnostic of sulfatic-weathering solutions. The former can be expected from waters associated with the weathering of siliceous crystalline rocks and their clastic derivatives, whereas, the glauberite and syngenite reflect more calcic lithologies. Solute magnesium derived from sulfuric-acid hydrolysis of mafic lithologies may appear in salt norms as the monohydrate sulfate, keiserite, or its more hydrous equivalent, epsomite. Usually, however, the magnesian component of hydrolysis appears in the salt norm as dolomite or as the alkalibearing complex salts bloedite $\left(\mathrm{Na}_{2} \mathrm{Mg}\left(\mathrm{SO}_{4}\right)_{2}\right)$, polyhalite $\left(\mathrm{K}_{2} \mathrm{MgCa}\left(\mathrm{SO}_{4}\right)_{3}\right)$, leonite $\left(\mathrm{K}_{2} \mathrm{Mg}\left(\mathrm{SO}_{4}\right){ }_{2} \cdot 4 \mathrm{H}_{2} \mathrm{O}\right)$, or kafnite $\left(\mathrm{KMg}\left(\mathrm{SO}_{4}\right) \mathrm{Cl} \cdot 3 \mathrm{H}_{2} \mathrm{O}\right)$. The occurrence of such sulfates in the salt norm indicates sulfuric-acid hydrolysis of mixedmafic silicate, either from crystalline rocks (table 9, \#17) or fine clastic sediments (table 9, 非5). Examples of sulfate-rich norms spanning the whole range of crystalline and clastic 1ithologies are given in table 9 for waters associated with granite in Virginia (非18), granitic basement derived glacial deposits in Iowa (非1) or gabbro at Waterloo, Maryland (非28), basic plutonic rocks at Sudbury, Ontario(非7), and calcic micaceous slate from northern Michigan (\#23).

\section{Marine Norms}

Seawater-type norms dominated by sulfate and chloride salts are particularly characterized by magnestum-associated chloride. This association cannot be obtained from hydrothermal sources because of the aqueous insolubility of $\mathrm{Mg}-\mathrm{silicates}$ at elevated temperature. Such an association in the salt norm from other than ultimately marine sources would require dissolution of chloride-bearing mafic minerals.

Normative diagnosis of marine solute sources is complicated not only by 
mixing or continental recycling, but also by solute redistribution within and marginal to the marine environment. Three subdivisions can readily be recognized: connate, resolution, and hypersaline. These categories are based on abundance, as well as the presence or absence of key phases in the salt norm. Thus, any unaltered connate seawater dilution or dilution therof should give the seawater salt norm (table 8 ) with the characteristic assemblage halite-anhydrite-kieserite-carnallite-bischofite in the proportions given (as also shown in fig. 4). A solute matrix derived from resolution of the most common evaporite minerals, halite and gypsum, is derived in the same way as other meteoric waters; the matrix will be enriched in $\mathrm{NaCl}_{1}$ and $\mathrm{CaSO}_{4}$ and depleted in the other constituents. In contrast, the solutes of a hypersaline marine bittern will be depleted in $\mathrm{NaCl}_{\text {and }} \mathrm{CaSO}_{4}$ because of fractional precipitation of those salts, but the salt norm will include excess magnesium and, most likely, potassium-bearing chloride salts. This is because the molar ratio of chloride to sodium in seawater is greater than unity (the molar value is 1.17 ), so that the next most abundant cations, $\mathrm{Mg}$ and $\mathrm{K}$, both appear as chlorides in the salt norm. Changes in proportions of the major normative salts corresponding to the evaporative concentration of seawater are given in table 10, as calculated from the analyses of hypersaline 1iquors in coastal marine-salt evaporation ponds.

of all the samples for which salt norms were calculated, only a few computations produced results similar to those expected for dilution of connate seawater. This is expected, as mixing, continental recycling, or mineral-water interaction of any sort should produce differences from seawater proportions. Because of the relative stabilities of the minerals considered by SNORM, additions of calcium, carbonate, or sulfate to a seawater solute matrix will appear in the salt norm as excess magnesite and anhydrite; this also can eliminate bischofite and introduce sylvite into the norm as $\mathrm{Mg}$ becomes associated with carbonate or sulfate rather than with chloride. Additions of sodium will be seen as $\mathrm{NaCl}$, with an associated redistribution of other mineral proportions, depending on the accompanying anion. Thus, an excess of magnesite, anhydrite, or halite over that in the seawater norm appears indicative of mixing with meteoric solutions or continental cycling. The effects of marine aerosols may be seen in the dilute waters of some areas subject to coastal precipitation patterns (table 9, 非5 and 非7).

The waters that most closely approach the seawater norm are from the continental saline basins of northern Algeria (table 9, Chott el Jerid, \#37) and western Australia (table 11). The former has an overall excess of chlorides and a deficiency of sulfate, indicating hypersaline conditions. However, the halite compared to the seawater norm suggests some resolution as we11. The Yilgarn examples include (1) groundwater norms with definite, 


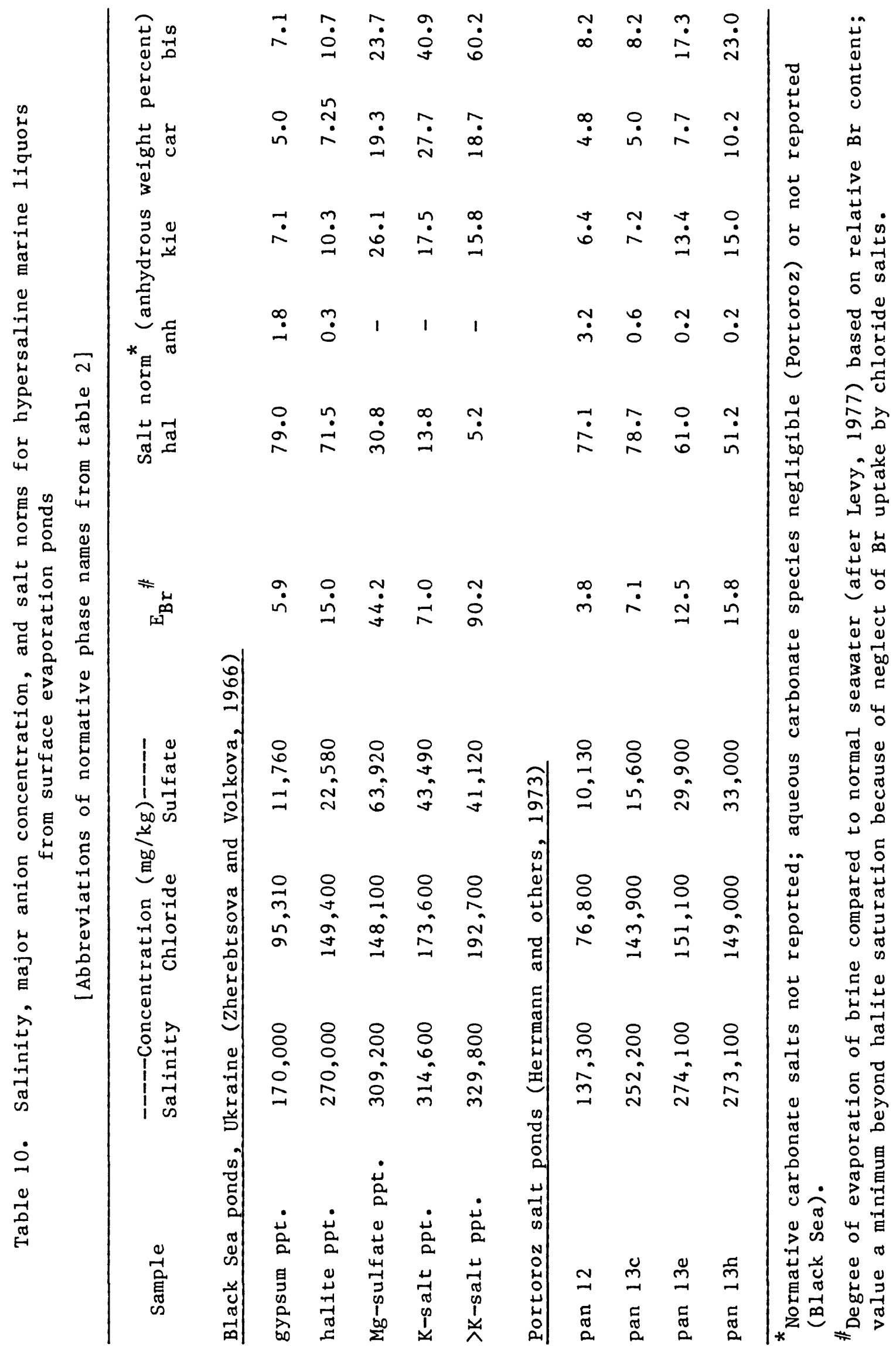




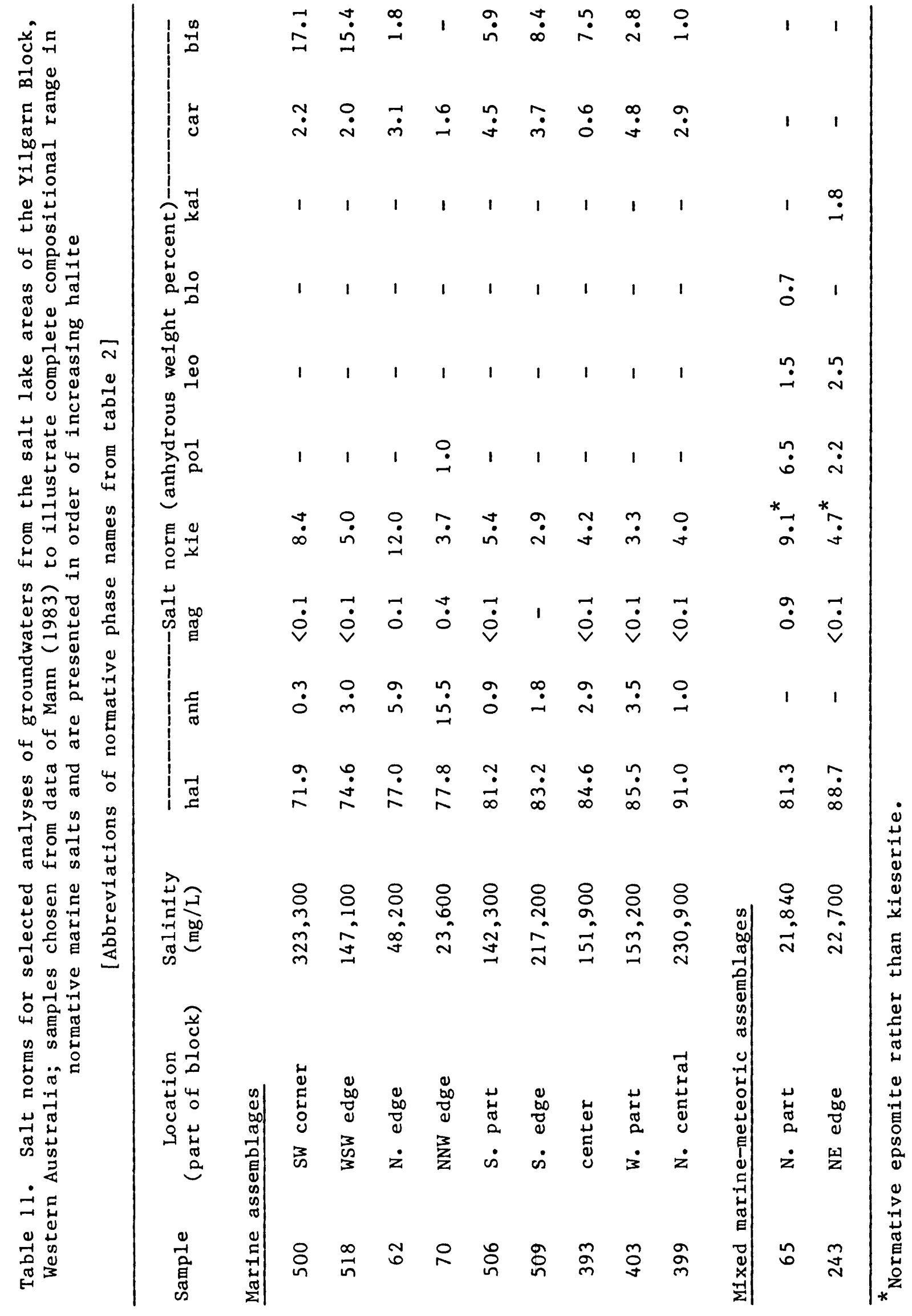


though small, deficiencies of halite and anhydrite along with sufficient bischofite; these salts indicate clear hypersaline affinities (table 11, \#500

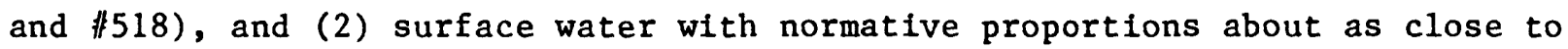
seawater as might be imagined in continental environs. Most of the Yilgarn salt norms, however, show a telltale excess of halite resulting from resolution. In fact, the majority of the Yilgarn salt norms (table 11) produce enough excess halite to suggest recycling of marine solutes with little contribution from direct weathering of the granitic crystalline basement of the region (unless dominated by chloride-bearing mafic minerals). However, the normative salt abundances for some Yilgarn samples

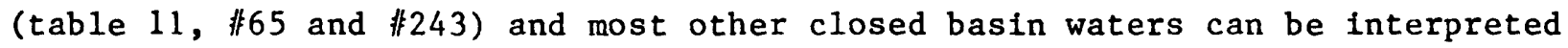
as the result of mixing of meteoric weathering solutions with a recycled marine-solute matrix. Well water from the north Sahara produced a complete seawater assemblage in the salt norm (table 9, 150 ) but with hallte and bischofite quantities much reduced and anhydrite and magnesite increased over a seawater norm primarily because of addition of sulfate and carbonate solutes from continental sources. Similarly, well water of the southern Sinal (table 9, \#39), is deficient in normative halite and has an excess of magnesium chloride suggesting a hypersaline solute origin as supported by strontiumisotope evidence (Starinsky and others, 1983). Excess normative anhydrite and magnesite, however, suggest additional (meteroic) solute contributions.

A key normative mineral indicator of meteoric additions to a marine-type, sulfo-chloride anion matrix is the unusual mineral, kainite $\mathrm{KMg}\left(\mathrm{SO}_{4}\right) \mathrm{Cl} \cdot 3 \mathrm{H}_{2} \mathrm{O}$. This phase appears in the norms of samples from the edge of the Yilgarn block (table 11, 非43) and from the Salt Lake playa of West Texas (table 9, 非1), which has derived the bulk of its solutes from weathering of the evaporitic Permian strata of the area. These salt norms represent the addition of excess sulfate to a marine solute matrix, while the proportions of alkalies and $\mathrm{Mg}$ were maintained.

A less diagnostic mineral commonly appearing in salt norms for modified marine waters is sylvite. If a water containing alkaline-earth or sodium chloride is mixed with a water containing potassium sulfo-carbonate from weathering, the salt norm calculation will associate the carbonate and sulfate with the other cations. After consuming avallable $\mathrm{Mg}$ in polyhalite, kainite, or carnallite, $\mathrm{KCl}$ is left as a distinct phase. Mixing of any other type of water with a residual marine bittern merely increases the likelihood of sylvite occurring as a single phase in the salt norm. Thus, additional information besides the presence of sylvite in the norm is needed to suggest solute affinities. The appearance of sylvite in normative alkali sulfocarbonate assemblages attests to its compatibility with weathering solutions; however, its presence within other chloride-dominant normative assemblages 
bespeaks its involvement in different phenomena, which will be discussed below.

Another normative mineral that can serve as an indicator of mixing of weathering solutions with a seawater-type solute matrix is kieserite. The abundance of normative kieserite can be reduced by addition of redissolved halite and/or calcium sulfate. Normative kieserite is increased in a solute matrix with additions of sulfate from weathering, regardless of whether subsequent sequential evaporative precipitation of $\mathrm{CaSO}_{4}$ and/or $\mathrm{NaCl}$ occurs (table 9, 非 15 and $\#_{16}$ ). The addition of dilute calcium sulfo-carbonate solutes typical of meteoric waters to oxic, gypsum-saturated, hypersaline fluids also will deplete normative kieserite through loss of sulfate with calcium and of magnesium with carbonate (the latter will also result from sulfate reduction). Without the low values for activity of water generated by coexistant hydroscopic chlorides, kieserite is unstable relative to its more hydrous equivalent, epsomite $\left(\mathrm{MgSO}_{4}{ }^{\circ} 7 \mathrm{H}_{2} \mathrm{O} ;\right.$ table $\left.9, \ldots 27\right)$. Kieserite occurs in the norm of all but 4 of 48 analyses from the Yilgarn block, western Australia (table 11).

Waters illustrating the extreme proportions of solute $\mathrm{NaCl}$ that can result from halite resolution in the subsurface include a salt dome mine seepage (table 9, \#33) and a surface spring associated with a shallow subsurface dome (非4). The clear indication that excess halite from salt resolution predominates over solute diagenesis, as suggested by Hanor (1984), also is indicated in the salt norm for the average of 40 formation waters from the Louisiana Gulf Coast (table 9, \#32).

The chloride minerals characteristic of hypersaline marine fluids and similar continental and modified sedimentary basin brines, as well, are bischofite $\left(\mathrm{MgCl}_{2} \cdot 6 \mathrm{H}_{2} \mathrm{O}\right)$ and the $\mathrm{K}-\mathrm{Mg}$ double halide, carnallite $\left(\mathrm{KMgCl}_{3} \cdot 6 \mathrm{H}_{2} \mathrm{O}\right)$. Small quantities of these minerals also appear in the norm of relatively dilute ground waters associated with diverse rock types, suggesting the presence of seawater-type solutes and possibly aerosols; in ground waters from coastal sediments (table 9, 非), the latter is most likely the case. Ground waters in crystalline rock terranes of the United States, Canada, and Scandanavia (table 9, \#5, \#45, and \#46), however, may contain solutes of diagenetic origin. Substantial normative amounts of bischofite. carnallite, and/or sylvite are computed for brines of clearly saline strata or dilutions

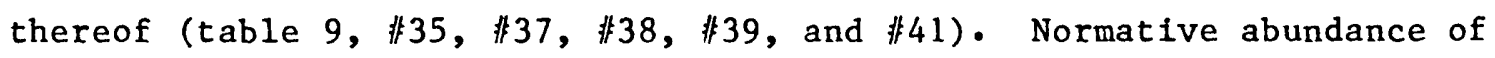
carnallite and bischofite more than the amounts found in the seawater norm appear to be clearly associated with hypersaline waters. 


\section{Diagenetic Norms}

The calcium-bearing chloride minerals, antarcticite $\left(\mathrm{CaCl}_{2}{ }^{6} \mathrm{H}_{2} \mathrm{O}\right)$ and tachyhydrite $\left(\mathrm{CaMg}_{2} \mathrm{Cl}_{6} \cdot 12 \mathrm{H}_{2} \mathrm{O}\right)$, indicate solute diagenesis and the highly altered fluid compositions with respect to earth-surface conditons. Yet, calcium chloride-bearing normative assemblages were computed for a number of analyses representing diverse conditions. Nearly all such salt norms were obtained from subsurface fluids associated with deep sedimentary basins, highly saline strata, or crystalline shield areas (table 9, 非2-33, 非5-36, \#40-44, and 非6). Notable exceptions occur in a few salt norms from coastal marine sediments (table 9, 非8). Assemblages containing calcium-bearing chlorides are most readily interpreted in terms of the diagenetic alteration of a residual marine-solute matrix dominated by magnesium salts through exchange of $\mathrm{Mg}$ and $\mathrm{Na}$ in solution for $\mathrm{Ca}$ in solids--that is, carbonate, clay minerals, or feldspar. Such exchange in silicates is promoted by elevated temperature through decrease in the solubility of magnesium silicate phases. The resulting fluld can be expected to produce an antarcticite-sylvite norm (table 9, \#36). The blending of marine bittern with a deep sedimentary basin brine or hydrothermal fluid is the process postulated by Knauth and others (1980) for the Loulsiana salt dome brines. Addition of exchanged solute calcium to a marine bittern would all but eliminate sulfate from the fluid by precipitation of anhydrite. In variable proportions, exchange of other ions for calcium is characteristic of all the most concentrated solutions encountered in the subsurface.

Diagenetic salt norms can apparently be subdivided on the basis of the phase ratios of calcium chloride to magnesium chloride. The development of calcium chloride brines in the Bardawil Lagoon area of north Sinai by evaporative concentration, by mixing with shallow meteoric ground waters, and by dolomitization of carbonate sediments has been documented by Levy (1977). Salt norms for representative analyses from the Bardawil Lagoon are given in table 12. In no instance does the $\mathrm{Ca} / \mathrm{Mg}$ concentration (or salt norm antarcticite/tachyhydite) ratio exceed unity. However, the decreasing ratio of activity coefficients for $\mathrm{Ca} / \mathrm{Mg}$ with increasing fluid concentration permits an increasing molar $\mathrm{Ca} / \mathrm{Mg}$ ratio in equilibrium with dolomite. The ratio to be found in many natural solutions, however, will differ with respect to the solute matrix and the structural state of the $\mathrm{Ca}$ and $\mathrm{Mg}$ carbonates. Although it is impossible to determine an exact 1 imit for $\mathrm{Ca} / \mathrm{Mg}$ above which dolomitization alone cannot account for the relative normative abundances, the ratio probably is from 4 to 5 (Stoessel and Moore, 1984).

Very large ratios of normative antarcticite to magnesium chloride salt ratios clearly are associated with silicate authigenesis--most specifically, 


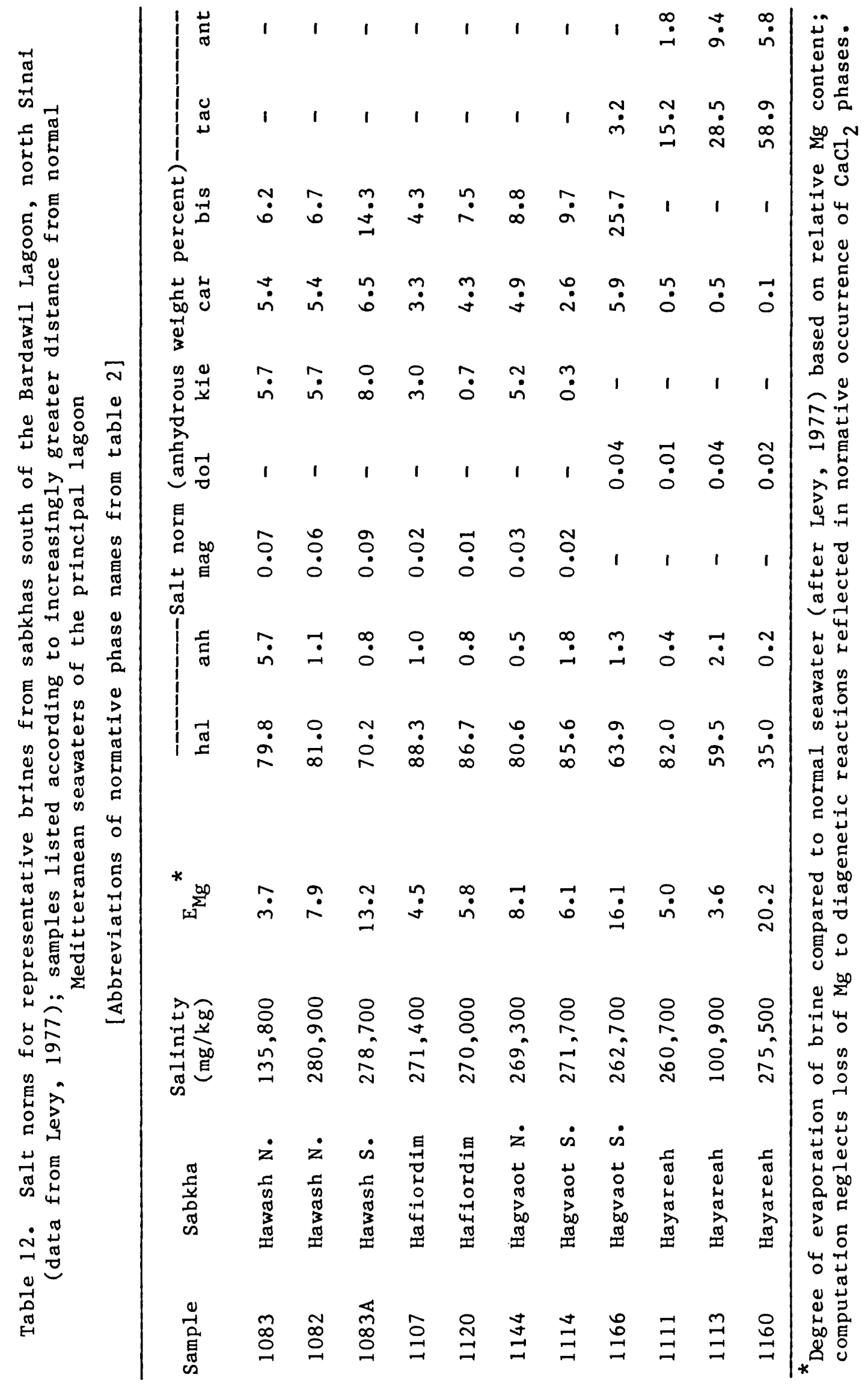


the formation of chlorite and albite. The best examples in table 9 are in the crystalline shield brine from Canada (\$42) and the sedimentary basin brine of Michigan (非3). Additions of minor amounts of these solute matrices to alkali carbonate or sulfate-bearing waters can readily obliterate the $\mathrm{CaCl}_{2}$ signature (as perhaps in table 9, \#39 and \#45), but salt norm examples are found where small amounts of antarcticite suggest such a contribution (table 9, \#44 and \#46). Although calcium is usually strongly preferred on clay-mineral cation exchange sites, the possibility of displacing some calcium to the solution by high solute concentrations of other cations must, however, be considered.

\section{Summary}

Examination of more than 500 salt norms calculated from water analyses representing a wide range of concentrations and hydrochemical settings has suggested that certain key phases or assemblages are characteristic of solute origin. In addition, it appears that the interpretation of the salt norm can depend on the relative abundance of diagnostic phases, as well as their presence or absence. Normative assemblages calculated by SNORM seem to fall into three major categories: meteoric, marine, or diagenetic. Although the presence of alkali-bearing carbonates and sulfates in the salt norm seems to distinguish meteoric waters and their pricipal supplemental weathering agent, differentiation of types of marine or diagenetic fluids requires comparison of relative abundances of normative salts. Salt norms of resolution, connate, or hypersaline fluids of marine or continental recycled seawater type are distinguished by the relative amounts of halite, anhydrite and $\mathrm{Mg}$-bearing chlorides, whereas different principal diagenetic processes operating on subsurface fluids are reflected in alkaline-earth chloride ratios. Although the detailed criteria have been based on the most indicative data sets known to the authors, the tests thusfar have hardly been exhaustive. 
A1 Droubi, Abdallah, Fritz, Bertrand, Gac, Jaques-Ives, and Tardy, Yves, 1980, Generalized residual alkalinity concept; application to prediction of the chemical evolution of natural waters by evaporation: American Journal of Science, v. 280, p. 560-572.

Bowser, C. J. and Dickson, F. W., 1966, Chemical zonation of the borates at Kramer, California, in Rau, J. L., ed., 2nd Symposium on Salt: Northern Ohio Geological Society, Cleveland, Ohio, v. 1, p. 122-132.

Boyd, F. M., 1982, Hydrogeology of the Northern Salt Basin of West Texas and New Mexico: Ph. D. thesis, University of Texas at Austin, p. 61-71. Braitsch, Otto, 1971, Salt Deposits, their Origin and Composition: SpringerVerlag, 297 p.

Carpenter, A. B., 1978, Origin and chemical evolution of brines in sedimentary basins: Oklahoma Geological Survey Circular 79, p. 60-78. , 1979, Interim report on lead and zinc in oil-field brines in the central Gulf Coast and in southern Michigan: AIME Annual Meeting, New Orleans, La., Report 79-95, 15 p.

Clarke, F. E. and Jones, B. F., 1972, Significance of ground-water chemistry in performance of North Sahara tube wells in Algeria and Tunisia: U.S. Geological Survey Water Supp1y Paper 1757-M, p. 1-39.

Cross, C. W., Iddings, J. P., Pirsson, L. V., and Washington, H. S., 1902, A quantitative chemico-mineralogical classification and nomenclature of igneous rocks: Journal of Geology, v. 10, p. 555-690.

Dickey, P. A., Collins, A. G., and Fajardo, I., 1972, Chemical composition of deep formation waters in southwestern Louisiana: American Association of Petroleum Geologists Bulletin, v. 56, p. 1530-1533.

Drever, J. I., 1982, The Geochemistry of Natural Waters, Prentice Ha11, Englewood Cliffs, N. J., 388 p.

Englund, Jens-0laf, 1983, Chemistry and flow patterns in some ground-waters of southeastern Norway: Norges Geologiske Undersokelse, offprint 380, p. 221-234.

Englund, Jens-0laf and Myhrstad, J. A., 1980, Groundwater chemistry of some selected areas in southeastern Norway: Nordic Hydrology, v. 11, p. 33-54. Ericksen, G. E., Chong D., Guillermo, and Vila G., Tomas, 1976, Lithium resources of salars in the central Andes: U.S. Geol. Survey Prof. Paper $1005, \mathrm{p} \cdot 66-74$.

Eugster, H. P., 1980, Geochemistry of evaporitic lacustrine deposits: Annual Review of Earth and Planetary Science, v. 8, p. 35-63.

Eugster, H. P. and Hardie, L. A., 1978, Saline lakes, in Lerman, A., ed., Lakes: Chemistry, Geology, Physics: Springer-Verlag, New York, p. 237-293. 
Eugster, H. P., Harvie, C. E., and Weare, J. H., 1980, Mineral equilibria in the six-component sea water system, $\mathrm{Na}-\mathrm{K}-\mathrm{Mg}-\mathrm{Ca}-\mathrm{SO}_{4}-\mathrm{Cl}-\mathrm{H}_{2} \mathrm{O}$, at $25^{\circ} \mathrm{C}$ : Geochimica et Cosmochimica Acta, v. 44, p. 1355-1348.

Eugster, H. P. and Jones, B. F., 1979, Behavior of major solutes during closed-basin brine evolution: American Journal of Science, v. 279, p. 609-631.

Fleischer, E., Goldberg, M•, Gat, J. R•, and Magaritz, M., 1977, Isotopic composition of formation waters fromm deep drillings in southern Israel: Geochimica et Cosmochimica Acta, v. 41, p. 511-525.

Frape, S. K. and Fritz, Peter, 1982, The chemsitry and isotopic composition of saline groundwaters from the Sudbury Basin, Ontario: Canadian Journal of Earth Sciences, v. 19, p. 645-661.

Frape, S. K., Fritz, Peter, and McNutt, R. H., 1984, Water-rock Interaction and chemistry of groundwaters from the Canadian Shield: Geochimica et Cosmochimica Acta, v. 48, p. 1617-1627.

Garre1s, R. M., 1967, Genesis of some ground waters from 1gneous rocks, in Abelson, P. H., ed., Researches in Geochemistry: John Wiley, New York, v. 2 , p. 405-421.

Gat, J. R. and Issar, A., 1974, Desert 1sotope hydrology: water sources of the Sinai Desert: Geochimica et Cosmochimica Acta, v. 38, p. 1117-1131.

Gueddari, Moncef, Monnin, Christophe, Perret, Dominique, Fritz, Bertrand, and Tardy, Yves 1983, Geochemistry of brines of the Cott el Jerid in southern Tunisia -- application of Pitzer's equations: Chemical Geology, v. 39, p. 165-178.

Gulbrandsen, R. A., 1975, Whitlockite and apatite of surficlal phosphate occurrences on Enderbury Island, Phoenix Islands, Paciflc Ocean: Journal of Research, U. S. Geological Survey, v. 3, p. 409-414.

Hanor, J. S., 1984, Variation in the chemical composition of oll-field brines with depth in northern Loulsiana and southern Arkansas: implications for mechanism and rates of mass transport and diagenetic reaction: Transactions--Gulf Coast Association of Geological Societies, v. 34 , p. 55-61.

Hardie, L. A. and Eugster, H. P., 1970, The evolution of closed-basin brines: Mineralogical Society of America, Special Publication 3, p. 273-290.

Harvie, C. E., Eugster, H. P., and Weare, J. H., 1982, Mineral equilibria in the six-component seawater system, $\mathrm{Na}-\mathrm{K}-\mathrm{Mg}-\mathrm{Ca}-\mathrm{SO}_{4}-\mathrm{Cl}-\mathrm{H}_{2} \mathrm{O}$ at $25^{\circ} \mathrm{C}$.

II: Compositions of the saturated solutions: Geochimica et Cosmochimica Acta, v. 46, p. 1603-1618.

Harvie, C. E., Mфller-Weare, Nancy, and Weare, J. H., 1984, The prediction of mineral solubilities in natural waters: The $\mathrm{Na}-\mathrm{K}-\mathrm{Mg}-\mathrm{Ca}-\mathrm{H}-\mathrm{Cl}-\mathrm{SO}_{4}-\mathrm{OH}-\mathrm{HCO}_{3}-$ $\mathrm{CO}_{3}-\mathrm{CO}_{2}-\mathrm{H}_{2} \mathrm{O}$ sytem to high ionic strengths at $25^{\circ} \mathrm{C}$ : Geochimica et Cosmochimica Acta, v. 48, p. 723-751. 
Harvie, C. E. and Weare, J. H., 1980, The prediction of mineral solubilities in natural waters: The $\mathrm{Na}-\mathrm{K}-\mathrm{Mg}-\mathrm{Ca}-\mathrm{Cl}-\mathrm{SO}_{4}-\mathrm{H}_{2} \mathrm{O}$ system from zero to high concentration at $25^{\circ} \mathrm{C}$ : Geochimica et Cosmochimica Acta, v. 44, p. 981-997.

Hem, J. D., 1970, Study and interpretation of the chemical characteristics of natural waters: U. S. Geological Survey, Water-Supply Paper 1473, 363 p. Herrmann, A. G., Knake, Doris, Schneider, Jurgen, and Peters, Heide, 1973, Geochemistry of modern seawater and brines from salt pans: main components and bromine distribution: Contributions to Mineralogy and Petrology, v. 40, p. 1-24.

Holland, H. D., 1984, The Chemical Evolution of the Atmosphere and Oceans: Princeton University Press, Princeton, N. J., 528 p.

Howard, K. W. F. and Lloyd, J. W., 1983, Major ion characterization of coastal saline ground waters: Ground Water, v. 21, p. 429-437.

Jones, B. F., 1966, Geochemical evolution of closed basin water in the western Great Basin, In Rau, J. L., ed., 2nd Symposium on Salt, Northern Ohio Geological Society, Cleveland, Ohio, v. 1, p. 181-200. , ed., 1970, Symposium on the mineralogy and geochemistry of non-marine evaporites: Mineralogical Soclety America, Special Paper 3, p. 213-319.

Knauth, L. P., Kumar, M. B., and Martinez, J. D., 1980, Isotope geochemistry of water in Gulf Coast salt domes: Journal of Geophysical Research, v. $85, \mathrm{p} \cdot 4863-4871$.

Kühn, Robert, 1968, Geochemistry of the German potash deposits, in Mattox, R. B., ed., Saline Deposits: Geological Society of America Spectal Paper 88 , p. 427-504.

Kumar, M. B., 1983, Character of meteoric leaks in the salt mines of southern Louisiana, USA: Journal of Hydrology, v. 66, p. 351-363.

Lambert, S. J., 1978, Geochemistry of Delaware Basin ground waters: in Austin, G. S., ed., Geology and Mineral Deposits of Ochoan Rocks in Delaware Basin and Adjacent Areas, Mew Mexico Bureau of Mines and Mineral Resources, Circular 159, p. 33-38.

Levy, Yitzhak, 1977, The origin and evolution of brine in coastal sabkhas, northern Sinai: Journal of Sedimentary Petrology, v. 47, p. 451-462. Livingstone, D. A., 1963, Chemical composition of rivers and lakes, in Fleischer, Michael, ed., Data of Geochemistry [6th ed.]: U.S. Geol. Survey Prof. Paper 440-G, 64 p.

Mackenzie, F. T. and Garrels, R. M., 1966, Chemical mass balance between rivers and oceans: American Journal of Science, v. 264, p. 507-525. Mann, A. W., 1983, Hydrogeochemistry and weathering on the Yilgarn Block, Western Australia--ferrolysis and heavy metals in continental brines: Geochimica et Cosmochimica Acta, v. 47, p. 181-190. 
Marfil, Rafaela, Bermejo, E. P., and de 1a Pena, J. A., 1975, Sedimentacion salina actual en las lagunas de la zona Corral Rubio-La Higuera (provincia de Albacete): Estudios Geologicos, v. 31, p. 543-553.

Mayhew, E. J. and Heylmun, E. B., 1965, Concentrated subsurface brines in the Moab Region, Utah: Utah Geological and Mineralogical Survey, Special Studies 13, $28 \mathrm{p}$.

Muessig, Siegfried, 1958, First known occurrence of inyoite in a playa, at Laguna Salinas, Peru: American Mineralogist, v. 43, p. 1144-1147. , 1959, Primary borates in playa deposits: Minerals of high hydration: Economic Geology, v. 54, p. 495-501. , 1966, Recent South American borate deposits, in Rau, J. L., ed., 2nd Symposium on Salt: Northern Ohio Geological Society, Cleveland, Ohio, v. 1, p. 151-159.

Parker, V. B., Wagman, D. D., and Evans, W. H., 1971, Selected values of chemical thermodynamic properties: Tables for the alkaline earth elements, National Bureau of Standards: Technical Note 270-6, 106 p. Plummer, L. N., Jones, B. F., and Truesdell, A. H., 1976, WATEQF - a Fortran IV version of WATEQ, a computer program for calculating chemical equilibrium of natural waters: U.S. Geological Survey Water-Resources Investigations $76-13,61 \mathrm{p}$.

Rankama, Kalervo and Sahama, Th. G., 1950, Geochemistry: University of Chicago Press, 912 p.

Riley, J. P. and Chester, R., 1971, Introduction to Marine Chemistry: Academic Press, New York, 465 p.

Rettig, S. L., Jones, B. F., and Risacher, Francois, 1980, Geochemical evolution of brines in the Salar of Uyuni, Bolivia: Chemical Geology, v. $30, p \cdot 57-79$.

Robie, R. A., Hemingway, B. S., and Fisher, J. R., 1978, Thermodynamic properties of minerals and related substances at $298.15 \mathrm{~K}$ and 1 bar ( $10^{5}$ pascals) pressure and at higher temperatures: U.S. Geological Survey Bulletin 1452, 456 p.

Smith, G. I. and Haines, D. V., 1964, Character and distribution of nonclastic minerals in the Searles Lake evaporite deposit, California: U.S. Geological Survey Bulletin 1181-P, 58 p.

Sonnenfeld, Peter, 1984, Brines and Evaporites: Academic Press, New York, $613 \mathrm{p}$.

Soriano, Jose, Marfil, Rafaela, and de la Pena, J. A., 1977, Sedimentacion salina actual en las lagunas del norte de Alcazar de San Juan (Ciudad Rea1): Estudios Geologicos, v. 33, p. 123-130.

Spencer, R. J., Eugster, H. P., Jones, B. F., and Rettig, S. L., 1983, Geochemistry of Great Salt Lake, Utah I: Hydrochemistry since 1850:: Geochimica et Cosmochimica Acta, v. 49, p. 727-737. 
Starinsky, A., Bielski, M., Ecker, A., and Steinitz, G., 1983, Tracing the origin of salts in groundwater by $\mathrm{Sr}$ isotopic composition (the crystalline complex of the Southern Sinal, Egypt): Isotope Geoscience, v. 1, p. 257-267.

Stewart, D. B., Jones, B. F., Roedder, E. W., and Potter, R. W., 1980, Summary of United States Geological Survey Investigations of fluid-rock-waste reactions in evaporite environments under repository conditions from "Underground Disposal of Radioactive Waste,": International Atomic Energy Agency, Vienna, 1980, v. 1, p. 335-344.

Stewart, F. J., 1963, Marine evaporites, in Fleischer, Michael, ed., Data of Geochemistry (6th ed.): U. S. Geological Survey Professional Paper 440-Y, $53 \mathrm{p}$.

Stoessel, R. K., and Moore, C. H., 1983, Chemical constraints and origins of four suggested groups of Gulf Coast Reservoir fluids: American Association of Petroleum Geologists Bulletin, v. 67, p. 896-906.

Truesde11, A. H. and Jones, B. F., 1974, WATEQ: A computer program for calculating chemical equilibria of natural waters: U.S. Geological Survey, Journal of Research, v. 2, p. 233-248.

Wagman, D. D•, Evans, W. H•, Parker, V. B•, Halow, I•, Bailey, S. M•, and Schumm, R. H., 1968, Selected values of chemical thermodynamic properties: Tables for the first thirty-four elements in the standard order of arrangement: National Bureau of Standards, Technical Note 270-3, 264 p. Wagman, D. D., Evans, W. H., Parker, V. B., Schumm, R. H., and Nuttall, R. L., 1981, Selected values of chemical thermodynamic properties: Compounds of uranium, protactinium, thorium, actinfum, and the alkall metals: National Bureau of Standards, Technical Note 270-8, 134 p.

Wedepoh1, K. H., 1971, Geochemistry: Holt, Renehart, and Winston, New York, $231 \mathrm{p}$.

White, D. E., 1968, Environments of generation of some base-metal ore deposits: Economic Geology, v. 63, p. 301-335.

White, D. E., Hem, J. D., and Waring, G. A., 1963, Chemical composition of subsurface waters, in Fleischer, Michael, ed., Data of Geochemistry [6th ed.]: U.S. Geol. Survey Prof. Paper 440-F, 67 p.

Zak, Israel and Gat, J. R., 1975, Saline waters and residual brines in the Shiraz-Sarvistan Basin, Iran: Chemical Geology, v. 16, p. 179-188.

Zherebtsova, I. K. and Volkova, N. N., 1966, Experimental study of behavior of trace elements in the process of natural solar evaporfation of Black Sea water and Sasyk-Sivash brine: Geochemistry International, v. 3, p. 656-670. 
APPENDIX I

Source codes

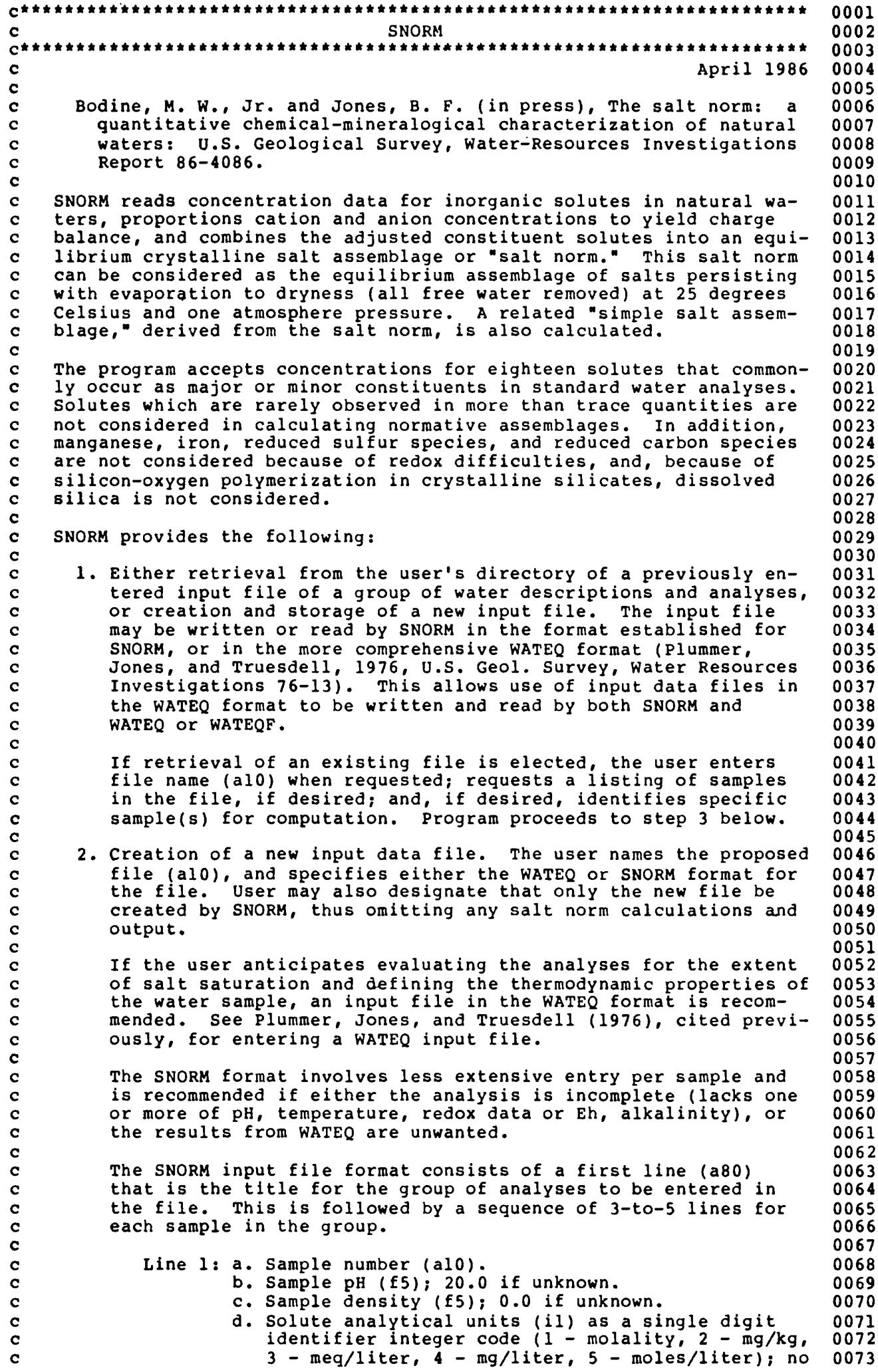


Line 2: Concentrations of six major solutes (Ca, $\mathrm{Mg}, \mathrm{K}, \mathrm{Na}$ Cl, so4) in analytical units specified above (5eil).

Line 3: Concentrations of other solutes in analytical units specified above; a solute identifler (i2) and its concen tration (elo) is entered for up to 5 solutes per line; if a line becomes filled with solute data, a new line be comes available; no entry or entering oo for the soluteidentifier integer after all permissable solutes have been entered signifies conclusion of entry for that sample, and, after verification, line l returns to allow entering data for the next sample in the group.

After each line is entered during construction of an input file (in either WATEQ or SNORM format), the line is printed at the user's terminal and verification is reguested. If entry is correct, the entry is verified and the line is appended onto the developing input file; if not verifled, the user is requested to reenter the 1 ine.

After completing entry into the new input file, the file is stored in the user's directory under the assigned name.

3. User selection of the following options for all samples in a given input file:

a. Output of SNORM data bank. User may designate output of the data bank that 1 ists all solutes, each with its charge and atomic weight, and all salts, each with its mineral name, chemical formula, and composition in terms of the solute species. Additional species $(\mathrm{O}, \mathrm{OH}$, and $\mathrm{H} 2 \mathrm{O})$ are in cluded with the solutes to facilitate calculating salt compositions and molecular weights.

0103

0104

0105

0106

0107

0108

0109

0110

0111

0112

b. Capability of the output device. User designates if output to be directly displayed or printed, and, if so, whether the output device accepts line length of <132 characters (output formatted at 80 characters per line) or >131 characters (output formatted at 132 characters per line).

c. Storage of output. User may request creation of SNORM out put file(s), formatted at 132 characters per line, that will be stored in the user's directory for subsequent printing. User designates if the requested output file(s) will be constructed to be read by printer that recognizes FORTRAN carriage control, one that does not, or both.

d. Alternative concentration units of solutes and normative salts. Concentrations of the normative salts for each sample are listed in weight and moles per unit of the original analysis, i.e. "per kg water," "per kg solution," or "per liter solution." The user may designate salt concentrations be listed in units other than those of the analysis, and if so elected, solute concentrations will be listed in both the requested units and the units of the analysis, and normative salt concentrations will be listed in the requested units. If recasting between "per $\mathrm{kg}$ " and "per liter" units is prescribed, density of the sample must be known; if density unknown, original units of the analysis will be retained.

e. Listing of salt equivalencies rather than mole abundances. User may designate that normative salt abundances be listed in salt equivalencies (concentration and percent) rather than in mole quantities. A salt equivalent is defined as the product of the anion charge of a mole of the salt and the salt's mole abundance.

f. Redox reassignment of nitrogen species. User may specify redox state of nitrogen species (ammonium and nitrate) be assigned so that either any ammonium is recast as nitrate, or, alternatively, any nitrate is recast as ammonium. 
to eliminate nitrate from the norm without affecting the original solute charge distribution, he may elect to substitute bicarbonate for nitrate. Had the user elected to convert ammonium to nitrate, this nitrate would also be transformed to bicarbonate.

h. Assignment of zero concentration to one or more solutes. User may elect to determine the norm excluding one or more solutes from the calculation; this is accomplished by identifying from 1 to 10 solutes whose concentrations are to be set to 0.0 prior to adjusting for charge balance.

Election of one or more options from ( $f$ ) through (h) above may affect the salt norm by altering solute characteristics of the sample. Election of these options does not alter the output listing of solute concentrations in the original analysis; the results of the elected options are included and identified in the output listing of solute concentrations that are adjused to achieve charge balance.

These options, (f) through ( $h$ ), are only available to the user if a previously stored input file is retrieved by SNORM; they are not available if a new input file is created. The norm for any sample in the input file whose adjusted solute concentrations (and the resultant salt norm) are not altered after implementing the elected option(s) is not calculated, and all output for that sample is omitted.

Each option (a through $h$ ) is entered as a response to a query with a listing of the alternative responses displayed on the user's terminal; the user enters the appropriate response followed by a 〈RETURN>.

4. Calculation and printing of the following for each sample in the file: (a) solute concentrations in weight and mole quanti ties for both the analytical values of the original analysis and the modified values that have been adjusted to achieve charge balance; (b) mole ratios from the original analytical data; (c) the normative salt assemblage with weight (both for correct hydration state of the salt and for its anhydrous equivalent) and mole concentrations of each normative salt per unit of solution, and weight (again for correct hydration state and its anhydrous equivalent) and mole percentages in the solid as semblage; (d) a simple salt assemblage that is derived from the normative assemblage with weight and mole percent of each simple salt in the simple salt assemblage; and (e) a summary of calculations required to calculate the norm (number of salt as sociations tested, number of trial assemblages created, and number of trial assemblages for which salt abundances were determined). A title for the group of samples in the file, sample description (sample number, location, brief description),

solutes, normative salts, and simple salts

0208

0210

Solutes that are assigned to the normative salt assemblage comprise 0211 the following.

0211

0213

0214

$\begin{array}{lllllll}\mathrm{Mg}++ & \mathrm{Ba}++ & \mathrm{K}+ & \mathrm{HCO}- & \mathrm{Cl}- & \mathrm{F}- & 0214 \\ \mathrm{Ca}++ & \mathrm{Li}+ & \mathrm{NH} 4+ & \mathrm{CO}-- & \mathrm{Br}- & \mathrm{NO} 3- & 0215 \\ \mathrm{Sr}++ & \mathrm{Na}+ & \mathrm{B} & \mathrm{SO} 4-- & \mathrm{I}- & \mathrm{PO4---} & 0216\end{array}$




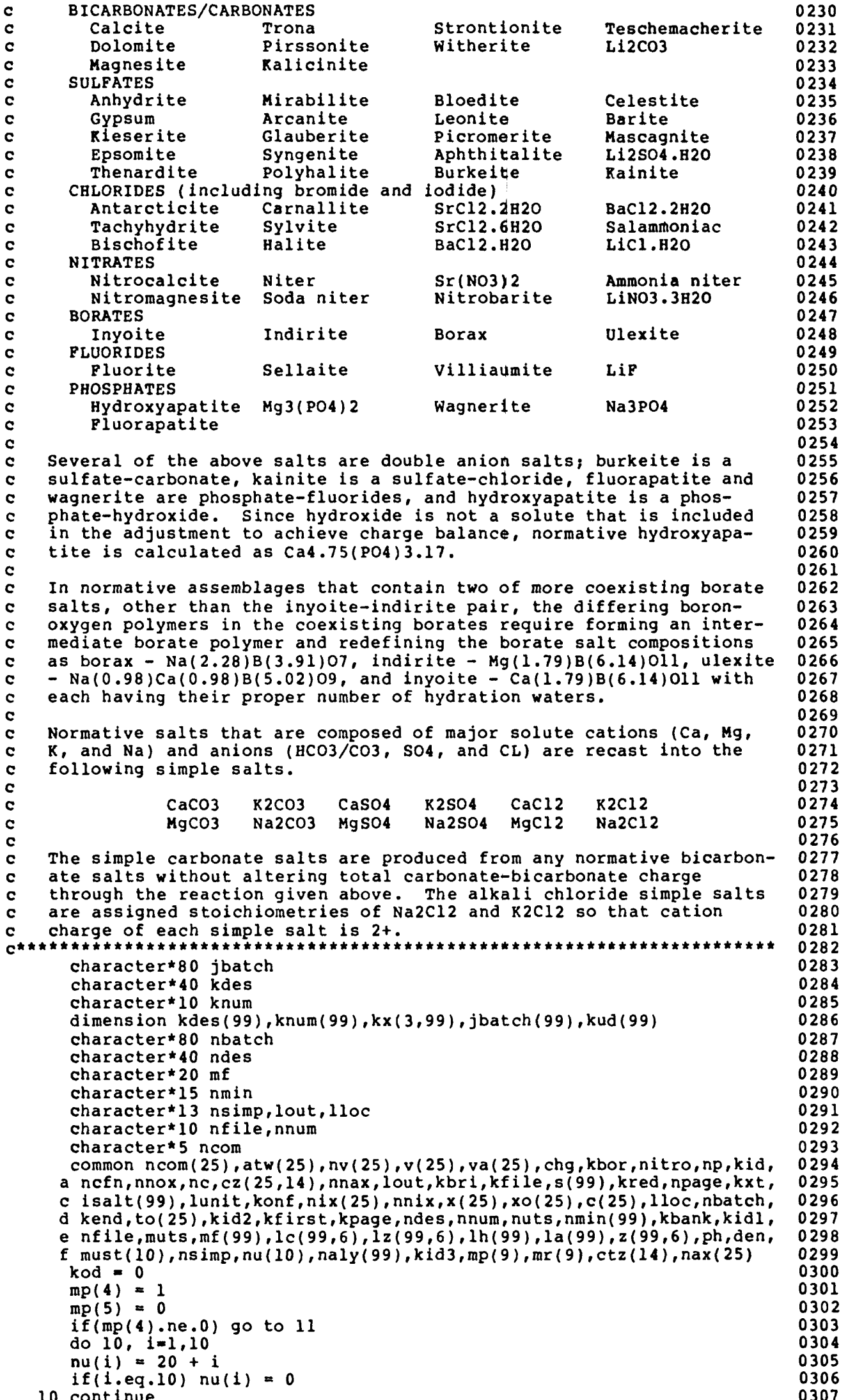

10 continue 
11 continue

If (mp (4).ne.1) go to 21

do $20 \quad 1=1,10$

$\mathrm{nu}(\mathrm{i})=10+1$

if(1.eg.4) nu(i) $=5$

if (i.eg.9) nu(1) $=14$

if (1.eq.10) nu(1) $=1$

0309

0310

1f(1.eq.10) nu(1)=

0312

20 cont inue

21 continue

call prep

if (kpage.eg.3) go to 900

0313

0314

0315

0316

0318

0319

0320

$\begin{array}{ll}\text { if (kfile.eq.0) go to } 200 \\ \text { if ( } k f i l e . n e .2) & 0321\end{array}$

$\begin{array}{lll}\text { if (kfile.ne.2) open (nu(4), form=' formatted', status='new', file=lout) } & 0322 \\ \text { if (kflle.ne.l) open (nu(5), form=' formatted', status='new', file=lloc) } & 0323\end{array}$

go to 200

100 continue

go to 800

0324

0325

0326

0327

$k i d=0 \quad 0328$

kfirst $=0 \quad 0329$

300 continue

0330

call load

0331

$k i d=k i d l+1$

0332

if(kid3.eq.l) print 810

if (kend.eq.1) go to $500 \quad 0334$

if (nnox.eq.0) go to $450 \quad 0335$

0336

$\operatorname{kod}=\operatorname{kod}+1 \quad 0337$

$\operatorname{kud}(\operatorname{kod})=k i d l \quad 0338$

if (kid.eq.0) kdes(kod) = ndes $\quad 0339$

if (kid.eq.0) knum(kod) = nnum 0340

if(kid.eq.l) jbatch(kod) = nbatch

$\begin{array}{ll}\text { do } 400 \quad i=1,3 & 0342\end{array}$

$k \times(i, k o d)=m r(i) \quad 0343$

400 continue $\quad 0344$

450 continue $\quad 0345$

$\begin{array}{ll}\text { go to } 300 & 0346\end{array}$

0347

if (kidl.eq.0) go to $800 \quad 0348$

if (kod.eq.0) go to $800 \quad 0349$

if (kpage.1t.2) lunit $=\mathrm{nu}(10) \quad 0350$

if (kpage.eg.2.and.kfile.ne.2) lunit $=$ nu(4) 0351

if (kpage.eq.2. and.kfile.eq.2) lunit $=$ nu(5) 0352

600 continue

write (lunit, 801 )

do $700 \quad i=1$, kod

if (kid.eq.0) write(lunit,802) kud(1), knum(i), kdes(1)

if(kid.eq.l) write(lunit,804) kud(1),jbatch(i) 0358

write(lunit,803) $(k \times(j, 1), j=1,3) \quad 0359$

700 continue

if (kflle.eg.0.or.lunit.eq.nu(5)) go to 800

if (lunit.eq.nu(4).and.kfile.eq.1) go to $800 \quad 0362$

if (lunit.eq.nu(4)) lunit $=$ nu(5) 0363

if (lunit.1t.nu(4).and.kfile.ne.2) lunit = nu(4) 0364

if(lunit.1t.nu(4)) lunit $=$ nu(5) $\quad 0365$

go to $600 \quad 0366$

800 continue $\quad 0367$

$\begin{array}{ll}\text { close (nu(2)) } & 0368\end{array}$

If (mp (5).eq.1) close(nu(7)) 0369

if (kflle.eq.0) go to $900 \quad 0370$

1f(kflle.ne.2) close(nu(4)) $\quad 0371$

if (kfile.ne.1) close (nu(5))

0373

$\begin{array}{ll}8 \text { top } & 0374\end{array}$

801 format (' 1 ',////,19x,' SUMmaRY OF REQUIREd CALCulations',/) 0375

802 format (', 12,1.', al0,15x,a40) 0376

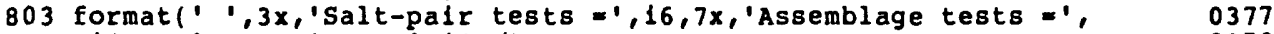

a $14,7 x$, ' Inversions $=1,14, /) \quad 0378$

805 format (' ', $1,080, /)$

804 format (' ',12,', ',a80) 0380

810 format (' ' 'Unable to read input file in either SNORM or', 0381

a' WATEQ format! ' , /20x,'RUN TERMINATED')

end

C

0383 


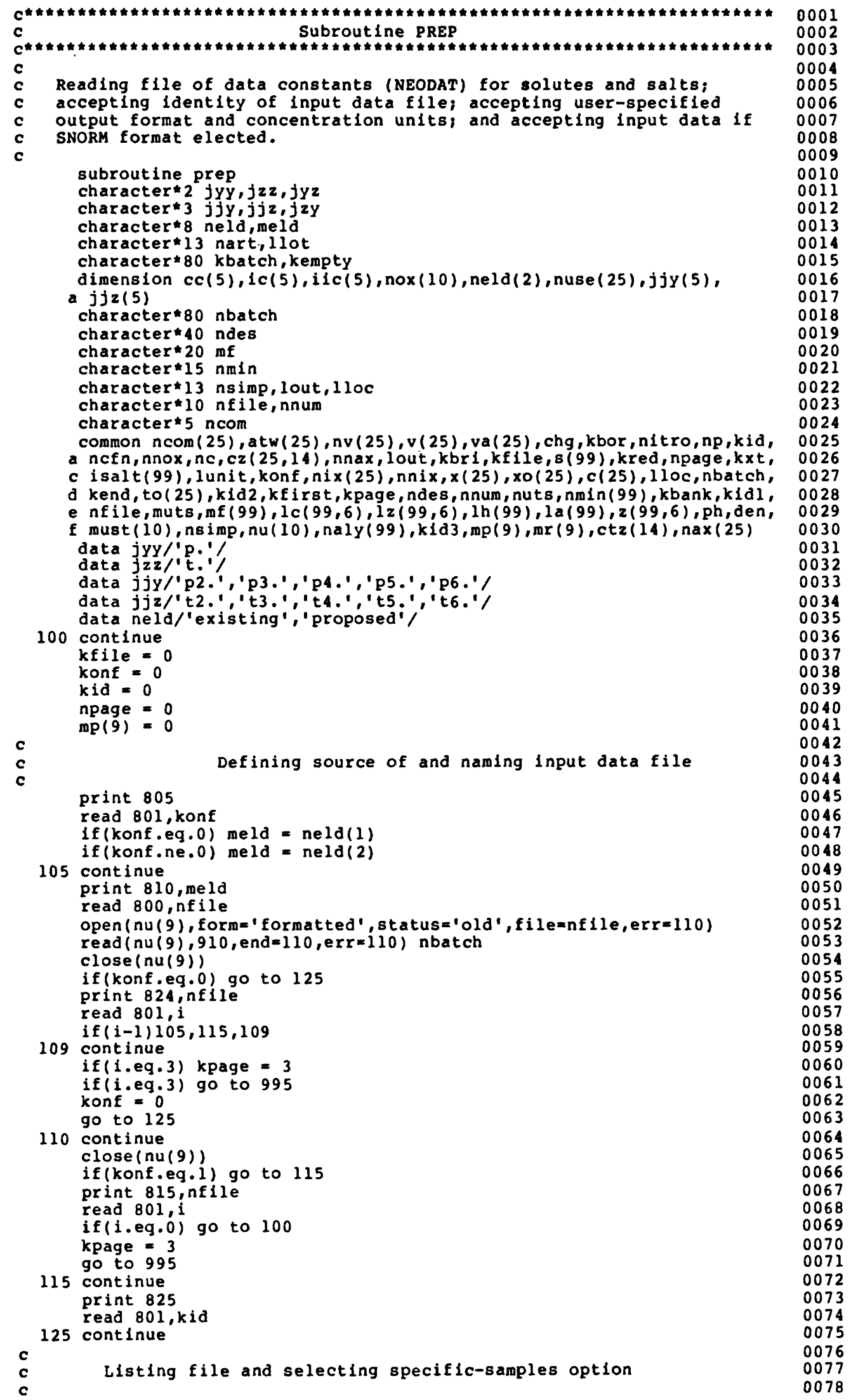


nsel $=0$

if (konf.eq.1) go to 147

print 811

read 801,1

if(i.eg.0) go to 139

$\operatorname{kadl}=0$

nolist $=0$

open (nu (6), form= ' formatted', status=' old' , file=nfile, err=126)

go to 127

126 continue

nolist $=1$

print 816

go to 138

127 continue

read(nu(6),910) nbatch

128 continue

read (nu (6), 930, err $=131$, end $=138$ ) nnum, ndes, ph, den, nuts

if (kadl.eq.0.and.nuts.eg.0) go to 131

if (nuts.eq.0) go to 138

kadl $=$ kadl +1

if (kadl.eq.1) print 910, nbatch

if (kadl.eq.1) print 854

print 813, kadi, nnum, ndes

$\operatorname{read}(\operatorname{nu}(6), 940$, err $=126$, end $=138)(c(i), 1=1,6)$

129 continue

read $(\operatorname{nu}(6), 960$, err $=126$, end $=138)(i c(i), c c(i), i=1,5)$

do $130 \quad i=1,5$

if (ic (i).eg.0) go to 128

130 continue

go to 129

131 continue

rewind nu(6)

kad1 $=0$

write (kbatch, 818)

read (kbatch,910) kempty

print 854

132 continue

read ( nu( 6$), 910$, end $=138$ ) kbatch

kadl $=$ kadi +1

print 814, kadl, kbatch

read (nu (6), 910 , err $=126$, end $=138$ ) kbatch

read (nu ( 6$), 910$, er $x=126$, end $=138$ ) kbatch

read (nu $(6), 910$, err $=126$, end $=138$ ) kbatch

do $133 j=1,20$

read $(n u(6), 910$, err $=126$, end $=138)$ kbatch

if (kbatch.eq.kempty) go to 132

133 continue
138 continue

close (nu(6))

139 continue

print 821

read 801 , nsel

if (nsel.eq.0) go to 147

if (nsel.eg.2) go to 146

0080

0081

0082

0083

0084

0085

0086

0087

0088

0089

0090

0091

0092

0093

0094

0095

0096

0097

0098

0099

0100

0101

0102

0103

0104

0105

0106

0107

0108

0109

0110

0111

0112

0113

0114

0115

0116

0117

0118

0119

0120

0121

0122

0123

0124

0125

0126

0127

0128

0129

0130

0131

0132

0133

0134

print 822

$\operatorname{read}(\operatorname{nu}(10), 823, \operatorname{err}=142)$ (nuse $(k), k=1,25)$

0135

go to 144

0135

0137

0138

print 803

go to 140

0139

0140

print $823,($ nuse $(k), k=1,25)$

print 802

read 801 , nerr

if (nerr.ne.0) go to 140

if (nsel.eq.1) go to 147

146 continue

if (nsel.eg.2) nsel $=0$

$\operatorname{mp}(9)=1$

145 continue

print 847

$\operatorname{read}(\operatorname{nu}(10), 870, \operatorname{err}=1451)(\operatorname{must}(i), i=1,10)$

0141

0142

0143

0144

0145

0146

0147

0148

0149

0150

0151

go to 1452

015

0153

0154

print 803

go to 145

1452 continue

0155

0156 


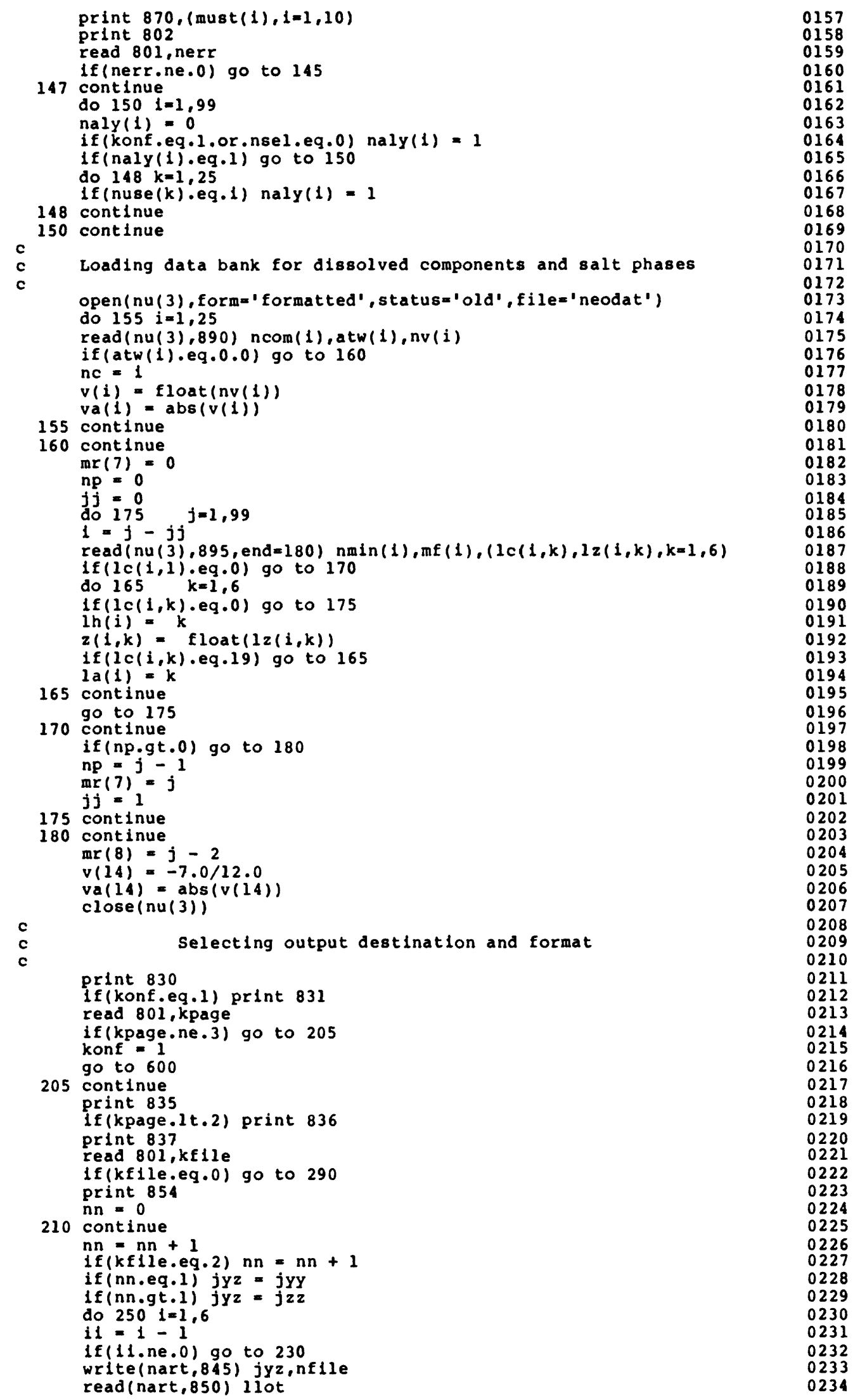


go to 240

230 continue

if(nn.eq.1) jzy $=j j y(11) \quad 0237$

$\begin{array}{ll}\text { if (nn.gt.l) jzy }=j j z(i i) & 0238\end{array}$

write(nart,848) jzy,nfile $\quad 0239$

read(nart,851) llot 0240

240 continue

open (nu(4), form=' formatted', status='old', file=1lot, err=260)

read $(n u(4), 910$, err $=260$, end $=260) \mathrm{kbatch} \quad 0243$

close (nu(4)) 0244

250 continue

print 961

kpage $=3$

go to 995

0245

0246

0247

0248

0249

260 continue

if (nn.eg.l) lout $=110 t$

0250

if (nn.gt.l) lloc $=110 t$

0251

close (nu(4))

if (nn.eg.1) print 855 , lout

0252

if (nn.eg.l.and.kfile.ne.1) go to $210 \quad 0255$

290 continue

print 854

0256

0257

c

print 854

Electing calculation options

0258

0260

300 continue

kbank $=0$

kred $=0$

0261

0262

0263

nitro $=0$

0264

nefn $=0$

$n n i x=0$

$\operatorname{mr}(9)=0$

0265

0266

0267

do $310 \quad i=1,25$

0268

nix(i) $=0$

0269

if(i.it.11) nox(i) $=0 \quad 0270$

310 continue

315 continue

print 861

0271

0272

0273

if(konf.eq.0) print $862 \quad 0274$

320 continue

read 801 , ipt

if (ipt.eq.0) go to 375

0275

0276

0277

0278

0279

if (ipt.eg.

$\begin{array}{ll}\text { if (ipt.eq.3) mr(9) }=1 & 0280 \\ \text { if (ipt.eq.4) nitro }=1 & 0281\end{array}$

if(ipt.eq.5) nitro $=2 \quad 0282$

if(ipt.eg.6) ncfn $=1 \quad 0283$

if (ipt.eq.7) go to $330 \quad 0284$

if(ipt.eq.1) print $881 \quad 0285$

if(ipt.eq.3) print $886 \quad 0286$

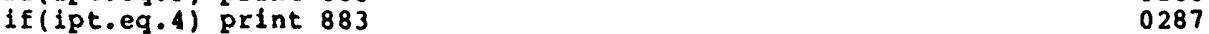

if(ipt.eq.5) print $884 \quad 0288$

if(ipt.eq.6) print $885 \quad 0289$

325 continue

print 880

0290

0291

0292

go to 320

0293

0294

print 865

$\operatorname{read}(\operatorname{nu}(10), 870, \operatorname{err}=335)(\operatorname{nox}(i), i=1,10)$

0295

0296

0297

0298

0299

0300

0301

0302

0303

0304

0305

0306

0307

0308

0309

0310

0311

if (nitro.eq. 2 ) $\mathrm{nix}(10)=0$

0312 


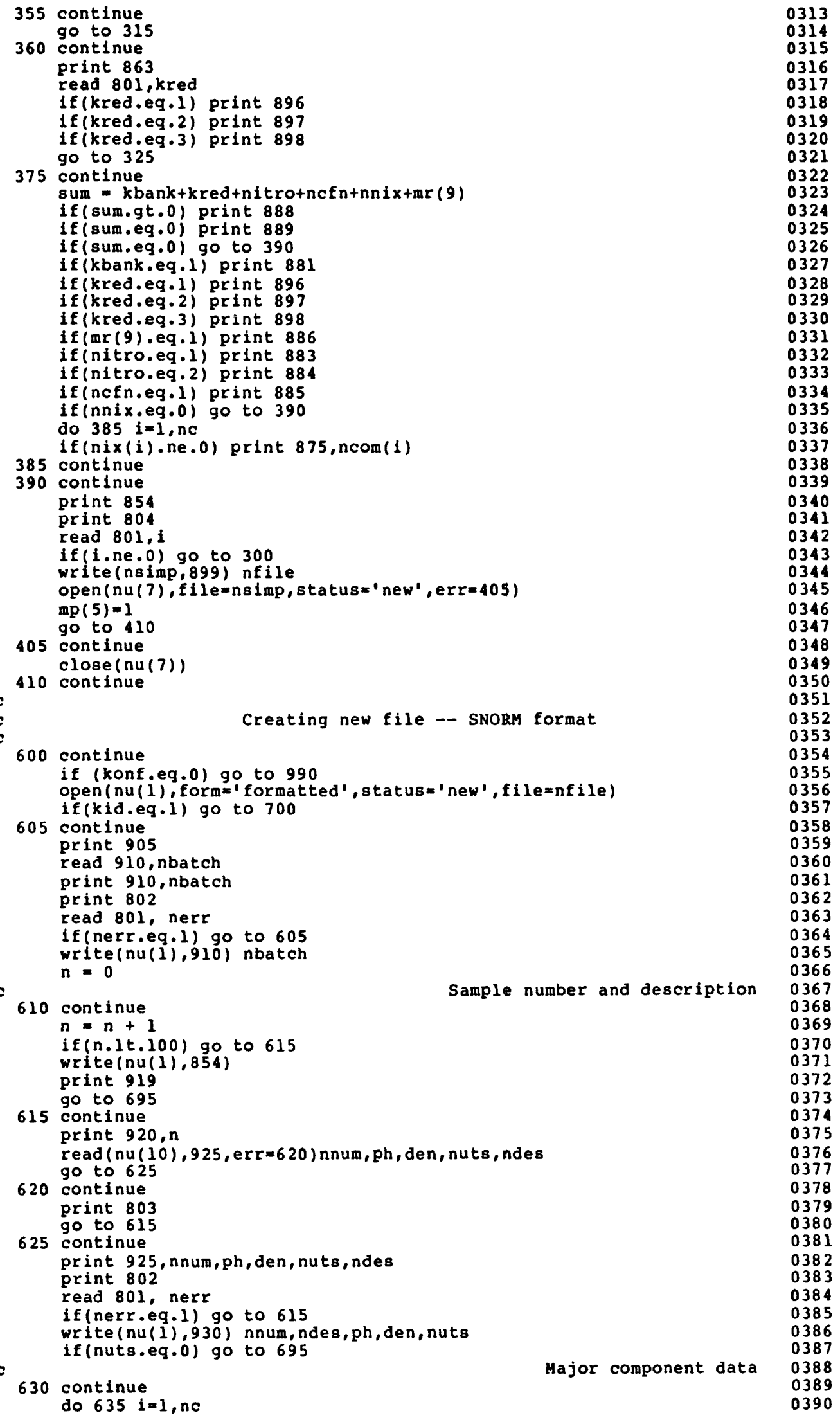


$c(1)=0.0$

635 continue

print $935, n$

$\operatorname{read}(\operatorname{nu}(10), 940, \operatorname{err}=640)(c(1), i=1,6)$

go to 645

640 continue

print 803

go to 630

645 continue

print $940,(c(1), 1=1,6)$

print 802

read 801 , nerr

if (nerr.eg.1) go to 630

c

write(nu(1),940) (c(i), $1=1,6)$

0394

0395

0396

0397

0398

0399

0400

0401

0402

0403

0404

print $945, n$

Other component data

0405

0406

0407

650 continue

do $655 \quad 1=1,5$

iic (i) $=0$

ic (i) $=0$

$\operatorname{cc}(i)=0.0$

655 continue

print 950

$\operatorname{read}(\operatorname{nu}(10), 955, \operatorname{err}=660)(1 \mathrm{c}(1), \operatorname{cc}(1), 1=1,5)$

go to 670

660 continue

print 803

go to 650

670 continue

print $955,(1 \mathrm{c}(1), \mathrm{cc}(1), 1=1,5)$

print 802

read 801 , nerr

if(nerr.eq.1) go to 650

do $675 \quad i=1,5$

if (ic(i).eq.0) go to 680

if(ic(i).eq.1) iic(i) $=8$

if (ic(1).eg.2) ifc(1) $=17$

if(ic(i).eg.3) iic(i) $=9$

If(ic(1).eg.4) lic(i) $=10$

if (ic(i).eq.5) iic(i) $=11$

if(ic(i).eq.6) ilc(i) = 12

if (ic(i).eq.7) iic(i) $=13$

if (ic(i) eg.8) iic(i) $=14$

if(ic(i).eq.9) lic(i) $=18$

if(ic(i).eq.10) iic(i) $=19$

if (ic(i).eq.11) iic(i) $=20$

if(ic(i).eq.12) iic(i) $=21$

0408

0409

0410

0411

0412

0413

0414

0415

0416

0417

0418

0419

0420

0421

0422

0423

0424

0425

0426

0427

0428

0429

0430

0431

0432

0433

0434

0435

0436

0437

0438

0439

680 continue

write (nu(1),960) (iic(i), cc(i), $i=1,5)$

do $685 \quad i=1,5$

if(ic(i).eq.0) go to 690

685 continue

go to 650

690 continue

go to 610

695 continue

go to 900

700 continue

call salwat

900 continue

close (nu(1))

990 continue

if (kpage.eg.3) go to 995

if (kpage.eq.0) print 975

if (konf.eq.0) print 980

if (konf.ne.0) print 985, nfile

read $801, i i i$

if (iiii.eg.9) go to 100

if(iiii.eq.8) kpage $=3$

995 continue

konf $=0$

return

800 format (a10)

801 format (i1)

802 format (" ', Is this entry correct ("0" = yes; "1" = no)??')

0440

0441

0442

0443

0444

0445

0446

0447

0448

0449

0450

0451

0452

0453

0454

0455

0456

0457

0458

0459

0460

0461

0462

0463

0464

0465

0466

0467

803 format (' ', 'INPUT ERROR -- re-enter these datal')

0468 
805 format(' ',10x,' INPUT DATA SOURCE, OUTPUT OPTIONS, AND ',

a'NEW INPUT DATA ENTRY',/',

'Status of water analyses for salt norm calculation'. $a^{\prime}$ (ENTER one code integer): ', $/, 3 x$,

b'" 0 " Analyses currently on file as segment in',

c' user''s directory',/3x," I" Analyses to be entered'. $d^{\prime}$ and form a new data segment')

810 format (' ', 'ENTER NAME of ',a8,' input data segment', a ' (up to 10 character string):')

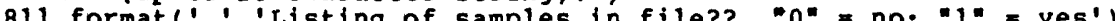

813 format (i2,', $5 x$, a10,10x, a40)

814 format'" ' Sample ', i2, $/, 280$ )

816 format (' 'SORRY - Unable to 1 ist samples!')

818 format (10):

821 format ' ', Selection of samples in file for output: ', $/, 5 x$, a" o" All samples in file.', $5 x$,

b' " 1 " only those to be listed by position in file.', $/, 5 x$,

$c^{\prime \prime} 2^{\prime \prime}$ Only those with solutes to be specified. $1,1,5 x_{1}$

d'" 3" Both "1" and " 2 " above.')

822 format(' ', 'Enter up to 25 two-integer 1dentifiers: ', $/$, $\left.124(1--1,1 x), 1-x^{\prime}\right)$

823 format $(24(i 2,1 x), i 2)$

919 format (' $, 16 x, 99$ analyses entered in file - file ful1!', $128 x$, 'DATA ENTRY CLOSED! $!^{\prime}, /, 18 x$,

2 'Create new file for remainder of analyses!')

815 format (' ',al0,' This segment either does not exist or has no ', a'data!! ENTER:',/,19x,' O" Begin again; or "I" TERMINATE RUN.')

824 format, ' $/ /$ ' YOU ALREADY HAVE A SEGMENT (FILE) WITH THIS NAMEII" a,$/, 15 x$, 'segment name $=1$, a10, a'Creation of the proposed segment with this name will override',, b'and destroy the existing segmentl ENTER one code integer:'. $b /, 5 x, " 0$ " RENAME proposed new segment,, 1 , c5x, '1* CONTINUE and destroy existing segment', $/, 5 x$, c'" CALCULATE salt norm for the existing segment!, $/, 5 x$, d' 3" TERMINATE this run')

825 format(' ', 'Desired format of proposed input file:', $a^{\prime} \quad 0^{*}=$ SNORM; 1 : $=$ WATEQ')

830 format(' ', Print-out destination (ENTER one code integer): ', /,8x $a^{\prime}$ '[Selecting " 0 " or " 1 " will allow subsequent storage selection]', $a /, 2 x$, " output to remote terminal with $>130$ spaces/11ne,$/, 2 x$, b. "I" output to remote terminal with $<130$ spaces/1ine,$/, 2 x$, d'"2" Output only as segment to be stored in directory')

831 format(" .1x, $3^{\circ}$ NO OUTPUT -- only creating new segment of ' a'input data')

835 format(' '" 'storage of output as segment(s) in user''s directory' $a, "$ (ENTER one code integer):')

836 format(' ', Ix, "O" No output storage desired.')

837 format', ',1x,'"1" For subsequent spooling to 1 ine printer '. a'recognizing carriage control.',/,2x, b'" 2" For subsequent spooling to output device without ', c'carriage control.', /,2x, " $3=$ Both " 1 " and " 2 " above.')

861 format (', 'ENTER ONE desired option identifier integer: ', /,10x, $a^{\prime}$ [If entry $>0$, additional options can be subsequently selected]' $a, 1,3 x, 10$ NO FURTHER OPTIONS DESIRED $, 1,3 x$, b' 1" Print-out of SNORM solute and salt data bank', /, 3x, c'. 2* Salts in units other than those of water analysis', $/, 3 x$, d'* Salt equivalencies rather than mole quantities')

862 format (' $, 2 x, 4^{\prime \prime}$ Dissolved nitrate recast as ammonium', $/, 3 x$, a' 5" Dissolved ammonium recast as nitrate',/,3x,

b'"6" Dissolved nitrate replaced by bicarbonate', /, 3x, c'"7" Selected solutes reset to 0.0 concentration';

863 format(" '. 'Salt output units (enter an integer code): ', /, 5x, $a^{\prime \prime}{ }^{*}$ " Salt per kllogram of water units', $/, 5 x$, b'= 2 . Salt per kilogram of solution units , /,5x, c'" 3. Salt per liter of solution units')

845 format $(a 2, a 10)$

847 format (" "ENTER two-digit code number for up to ten solutes ', a'that must be present:'

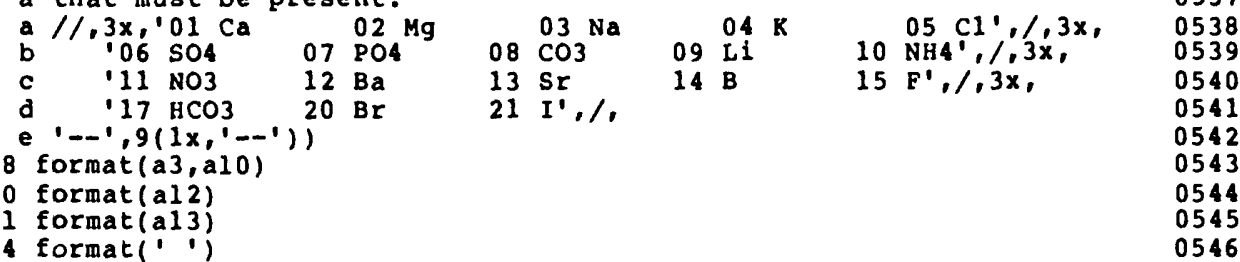


855 format(' ','Your output segment with carriage control $=1$, al3)

860 format'. ' 'Your output segment with no carriage control $=1$,al3)

865 format' ' ' ENTER two-digit code number for up to ten solutes',

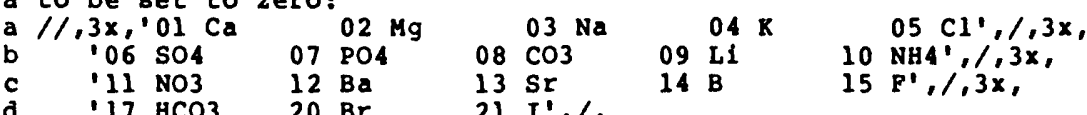

d $117 \mathrm{HCO}^{2} 20 \mathrm{Br}$

$13 \mathrm{sr}$

$15 \mathrm{Fi}, 1,3 x^{\prime}$

e $1--1,9(1 x, 1--1))$

870 format $(12,9(1 x, 12))$

875 format (', 'Zero concentration set for ',a5)

880 format (' ' 'Another option??', a (ENTER " 0 " or desired optión identifier)')

881 format (' ' Output to list solute and salt data bank')

883 format(' ' 'Nitrate to be recast as ammonium')

884 format (' 'Ammonium to be recast as nitrate')

885 format(" '.Nitrate to be recast as bicarbonate')

886 format(' ' 'Salt equivalencies rather than mole quantities.')

888 format (' ' $/$, 'ELECTED OPTIONS')

889 format (' ', $/$, 'NO OPTIONS ELECTED')

890 format $(a 5,1 x, f 9.5,3 x, 12)$

895 format $(a 15, a 20,6(1 x, i 2,1 x, i 2))$

896 format(". 'If possible, salts in per $\mathrm{kg}-\mathrm{H} 20$ units')

897 format(' ', 'If possible, salts in per $\mathbf{k g}$ solution units')

898 format (' ' ' If possible, salts in per liter solution units')

899 format ('SS.', alo)

905 format( $1 x$, 'Give title for this group of waters'

a ' (up to 80 character string).')

910 format $(a 80)$

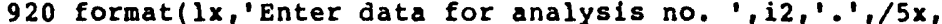

a ' 1 . sample number (up to 10 character string).,$/ 5 x$,

b '2: sample ph, 20.0 if unknown (decimal point reguired)., $15 x$,

c '3. sample density, 0.0 if unknown (decimal point req.).', $/ 5 x$,

d '4. concentration units of analysis (integer code).,$/ 10 x$,

f ' I" = molality',/10x,

$\mathrm{g} \cdot \mathrm{2}^{\prime \prime}=\mathrm{mg} / \mathrm{kg}$ solution $(\mathrm{ppm})^{\prime}, / 10 \mathrm{x}$

h ' " $3^{\prime \prime}=$ milliequivalents/liter',/10x,

i '"4" = mg/liter',/10x,

$1{ }^{\prime \prime}$ " $^{\prime}=$ millimoles/liter', $/ 5 x$

$j$ '5. sample description (up to 40 character string). ',/

$k \cdot 1,10 x, 2^{\prime}, 6 x, 3^{\prime}, 5 x, 4^{\prime}, 1 x, 5^{\prime}, 1$

$\left.110\left({ }^{\prime}-1\right), 1 x, 6(1-1), 1 x, 5(1-1), 1 x, 1-1,1 x, 40(1-1)\right)$

925 format $(a 10,1 x, f 6.3,1 x, f 5.3,1 x, 11,1 x, a 40)$

930 format $(a) 0,2 x, a 40,1 x, f 6.3,1 x, f 5.3,1 x, 11)$

935 format( $1 x$. 'Enter analytical data for major elements'

a ' (analysis ',12,'): ',/11x,' (decimal point required)',/,

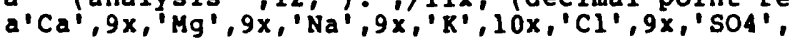

b/,6(10('-1),1x))

940 format ( 6 el1.5)

945 format(1x,' Enter identifier integer and data for five species', a ' (analysis ', i2,'):',

a $/ 10 x, '$ (decimal point required in data value)',

a $/ 5 x, 101$ CO3',10x, 05 NO3',10x,'09 NH4',

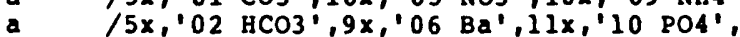

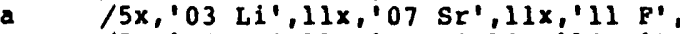

a $\left./ 5 x, 104 \mathrm{Br}, 11 x, 108 \mathrm{~B}^{\prime}, 12 x, 12 \mathrm{I}^{\prime}\right)$

950 format $(5(1--1,1 \times, 10(1-1), 1 x))$

955 format $(5(12,1 x$, elo.4,1x)

960 format $(5(1 x, 12,1 x, e 10.4))$

961 format(' ', Ali output files filled; PROGRAM TERMINATED!l $1, /, 5 \mathrm{x}$, 'Delete unneeded output files and reexecute SNORMI!')

975 format (',20x, 'ADJUST PRINTER PAGE')

980 formatl. '"ENTER: "9" to start over', /,9x,1"8" to terminate', a' program', $/, 3 x$, 'otherwise enter (RETURN>')

985 format(" "ENTER: "9" to start over (your new data file, " ,alo, a'", will be retained)' $/, 9 x, " 8$ " to terminate'.

b' program $(1,10 x, \cdots, 10 x, 1 \cdots, 10 x, \cdots, 10 x, 1) 1,1,3 x$,

c'otherwise enter (RETURN>') end

0551

0552

0553

0554

0555

0556

0557

0558

0559

0560

0561

0562

0564

0565

0566

0567

0568

0569

0570

0571

0572

0573

0574

0575

0576

0577

0578

0579

0580

0581

0582

0583

0584

0585

0586

0587

0588

0589

0590

0591

0592

0593

0594

0595

0596

0597

0598

0599

0600

0601

0602

0603

0604

0605

0606

0607

0608

0609

0610

0611

0612

0613

0614

0615

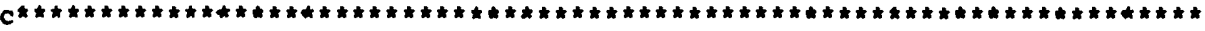

0616 


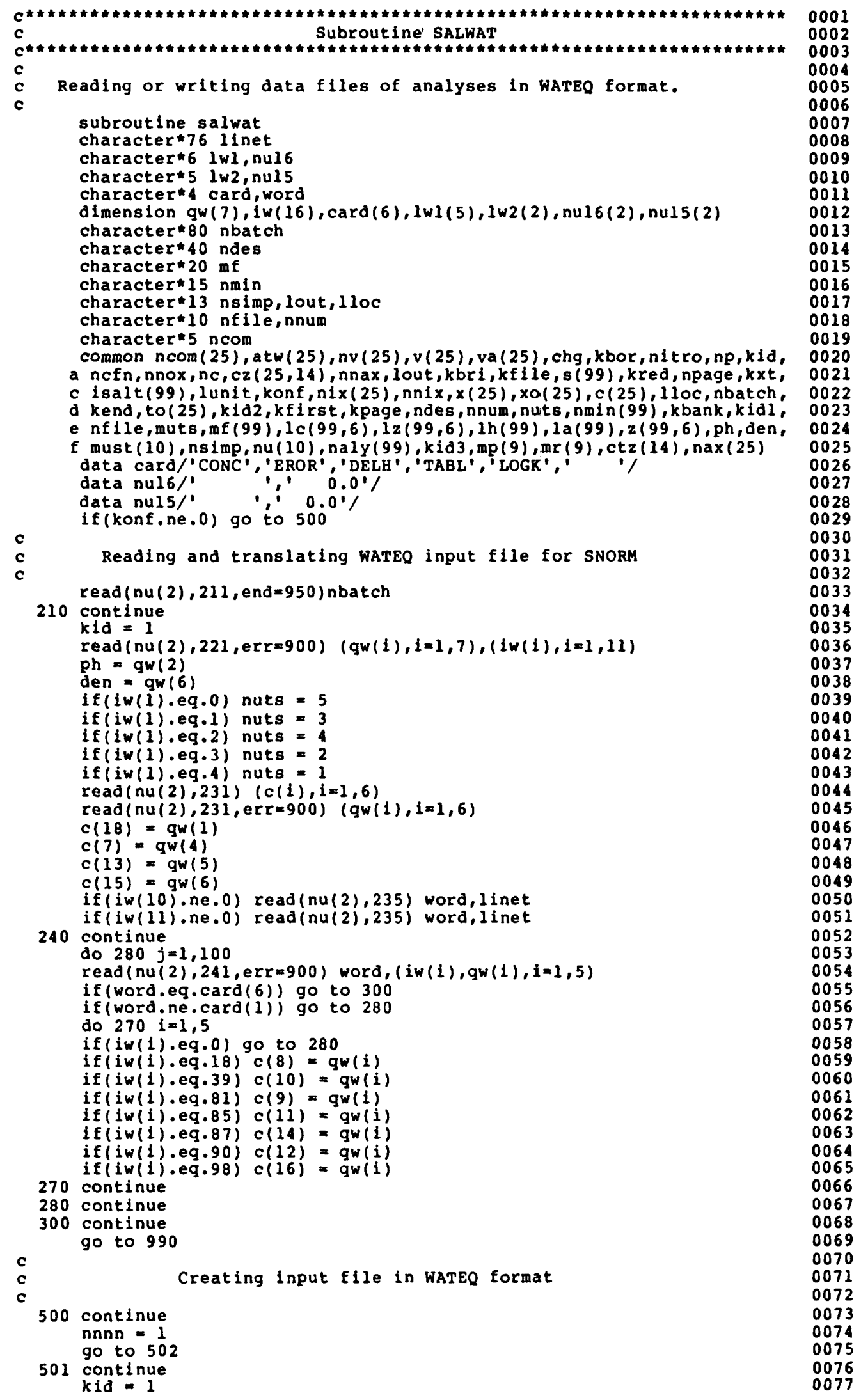


print 601

read 600,1

if (1.eq.i) go to 990

nnnn = nnnn + I

if (nnnn.1t.100) go to 502

print 645

go to 990

502 continue

print 602

read 604 , nbatch

print 604 , nbatch

print 605

read $600, i$

if (1.eq.1) go to 502

c

write (nu(1),604) nbatch

503 continue

Title, Job description "TITL" 0078

0079

0080

0081

0082

0083

0084

0085

0086

0087

0088

0089

0090

0091

0092

0093

TEMP, PH, EHM, EHMC, EMFZ, DENS, DOX 0094

print 606

$\operatorname{read}(\mathrm{nu}(10), 607, \operatorname{err}=505) \quad(1 \mathrm{wl}(i), i=1,5),(1 w 2(i), 1=1,2)$

0095

0096

0097

do $504 i=1,5$

if(lwl(1).eg.nul6(1)) 1 wl(i) $=$ nul6(2)

if(i.gt.2) go to 504

if(1w2(i).eq.nul5(1)) Iw2(i) = nul5(2)

0098

0099

0100

0101

504 continue

go to 506

505 continue

print 603

go to 503

506 continue

print $607,(1 w 1(i), i=1,5),(1 w 2(i), i=1,2)$

0102

0103

0104

0105

0106

0107

0108

print 605

0109

read 600 ,

0110

if (i.eg.i) go to 503 oll1

PLAG, CORALK, PECALC, IGO, PRT(1 to 4), IDAVES, ISPEC, IMIN 0112

507 continue

print 608

read (nu(10),609, err $=508$ ) (iw(i) $, 1=1,11$ )

go to 509

508 continue

print 603

go to 507

509 continue

print $609,(1 w(1), 1=1,11)$

print 605

read 600,1

if (i.eg.1) go to 507

write(nu(1),610,err=504) (1wl(i),i=1,5),

0113

0114

0116

0117

0118

0119

0120

0121

0122

0123

0124

0125

0126

0127

$j 10=i w(10)$

c

$j 11=i w(11)$

0128

511 continue

Solute concentrations ( $\mathrm{Ca}, \mathrm{Mg}, \mathrm{Na}, \mathrm{K}, \mathrm{Cl}, \mathrm{SO4})$

0129

print 611

read $(\operatorname{nu}(10), 612$, err $=512)(\mathrm{qw}(1), 1=1,6)$

0130

0131

0132

0133

go to 513

512 continue

print 603

0134

0135

go to 511

0136

0137

$\begin{array}{ll}\text { print } 612,(\mathrm{qw}(i), i=1,6) & 0138 \\ \text { print } 605 & 0139\end{array}$

read 600,1

if (i.eq.1) go to 511

write(nu(1),612, err=512) (qw(i), i=1,6) 0142

515 continue

Solute concentrations (HCO3, Si02, $\mathrm{Pe}, \mathrm{PO4}, \mathrm{Sr}, \mathrm{F}$ ) 014

print 613

$\operatorname{read}(\operatorname{nu}(10), 612, \operatorname{err}=516) \quad(\mathrm{qw}(1), i=1,6)$

0144

0145

0146

0147

0148

0149

0150

0151

0153

0154

print 605

read 600,1

if(i.ne.0) go to 515 
c

521 continue

write $(\operatorname{nu}(1), 612, \operatorname{err}=516) \quad(q w(i), i=1,6)$

Aqueous species selected for output "KSPEC(i)" 0157

if $(j 10 . \mathrm{eq} .0) \mathrm{go}$ to 525

print $615, j 10$

$\operatorname{read}(n u(10), 616, \operatorname{err}=522) \quad(i w(i), 1=1,16)$

0158

go to 523

522 continue

print 603

go to 521

523 continue

print $616,(i w(i), i=1,16)$

print 605

read 600,1

if $(i . n e .0)$ go to 521

c

write (nu (1) ,616,err $=52$

525 continue

if $(j 11 . \mathrm{eg} .0)$ go to 531

print $617, j 11$

read(nu(10),616, err $=526)(1 w(i), i=1,16)$

iw(i), i=1,16)

$W(i), i=1,16)$
Minerals selected for output "KMIN(i)" 0171
0172

go to 527

526 continue

print 603

go to 525

527 continue

print $616,(i w(i), i=1,16)$

print 605

read 600,1

if (i.eg.i) go to 525

c

write(nu(1),616,err =526) (iw(i),i=1,16)

531 continue

Concentrations of other solutes "CONC"

print 620

read 600 , $i$

if $(1 . \mathrm{eg} .1)$ go to 535

0159

0162

0162
0163

0164

0165

0166

0167

0168

0169

0170

0172

0174

0175

0176

0177

0178

0179

0180

0181

0182

0183

0184

0185

0186

0187

0188

0189

0190

0191

534 continue

print 621

read (nu $(10), 622, \operatorname{err}=532)$ (iw(i), $q w(i), i=1,5)$

0192

0193

0194

go to 533

0195

532 continue

print 603

0196

0197

go to 534

533 continue

print 622 , (iw(i), gw(i), $i=1,5$ )

0198

0199

0200

print 605

read 600,1

if(i.eg.i) go to 534

word $=\operatorname{card}(1)$

if(iw(5).ne.0) go to 531 or

Overrides preset balance constraints "EROR" 0207
0208

535 continue

print 625

read $600, i$

if(i.eg.0) go to 540

0209

0210

0211

538 continue

print 626

go to 537

536 continue

print 603

go to 538

537 continue

print 622 , (iw(i), $q w(i), i=1,5$ )

print 605

read $600, i$

if $(i . n e .0)$ go to 538

word $=\operatorname{card}(2)$

0212

0214

0215

0216

0217

0218

0219

0220

0221

0222

0223

0224

write (nu (1),623, errm536) word, (iw(i), qw(i), i=1,5) 0225

c

540 continue

Overrides standard reaction enthalpies "DELH" 0226

print 630

read $600, i$

if(i.eg.0) go to 545

0227

0228

0229

0230

541 continue

print 631

0231

0232

$\operatorname{read}(\operatorname{nu}(10), 622, \operatorname{err}=542) \quad(i w(1), g w(i), i=1,5)$

0233 
$\begin{array}{ll}\text { go to } 543 & 0234\end{array}$

542 continue 0235

print $603 \quad 0236$

$\begin{array}{ll}\text { go to } 541 & 0237\end{array}$

0238

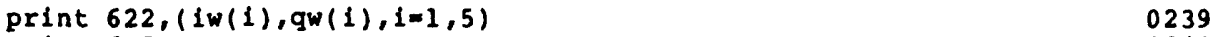

print $605 \quad 0240$

read $600,1 \quad 0241$

if(i.ne.0) go to $541 \quad 0242$

word $=\operatorname{card}(3)$

write (nu (1), 623,err=542) word, (iw(1), qw(1), $1=1,5$ ) 0244

If(Iw(5).ne.0) go to 541 . 0245

c

545 continue

Overrides log K's of reaction "TABL" 0246

read $600,1 \quad 0249$

if(1.eq.0) go to $550 \quad 0250$

546 continue $\quad 0251$

print $634 \quad 0252$

$\operatorname{read}(\operatorname{nu}(10), 622, \operatorname{err}=547)(\operatorname{iw}(1), q w(1), 1=1,5) \quad 0253$

go to $548 \quad 0254$

547 read $603 \quad 0255$

go to $546 \quad 0256$

0257

print $622,(1 w(1), q w(1), 1=1,5) \quad 0258$

print 6050259

read $600,1 \quad 0260$

if(1.ne.0) go to $546 \quad 0261$

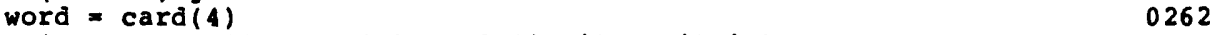

write(nu(1),623, err=547) word, (iw(1), qw(1),i=1,5)

if(iw(5). ne.0) go to 545

c

550 continue

Overrides $\log R^{\prime}$ 's vs T "LOGK" 0265

print 637

read $600, i$

0270

print 638

read $(\mathrm{nu}(10), 622, \operatorname{err}=552) \quad(1 \mathrm{w}(1), \mathrm{qw}(1), 1=1,5) \quad 0272$

go to $553 \quad 0273$

552 continue $\quad 0274$

print $603 \quad 0275$

go to $551 \quad 0276$

$\begin{array}{ll}553 \text { continue } & 0277\end{array}$

print $622,(1 w(1), q w(1), 1=1,5) \quad 0278$

$\begin{array}{ll}\text { print } 605 & 0279\end{array}$

read $600,1 \quad 0280$

if(1.ne.0) go to $551 \quad 0281$

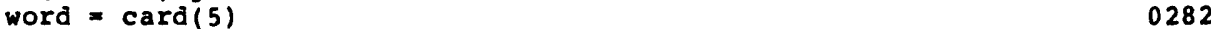

write $(\operatorname{nu}(1), 623, \operatorname{err}=552)$ word, (iw(i), qw(i), $i=1,5) \quad 0283$

go to $550 \quad 0284$

c

555 continue

End of input for this analysis $\begin{array}{r}0285 \\ 0286\end{array}$

word $=\operatorname{card}(6) \quad 0287$

write(nu(1),640) word $\quad 0288$

go to $501 \quad 0289$

900 continue $\quad 0290$

$\begin{array}{ll}\text { kid3 }=1 & 0291\end{array}$

950 continue $\quad 0292$

kend $=1 \quad 0293$

990 continue $\quad 0294$

return $\quad 0295$

0296

221 format $(5(\mathrm{f} 6.0,1 \mathrm{x}), 2 \mathrm{f5} .0,1 \mathrm{x}, 911,213) \quad 0297$

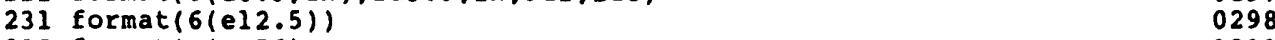

(299 029

241 format $(a 4,1 \times, 5(13, e 12.5))$

600 format (il) 0301

601 format(" ', 'Another water?? "0" =. Yes; "1" = No.') 0302

602 format(' ' 'Enter sample description (up to 80 character string)') 0303

603 format (' ',' INPUT ERROR -- reenter these data') 0304

604 format (a80) 0305

605 format (', 'IS THIS CORRECT?? "0" = Yes; "I" = No.') 0306

606 format (' ', ENTER: A. Temperature (deg. C).', /,8x,'B. pH.', /,6x, 0307 a'C-E. Eh data (see WATEQ documentation). $, 1,8 x, 8 x, 0308$

a'F. Density (g/cc).', $/$, 0309

b8x,'G. Dissolved oxygen (mg/1),',/,15x,' [Decimal point with each]' 0310 $C, 1, A^{\prime}, 6 x, B^{\prime}, 6 x, C^{\prime}, 6 x, D^{\prime}, 6 x, E^{\prime}, 6 x, P^{\prime}, 5 x, G^{\prime}, /, \quad 0311$ 
d5 $(6(1-1), 1 x), 2(5(1-1), 1 x)) \quad 0312$

607 format $(5(a 6,1 x), 2(a 5,1 x)) \quad 0313$

697 format $(5(f 6.0,1 x), 2(f 5.0,1 x)) \quad 0314$

608 format (" 'ENTER: A. Input concentrations (" 0 " =mole/1; ', 0315

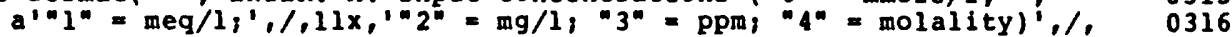

b $8 x,{ }^{\prime} B$. Alkalinity method (See WATEQ documentation),$/, 8 x$, , 0317

c'C. Redox method (See WATEQ documentation) $, /, 8 x, 1,8 x, \quad 0318$

d'D. Input error options (See WATEQ documentation)', $/, 6 \mathrm{x}, \quad 0319$

' 'E-H. Output deletion options (See WATEQ documentation) $, 1 / 8 x, \quad 0320$

f'I. Ion-pair activity coefficients (See WATEQ documentation) $\% /, \quad 0321$

$98 x, ' J$. Restricting output species (see WATBQ documentation) $, \%, \quad 0322$

h8x,'K. Restricting output minerals (See WATEQ documentation) $, \%, \quad 0323$

il5x, ' [All right justifled integer values]': 0324

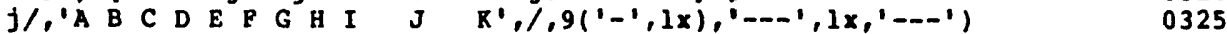

609 format $(9(11,1 x), 13,1 x, 13) \quad 0326$

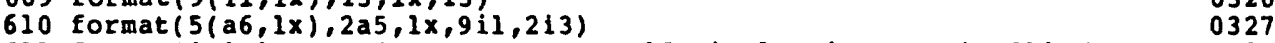

611 format (', 'ENTER CONCENTRATIONS: [decimal point required]',/, 0328 $a^{\prime} \mathrm{Ca}^{\prime}, 10 \mathrm{x}, \mathrm{Mg}^{\prime}, 10 \mathrm{x}, \mathrm{Na}^{\prime}, 10 \mathrm{x}, \mathrm{R}^{\prime}, 11 \mathrm{x}, \mathrm{Cl}^{\prime}, 10 \mathrm{x}, \mathrm{SO}^{\prime}, \mathrm{l}, \mathrm{O}$ b6 $(11(1-1 ;, 1 x)\} \quad 0330$

612 format ( $6 \mathrm{e} 12.5) \quad 0331$

613 format (' ', ENTER CONCENTRATIONS: [decimal point reguired]',/, 0332

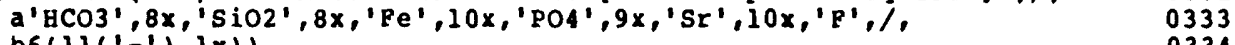
b6(11(1,1),1x)) 0334

615 format (' '.ENTER ' 13, ' index numbers of specified species', 0335 a' in output listing.',$/, 15 x$, ' [right-justified integers] ', , $\quad 0336$ b16(2x,'-1)) 0337

616 format (16i5) 0338

617 format (' ', 'ENTER ', i3,' index numbers of specified minerals', 0339 a' in output isting.' $, /, 15 x, '$ [right-justified integers]',/, bl6(2x,1--1))

620 format' ' ', Any additional solutes?? "O" = Yes; "1" = No', 0342 $a /, 5 x$, "CONC' ' card(s) in WATEQ')

621 format (' '. 'ENTER index integer and concentration (decimal', 0344 a point] for each in analysis: ', , b5 $x, 1017$ H2S', $x,, 018$ CO3',5x,'039 NH4',5x,'051 Al',,$\quad 0346$

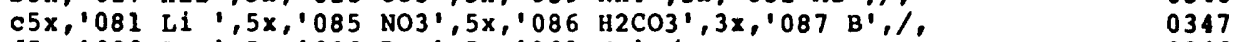

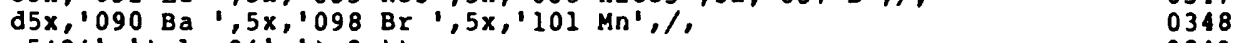
e $5(3(1-1), 1 x, 9(1-1), 3 x)) \quad 0349$

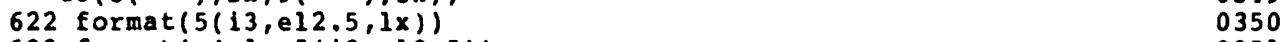

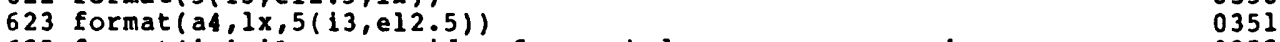

625 format (' '. 'Any override of mass balance convergence', 0352 a' constraints (WATEQ "EROR" card)?',/,12x," "0" = no! " 1 " = Yes') 0353

626 format (' ', 'ENTER reset values [decimal point] for:', $/$, a 0354 a4x,'Carbon',10x,'sulfate',9x,'pluoride',8x,'Phosphate',7x, 0355 b'Chloride', $/, 4 x, 4(9(1-1), 7 x), 9(1-1)) \quad 0356$

630 format!' 'Any override of standard enthalpies?? "0" = No; $\quad 0357$ b," I" = Yes (WATEQ "DELH" card)')

631 format(' ', ENTER reaction index number [right-justified integer]' 0359 $\begin{array}{ll}a, /, 7 x, 1 \text { and the new enthalpy value [decimal point] } 1,1, & 0360 \\ b 5(3(1,-1), 1 x, 9(1-1), 3 x)) & 0361\end{array}$

633 format (' 'Any overrides of reaction constants?? $0^{\prime \prime}=$ No:' 0362 $a^{\prime}, "{ }^{\prime \prime}=$ Yes (WATEQ "TABL" card)') 0363

634 format $('$ '. 'ENTER reaction index number (right-justified', 0364 a' integer]',/7x,' and new reaction constant [decimal point].',/, 0365 b5 $(3(1-1), 1 x, 9(1-1), 3 x)) . \quad 0366$

637 format (' '. Any overrides of $\log k$ vs. $T$ constants?? "ON= No:', 0367 b' "l" = Yes', /,15x,'WATEQ "LOGK" card)') 0368

638 format (' ', 'ENTER reaction index number [right-justified', $\quad 0369$ a' integer]', $/, 7 x$, and five new constants [decimal point', $\quad 0370$ b' with each] $1,1,3(1-1), 1 \times, 9(1-1), 4(7 x, 9(1-1))) \quad 0371$

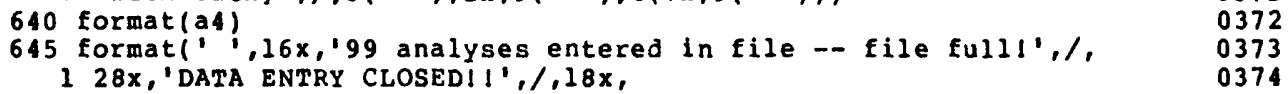

2 'Create new file for remainder of analyses (1')

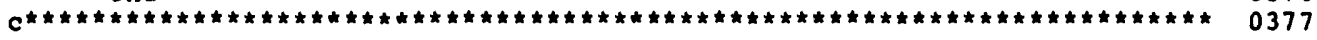

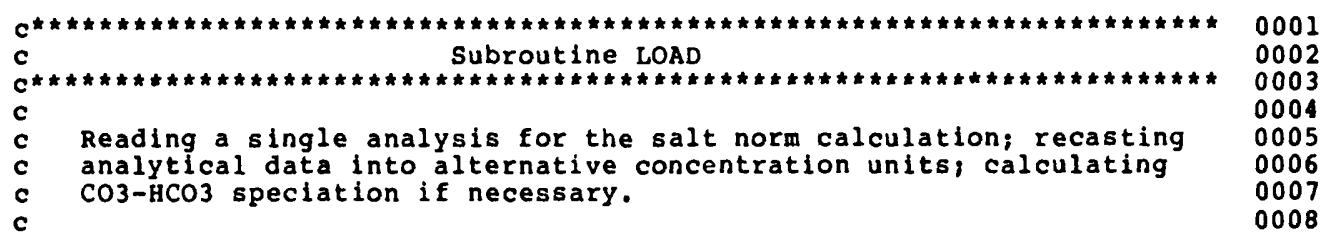




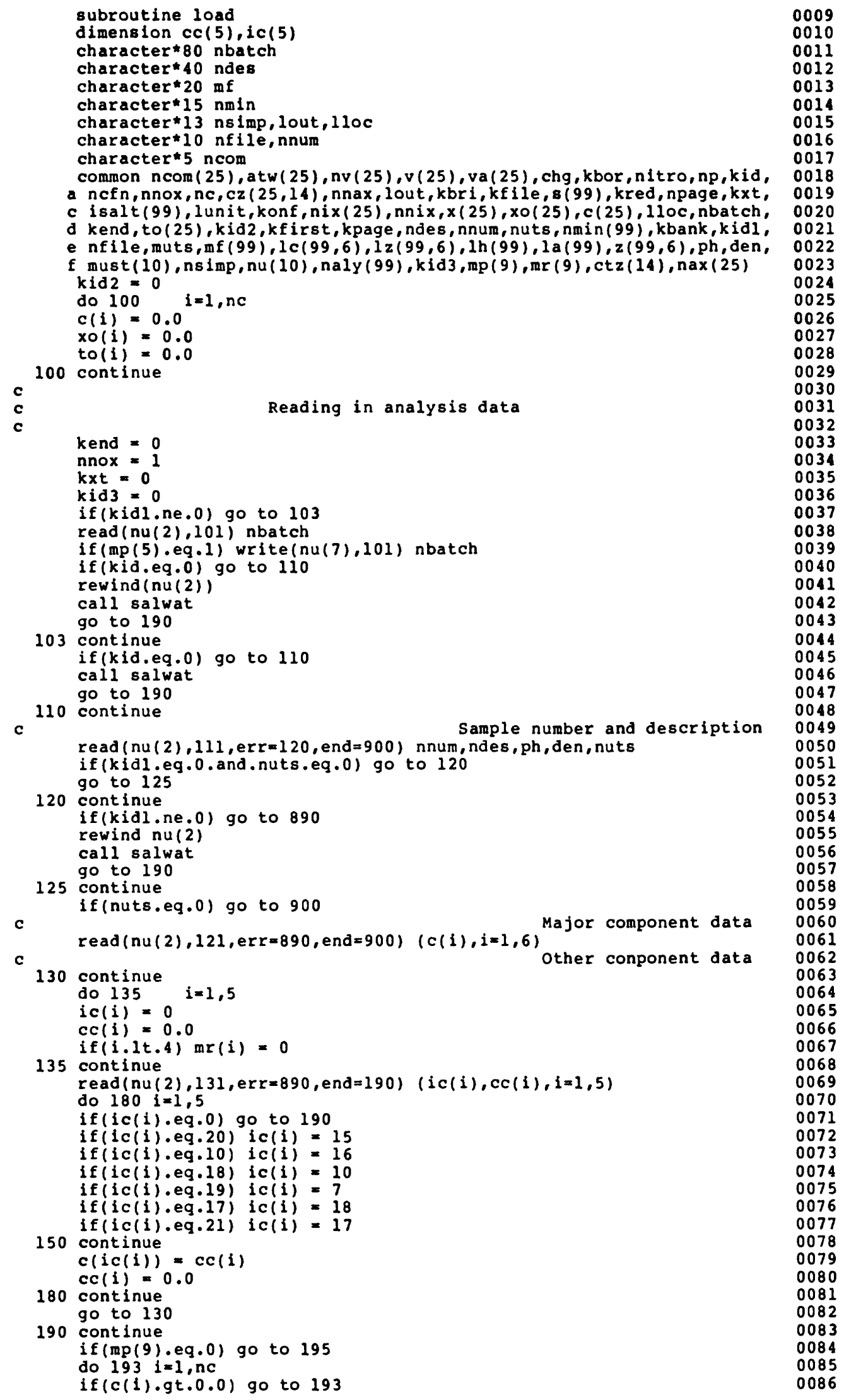




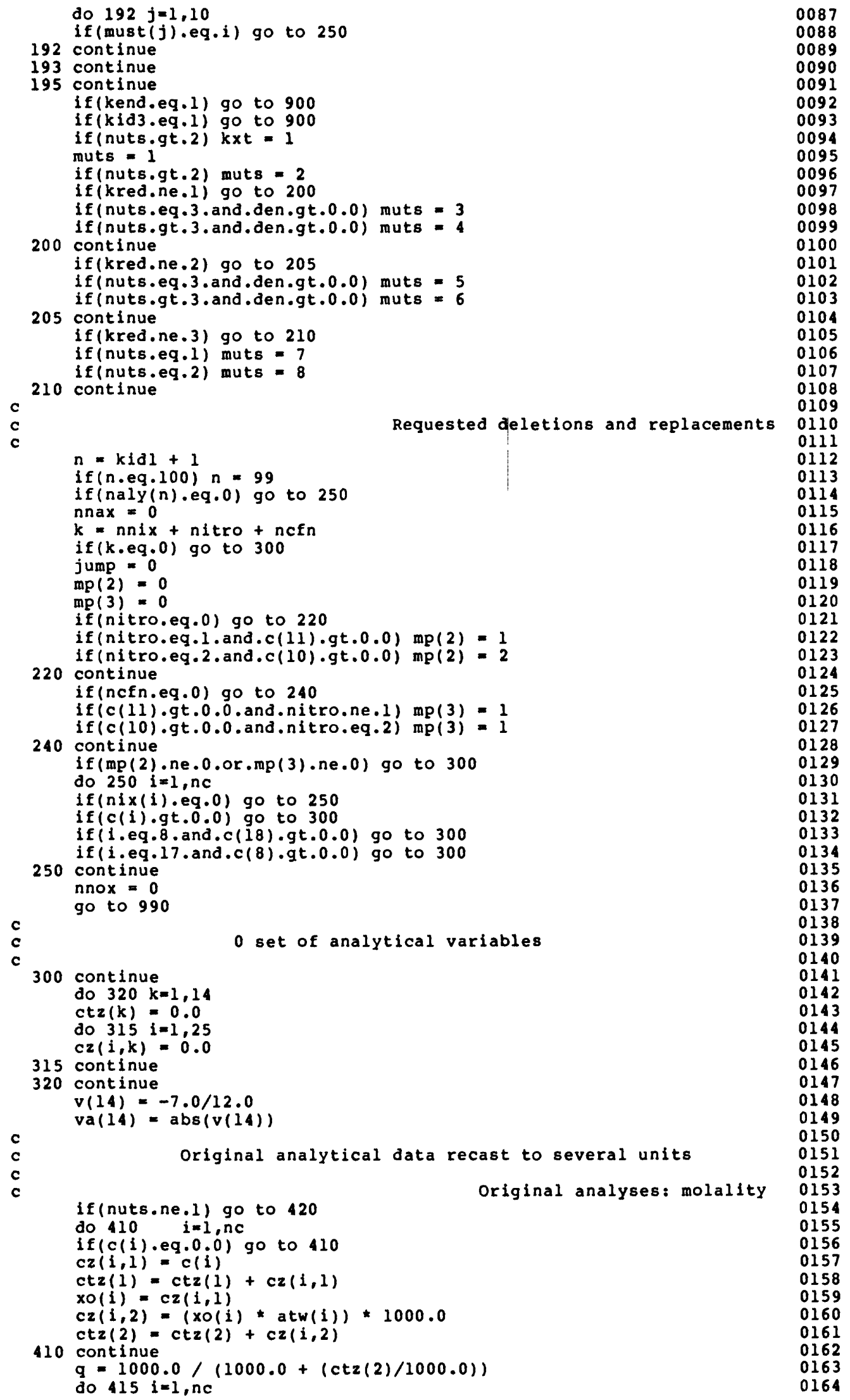




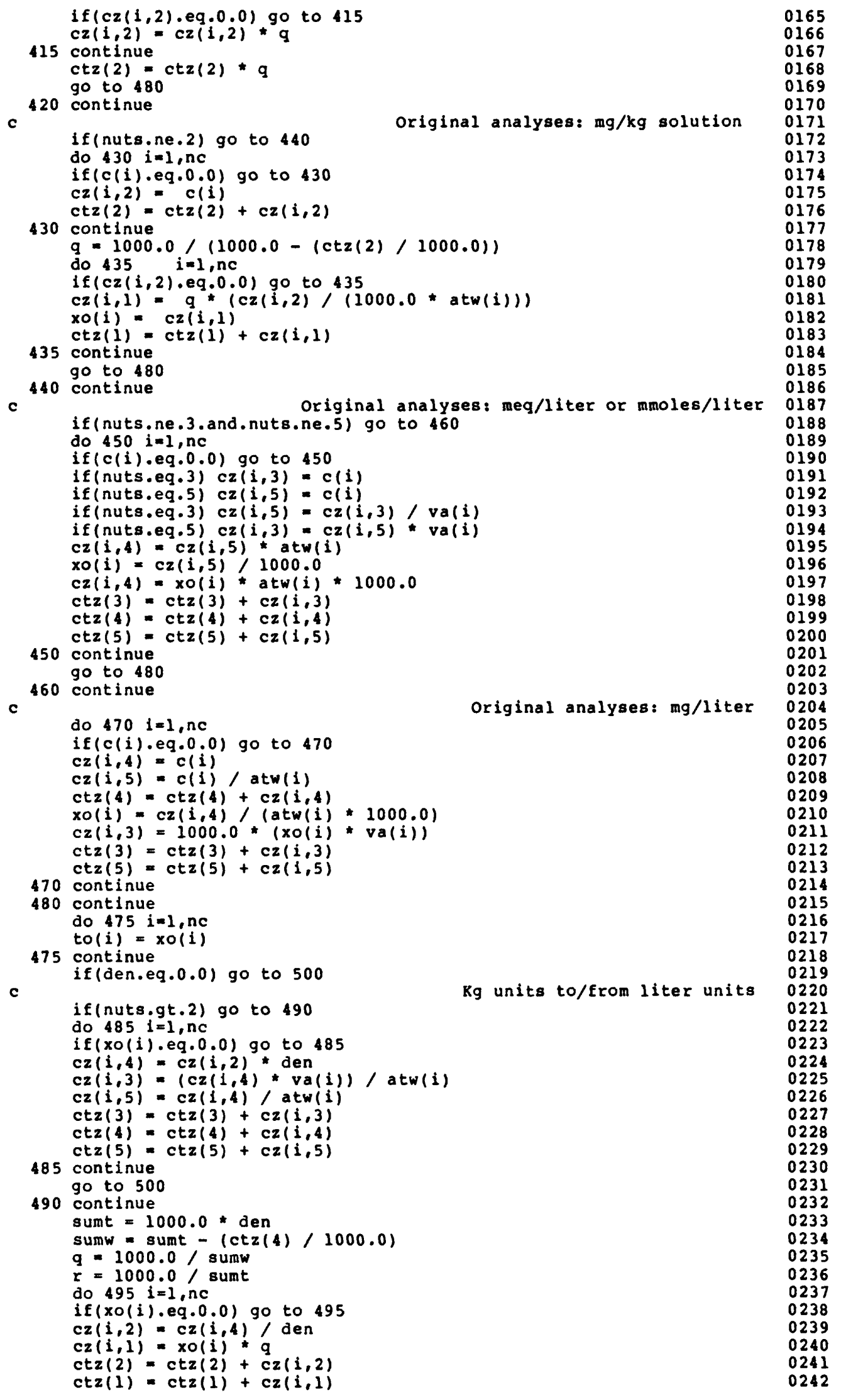




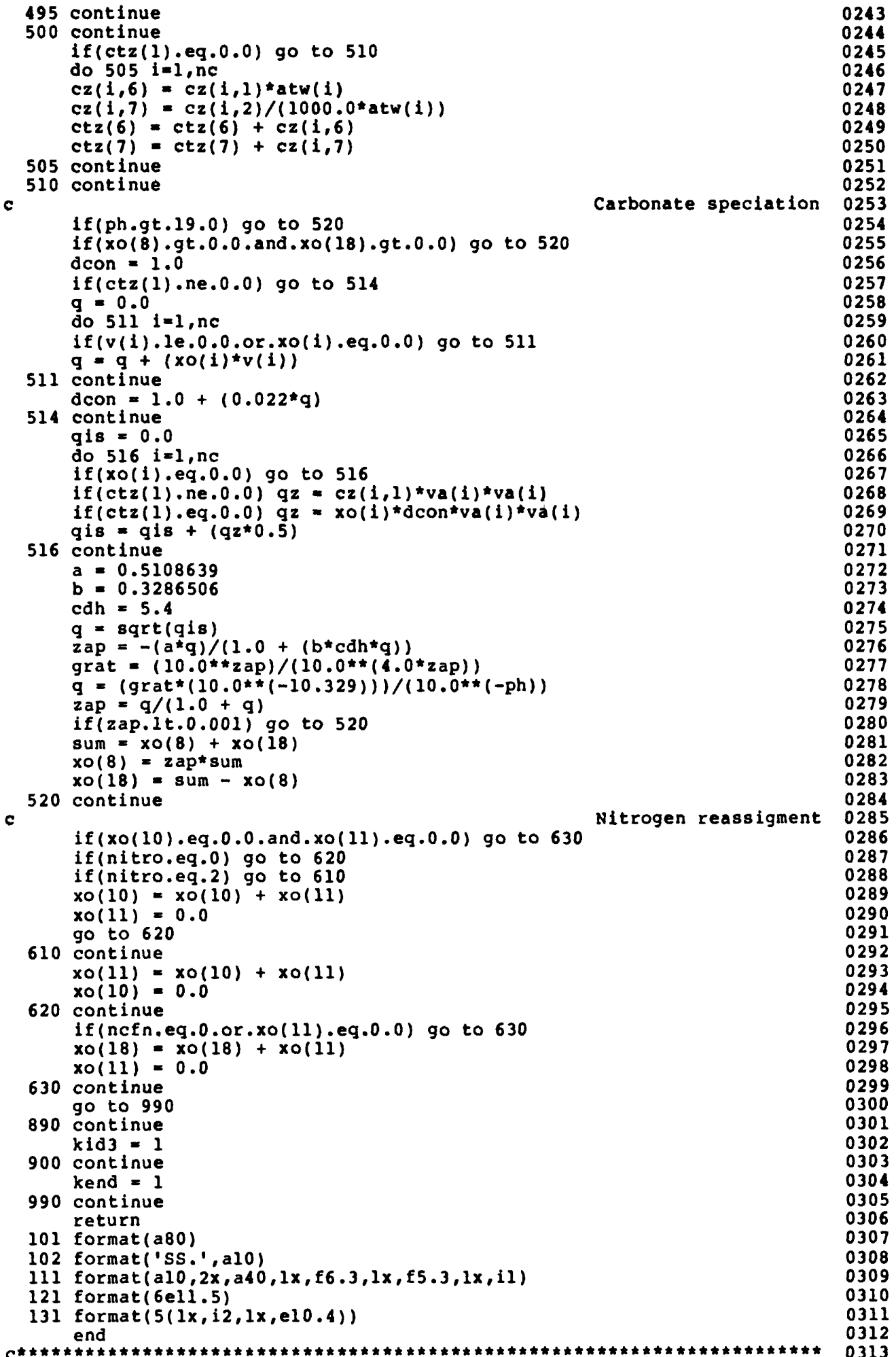




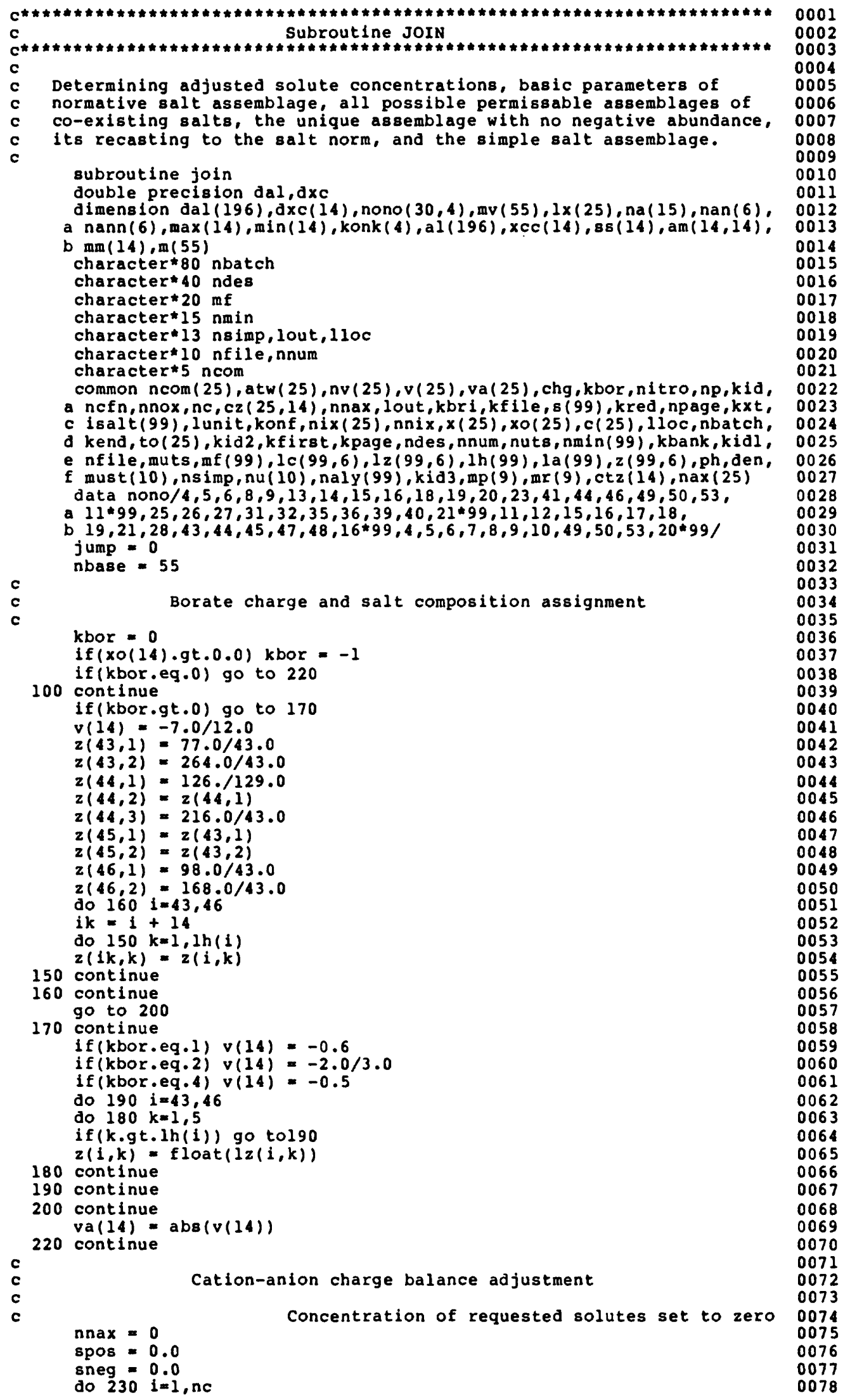




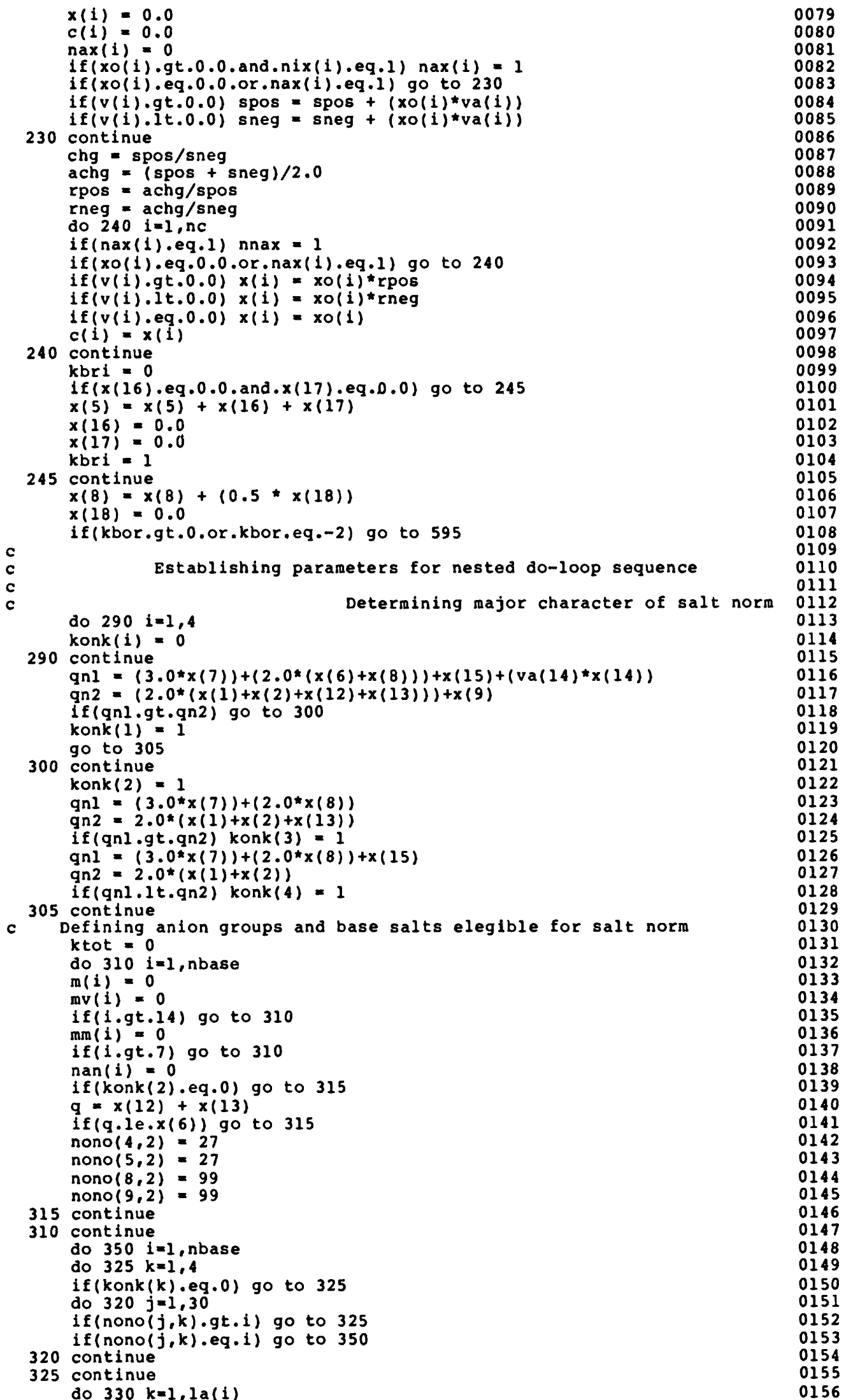


if $(1 \mathrm{c}(i, \mathrm{k}) . \mathrm{gt} .15)$ go to 330

if $(x(1 c(i, k))$.eq.0.0) go to 350

330 continue

ktot $=\mathbf{k t o t}+1$

$\operatorname{mv}($ ktot $)=i$

if (1.1t.11) $\operatorname{nan}(1)=\operatorname{nan}(1)+1$

if (1.gt.10.and.i.1t.25) $\operatorname{nan}(2)=\operatorname{nan}(2)+1 \quad 0163$

if(i.gt.24.and.1.1t.35) $\operatorname{nan}(3)=\operatorname{nan}(3)+1 \quad 0164$

if (i.gt.34.and.i.1t.43) $\operatorname{nan}(4)=\operatorname{nan}(4)+1 \quad 0165$

if (i.gt.42. and.1.1t.47) $\operatorname{nan}(5)=\operatorname{nan}(5)+1$

if(i.gt.46) nan(6) $=\operatorname{nan}(6)+1$

350 continue

if (ktot.eq.0) go to 899

c

nca $=0$

Designating solutes and anion groups in analysis 0170

do $360 \quad i=1,15$

if $(x(i), e q \cdot 0.0)$ go to 360 r

nca $=$ nca $+1 \quad 0174$

na(nca) = i 0175

360 continue $\quad 0176$

$\operatorname{minmax}=$ nca $-1 \quad 0177$

$k=0 \quad 0178$

nant $=0 \quad 0179$

do $370 \quad 1=1,6 \quad 0180$

if $(\operatorname{nan}(i) \cdot$ eq.0) go to 370

nant $=$ nant $+1 \quad 0182$

nann(nant) $=\operatorname{nan}(i) \quad 0183$

370 continue

Defining indexing 1 imits for each loop in nested series 0185

$\max (1)=k$ tot - (minmax - 1) 0186

$\begin{array}{ll}\min (1)=1 & 0187\end{array}$

do $3801=2$, minmax $\quad 0188$

$k=i-1 \quad 0189$

$\min (i)=\min (k)+1 \quad 0190$

$\begin{array}{ll}\max (i)=\max (k)+1 & 0191\end{array}$

380 continue $\quad 0192$

nsum $=0 \quad 0193$

do $400 \quad 1=1$, nant $\quad 0194$

nsum = nsum + nann(i) 0195

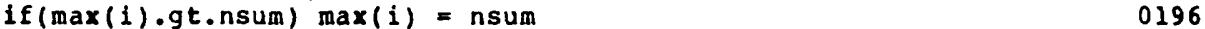

400 continue $\quad 0197$

$\begin{array}{ll}\text { nsum }=\text { ktot }+1 & 0198\end{array}$

$11=$ nant $\quad 0199$

ik = minmax $\quad 0200$

do $410 \quad i=1$, nant $\quad 0201$

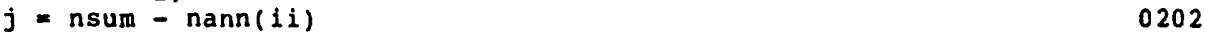

if (j.gt.min(ik)) $\min (i k)=j \quad 0203$

$\begin{array}{ll}\text { nsum }=j & 0204\end{array}$

$\begin{array}{ll}\text { ii }=11-1 & 0205\end{array}$

$i k=i k-1 \quad 0206$

do $420 \quad i=1$, minmax

c

c

continue

Nested do-loops defining potential salt assemblage

0212

0213

0214

0215

0216

0217

0218

0219

0220

0221

0222

0223

0224

0225

0226

0227

0228

0229

0230

0231

$\begin{array}{ll}\text { call pick(mr(1),5,i5,min6,min(6),m,mm,mv(i5),jump,minmax) } & 0232 \\ \text { if (jump) } 500,475,875 & 0233 \\ \text { continue } & 0234\end{array}$

$\begin{array}{ll}\text { call pick(mr(1),5,i5,min6,min(6),m,mm,mv(i5),jump,minmax) } & 0232 \\ \text { if (jump) } 500,475,875 & 0233 \\ \text { continue } & 0234\end{array}$

475 continue 
do $87016=\min 6, \max (6)$

call pick $(\operatorname{mr}(1), 6, i 6, \min 7, \min (7), m, m m, m v(16), j u m p, \operatorname{minmax}) \quad 0236$

if (jump) $500,470,870$

470 continue

do $865 \quad 17=\min 7, \max (7)$

if (Jump) $500,465,865$

465 continue

do 860 i $8=\mathrm{m} \ln 8, \max (8)$

if (jump) $500,460,860 \quad 0245$

460 continue

do 855 i $9=\operatorname{ming}, \max (9)$

call pick (mr (1),9,ig,minlo,min (10),m, mm, mv(ig) fump, minmax)

if (jump) $500,455,855 \quad 0249$

455 continue

do $850110=\min 10, \max (10)$

cal1 pick(mr(1),10,i10,minl1,min(11),m,mm,mv(110),jump,minmax) 0252

if (jump) $500,450,850$

450 continue

do 845 ill $=\min 11, \max (11)$

(

if (jump) $500,445,845$

445 continue

do 840 il $2=\min 12, \max (12)$

If (jump) $500,440,840 \quad 0261$

440 continue

do 835 i1 $3=\min 13, \max (13)$

cal1 pick(mr(1),13,i13,minl4,min(14),m,mm,av(i13),jump,minmax) 0264

if (jump) $500,435,835$

435 continue

do 830 il $14=\mathrm{min} 14$, $\max (14)$

(

if (jump) $500,430,830 \quad 0269$

430 continue

c

c

500 continue

Rejecting assemblage not containing all solutes

0270

0271

0272

0273

0274

$m r(2)=m r(2)+1 \quad 0275$

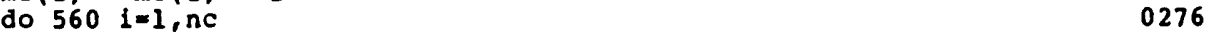

$\begin{array}{lr}1 \times(1)=0 & 0277\end{array}$

0278

$\begin{array}{lr}\text { do } 5801=1, \operatorname{minmax} & 0279\end{array}$

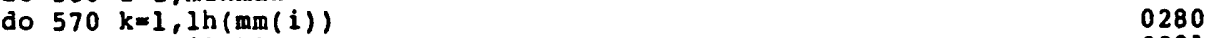

$\begin{array}{lr}k k=1 c(m m(i), k) & 0281\end{array}$

$\begin{array}{lr}1 \times(k k)=1 & 0282\end{array}$

570 continue $\quad 0283$

580 continue $\quad 0284$

do $590 \quad i=1$, nc $\quad 0285$

if (i.gt.15) go to $595 \quad 0286$

if $(x(1) . g t .0 .0$. and. $1 \times(1) . e q .0)$ go to $800 \quad 0287$

if $(x(1) . e g .0 .0$. and. $1 \times(1) . e q .1)$ go to $800 \quad 0288$

\begin{tabular}{ll}
0289 \\
\hline
\end{tabular}

595 continue

do $6051=1,196$

Constructing minmax $x$ minmax matrix 0291

0292

0293

al $(1)=0.0$

dal (i) $=0.0$

if(i.gt.99) go to 605

$s(1)=0.0$

if(i.gt.14) go to 605

$x \operatorname{cc}(1)=-0.0$

$\mathrm{dxc}(1)=0.0$

$\mathrm{ss}(i)=0.0$

do $600 \mathrm{k}=1,14$

$\operatorname{am}(k, i)=0.0$

600 continue

605 continue

if $(x(7) . g t .0 .0)$ nomit $=7$

if $(x(15) \cdot g t .0 .0)$ nomit $=15$

if $(x(14) \cdot g t .0 .0)$ nomit $=14$

if $(x(1)) \cdot g t .0 .0)$ nomit $=11$

if $(x(8) \cdot g t .0 .0)$ nomit $=8$

if $(x(6) \cdot g t .0 .0)$ nomit $=6$

if $(x(5) \cdot g t .0 .0)$ nomit $=5$

$i \mathrm{i}=0$

0294

0295

0296

0297

0298

0299

0300

0301

0302

0303

0304

0305

0306

0307

0308

0309

0310

0311 


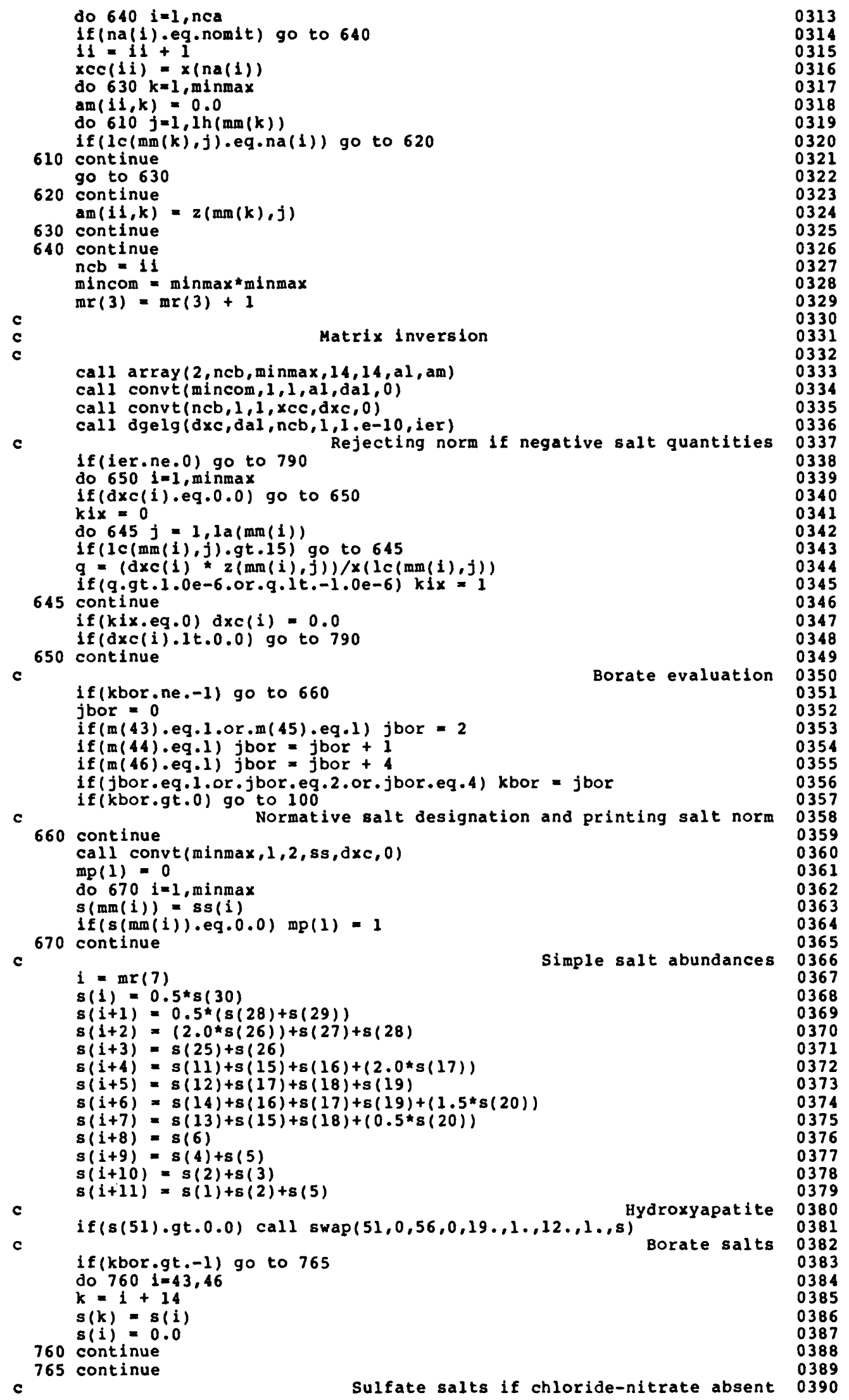




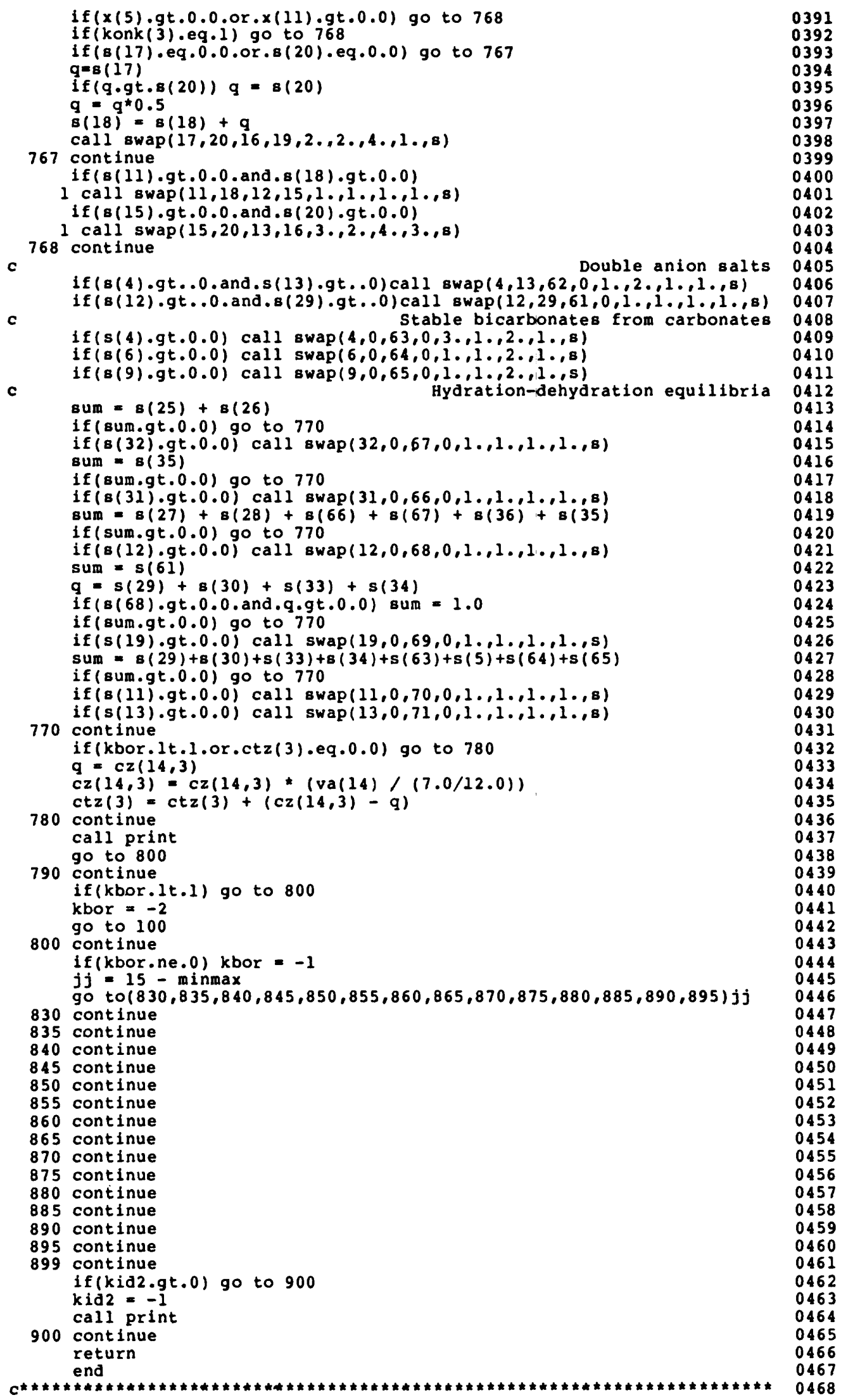




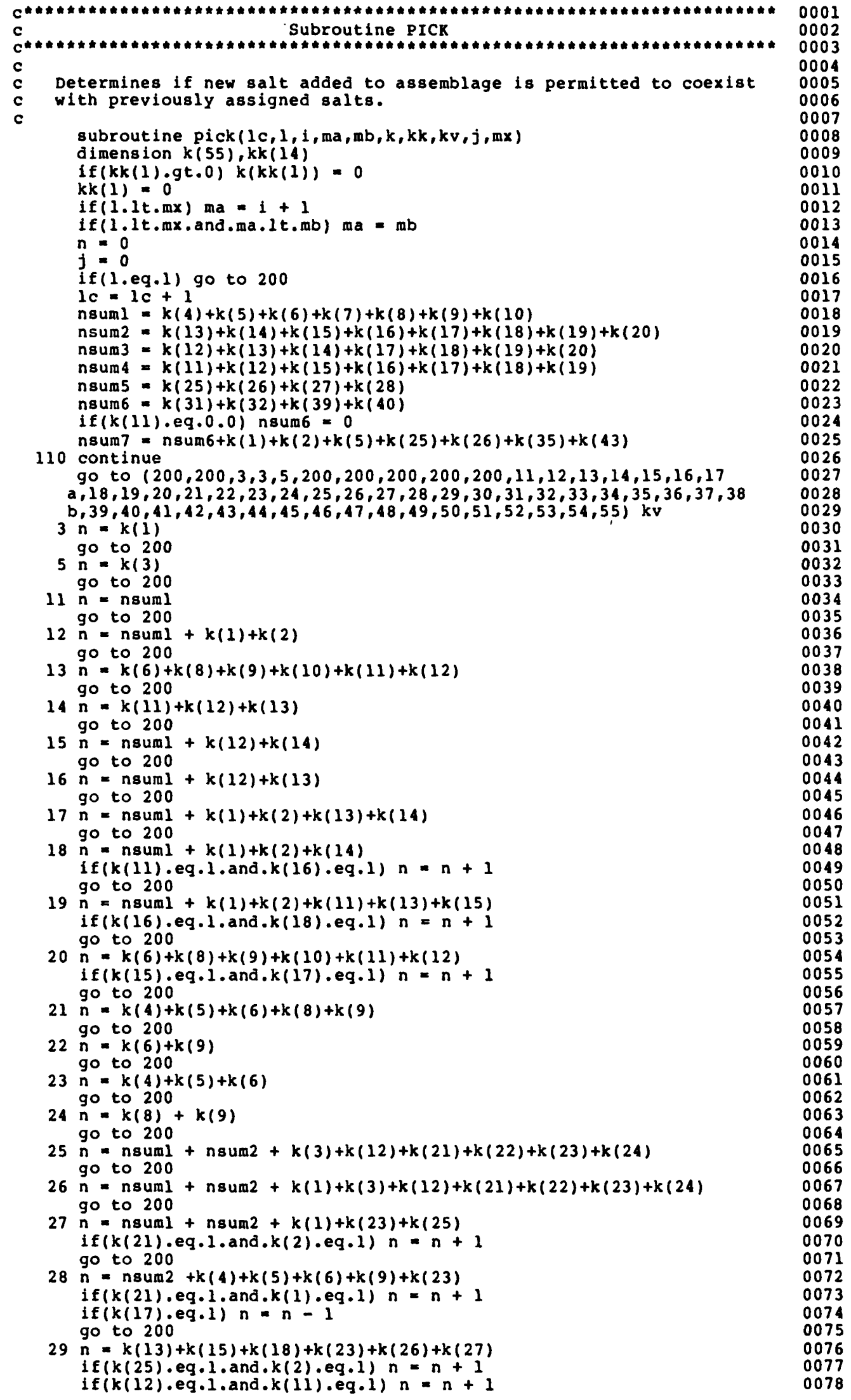


go to 200

$30 n=k(6)+k(9)+k(14)+k(23)$

if $(\mathrm{k}(19) \cdot \mathrm{eq} \cdot \mathrm{l} \cdot \mathrm{and} \cdot \mathrm{k}(16) \cdot \mathrm{eq} \cdot 1) \mathrm{n}=\mathbf{n}+1$

go to 200

$31 n=n s u m 2+k(4)+k(5)+k(6)+k(8)+k(9)+k(12)+k(23)$

if $(k(29) \cdot e q \cdot 1 \cdot$ and.k(11).eq.l.and.k(3).eq.1) $n=n+1$ go to 200

$32 n=n s u m 2+k(4)+k(5)+k(6)+k(9)+k(12)+k(21)+k(23)+k(24)$ if $(k(29) \cdot e q \cdot 1$ and.k(11).eq.1.and.k(2).eq.l) $n=n+1$ if $(\mathrm{k}(11) \cdot \mathrm{eq} \cdot 1 \cdot$ and.k(3).eq.i) $n=n+1$ go to 200

$33 n=k(6)$ go to 200

34 nsuml $=n$ suml $-k(10)$

$n=n$ suml $+n$ sum $2+k(12)+k(21)+k(23)$ go to 200

$35 n=n s u m l+n s u m 2+k(12)+k(21)+k(22)+k(23)+k(24)+k(31)+k(32)$ if $(\mathrm{k}(3) \cdot \mathrm{eq} \cdot 1 \cdot$ and.k(29).eq.1) $\mathrm{n}=\mathrm{n}+1$ go to 200

$36 n=n s u m 1+n s u m 2+k(1)+k(2)+k(23)+k(25)+k(25)+k(26)+k(29)+k(31)+$ a $k(34)$ go to 200

$37 n=k(25)+k(26)+k(27)+k(31)+k(32)+k(34)$

if $(k(28) \cdot e q \cdot 1 \cdot$ and. $k(1) \cdot e q \cdot 1) n=n+1$ if $(k(36)$ e eq.1. and.k(30).eq.1) $n=n+1$ go to 200

$38 \mathrm{n}=\mathrm{k}(6)+\mathrm{k}(9)+\mathrm{k}(14)+\mathrm{k}(16)+\mathrm{k}(17)+\mathrm{k}(19)+\mathrm{k}(20)+\mathrm{k}(23)+\mathrm{k}(25)+\mathrm{k}(26)+$ a $k(27)+k(29)+k(31)+k(32)+k(34)$

if $(k(28) \cdot e q \cdot 1$ and $\cdot k(2) \cdot e q \cdot 1) n=n+1$

if $(k(28) \cdot e q \cdot 2 \cdot$ and.k(l).eq.1) $n=n+1$ go to 200

$39 n=n$ sum $2+k(4)+k(5)+k(6)+k(8)+k(9)+k(12)+k(32)$ if $(k(28)$.eq.1.and.k(22).eq.1.and.k(1).eq.1) $n=n+1$ go to 200

$40 \mathrm{n}=\mathrm{nsum} 2+\mathrm{k}(4)+\mathrm{k}(5)+\mathrm{k}(6)+\mathrm{k}(9)+\mathrm{k}(12)+\mathrm{k}(21)+\mathrm{k}(23)$ if $(\mathrm{k}(29) \cdot \mathrm{eq} \cdot 1$. and.k(11).eq.1.and.k(3).eg.1) $n=n+1$ go to 200

$41 n=k(6)+k(14)+k(25)+k(26)+k(27)+k(28)+k(29)+k(30)+k(31)+$ a $k(32)+k(34)$ go to 200

42 nsuml = nsuml - k(10)

$n=n s u m l+n s u m 2+k(12)+k(21)+k(22)+k(23)+k(25)+k(26)+k(31)+k(32)$ go to 200

$43 n=k(4)+k(5)+k(12)+k(13)+k(15)+k(17)+k(18)$ go to 200 $44 \mathrm{n}=\mathrm{nsum} 6+\mathrm{nsum} 5+k(4)+k(5)+k(12)+k(13)+k(20)+k(35)$

$45 n=n \operatorname{sum} 6+k(1)+k(4)+k(5)+k(13)+k(15)+k(16)+k(20)+k(25)+$ a $k(26)+k(35)$ go to 200

$46 n=n s u m 5+n s u m 6+k(11)+k(12)+k(35)+k(36)+k(43)$ if $(k(17) \cdot e q \cdot 1$. and.k(15).eq.1) $n=n+1$ go to 200

$47 n=k(4)+k(5)+k(12)+k(17)+k(18)+k(19)+k(36)$ go to 200

$48 \mathrm{n}=\operatorname{nsum7}+\mathrm{k}(4)$ go to 200

$49 n=n$ sum $4+n s u m 5+k(10)+k(24)+k(34)+k(35)+k(36)+k(43)+k(44)+k(45)$ go to 200

$50 n=n$ num $4+n s u m 5+k(35)+k(36)$ go to 200

$51 \mathrm{n}=\mathrm{k}(12)+k(17)+k(18)+k(19)+k(47)+k(48)+k(49)+k(50)$ go to 200

$52 n=n s u m 7+k(47)+k(48)+k(49)+k(50)$ go to 200

$53 n=n s u m 4+n s u m 5+k(1)+k(2)+k(3)+k(5)+k(35)+k(36)+$ a $k(43)+k(44)+k(45)+k(47)+k(48)$ go to 200

$54 n=k(12)+k(17)+k(18)+k(19)+k(52)$ go to 200

$55 n=n s u m 7+k(47)$ go to 200

200 continue if $(\mathrm{n} . \mathrm{gt.0})$ go to 300 $k(k v)=1$

$\mathbf{k} \mathbf{k}(1)=\mathbf{k v}$

if $(1 \cdot e q \cdot m x) j=-1$ go to 390 


\begin{tabular}{|c|c|}
\hline $\begin{array}{l}300 \\
390\end{array}$ & $\begin{array}{l}\text { continue } \\
j=1 \\
\text { continue } \\
\text { return } \\
\text { end }\end{array}$ \\
\hline
\end{tabular}

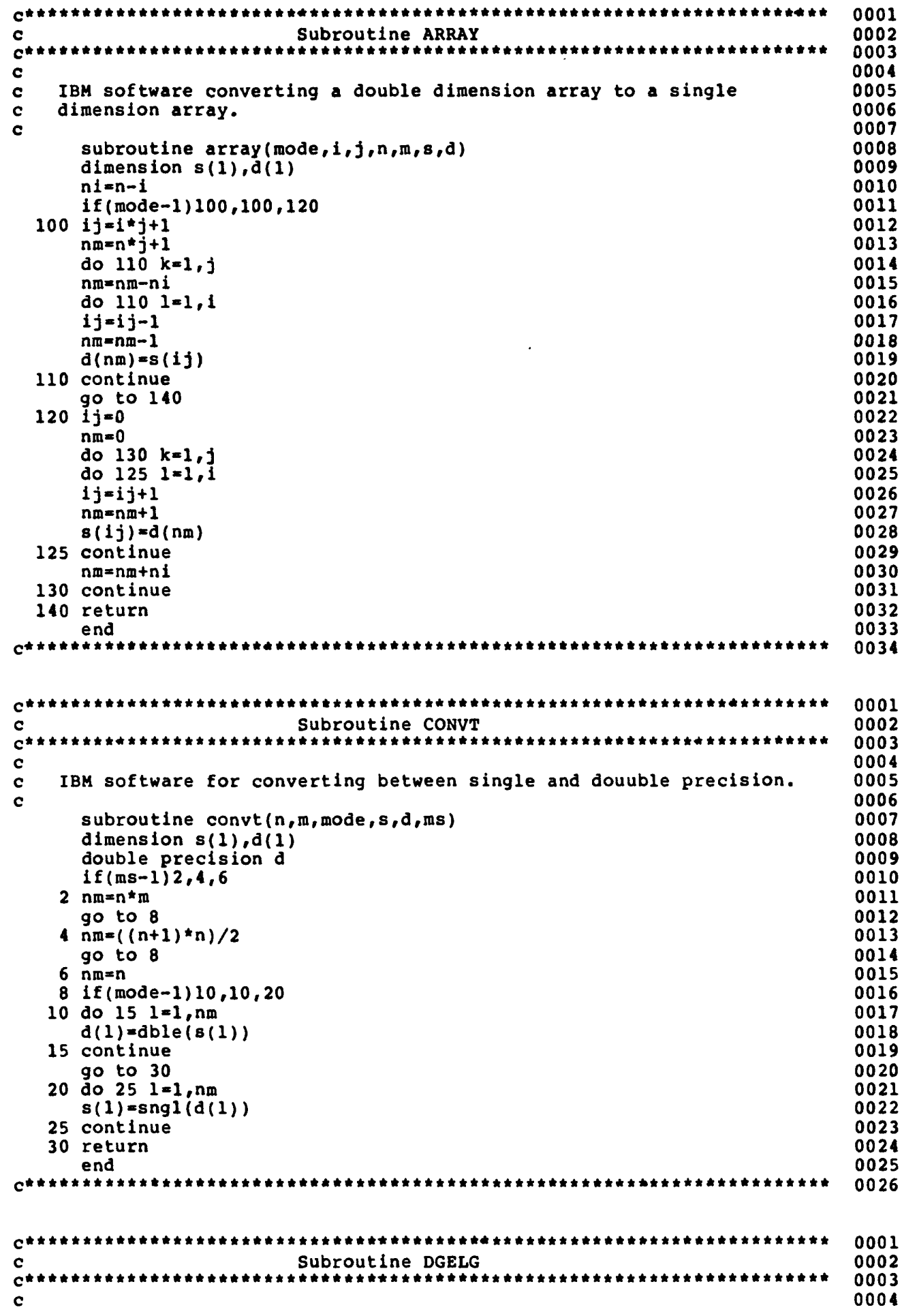


subroutine dgelg( $r, a, m, n, e p s, i e r)$

dimension $(1)$ in $(1)$ double precision $r, a, p i v, t b, t o l, p i v i \quad 0009$ if $(\mathrm{m}) 23,23,1$

1 ier $=0$

piv $=0$. do

0010

$m m=m * m$

0011

$n m=n * m$

do 3 in, $\mathrm{mm}$

$t b=d a b s(a(1))$

if $(t b-p$ iv) $3,3,2$

2 piv=tb

$i=1$

3 continue

tol=eps*piv

$18 \mathrm{t}=1$

do $17 \mathrm{k}=1$, $\mathrm{m}$

if (piv) $23,23,4$

4 if (ier) $7,5,7$

5 if (piv-tol) 6,6,7

6 ier $=k-1$

7 pivi=1.do/a(i)

$j=(i-1) / m$

$i=i-j * m-k$

$j=j+j-k$

do $8 \quad 1=k, n m, m$

$11=1+i$

tb=pivi*r(11)

$r(11)=r(1)$

$r(1)=t b$

8 continue

if $(k-m) 9,18,18$

0012

0013

0014

0015

0016

0017

0018

0019

0020

0021

0022

0023

0024

0025

0026

0027

0028

0029

0030

0031

0032

0033

0034

0035

0036

0037

0038

9 lend $=18 t+m-k$

0039

if $(j) 12,12,10$

0040

$10 i i=j * m$

do 11 l=1st, lend

0041

$\mathrm{t} b=\mathrm{a}(1)$

$11=1+i j$

$a(1)=a(11)$

$a(11)=t b$

0042

0043

0044

0045

0046

0047

0048

12 do $13 \quad 1=1 \mathrm{st}, \mathrm{mm}, \mathrm{m}$

$11=1+i$

tb=pivi*a(11)

0049

$a(11)=a(1)$

$a(1)=t b$

0050

0051

0052

0053

0054

continue

pive0.do

1s $t=1 s t+1$

0055

$j=0$

do 16 ijmlst, lend

0056

0057

0058

0059

pivi=-a(ii)

$i s t=i i+m$

$j=j+1$

do $15 \quad 1=i s t, m m, m$

0060

0061

0062

0063

$a(1)=a(1)+p i v i * a(11)$

0064

0065

0066

if (tb-piv) $15,15,14$

0067

0068

0069

$i=1$

15 continue

do $161=k, n m, m$

$11=1+j$

$r(11)=r(11)+p 1 v i \star r(1)$

0070

0071

0072

0073

0074

0075

$18 t=18 t+m$

17 continue

18 if $(m-1) 23,22,19$

19 is $t=m m+m$

$18 t=m+1$

do $21 i=2, m$

$i j=18 t-i$

ist $=18 t-18 t$

$1=i \mathrm{~B} t-\mathrm{m}$ 


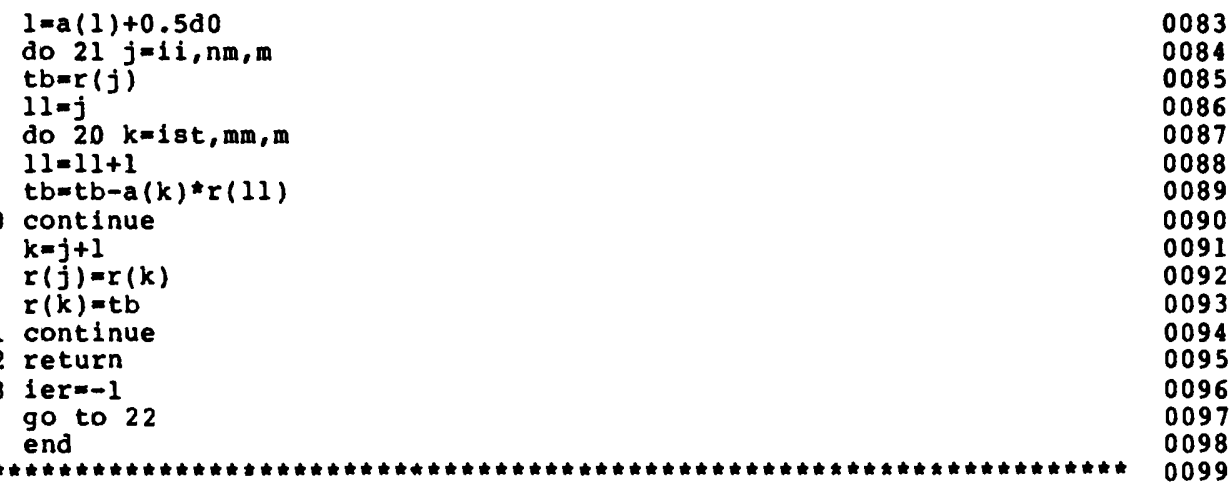

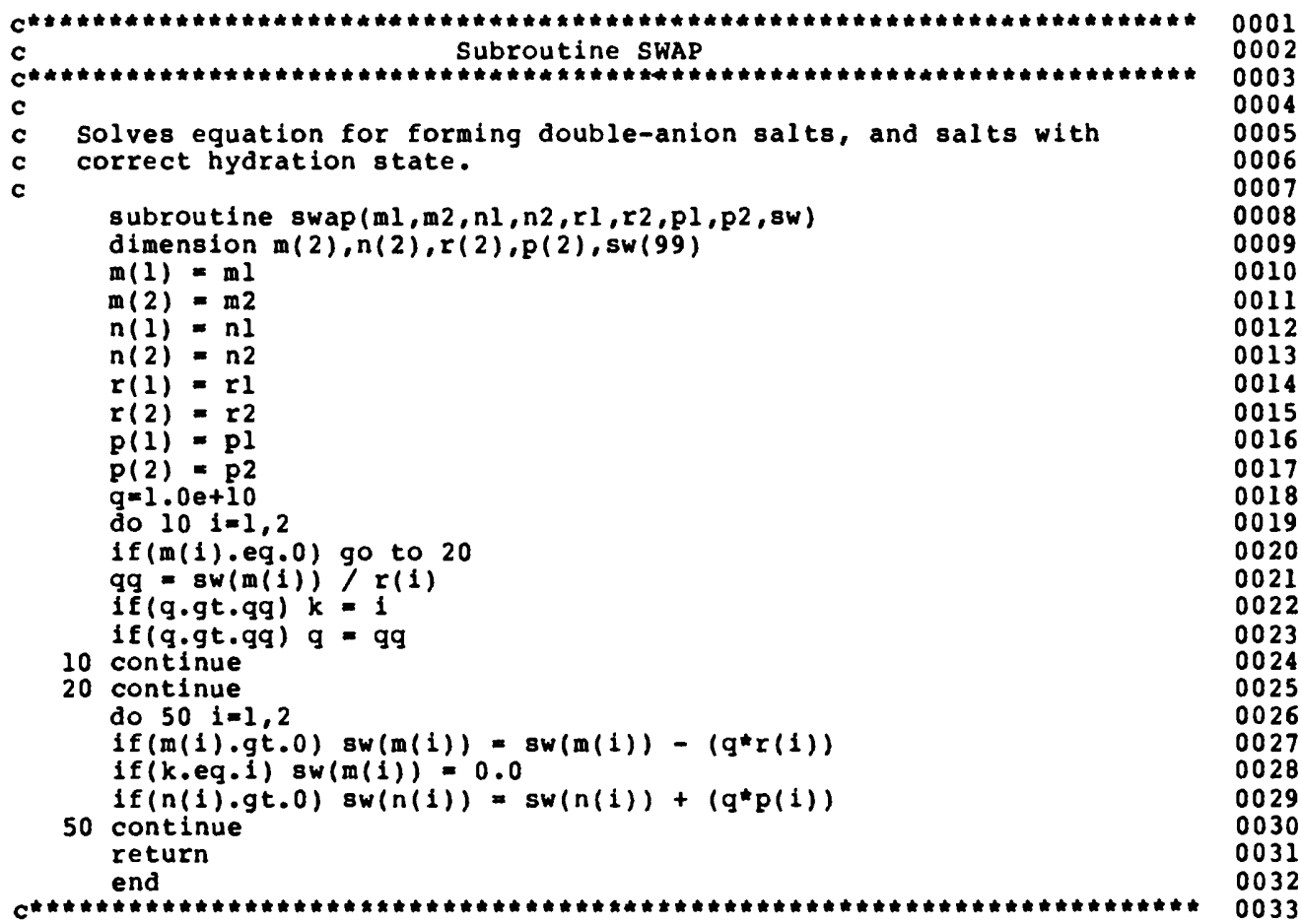

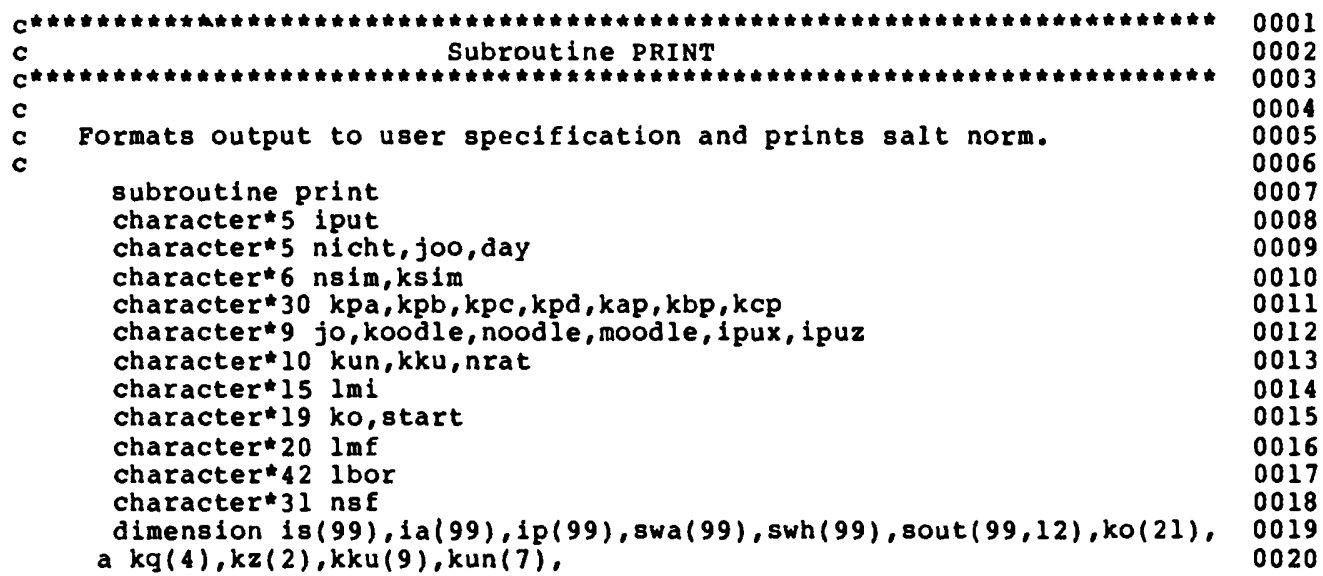


b li(25),jo(12), joo(2), oo(8), day (2), rat (21), nrat (21), kr(21), kc(21), c souts (12), iput (8), ndel (10), 8 a (99), ju(8), jv( 8 , ibor (5), jbor (4), d nsim(13), ksim(20), ipux (9), ipuz(4), ig(12),js(12),8sw(12),8sm(12) character $\$ 80$ nbatch

character $* 40$ ndes

character*20 mf

character*15 $\mathrm{nmin}$

character*13 nsimp, lout, 110c

character* 10 nfile, nnum

character $* 5$ ncom

common ncom (25), atw (25), nv (25),v(25), va (25), chg, kbor, nitro, np,kid,

a ncfn, nnox, nc, cz $(25,14)$, nnax, lout, kbri,kfile, $8(99)$, kred, npage,kxt,

c isalt (99), lunit, konf, nix (25), nnix, x(25), xo(25), c(25), lloc, nbatch,

d kend, to (25), kid2,kfirst, kpage, ndes, nnum, nuts, nmin (99), kbank,kidl,

e nfile,muts,mf $(99), 1 \mathrm{c}(99,6), 1 \mathrm{z}(99,6), 1 \mathrm{~h}(99), 1 \mathrm{a}(99), \mathrm{z}(99,6), \mathrm{ph}$, den,

f must(10), nsimp, nu(10),naly(99),kid3,mp(9),mr(9),ctz(14),nax(25)

data $\operatorname{lmi} / \%$

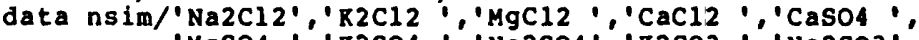

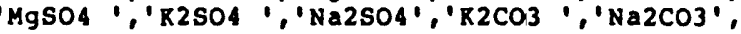

data noodle/

'MgCO3 $\because \mathrm{CaCO}^{2} \because$

data koodle/

data moodle/.

data nicht/ nd "

data $11 / 2,1,13,12,9,3,4,10,15,5,16,17,11,18,8,6,14,7,7 * 19 /$

data ipux $/$ mol/kg,$\cdot$ (mol), (wt), 1 (an-wt)

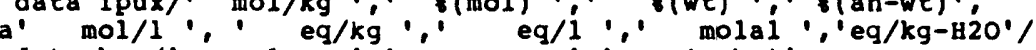

data kun/' moles ' ' mg ' ' mg (anhy)',

data $k$ a moles mole weight $\because$ wt. (anhy) per kilogram of water

data kpb/

data kpc/"

data kpd/ per kilogram of solution per liter of solution

normative salts - percent

data iput

$a^{\prime} \mathrm{H} / \mathbf{k g}^{\prime}$, $1 \%$

equiv. '

nqq $=0$

do $120 \quad i=1, n p$

if (kid2.eq.0) ia(i) $=0$

if $(k i d 2 . g t .0) i a(i)=i s a l t(i)$

isalt $(i)=0$

if(s(i).gt.0.0) isalt(i) $=1$

120 continue

150 continue

$k i d 2=k i d 2+1$

lunit $=\mathrm{nu}(10)$

ntime $=0$

$k p=0$

if (kpage.eq.1) $\mathrm{kp}=1$

if (kpage.eq. 2 ) lunit $=n u(4)$

if (kpage.eg.2.and.kfile.eq.2) lunit =nu(5)

200 continue

$1 \max =66$

if (lunit.eg.nu(5). and.npage.eg.0) $1 \mathrm{max}=62$

if(lunit.eq.nu(4)) $\operatorname{lmax}=60$

note $=1$

if $($ to $(8) \cdot g t .0 .0)$ note $=$ note +1

if $(\mathrm{mr}(9)$.eq. 1 . and.kid2.ne.0) note $=$ note +1

if (den.eq.0.0) note $=$ note +1 


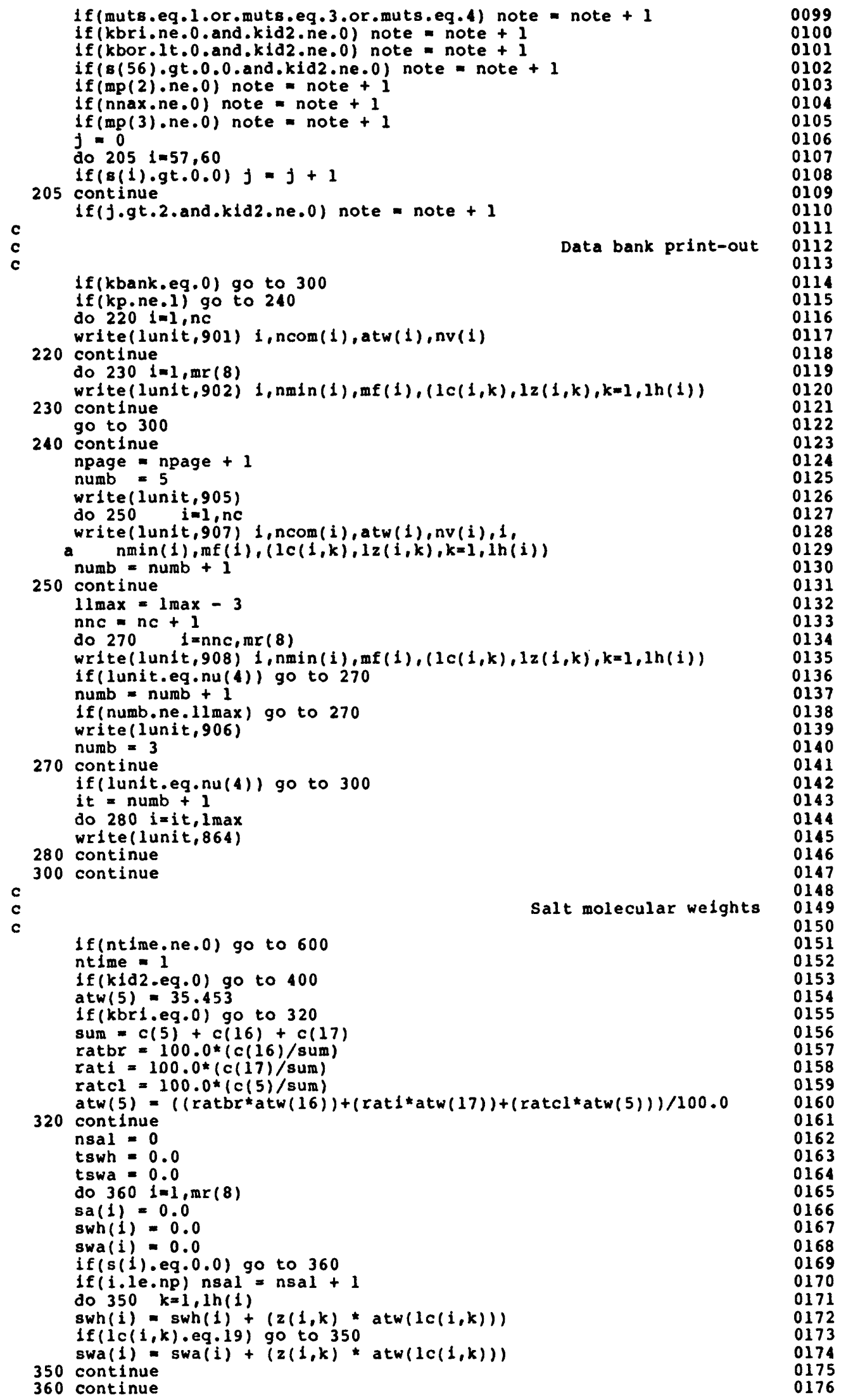




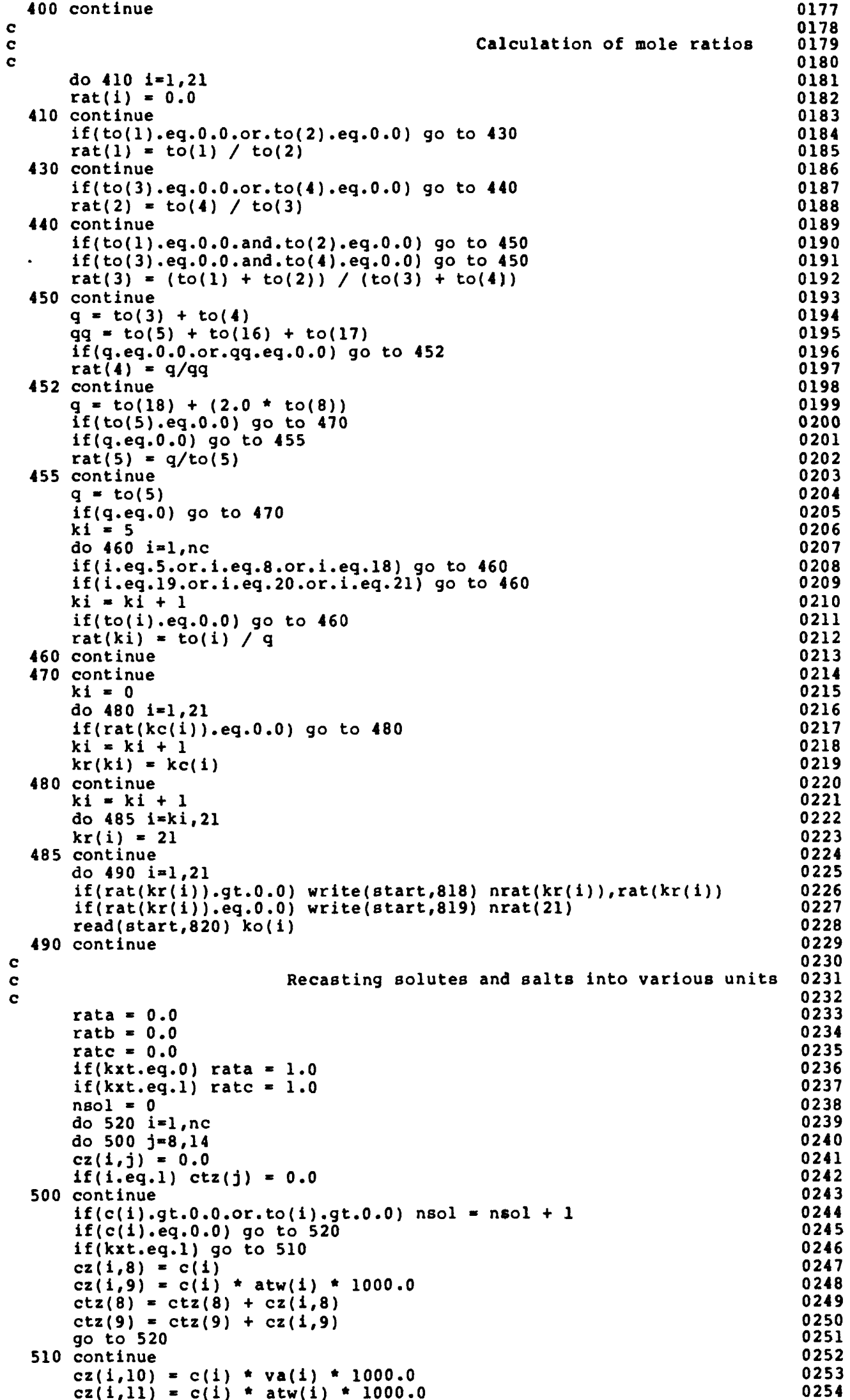


$c z(1,12)=c(i) * 1000.0 \quad 0255$

$\operatorname{ctz}(10)=\operatorname{ctz}(10)+c z(1,10) \quad 0256$

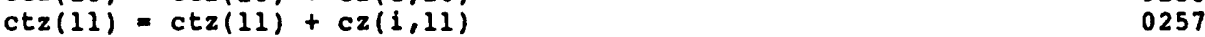

$\operatorname{ctz}(12)=\operatorname{ctz}(12)+c z(1,12)$

520 continue

if (kxt.eg.1) go to $530 \quad 0260$

ratb $=1000.0 /((\operatorname{ctz}(9) / 1000.0)+1000.0)$

$\begin{array}{ll}\operatorname{ctz}(9)=0.0 & 0262\end{array}$

ratc = ratb * den $\quad 0263$

do $525 i=1$, nc $\quad 0264$

If $(\mathrm{Cz}(1,9)$.eg.0.0) go to 525

$c z(i, 9)=c z(i, 9) *$ ratb $\quad 0266$

$c z(i, 11)=c z(1,9)$ *den $\quad 0267$

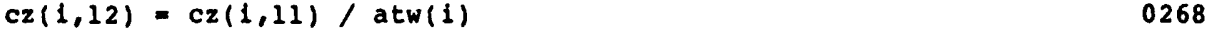

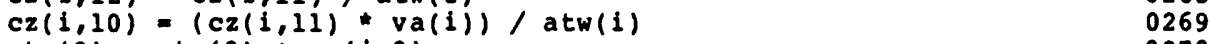

$\operatorname{ctz}(9)=\operatorname{ctz}(9)+\operatorname{cz}(1,9) \quad 0270$

$\begin{array}{ll}\operatorname{ctz}(10)=\operatorname{ctz}(10)+\operatorname{cz}(1,10) & 0271\end{array}$

$\begin{array}{ll}\operatorname{ctz}(11)=\operatorname{ctz}(11)+\operatorname{cz}(1,11) & 0272\end{array}$

$\operatorname{ctz}(12)=\operatorname{ctz}(12)+\operatorname{cz}(1,12) \quad 0273$

525 continue $\quad 0274$

$\begin{array}{ll}\text { go to } 540 & 0275\end{array}$

530 continue $\quad 0276$

if(den.eg.0.0) go to $540 \quad 0277$

ratb = ratc/den $\quad 0278$

rata $=1000.0 /((1000.0 *$ den $)-(\operatorname{ctz}(11) / 1000.0)) \quad 0279$

$\begin{array}{ll}\text { do } 535 i=1 \text {, nc } & 0280\end{array}$

lf(cz $(1,11)$.eg.0.0) go to $535 \quad 0281$

$c z(1,8)=($ rata * $c(i)) \quad 0282$

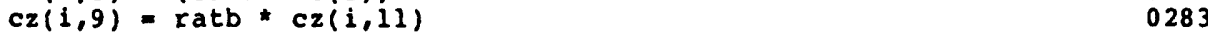

$\operatorname{ctz}(8)=\operatorname{ctz}(8)+\operatorname{cz}(1,8) \quad 0284$

$\operatorname{ctz}(9)=\operatorname{ctz}(9)+\operatorname{cz}(1,9) \quad 0285$

535 continue $\quad 0286$

$\begin{array}{ll}540 \text { continue } & 0287\end{array}$

lf $(\operatorname{ctz}(1) . \mathrm{eq.} 0.0)$ go to $543 \quad 0288$

do $542 i=1$, nc $\quad 0289$

if $(\mathrm{cz}(i, 8)$,eq.0.0) go to 542

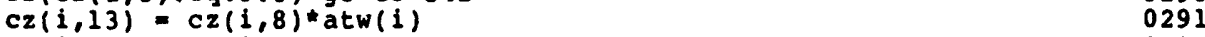

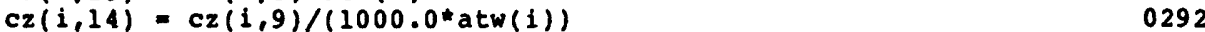

$\operatorname{ctz}(13)=\operatorname{ctz}(13)+\operatorname{cz}(1,13) \quad 0293$

$\operatorname{ctz}(14)=\operatorname{ctz}(14)+\operatorname{cz}(1,14) \quad 0294$

542 continue $\quad 0295$

543 continue $\quad 0296$

do $550 \mathrm{k}=1,12 \quad 0297$

$\begin{array}{ll}\text { souts }(k)=0.0 & 0298\end{array}$

js $(k)=0 \quad 0299$

$\operatorname{ssw}(k)=0.0 \quad 0300$

$\operatorname{ssm}(k)=0.0 \quad 0301$

do $545 \quad i=1,99 \quad 0302$

sout $(1, k)=0.0 \quad 093$

if (k.eq.1) ip(i) $=99 \quad 0304$

545 continue $\quad 0305$

$\begin{array}{ll}550 \text { continue } & 0306 \\ \text { if(kid2.eg.0) go to } 600 & 0307\end{array}$

$\begin{array}{ll}\text { jout }=0 & 0308\end{array}$

$\begin{array}{ll}\text { if (nuts.eq.1) jout }=1 & 0309\end{array}$

lf (kxt.eg.1) jout $=2 \quad 0310$

if (kred.eq.0) go to 554

if (kred.ne.1) go to $551 \quad 0312$

if $(\mathrm{kxt}$.eg. 0$)$ jout $=1 \quad 0313$

If(den.gt.0.0) jout $=1$

551 continue

if(kred.ne.2) go to $552 \quad 0316$

If (jout.eq.1) jout $=0 \quad 0317$

if (den.gt.0.0) jout $=0 \quad 0318$

552 continue

if (kred.ne.3) go to 554

if (den.gt.0.0) jout $=2$

554 continue

do $565 i=1, n p$

if $(s(1) \cdot e q .0 .0)$ go to 565

lf (jout.eg.0) sout $(i, 1)=8(i) *$ ratb 0325

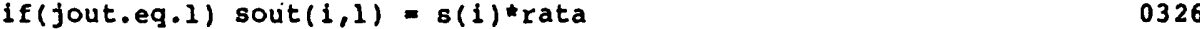

if (jout.eg.2) sout $(1,1)=8(i)$ *atc $\quad 0327$

sout $(1,2)=\operatorname{sout}(1,1) * \operatorname{swh}(1) * 1000.0 \quad 0328$

sout $(1,3)=\operatorname{sout}(1,1) *$ swa(1)*1000.0

if $(\mathrm{mr}(9)$.eq.0) go to 560

$g=0.0 \quad 0331$

do $555 j=1,1 a(1) \quad 0332$ 
if $(v(1 c(1, j)) \cdot g t .0 .0) q=q+(v(1 c(1, j)) * z(1, j)) \quad 0333$

0334

sout $(1,1)=\operatorname{sout}(1,1) * \mathrm{q} \quad 0335$

560 continue $\quad 0336$

souts $(1)=\operatorname{souts}(1)+\operatorname{sout}(1,1)$

souts $(2)=\operatorname{souts}(2)+\operatorname{sout}(1,2) \quad 0338$

souts $(3)=\operatorname{souts}(3)+\operatorname{sout}(1,3) \quad 0339$

565 continue

do $575 i=1, \mathrm{np}$

do $570 k=4,6$ 


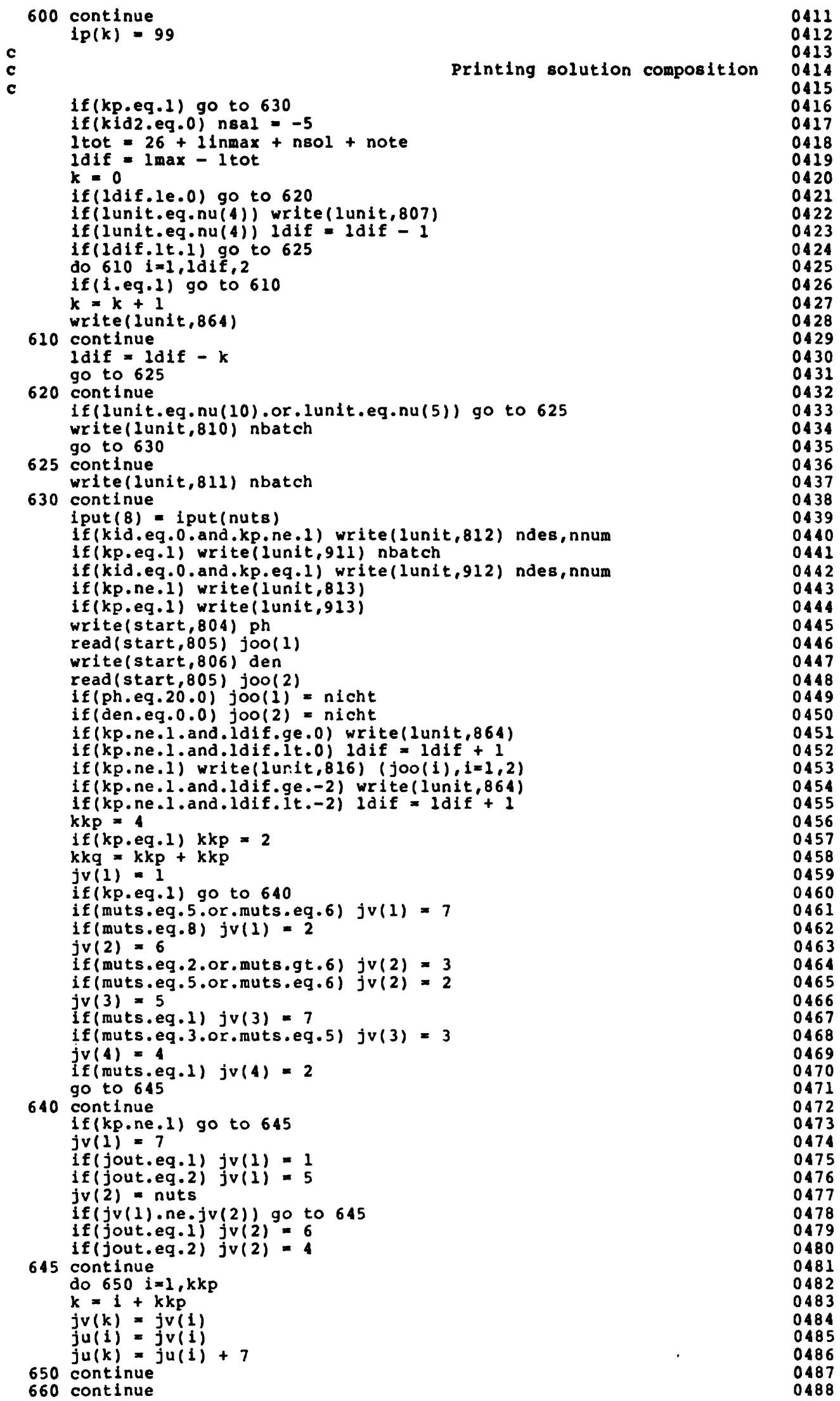


if(kp.ne.1) write(1unit,821) iput (8)

if (kp.eg.1) write(lunit,921) iput (8), (joo(i), i=1,2)

$k i=1$

if (kp.ne.1) write(lunit,822) (iput(jv(i)),i=1,4),

a ko(ki), (iput (jv(i)), i=5,8)

if (kp.eg.1) write(lunit,925)

if (kp.eq.1) write(lunit,926)

if(kp.eg.1)write(1unit,927)(iput(jv(1)),1=1,4),ko(ki)

$k i=k i+1$

if (kp.eq.l) write(lunit.928) ko(ki)

if (kp.ne.l. and.ldif.ge.-2) write(lunit,823) ko(ki)

if (kp.ne.l.and.ldif.ge. -2 ) $k i=k i+1$

if (kp.ne.1.and.ldif.1t.-2) ldif $=1 \mathrm{dif}+1$

if (kp.eq.1) ki $=k i+1$

$k i=k i-1$

do 685 i=1, nc

if (to $(1 \mathrm{i}(\mathrm{i})) \mathrm{eg} \cdot 0.0$ and.c(1i(i)).eg.0.0) go to 685

do $680 \quad \mathrm{k}=1, \mathrm{kkg}$

write(start, 801$) \mathrm{cz}(11(i), j u(k))$

read (start, 802$)$ jo(k)

if(cz(li(i),ju(k)).eq.0.0) jo(k)=koodle

680 continue

$i f(k i .1 t .21) k i=k i+1$

if (kp.ne.1) write(lunit,831) $\operatorname{ncom}(1 i(i)),(j \circ(k), k=1,4), k \circ(k i)$,

a $n \operatorname{com}(1 i(i)),(j o(k), k=5,8)$

if(kp.eg.1) write(lunit,931) $\operatorname{ncom}(11(i)),(j \circ(k), k=1,4), k o(k i)$

685 continue

if $(k i .1 t .21) k i=k i+1$

if(kp.ne.1) write(lunit,835) ko(ki)

if(kp.eq.1) write(lunit,935) ko(ki)

do $690 \mathrm{k}=1, \mathrm{kkg}$

write(start, 801 ) ctz(ju(k))

read (start, 802) jo(k)

if $(\mathrm{ctz}(j u(k)) \cdot e q \cdot 0.0) j o(k)=\operatorname{koodle}$

690 continue

if $(k i .1 t .21) k i=k i+1$

cbo $=v a(14)$

if (kp.ne.1) write $(1$ unit, 836$)(j \circ(k), k=1,4), k \circ(k i),(j \circ(k), k=5,8)$

if (kp.eq.1) write(lunit,936) (jo(k), $k=1,4), k o(k i)$

if (kp.ne.1.and.1dif.ge.-2) write(lunit,864)

if (kp.ne. l. and.1dif.lt. - 2) ldif $=1 \mathrm{dif}+1$

if (kbor.eq.0.or.kp.eq.l) write(lunit,840) chg

if (kp.ne.1.and.kbor.ne.0) write(lunit,845) chg,cbo

c
c
c

if(kp.eq.1.and.kbor.ne.0) write(lunit,945) cbo

if (kp.eq.1) write(lunit,864)

if (jout.eg.0) kap $=\mathrm{kpb}$

if (jout.eq.1) kap = kpa

if (jout.eq.2) $\mathrm{kap}=\mathrm{kpc}$

$\mathrm{kbp}=\mathrm{kpd}$

do $710 \quad i=1,8$

$1 i=1$

if(i.gt.6) ii $=i-3$

$k k u(i)=k u n(i i)$

710 continue

if $(\operatorname{mr}(9) \cdot \mathrm{eg} .1) \mathrm{kku}(1)=\operatorname{kun}(7)$

if $(\operatorname{mr}(9) \cdot \mathrm{eg} .1) \mathrm{kku}(4)=\operatorname{kun}(7)$

if (kp.ne.1) go to 720

do $715 i=1,4$

ipuz(i) = ipux(i)

715 continue

if(jout.eq.1) ipuz(1) $=1$ pux (8)

if (jout.eg.2) ipuz(1) $=$ ipux(5)

if $(\operatorname{mr}(9) . \mathrm{eq} .0)$ go to 720

if (jout.eq.0) ipuz(1) $=i \operatorname{pux}(6)$

if (jout.eg.1) ipuz(1) $=i \operatorname{pux}(9)$

720 continue

if (kp.ne.1.and.Idif.ge.-2) write(lunit.864)

if (kp.ne.l.and.1dif.1t.-2) ldif $=1 \mathrm{dif}+1$

if $(k i d 2 . e q .0)$ go to 750

if (kp.ne.l) write(lunit,853)

if (kp.ne.l) write(lunit,861) kap,kbp

if (kp.ne.1) write(lunit,862)

if(kp.ne.1) write(lunit, 863) (kku(i), i=1,8)

if(kp.eq.1) write(lunit,953)

printing salt norm

0489

0490

0491

0492

0493

0494

0495

0496

0497

0498

0499

0500

0501

0502

0503

0504

0505

0506

0507

0508

0509

0510

0511

0512

0513

0514

0515

0516

0517

0518

0519

0520

0521

0522

0523

0524

0525

0526

0527

0528

0529

0530

0531

0532

0533

0534

0535

0536

0537

0538

0539

0540

0541

0542

0543

0544

0545

0546

0547

0548

0549

0550

0551

0552

0553

0554

0555

0556

0557

0558

0559

0560

0561

0562

0563

0564

0565

0566 
if(kp.eq.1) write(lunit,950) (ipuz(i),i=1,4) 0567

if (kp.eq.1) write(lunit,864)

if (kp.ne.l.and.ldif.ge.-1) write(lunit,864) 0569

if (kp.ne.l.and.ldif.It.-l) ldif $=1 \mathrm{dif}+1 \quad 0570$

$k K=8 \quad 0571$

if (kp.eq.1) kk $=6 \quad 0572$

ninmax $=1$ inmax $\quad 0573$

if(kp.eq.1) ninmax = nsal $\quad 0574$

do $7401=1$, ninmax $\quad 0575$

do $735 \mathrm{k}=1, \mathrm{kk} \quad 0576$

$\begin{array}{ll}11=1 \mathrm{p}(1) & 0577\end{array}$

if (k.gt.6) $1 i=1 \quad 0578$

if (k.1t.4) write(start,801) sout $(11, k) \quad 0579$

if $(k . g t .3)$ write (start,803) sout(ii,k) 0580

read(start, 802$)$ jo $(k) \quad 0581$

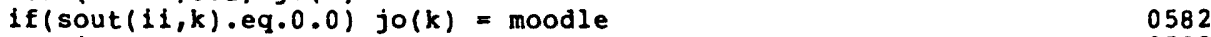

735 continue 0583

if(kp.ne.1) write(lunit,870)nmin(ip(i)), mf(ip(i)), $\quad 0584$

a $(j \circ(k), k=1,6), k s i m(1),(j \circ(k), k=7,8)$

if(kp.eq.l) write(lunit,970)nmin(ip(i)),mf(ip(1)),

a jo(1), $(j \circ(k), k=4,6) \quad 0587$

740 continue

do $745 \mathrm{k}=1$, $\mathrm{kk}$

if $(k .1 t .4)$ write (start, 801$)$ souts $(k)$

lf(k.gt.3) write (start, 803 ) souts $(k)$

5 continue

if(kp.ne.1) write(lunit,875)

if (kp.eq.1) write(lunit,975)

if(kp.ne.1) write(lunit, 876) (jo(k), $k=1,8)$

if (kp.eq.1) write(lunit,976) jo(1), (jo(k),k=4,6)

write(lunit, 864)

write (lunit,977)

do $747 \quad i=1,1 \mathrm{sim}$

do $746 k=7,8$

write (start,803) sout $(i, k)$

read(start, 802 ) jo(k)

746 continue

write(lunit, 978) ksim(1),jo(7), jo(8)

747 continue

write (lunit,981)

do $748 \quad k=7,8$

write (start, 803 ) souts $(k)$

read (start, 802$)$ jo $(k)$

748 continue

write (lunit, 979) jo(7), jo(8)

750 continue

if (kid2.ne.0) go to 755

if (kp.ne.1) write(lunit,895)

if(kp.eq.1) write(lunit,995)

755 continue

if (kp.ne.l) write(lunit, 813)

c

if(kp.eq.l) write(lunit,913)

Printing footnotes

knote $=1$

if(kp.ne.l.and.to(8).gt.0.0) write(lunit,881) knote

if (kp.ne.l.and.to(8).eg.0.0) write(lunit,891) knote

if (kp.eq.1) write(lunit,990) knote

if (kp.eq.l.and.to(8).gt.0.0) write(lunit.991)

if (kp.eq.1) write(lunit,992)

knote $=$ knote +1

if (kp.eq.l) go to 760

if (den.eq.0.0.and.kxt.eq.0) write(lunit,882) knote

if (den.eq.0.0.and.kxt.eq.I) write(lunit,883) knote

if (den.eq.0.0) knote $=$ knote +1

760 continue

$i=0$

if (muts.eq.1.or.muts.eq.3.or.muts.eq.4) $1=1$

if(i.eq.l) write(lunit,879) knote

if (i.eq.1) knote $=$ knote +1

if (mp (2).eq.1) write(lunit, 884) knote

if $(\mathrm{mp}(2) \cdot \mathrm{eq} \cdot 1)$ knote $=$ knote +1

if (mp (2).eq.2) write(lunit,885) knote

if $(\mathrm{mp}(2)$.eq.2) knote $=$ knote +1

if (mp (3).ne.0) write(lunit,886) knote

if (mp (3).ne.0) knote = knote +1

if(nnax.eq.0) go to 775

0592

0593

0594

0595

0598

0599

0600

0601

0602

0603

0604

0605

0606

0607

0608

0609

0610

0611

0612

0613

0614

0615

0616

0617

0618

0619

0620

0621

0622

0623

0624

0625

0626

0627

0628

0629

0630

0631

0632

0633

0634

0635

0636

0637

0638

0639

0640

0641

0642

0643

0644 


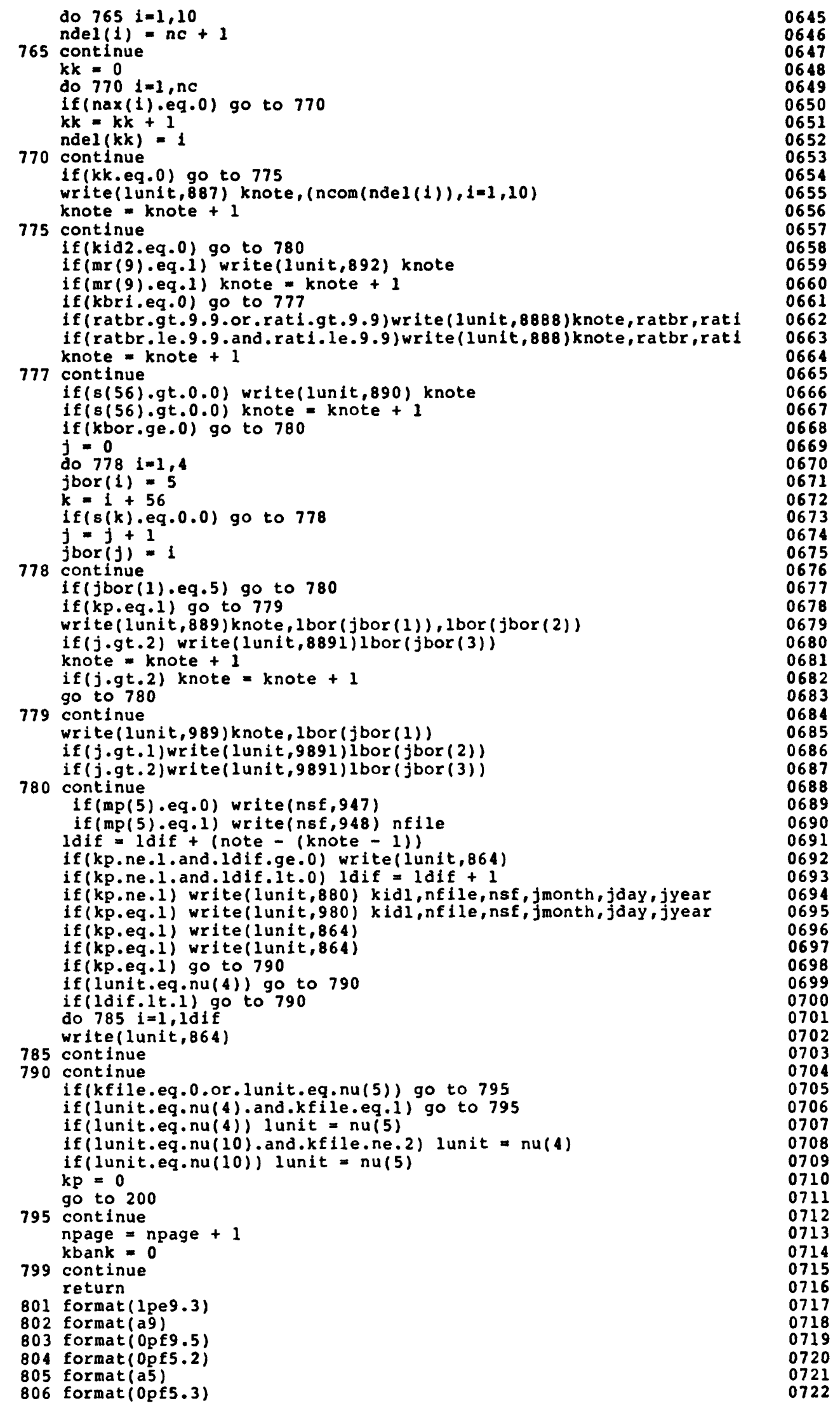


807 format (' 1 ', 1x) 0723

808 format (a9)

810 format (' 1 ', a80) $\quad 0725$

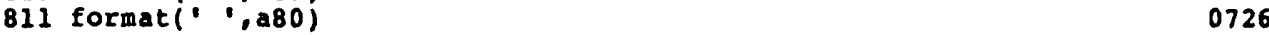

812 format (' ',a40,81x,a10) 0727

813 format (', $131(1-1))$

816 format(' ','Solution properties:',10x,'ph = ',a5,10x, 0729 a 'density $=(, a 5) \quad 0730$

818 format (ai0,1x,1pe8.2) 0731

819 format $(a 10,9 x) \quad 0732$

820 format (al9) 0733

821 format(" '4x, 'Water composition (analytical units: ',a5,')',15x, 0734 a'Mole ratios',8x, $\quad 0735$ a'Concentrations adjusted to achieve charge balance'./,2x, 0736 b $49(1-1), 31 \times, 49(1-1)) \quad 0737$

822 format $(\cdot, 8 x, 4(2 x, a 5,4 x), 3 x, a 19,14 x, 4(2 x, a 5,4 x)) \quad 0738$

823 format: $, 55 x, a 19) \quad 0739$

831 format (': $, 1 x, a 5,4(2 x, a 9), 5 x, a 19,7 x, a 5,4(2 x, a 9)) \quad 0740$

835 format!' $, 6 x, 4(2 x, 9(1-1)), 5 x, a 19,12 x, 4(2 x, 9(1-1))) \quad 0741$

836 format': '1x,'Total',4(2x,a9),5x,al9,7x,'Total',4(2x,a9)) 0742

840 format (' ',5x, 'Charge balance: $\operatorname{sum}[+] / \operatorname{sum}[-]=\mathrm{f}^{\mathrm{f} 6.4)} \quad 0743$

845 format (' ',5x,'Charge balance: sum $[+] /$ sum $[-]=1, f 6.4, \quad 0744$

$127 x$, 'Note: borate charge of $-1, f 5.3,9$ per boron.') 0745

864 format(" , , lx) 0746

853 format(' ' 'Normative salt assemblage',77x,'simple salts',/,1x, 0747 a $25('-1), 77 x, 12(1-1))$

861 format (', $36 x, a 30,1 x, a 30,15 x, 6 x$, 'percent')

0749

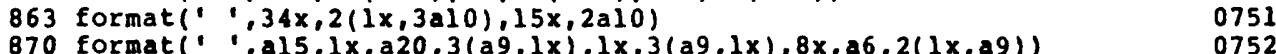

875 format (' $36 x, 3(9(-i), 1 x), 1 x, 3(9(9-1,1 x), 14 x, 2(1 x, 9(9-1)) \quad 0753$

876 format: : 25x,'Total',6x,3(a9,1x),1x,3(a9,1x),14x,2(1x,a9)) 0754

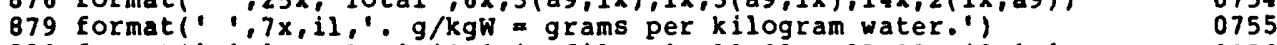

880 format' ','Sample ',i2,' in file: ',a10,29x,a31,30x,12,'-', 0756 $-12.2,-1,14)$

881 format(' ' 'NOTES: ',il,'. Solute mole ratios calculated from ' 0758 a 'initial analytical data; $\mathrm{HCO} 3$ includes $\mathrm{CO}_{3} \mathrm{via}$ ' 0759

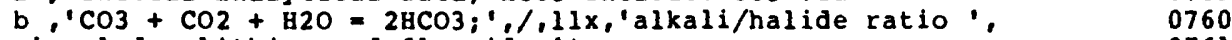
c'excludes lithium and fluoride.') 0761

891 formatl' ' 'NOTES: ', il,'. Solute mole ratios calculated from ' 0762 $a$, initial analytical data; alkali/halide ratio excludes lithium ' 0763 $b^{\prime}$ and fluoride.') 0764

882 format(' $1,7 x, i 1,1$. Analytical data in per $\mathrm{kg}$ units; density not ' 0765 a,'determined.') 0766

883 format $(', 7 x, i 1, '$. Analytical data in per liter units; density' 0767 a, 'not determined.') 0768

884 format (" $, 7 x, 11,1$ Oxidized nitrogen (NO3-) recast as reduced ', 0769 1 'form (NH4+).') 0770

885 format(' $, 7 x, 11, '$. Reduced nitrogen (NH4+) recast as oxidized ', 0771 1 'form (NO3-).') 0772

886 format(', $7 x, i 1, '$. Nitrate replaced by an'. 0773 a 'equal molar quantity of bicarbonate.') 0774

887 format $(: 7 x, 11, \div$. Solutes deleted: ',10a5) 0775

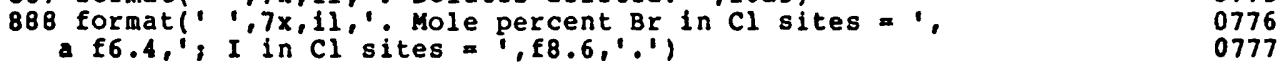

8888 format(' ',7x, il, '. Mole percent $\mathrm{Br}$ in $\mathrm{Cl}$ sites = ', 0778

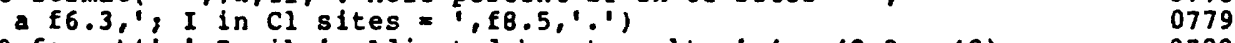

889 format $\{? .7 x, i 1, '$. Adjusted borate salts: $, 4 x, a 42,3 x, a 42$ ) 0780

8891 format (' ' $7 x, 29 x, 045$ ) 0781

890 format,' $: 7 x_{,}, 1$, . Adjusted hydroxyapatite composition: ', 0782 a Ca4.75(PO4)3.17(OH).') 0783

892 formats" ',7x,11,'. Salt "equiv" = total cation charge per mole ', 0784 a'times number of moles.'

895 format (' ' $/ /, 33 x$, 'NORMATIVE SALT ASSEMBLAGE INDETERMINABLE --', 0786 a' CALCULATION ABANDONED' 1 ' 0787

901 format? $, 15 x, 12,1,05,4 x, f 9.5,4 x, 13) \quad 0788$

902 format (' ', 12, ', a15,2x,a20,2x,5(2x,12,1x,12)) 0789

905 format (' 1 ', 56x,'SNORM DATA TABLE', $/ 1 \times, /, \quad 0790$

a $11 x$, 'Components',61x,'Salts',1x/.

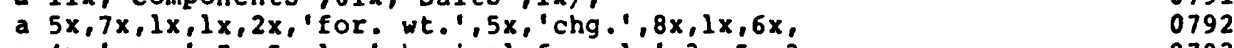

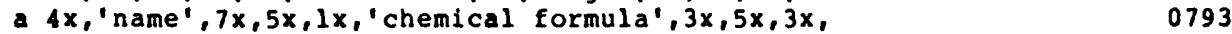

b 'component identifier with quantity', /1x) 0794

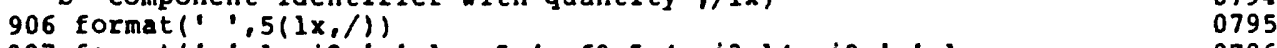

907 formatl' ',1x,12,' ', 1x, a5,4x,f9.5,4x,i3,14x,12,'.',1x, 0796

$\begin{array}{ll}\text { a al } 15,5 x, a 20,3 x & 0797 \\ \text { b } 5(3 x, 12,1 x, 12 j) & 0798\end{array}$

b $5(3 x, 12,1 x, 12 i) \quad 0798$

908 format $\left(:, 44 x, 12,,^{\prime}, 1 x, a 15,5 x, a 20,3 x, 5(3 x, 12,1 x, 12)\right)$ 


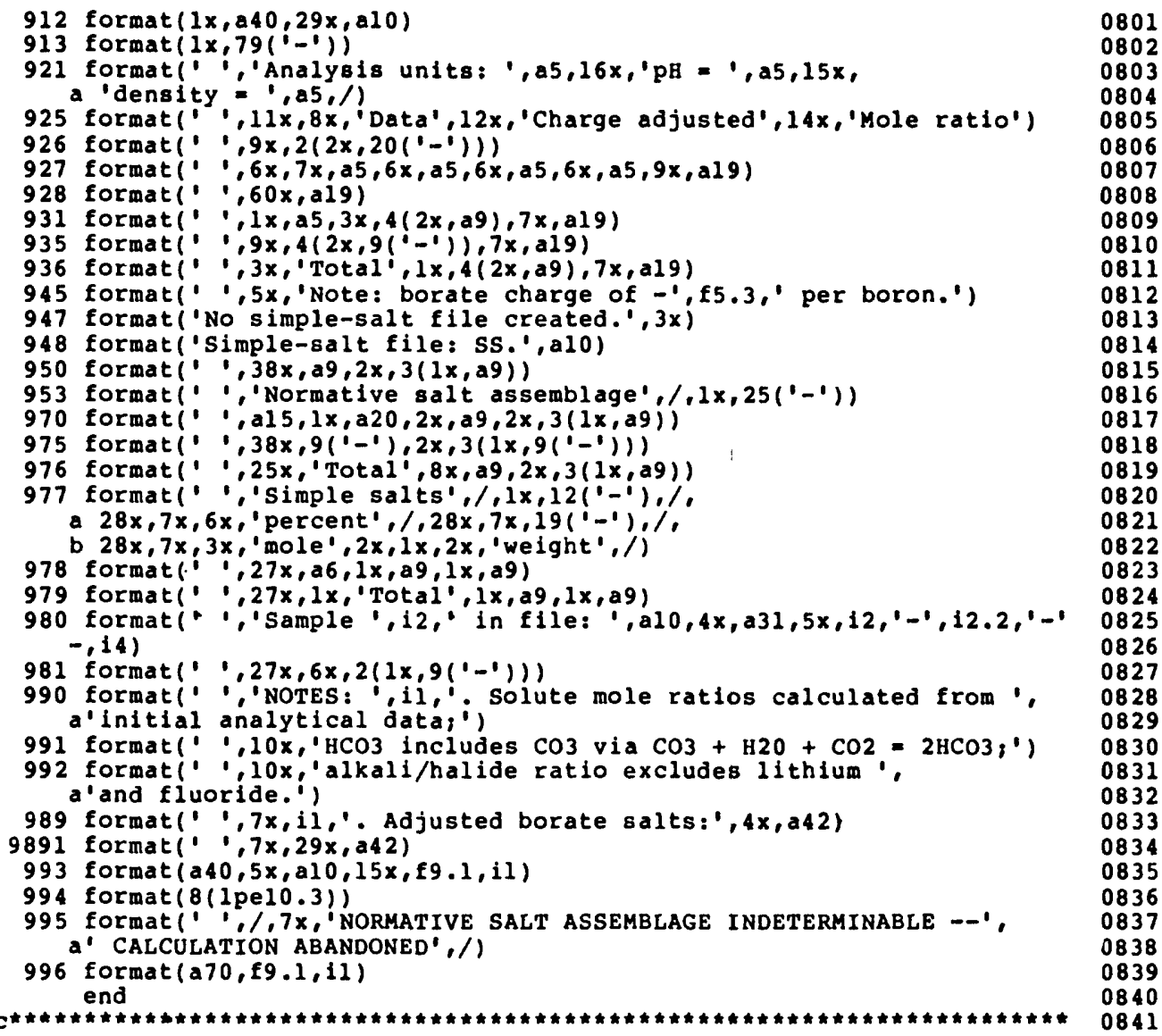

\section{Listing of NEODAT (File of Constants for SNORN)}

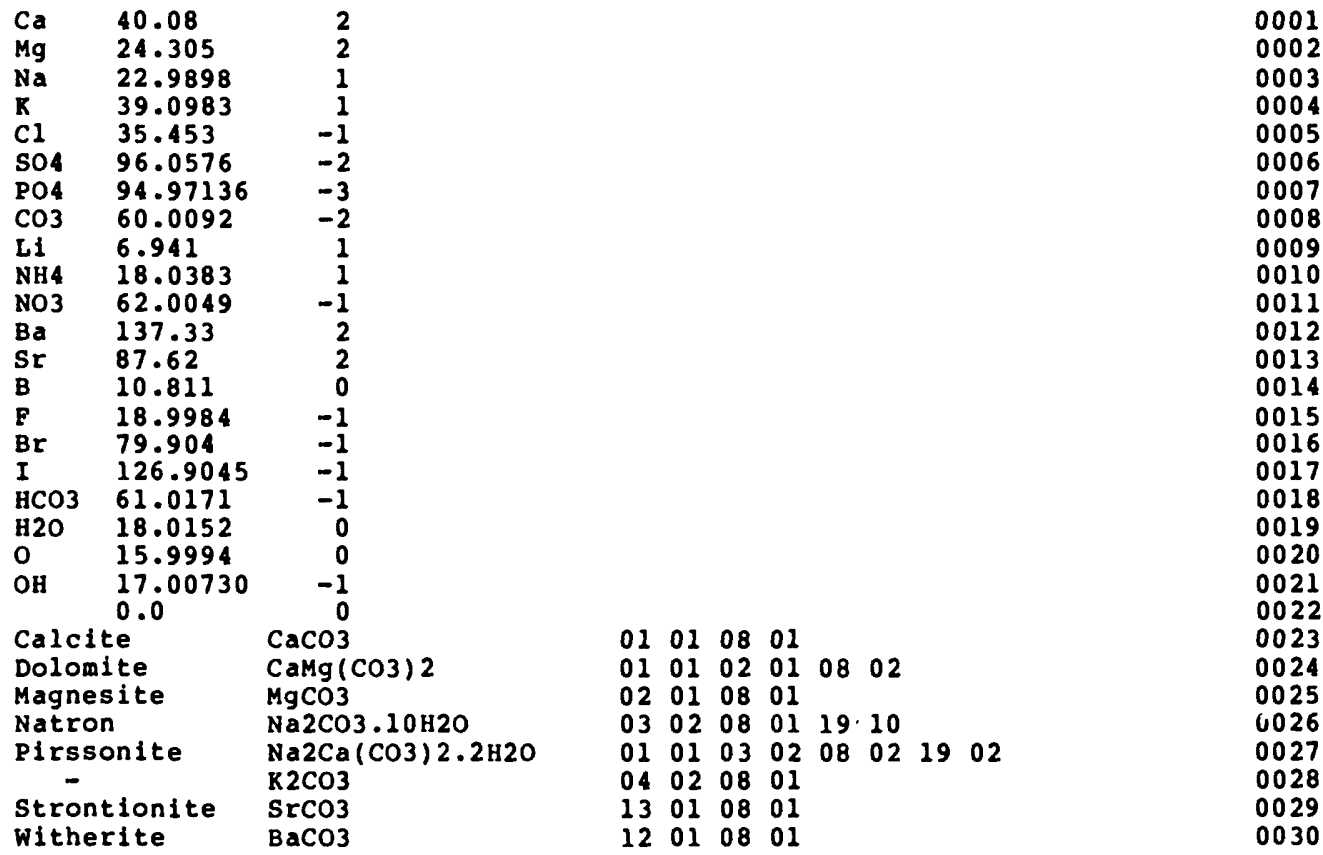




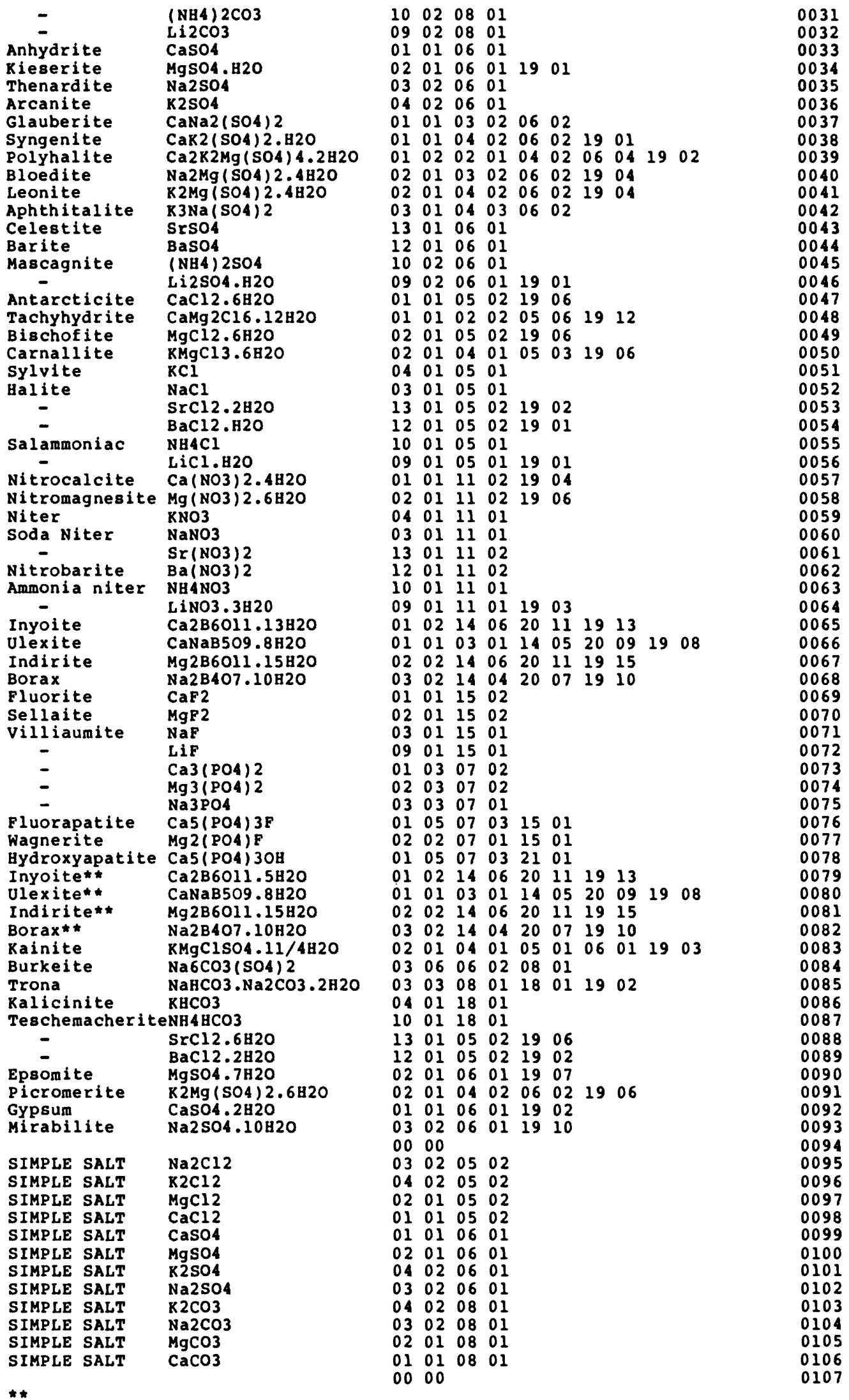




\section{APPENDIX II}

\section{Structure of SNORM}

SNORM consists of a driving subroutine (MAIN), ten operational subprograms (PREP, SALWAT, LOAD, JOIN, PICK, ARRAY, CONVT, DGELG, SWAP, and PRINT), and a data bank (NEODAT) of constants for the array of solutes, salt components, and salts. The complete program listing, including NEODAT, is given in Appendix I, and the major operational features of the subprograms are summarized in table II- 1 .

In order to both reduce the number of solutes and salts that SNORM must distribute and identify, and expedite the calculations to identify the salts and determine their abundances, we have defined "base solutes" and "base salts." The 15 "base solutes" (table II-2) constitute an abbreviated array of the 18 SNORM solutes ( $t a b l e ~ 1)$ that are required to define a salt assemblage; bromide and iodide are excluded as separate solutes by combining them with chloride, and bicarbonate is excluded by expressing total carbonatebicarbonate as carbonate. Similarly, the array of 63 normative salts (table 2) is reduced to 55 "base salts" (table II-3); the reduction is accomplished by using only the lowest hydration state for each of the six pairs of normative salts with alternative hydration states (table 7), and deleting the two double-anion salts, burkeite and kainite, by considering only the $\mathrm{Na}_{2} \mathrm{CO}_{3}-$ $\mathrm{Na}_{2} \mathrm{SO}_{4}$ (thenardite) and the $\mathrm{MgSO}_{4}-\mathrm{KCl}$ (kieserite-sylvite) "base salt" pairs, respectively. Furthermore, each of the normative bicarbonate-bearing salts, trona, kalicinite, and teschemacherite, are expressed as their respective carbonate "base salts," and hydroxyapatite, with its modified composition (table 2), is expressed as the "base salt" $\mathrm{Ca}_{3}\left(\mathrm{PO}_{4}\right)_{2}$. With these four latter exceptions, all "base salts" are normative salts.

In identifying the proper assemblage of "base salts," the "base-salt assemblage" in JOIN ( $t a b l e ~ I I-1)$, the groups of normative salt exclusions based on gross compositional properties of the water (table 5), and the prohibited normative salt associations (table 6) are modified in SNORM (table II-4 and II-5, respectively) to reflect parallel relations among the "base salts." All equilibria defining excluded groups of "base salts" (table II-4) and prohibited "base salt" associations ( $t a b l e$ II-5) were calculated using normative salts; the "base salts" substitute for normative salts in SNORM only to expedite calculations, not to define phase equilibria. Thus, for example, the prohibited $\mathrm{Na}_{2} \mathrm{CO}_{3}$-glauberite pair is designated (table II-5) because the trona-glauberite pair reacts to form the stable calcite-thenardite or calcitemirabilite pairs (table 6). The final set of calculations in JOIN transforms the "base-salt assemblage" into the normative salt assemblage through a series of simple exchange or hydration reactions (see SWAP in table II-1). 
Table II-1. Subprograms in SNORM and their major operational features

Sub

program

MAIN

PREP

SALWAT

LOAD

JOIN

Major operational features

SNORM's driver: calls PREP to enable execution, identify/create user-designated input data file, and accept user-designated options; sequentially calls LOAD and JOIN for each analysis in the file; accumulates and prints summary of number of calculations and iterations required for computing salt norm for each sample; and terminates program execution.

Called by MAIN: reads data bank (NEODAT) for solutes and salt components (table IV-2), "base" and normative salts (table IV-3), and simple salts (Appendix III); accepts identity of user-designated input data file; accepts user-designated output format(s), output character (concentration units, etc.), and, if input file already in user's directory, sample selection and solute modification options; if new data file to be entered, requests format designation (SNORM or WATEQ), calls SALWAT to create input data file with WATEQ format, requests descriptive and analytical data for water analyses and creates new input data file with SNORM format.

Called by PREP: requests descriptive and analytical data for water analyses and creates input data file in WATEQ format.

Called by LOAD: reads one WATEQ-formatted analysis from the input data file into LOAD.

Called by MAIN for each analysis in input data file: reads one analysis from SNORM-formatted input data file, or one WATEQformatted analysis from SALWAT; recasts analytical data into all possible alternative weight and mole concentrations per kilogram water, kilogram solution, and liter units; calculates carbonate fraction of analyzed bicarbonate if warrented.

Called by MAIN: accepts data for the sample from LOAD; determines solute adjusted concentrations after incorporating user-designated solute modifications, recasting boron charge to "average" borate charge per boron, and calculating concentrations to yield charge balance between cations and anions; if compositon modifications are designated but do not affect adjusted concentration, returns to MAIN with flag to call LOAD to enter the next analysis from the input data file; recasts analysis as "base solutes" (table II-2); forms array of "eligible base salts" (see footnote 1) from listing of "base salts" (table II-3) by rejecting those "base salts" whose compositions are not represented in the analysis and those that are excluded based on gross compositional character of the water (table II-4); calculates number of "base salt" phases in a "trial base-salt assemblage;" forms all possible assemblages ("trial base salt assemblages") from the array of "eligible base salts" in which the assemblage qualitatively accomodates each base solute in the analysis and, by calling PICK, contains none of the prohibited "base 
Table II-1 (continued)

Sub

program

Major operational features

salt" associations in table II-5 (see footnote 2); calculates "base salt" abundances in each successive "trial base-salt assemblage" by defining and solving a set of simultaneous equations (see footnote 3) through successively calling ARRAY, CONVT, DGELG, and CONVT; rejects "trial base-salt assemblage" that fails the test by containing one or more "base salts" with negative abundance, and returns to form and test the next "trial base-salt assemblage;" retains "trial base-salt assemblage" that yields no negative "basesalt" abundances as the "base-salt assemblage;" if the "base-salt assemblage" contains a single borate salt (or the inyoite-indirite pair), assigns correct borate charge per boron for that salt (table 3 ), recalculates adjusted solute concentrations to achieve charge balance, and, again calling ARRAY, CONVT, DGELG, and CONVT, recalculates salt abundances in the "base-salt assemblage" with correct stoichiometry for the borate salt; calculates a salt norm from a "base-salt" assemblage, by calling SWAP, and calculates the simple-salt assemblage from the "base-salt assemblage;" calls PRINT to format the water-sample data and results, and transmit them to the user-designated output device(s); returns to form and test remaining "trial base-salt assemblages" (see footnote 4 ).

PICK Called by JOIN: tests the validity of each new "base-salt" proposal to a developing "trial base-salt assemblage" through setting a flag to reject that proposal in JOIN if the proposad salt forms any of the prohibited associations in table II-5.

ARRAY Standard IBM software called by JOIN: recasts a two-dimensional matrix of variables (the stoichiometric abundance of each solute in each salt in a "trial base-salt assemblage") into a linear array.

CONVT Standard IBM software called by JOIN: converts single precision variables in the linear array formed by ARRAY into double precision variables; converts the results of DGELG from double precision variables to single precision variables.

DGELG Standart IBM software called by JOIN: solves the set of linear simultaneous equations, properly defined by ARRAY and CONVT, that equates each solute's abundance in the water to the sum of the products of the abundance of each "base salt" and that solute's stoichiometry in each salt; the results are the abundances of each of the "base salts" in the "trial base-salt assemblage."

SWAP Called by JOIN: recasts "base-salt assemblage" into normative salt assemblage through performing the appropriate exchange reaction for each instance of (1) forming a normative double-cation salt (burkeite or kainite) from the appropriate "base salts," (2) recasting "base salt" $\mathrm{Ca}_{3}\left(\mathrm{PO}_{4}\right)_{2}$ as hydroxyapatite with modified 
Table II-1 (continued)

Sub

program

Major operational features

composition, ( 3 ) recasting an alkali carbonate (table II-2) as the normative (bi)carbonate salt, (4) modifying sulfate salt associations (reactions $\mathrm{K}, \mathrm{J}, \mathrm{G}$ in table II- 1 ) in absence of chloride and nitrate in the analysis, and (5) assigning correct hydration state to each of six pairs of alternative hydration levels (table 7).

PRINT Called by JOIN: calculates solute molar ratios, formats and transmits water-sample data (sample descriptive data, and solute concentrations and ratios) and results of SNORM computations (identity and abundance of normative and simple salts) to the userdesignated output device(s); if unable to compute norm (see footnote 4 ), replaces normative data with statement to that effect.

\section{Footnotes}

1. The "eligible base salts," after their designation for a given water analysis, are recast into a linear array by anion groups in the analysis (carbonates, sulfates, chlorides, nitrates, borates, and fluorides and phosphates), and assigned sequential identifier integer indices.

2. The "trial base-salt assemblages" are qualitatively formed in a sequence of nested loops; the number of loops equals the number of salts permitted in the assemblage. The value of the index in each loop is also the identifier integer of a "base salt" in the linear array of "eligible base salts;" thus, assignment of an index value to each successive loop in the heierarchy defines a full complement of base salts in the assemblage. Each loop increments through its flexible, but assigned range of indices. The limiting minimum for the indexing range in the first (outermost) loop is unity (the identifier of the first "base salt" in the linear array of "eligible base salts); in each successive (inner) loop the limiting minimum is assigned with the greater of one of two values, a value that is incremented by unity over the current index value in the preceeding (outer) loop, or, if required, a larger value that assures that each anion group in the array of eligible base salts will be represented in the full assemblage. The limiting maximum for the final (innermost) loop is the identifier integer for the last salt in the "eligible base salt" array; the limiting maximum for each of the preceeding (outer) loops is the integer that both assures enough salts remain in the array to complete the assemblage, and that each anion group will be represented in the assemblage.

With each proposed new addition to all developing "trial base-salt assemblages," JOIN calls PICK to identify any prohibited "base-salt" associations (table II-5). If. PICK flags any prohibited associations between the proposed addition and any "base salt(s)" previously assigned to the developing assemblage, the index of that loop is incremented to the 
Table II-1 footnotes (continued)

next identifier integer for testing with PICK; alternatively, if the proposed new addition to the developing assemblage is not flagged by PICK (no prohibited associations), that proposed salt becomes part of the developing "trial base-salt assemblage," and each succeeding (inner) loop, following the same procedures, assigns another salt to the assemblage. After the innermost loop has been indexed and an assemblage completed, the base-salt compositions are scanned to assure each cation "base solute" in the analysis is represented in at least one "base salt;" if not, the assemblage is rejected, but if so, the assemblage is retained as a "trial base-salt assemblage." In this manner each successive "trial base-salt assemblage" is formulated with no prohibited "base-salt" associations and all "base solutes" are represented in the assemblage.

Eliminating occurrence of any prohibited associations and assuring that all solutes are represented in each "trial base-salt assemblage" markedly reduces the number of assemblages that would have been formed on a strictly mathematical basis. For example, the seawater analysis (Appendix III) with 13 "base-solute" components generates an assemblage of 12 salts with each "trial base-salt assemblage" formed from an array of 26 "eligible base salts;" mathematically, this would be represented by $9.66 \times 10^{6}$ different assemblages--the number of possible combinations of 26 salts taken 12 at a time. However, testing for prohibited associations 92,747 times and assuring each anion solute's representation in the assemblage produced only 1092 different assemblages; this was reduced to 567 "trial base-salt assemblages" after rejecting those assemblages that lacked one or more cation "base-solute(s)" in the resultant assemblages.

3. Salt abundances in a "trial base-salt assemblage" are determined by forming and solving a set of linear simultaneous equations. The number of equation equals the number of "base salts," $N$, in the assemblage. Each equation defines the quantitative distribution of a "base solute," a, throughout the "base salts" in the assemblage, and has the form

$$
z_{a}^{A} m_{A}+z_{a}^{B} m_{B}+z_{a}^{C_{m}}+\cdots+z_{a} m_{N}^{N}=M_{a}
$$

where, in the first term on the left side of the equation, for example, $z$ is the number of moles of "base solute" a in one formula unit of "base salt" $A, m$ is the unknown number of moles of "base salt" $A$ in the assemblage, and, on the right side of the equation, $M$ is the adjusted molar concentration of "base solute" a in the analysis. Construction of ( $n$ - 1) parallel equations with $n$ being the number of "base solutes" (chloride is normally omitted) yields a number of equations that equals the number of unknown "base-salt" abundances. The coefficients $z$ for each term on the left side of each equation form an $\mathrm{N} \times \mathrm{N}$ matrix, and the ( $n$ - 1) molar abundances, M, of "base solutes" on the right side of the equations form a linear array of length $N$. The matrix, properly formatted in ARRAY and CONVT, is inverted in DGELG with the results of the inversion defining the "base salt" molar abundances $\left(\mathrm{m}_{A}, \mathrm{~m}_{B}, \mathrm{~m}_{C} \cdots \mathrm{m}_{\mathrm{N}}\right)$.

4. Two alternative outputs mark failure of SNORM to define the norm for a 
Table II-1 footnotes (continued)

given,water sample. First, if two or more "trial base-salt assemblages" qualify as "base-salt assemblages", each resultant "norm" is printed as though each were a different sample; such multiple norms undoubtedly signify one or more omissions from the listing of prohibited salt associations in PICK ( $t a b l e$ II-5). Second, if after testing every "trial base-salt assemblage" none qualify as a "base-salt assemblage," PRINT accepts all water-sample data from JOIN and adds the statement that the norm could not be determined. This latter result may be caused by one of two possibilities: an error in PICK (a pair of conflicting, thus unresolvable, prohibited "base salt" associations in table II-5), or, more likely, an unusual, extreme water composition whose solutes could not be quantitatively distributed into any assemblage of "base salts", such as, for example, a hypothetical $\mathrm{K}-\mathrm{F}-\mathrm{rich}$, otherwise dilute water, but with no potassium fluoride salt in the SNORM data bank (table II-2).

Table II-2. Solutes and salt components in SNORM data file (NEODAT)

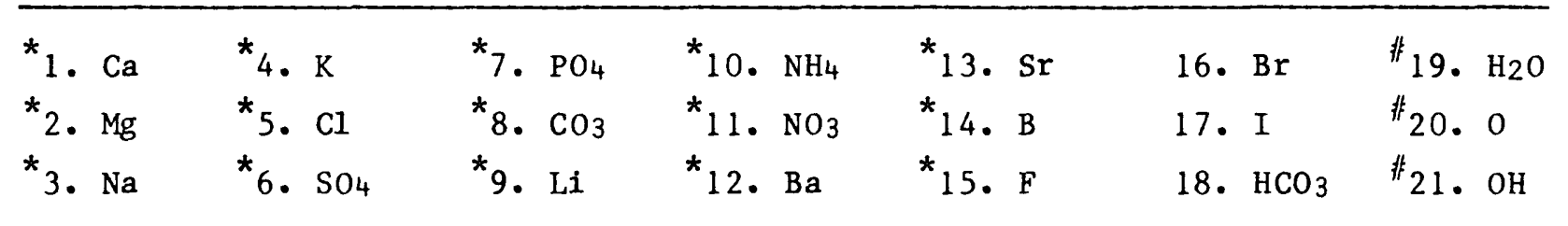

\footnotetext{
* Base solutes" used in calculation of base-salt assemblage.

"Not SNORM solutes; used to calculate salt compositions and formula weights.
} 
Table II-3. Salts in SNORM data file (NEODAT) and their chemical formulae [Each is a normative salt unless otherwise indicated]

\begin{tabular}{|c|c|c|c|}
\hline 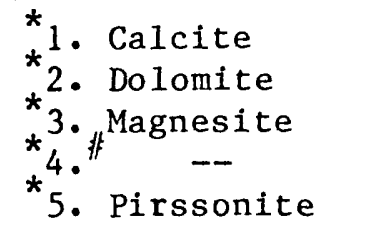 & $\begin{array}{l}\mathrm{CaCO}_{3} \\
\mathrm{CaMg}_{\left(\mathrm{CO}_{3}\right)_{2}} \\
\mathrm{MgCO}_{3} \\
\mathrm{Na}_{2} \mathrm{CO}_{3} \\
\mathrm{Na}_{2} \mathrm{Ca}\left(\mathrm{CO}_{3}\right)_{2} \cdot 2 \mathrm{H}_{2} \mathrm{O}\end{array}$ & $\begin{array}{l}* 36 \text {. Nitromagnesite } \\
\star 37 \text {. Niter } \\
\star 38 \text {. Soda niter } \\
* 39 \text {. - } \\
\star \text { 40. Nitrobarite }\end{array}$ & $\begin{array}{l}\mathrm{Mg}\left(\mathrm{NO}_{3}\right)_{2} \cdot 6 \mathrm{H}_{2} \mathrm{O} \\
\mathrm{KNO}_{3} \\
\mathrm{NaNO}_{3} \\
\mathrm{Sr}\left(\mathrm{NO}_{3}\right)_{2} \\
\mathrm{Ba}\left(\mathrm{NO}_{3}\right)_{2}\end{array}$ \\
\hline 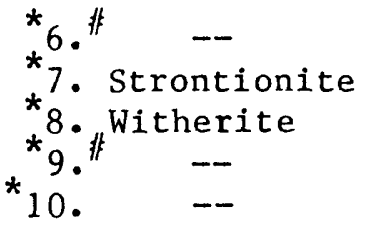 & $\begin{array}{l}\mathrm{K}_{2} \mathrm{CO}_{3} \\
\mathrm{SrCO}_{3} \\
\mathrm{BaCO}_{3} \\
\left(\mathrm{NH}_{4}\right)_{2} \mathrm{CO}_{3} \\
\mathrm{Li}_{2} \mathrm{CO}_{3}\end{array}$ & $\begin{array}{l}* 41 \text {. Ammonia niter } \\
* 42 \text {. - } \\
* 43 \text {. Inyoite } \\
* 44 \text {. Ulexite } \\
* 45 \text {. Indirite }\end{array}$ & $\begin{array}{l}\mathrm{NH}_{4} \mathrm{NO}_{3} \\
\mathrm{LiNO}_{3} \cdot 3 \mathrm{H}_{2} \mathrm{O} \\
\mathrm{Ca}_{2} \mathrm{~B}_{6} \mathrm{O}_{11} \cdot 13 \mathrm{H}_{2} \mathrm{O} \\
\mathrm{NaCaB}_{5} \mathrm{O}_{9} \cdot 8 \mathrm{H}_{2} \mathrm{O} \\
\mathrm{Mg} 2 \mathrm{~B}_{6} \mathrm{O}_{11} \cdot 1 \mathrm{H}_{2} \mathrm{O}\end{array}$ \\
\hline 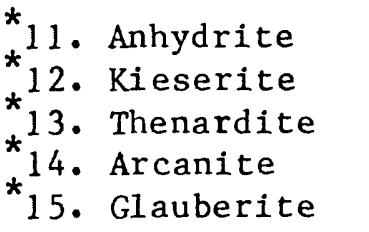 & $\begin{array}{l}\mathrm{CaSO}_{4} \\
\mathrm{MgSO}_{4} \cdot \mathrm{H}_{2} \mathrm{O} \\
\mathrm{Na}_{2} \mathrm{SO}_{4} \\
\mathrm{~K}_{2} \mathrm{SO}_{4} \\
\mathrm{Na}_{2} \mathrm{Ca}\left(\mathrm{SO}_{4}\right)_{2}\end{array}$ & $\begin{array}{ll}* 46 . & \text { Borax } \\
* 47 . & \text { Fluorite } \\
* 48 . & \text { Sellaite } \\
* 49 . & \text { Villiaumite } \\
* 40 . & --\end{array}$ & $\begin{array}{l}\mathrm{Na}_{2} \mathrm{~B}_{4} \mathrm{O}_{7} \cdot 10 \mathrm{H}_{2} \mathrm{O} \\
\mathrm{CaF}_{2} \\
\mathrm{MgF}_{2} \\
\mathrm{NaF} \\
\mathrm{LiF}\end{array}$ \\
\hline $\begin{array}{l}* 16 . \text { Syngenite } \\
* 17 . \text { Polyhalite } \\
* 18 . \text { Bloedite } \\
* 19 . \text { Leonite } \\
* \text { 20. Aphthitalite }\end{array}$ & $\begin{array}{l}\mathrm{K}_{2} \mathrm{Ca}\left(\mathrm{SO}_{4}\right)_{2} \bullet \mathrm{H}_{2} \mathrm{O} \\
\mathrm{K}_{2} \mathrm{Ca} 2 \mathrm{Mg}\left(\mathrm{SO}_{4}\right)_{4} \cdot 2 \mathrm{H}_{2} \mathrm{O} \\
\mathrm{Na}_{2} \mathrm{Mg}\left(\mathrm{SO}_{4}\right)_{2} \cdot 4 \mathrm{H}_{2} \mathrm{O} \\
\mathrm{K}_{2} \mathrm{Mg}\left(\mathrm{SO}_{4}\right)_{2} \cdot 4 \mathrm{H}_{2} \mathrm{O} \\
\mathrm{K}_{3} \mathrm{Na}\left(\mathrm{SO}_{4}\right)_{2}\end{array}$ & $\begin{array}{ll}* 51 . \# & -- \\
* 51 . & -- \\
* 52 . & -- \\
53 . & \\
* 54 . & \text { Fluorapatite } \\
* 55 . & \text { Wagnerite }\end{array}$ & $\begin{array}{l}\mathrm{Ca}_{3}\left(\mathrm{PO}_{4}\right)_{2} \\
\mathrm{Mg}_{3}\left(\mathrm{PO}_{4}\right)_{2} \\
\mathrm{Na}_{3} \mathrm{PO}_{4} \\
\mathrm{Ca}_{5}\left(\mathrm{PO}_{4}\right)_{3} \mathrm{~F} \\
\mathrm{Mg}_{2} \mathrm{PO}_{4} \mathrm{~F}\end{array}$ \\
\hline $\begin{array}{l}* 21 . \text { Celestite } \\
* 22 . \text { Barite } \\
* 23 . \text { Mascagnite } \\
* 24 . \quad-- \\
*^{*} 25 . \text { Antarcticite }\end{array}$ & $\begin{array}{l}\mathrm{SrSO}_{4} \\
\mathrm{BaSO}_{4} \\
\left(\mathrm{NH}_{4}\right)_{2} \mathrm{SO}_{4} \\
\mathrm{Li}_{2} \mathrm{SO}_{4} \\
\mathrm{CaCl}_{2} \cdot 6 \mathrm{H}_{2} \mathrm{O}\end{array}$ & $\begin{array}{l}56 .{ }^{\text {Q }} \text { Hydroxyapatite } \\
57 .+ \text { Inyoite } \\
58 .+ \text { Ulexite } \\
59 .{ }^{+} \text {Indirite } \\
60 .{ }^{+} \text {Borax }\end{array}$ & $\begin{array}{l}\mathrm{Ca}_{5}\left(\mathrm{PO}_{4}\right) 3 \mathrm{OH} \\
\mathrm{Ca}_{2} \mathrm{~B}_{6} \mathrm{O}_{1} \cdot 13 \mathrm{H}_{2} \mathrm{O} \\
\mathrm{NaCaB}_{5} \mathrm{O}^{\cdot} \cdot 8 \mathrm{H}_{2} \mathrm{O} \\
\mathrm{Mg}_{2} \mathrm{~B}_{6} \mathrm{O}_{1} \cdot 15 \mathrm{H}_{2} \mathrm{O} \\
\mathrm{Na}_{2} \mathrm{~B}_{4} \mathrm{O}_{7} \cdot 10 \mathrm{H}_{2} \mathrm{O}\end{array}$ \\
\hline $\begin{array}{l}* 26 . \text { Tachyhydrite } \\
* 27 . \text { Bischofite } \\
* 28 . \text { Carnallite } \\
*_{29} \text { Sylvite } \\
{ }^{*} \text { 30. Halite }\end{array}$ & $\begin{array}{l}\mathrm{CaMg}_{2} \mathrm{Cl}_{6} \cdot 12 \mathrm{H}_{2} \mathrm{O} \\
\mathrm{MgCl}_{2} \cdot 6 \mathrm{H}_{2} \mathrm{O} \\
\mathrm{KMGCl}_{3} \cdot 6 \mathrm{H}_{2} \mathrm{O} \\
\mathrm{KCl} \\
\mathrm{NaCl}\end{array}$ & $\begin{array}{l}\text { 61. Kainite } \\
\text { 62. Burkeite } \\
\text { 63. Trona } \\
\text { 64. Kalicinite } \\
\text { 65. Teschemacherite }\end{array}$ & $\begin{array}{l}\mathrm{KMgClSO}_{4} \cdot 3 \mathrm{H}_{2} \mathrm{O} \\
\mathrm{Na}_{6} \mathrm{CO}_{3}\left(\mathrm{SO}_{4}\right) 2 \\
\left.\mathrm{Na}_{3} \mathrm{H}_{(} \mathrm{CO}_{3}\right) 2 \cdot 2 \mathrm{H}_{2} \mathrm{O} \\
\mathrm{KHCO}_{3} \\
\mathrm{NH}_{4} \mathrm{HCO}_{3}\end{array}$ \\
\hline $\begin{array}{lc}* 31 . & -- \\
* 32 . & - \\
* 33 . & \text { Salammoniac } \\
* 34 . & -- \\
* 34 . & \text { Nitrocalcite }\end{array}$ & $\begin{array}{l}\mathrm{SrCl}_{2} \cdot 2 \mathrm{H}_{2} \mathrm{O} \\
\mathrm{BaCl}_{2} \cdot \mathrm{H}_{2} \mathrm{O} \\
\mathrm{NH}_{4} \mathrm{Cl} \\
\mathrm{LiCl}_{2} \cdot \mathrm{H}_{2} \mathrm{O} \\
\mathrm{Ca}\left(\mathrm{NO}_{3}\right)_{2} \cdot 4 \mathrm{H}_{2} \mathrm{O}\end{array}$ & $\begin{array}{l}\text { 66. } \\
\text { 67. -- } \\
\text { 68. Epsomite } \\
\text { 69. Picromerite } \\
\text { 70. Gypsum }\end{array}$ & $\begin{array}{l}\mathrm{SrCl}_{2} \cdot 6 \mathrm{H}_{2} \mathrm{O} \\
\mathrm{BaCl}_{2} \cdot 2 \mathrm{H}_{2} \mathrm{O} \\
\mathrm{MgSO}_{4} \cdot 7 \mathrm{H}_{2} \mathrm{O} \\
\left.\mathrm{K}_{2} \mathrm{Mg}_{2} \mathrm{SO}_{2}\right)_{2} \cdot 6 \mathrm{H}_{2} \mathrm{O} \\
\mathrm{CaSO}_{4} \cdot 2 \mathrm{H}_{2} \mathrm{O}\end{array}$ \\
\hline & & 71. Mirabilite & $\mathrm{Na}_{2} \mathrm{SO}_{4} \cdot 10 \mathrm{H}_{2} \mathrm{O}$ \\
\hline
\end{tabular}

\footnotetext{
* "Base salts" used to compute the "base-salt assemblage."

"Not normative salts; included as base salt to expedite calculations.

${ }^{Q}$ Hydroxyapatite calculated as $\mathrm{Ca}_{4} .75\left(\mathrm{PO}_{4}\right)_{3.17}$.

${ }^{+}$Replace base-salt borates $(43-46)$ if calculated with average borate charge of $-7 / 12(-0.583)$ per boron: inyoite, Cal.79B6.14011; borax, Na2.28B3.9107; ulexite, Ca0.98Na0.98B5.0209; and indirite, $\mathrm{Mg} 1.79 \mathrm{~B} 6.14011$.
} 
Table II-4. "Base salts" excluded from trial "base salt assemblages" in SNORM as a function of charge ratios of selected cation and anion groups of solutes

[Salt numbers from table II-3]

$\left[2\left(m_{\mathrm{Ca}}+\mathrm{m}_{\mathrm{Mg}}+\mathrm{m}_{\mathrm{Ba}}+\mathrm{m}_{\mathrm{Sr}}\right)+\mathrm{m}_{\mathrm{Li}}\right] /\left[3 \mathrm{~m}_{\mathrm{PO}_{4}}+2\left(\mathrm{~m}_{\mathrm{SO}_{4}}+\mathrm{m}_{\mathrm{CO}_{3}}\right)+\mathrm{m}_{\mathrm{F}}+7 / 12 \mathrm{~m}_{\mathrm{B}}{ }^{*}\right]>1$

4. $\mathrm{Na}_{2} \mathrm{CO}_{3}$ 15. Glauberite 41. Ammonia niter

5. Pirssonite 16. Syngenite

6. $\mathrm{K}_{2} \mathrm{CO}_{3}$ 18. Bloedite

44. Ulexite

8. Witherite 19. Leonite

46. Borax

9. $\left(\mathrm{NH}_{4}\right)_{2} \mathrm{CO}_{3}$

20. Aphthitalite

13. Thenardite

23. Mascagnite

49. Villiaumite

50. LiF

14. Arcanite

53. $\mathrm{Na}_{3} \mathrm{PO}_{4}$

$$
\begin{aligned}
{\left[2\left(\mathrm{~m}_{\mathrm{Ca}}+\mathrm{m}_{\mathrm{Mg}}+\mathrm{m}_{\mathrm{Ba}}+\mathrm{m}_{\mathrm{Sr}}\right)+\mathrm{m}_{\mathrm{Li}}\right] /\left[3 \mathrm{~m}_{\mathrm{PO}_{4}}+2\left(\mathrm{~m}_{\mathrm{SO}_{4}}+\mathrm{m}_{\mathrm{CO}_{3}}\right)+\mathrm{m}_{\mathrm{F}}+7 / 12 \mathrm{~m}_{\mathrm{B}} *\right]<1 } \\
\begin{array}{lll}
\text { 25. Antarcticite } & 31 . \mathrm{SrCl}_{2} \cdot 2 \mathrm{H}_{20} \mathrm{O} & \text { 36. Nitromagnesite } \\
\text { 26. Tachyhydrite } & \text { 32. } \mathrm{BaCl}_{2} \mathrm{H}_{20} \mathrm{39} & \text { 3r(NO3) } 2 \\
\text { 27. Bischofite } & \text { 35. Nitrocalcite } & \text { 40. Nitrobarite }
\end{array}
\end{aligned}
$$

$\left[2\left(m_{\mathrm{Ca}}+\mathrm{m}_{\mathrm{Mg}}+\mathrm{m}_{\mathrm{Sr}}\right)\right] /\left[3 \mathrm{~m}_{\mathrm{PO}_{4}}+2 \mathrm{~m}_{\mathrm{CO}_{3}}\right]<1$

11. Anhydrite

18. Bloedite

19. Leonite

21. Celestite

15. Glauberite

28. Carnallite

16. Syngenite

43. Inyoite

44. Ulexite

45. Indirite

47. Fluorite

17. Polyhalite

48. Sellaite

$$
\left[2\left(\mathrm{~m}_{\mathrm{Ca}}+\mathrm{m}_{\mathrm{Mg}}\right)\right] /\left[3 \mathrm{~m}_{\mathrm{PO}_{4}}+2 \mathrm{~m}_{\mathrm{CO}_{3}}+\mathrm{m}_{\mathrm{F}}\right]>1
$$

4. $\mathrm{Na}_{2} \mathrm{CO}_{3}$

5. Pirssonite

8. Witherite

9. $\left(\mathrm{NH}_{4}\right)_{2} \mathrm{CO}_{3}$

10. $\mathrm{Li}_{2} \mathrm{CO}_{3}$

49. Villiaumite

6. $\mathrm{K}_{2} \mathrm{CO}_{3}$

50. LiF

7. Strontionite

53. $\mathrm{Na}_{3} \mathrm{PO}_{4}$

* Borate assigned an average charge of $-7 / 12(-0.583)$ per boron (see text). 


\section{APPENDIX III}

\section{User Procedures and Options}

SNORM is interactive; it requests information and the user enters an appropriate response. The user creates or calls an input file containing the desired group of water analyses, and enters other parameters including the character of the output device(s), various output options, and user-elected modifications to the analyses. The results for each sample in the file are then computed and transmitted to the designated output device(s).

An example of output from SNORM is given in Appendix I for seawater. The major features of the output are: (1) title and description of the sample, and other data (density, $\mathrm{pH}$, units of analysis); (2) solute data in units of the analysis and related molar and weight units, and selected molar ratios; (3) adjusted solute data in the same units as the analytical data that incorporate any user-designated solute modifications and achieve charge balance for solute distribution into the normative salts; (4) the salt norm with the concentration of each salt in the same units as listed for the solutes, and in percentage (molar and weight) of the normative assemblage with weight percentage given both in terms of the normative salts and, to more closely reflect relative solute abundances, in terms of their anhydrous stoichiometries; and (5) the simple salt assemblage as percentages (molar and welght) of each salt in the assemblage. After output for all samples in the file has been generated, a compilation of the programmatic operations that were required to calculate the norm for each sample is tabulated. For the seawater example (Appendix IV), 117,667 "salt pair tests" were made to assure no prohibited salt associations. These defined 1,954 possible potential assemblages each of which were qualitatively tested ("assemblage tests") to reject those assemblages that lacked one or more solute(s). The 851 surviving assemblages were each quantitatively tested ("Inversions") to identify the single assemblage whose salt abundances could be successfully calculated (see Appendix II).

After SNORM is initiated, the program first asks the user a series of questions or requests for data to which the user replies with either appropriate integer code identifiers or, if entering new analyses, the requested descriptive and numerical data. Most user entries are displayed immediately after entry with a request for elther verification of the entry or an opportunity to re-enter if an entry error was made.

\section{Designating and creating input file}

The user designates whether the norm is to be calculated from analytical data already in an existing input data file in the user's directory or from 
data that will be entered to create a new input file. In either case, the user then enters the name of the existing/proposed input data file. If the user designated creation of a new file but enters a file name already in the user's directory, the program requires either renaming the proposed new file or verification that that name is to be used with the result that the material currently in that file will be deleted and replaced by the new data.

If an existing data file is called, the user can elect to receive a listing of the water analyses in that file (sample number and sample description) that are sequentially numbered (locator number) in order of their occurrence in the file. The user then specifies whether the normative calculation should be made on all analyses in the file, or on only specifically designated samples in the file. If the latter option is selected, the user enters up to 25 integer values identifying the desired analyses; each integer is the locator number of an analysis in that file. With this option the normative salt calculation will be omitted for all analyses in the file that are not specifically designated; if the user mistakingly enters a locator number that exceeds the number of samples in the file, it will be ignored by SNORM. The user may also elect computation for only those analyses in the file in which the concentration of one or more (up to 10) specific solutes is given; the user designates the essential solute(s) with the result that the norm for any analysis in the file lacking data for any specified solute will not be calculated.

Creation of a new data file first requires specifying its format; the user may elect elther the format that will contain only the information required by SNORM to compute the salt norm (SNORM format) or the format that will include more extensive data (redox information, concentrations of additional solutes, choice of options for calculating activity coefficlents, etc.) for reading into WATEQ or WATEQF (WATEQ format). SNORM is able to create and read efther format, but WATEQ and WATEQF are unable to read the SNORM format; thus, if the user anticipates a need for results from both SNORM (the salt norm) and WATEQ (mineral equilibria with the water), creating new files in the WATEQ format is recommended. The ensuing discussion, however, will be restricted to entering data in the SNORM format; the user should refer to Truesdell and Jones (1974) and Plummer and others (1976) for a discussion of WATEQ input features, procedures, and options.

SNORM's first request when creating a data input file in the SNORM format is a title for the group of analyses. This is followed by a sequence of three requests for successive one-line entries for each water analysis in the group: (1) sample number, sample $\mathrm{pH}$ if known, sample density if known, concentration units of solute analytical data (molality, ppm, meq/L, mg/L, or mmoles/L), and 
any desired short descriptive phrase about the sample or its location; (2) the concentration data for six major solutes ( $\mathrm{Ca}, \mathrm{Mg}, \mathrm{Na}, \mathrm{K}, \mathrm{Cl}$, and $\mathrm{SO}_{4}$ ); and (3) a solute-identifier code integer and its concentration data for up to five of the remaining solutes from table 1 . If data (identifler code and concentration) are entered for the last position in the entry string, the request is repeated to allow entry of the data for additional solutes; the first entry of "00" (or blank) for the solute identifier in the entry string signifies all data for that analysis have been entered and the program returns to the first of the three requests (sample number, etc.) to accept data for the next analysis. After all analyses in the group have been entered (up to 99 Individual water analyses may be entered in a file), the user enters " 0 " (or blank) for the first of the three requests to signify completion of the new input data file. After each line of data entry when creating a new file in elther the SNORM or WATEQ format, the entry is displayed and the user either acknowledges verification of the entry or requests that the line be reentered.

Designating output devices

The user may select one or more of several possible forms for the SNORM ouptut. It may either be displayed or printed at the user's terminal at the time of executing the program, or stored as output files in the user's directory for later display or printing whenever and wherever the user specifies.

If the results are to be displayed or printed at the user's terminal at the time of program execution, one of two formats are avallable. The standard format uses a line-length of 131 characters that is accepted by printers with 15-1nch wide paper as well as some portable printers with 8.5-1nch paper and CRT display terminals. The alternative format with an 80 character linelength must be specified for many remote CRT display terminals and portable printers with 8.5 -inch paper. The short line-length format is abbreviated from the standard format (Appendix IV) but no essential output is omitted; only the number of alternative concentration units for the solutes and the normative salts is reduced. The default (no user response) to this option is display/printing of the results in the standard format.

With or without Immediate display/printing at the user's terminal, output can be transferred into an output data file in the user's directory for subsequent spooling to any output device with a 131 character 1ine-1ength capacity (the short line-length format cannot be stored in a file). The user has the option of creating an output data file in one of two forms, or both. One form will incorporate the standard "new page" Fortran carriage control that can be implemented by some printers, particularly line printers; the 
second form omits the "new page" carriage control and assigns the results of each analysis to a 66 line segment (the number of lines on an 11-inch length of standard computer paper) for use on remote printers not recognizing the "new page" carriage control. Output files are named in SNORM by prefixing the input data file name with either a p. or $t . ;$ the former is assigned to an output file with carriage control, and the latter to a file without carriage control. The default for this option is to not create any output files.

A final output option, which is available if the user is entering new data to create an input data $\mathrm{flle}$, is to create and store the file without any output or normative calculations.

Designating character of output

The user may request a print-out of the data bank of solutes, normative salts, and simple salts (Appendix IV) to accompany the print-out of a group of salt norms. The listing of solutes consists of the chemical formula, the charge, and the gram formula weight of each. Included with the solutes are uncharged oxygen (borate formation from analyzed boron), the hydroxyl ion (hydroxyapatite formation), and molecular water (hydration water). The chemical formula, mineral name if naturally occurring, and composition in terms of moles of solute components forming its stoichiometry are listed for each normative and simple salt.

SNORM, without instructions otherwise, recasts solute and salt concentrations into the default units specified in table III-1 for output in either the standard or short line-length format. In each case, the units for salt concentrations are included in the listings of solute concentrations, and the units of both solutes and salts include the units of the original analysis. The program allows the user to override the default units and specify that salt (and solute) concentration units for all samples in the file be one of "per kilogram water," "per kilogram," or "per 1iter" units. Such a specification is useful, for example, if a group (file) of samples consists of analyses with with some reported in "per 1iter" and others reported in "per kilogram" units, and the user wishes to compare the samples or plot concentration values, common concentration units throughout the file are needed. Note, that converting from or to "per liter" units requires a density measurement; if that is lacking for any given sample, the conversion for that sample is not made and the default units are retained.

Finally, the default output of the normative assemblage includes mole concentration of each normative salt in the water sample and mole percent of each salt in the normative assemblage. The user may elect to have these values reported as salt equivalencies rather than mole units (for example, one 


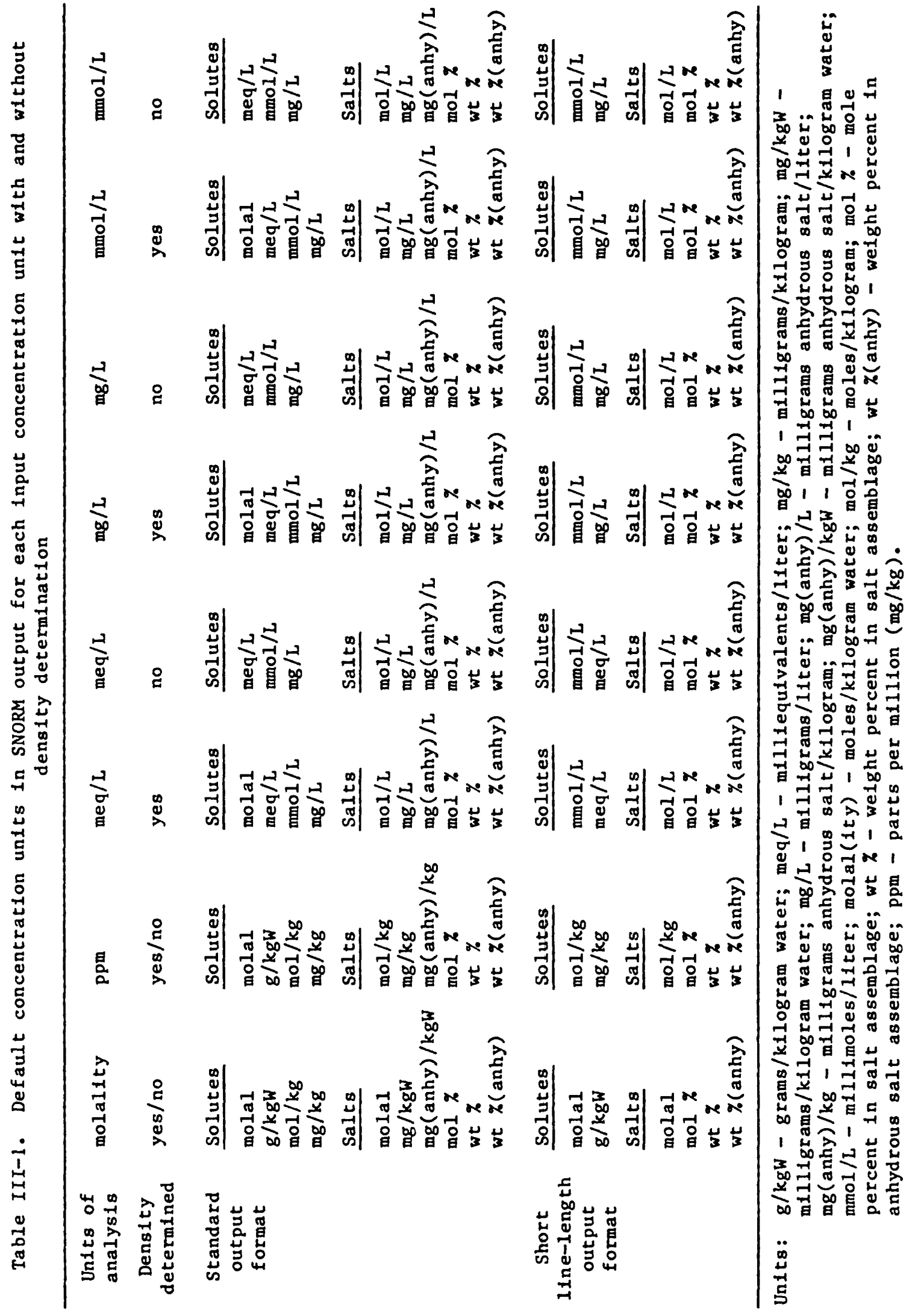


mole of polyhalite converts to elght equivalents, the cation charge per mole, of polyhalite). Some users may prefer this option since equivalencies among a group of salts more consistently reflect their relative abundance in the assemblage than do molar quantities.

Designating solute modifications

If salt norms are to be computed for an existing data file, the user has several options that modify the adjusted composition of the samples and the resultant normative assemblage throughout the file. These options are not avallable if the user is creating a new input data file because, if solute modifications are requested, norms are calculated and output generated for only those samples in the file in which the modifications have an effect.

Three of the options involve the nitrogen species, ammonia and nitrate. They form the only redox couple in SNORM and the user may wish to compare the results under alternative redox conditions. For that purpose, all nitrate can be recast as ammonia, or all ammonia as nitrate. In requesting either of these options, the user should be aware that adjusted concentrations of all solutes will be modifled because recasting an anion as a cation perturbs the former charge distribution. If the user feels that nitrate in a water is a contaminant, for example, from agricultural waste, the user may elect to remove nitrate from the analysis without affecting charge distribution; this can be accomplished by requesting that nitrate be stolchiometrically replaced by bicarbonate. We selected bicarbonate because most cases of nitrate pollution occur in dilute surface waters in which bicarbonate is characteristically the dominant anion.

The fourth option eliminates any one or more (up to 10) solutes from the normative calculation by setting its concentration to 0.0 in the adjusted solute concentrations calculation. Thus, for example, nitrate (and ammonia) could be deleted from the normative calculation in this manner. As with the nitrate-ammonium exchange, use of this option will alter all adjusted solute concentrations in order to retain charge balance.

The print-out of each analysis subject to any of these solute modifications will list the water composition as originally reported in its several appropriate concentration units; only the adjusted concentrations that achieve charge balance and the resultant normative assemblage will reflect the elected modifications. Furthermore, the printout of each analysis will be footnoted as to the nature of any such modification. 


\section{APPENDIX V}

\section{Phase relations among normative salts}

Each prohibited salt association in table 6 represents an equilibrium between the prohibited association and a stable, isochemical (exclusive of water and carbon dioxide) equivalent. For example, the pirssonite-magnesite pair is prohibited, and its isochemical equivalent, trona-dolomite, is stable; the equilibrium

$$
\begin{aligned}
& 2 \mathrm{Na}_{3} \mathrm{H}\left(\mathrm{CO}_{3}\right)_{2} \cdot 2 \mathrm{H}_{2} \mathrm{O}+3 \mathrm{CaMg}\left(\mathrm{O}_{3}\right)_{2}+\mathrm{H}_{2} \mathrm{O}=3 \mathrm{Na}_{2} \mathrm{Ca}\left(\infty_{3}\right)_{2} \cdot 2 \mathrm{H}_{2} \mathrm{O}+3 \mathrm{MgCO}_{3}+\mathrm{CO}_{2} \\
& \text { trona dolomite pirssonite magnesite }
\end{aligned}
$$

requires a water activity equal to or greater than 2.28 for stability of the pirssonite-magnesite pair. Such equilibria, or assumptions of equilibria if free energy data are lacking, can be used to illustrate phase relations among normative salts at $25^{\circ} \mathrm{C}, 1$ bar pressure, and if carbonate-bicarbonate exchange is involved, a carbon dioxide partial pressure of $10^{-3.5}$ bars.

Some important phase relations in SNORM are shown in the following figures and tables: Ca-Mg-Na (bi)carbonates (fig. V-l); Ca-Mg-K-Na sulfates (figs. $\mathrm{V}-2$ and $\mathrm{V}-3$, and tables $\mathrm{V}-1$ through $\mathrm{V}-4), \mathrm{Ca}-\mathrm{Mg}-\mathrm{K}-\mathrm{Na}$ sulfates and

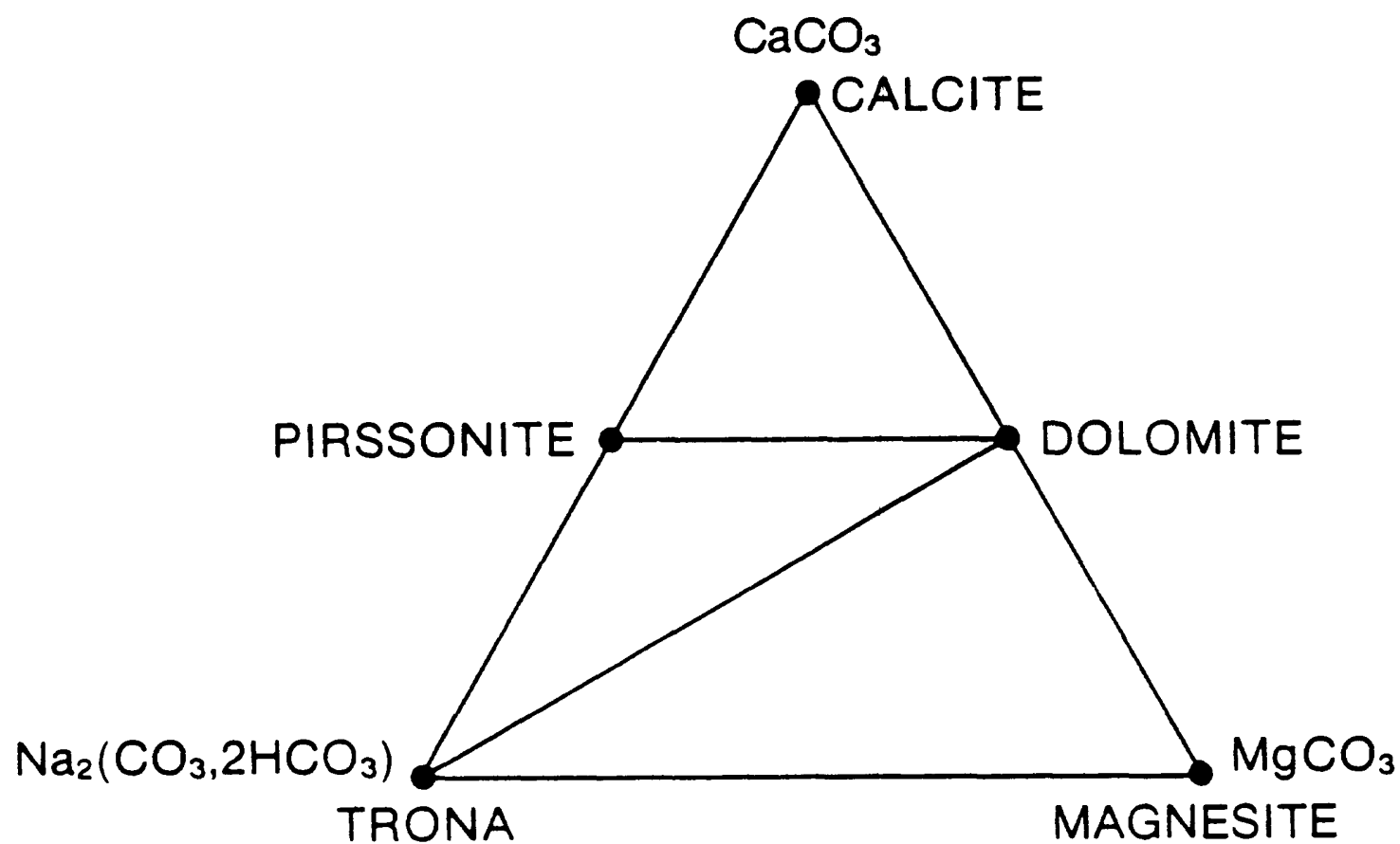

Figure V-1. Calculated phase relations among salts in the $\mathrm{CaCO}_{3}-\mathrm{MgCO}_{3}-$ $\mathrm{Na}_{2}\left(2 \mathrm{HCO}_{3}, \mathrm{CO}_{3}\right)-\mathrm{H}_{2} \mathrm{O}$ system at $25^{\circ} \mathrm{C}, 1$ bar pressure, and $10^{-3.5}$ bars carbon dioxide partial pressure; kalicinite stable with all assemblages. 
(bi) carbonates ( $f$ ig. $\mathrm{V}-4$ ), and simple-salt components of all sulfate and carbonate salts ( $f$ ig. V-5); $\mathrm{Ca}-\mathrm{Mg}-\mathrm{K}$ chlorides (fig. V-6), Ca-Mg chlorides and carbonates ( $f i g \cdot \mathrm{V}-7$ ), $\mathrm{Ca}-\mathrm{Mg}-\mathrm{K}-\mathrm{Na}$ chlorides and sulfates (fig. V-8), and simple-salt components of all chloride and carbonate salts, and all chloride and sulfate salts ( $\mathrm{flg} \cdot \mathrm{V}-9$ ); $\mathrm{Ca}-\mathrm{Mg}-\mathrm{K}$ nitrates and chlorides (fig. $\mathrm{V}-10$ ), and simple-salt components of all nitrate and carbonate salts, all nitrate and sulfate salts, and all nitrate and chloride salts (fig. V-ll); and $\mathrm{Ca}-\mathrm{Mg}-\mathrm{Na}$ fluorides and phosphates (fig. $\mathrm{V}-12$ ), and $\mathrm{Ca}-\mathrm{Mg}$ fluorides and carbonates, fluorides and sulfates, and fluorides and chlorides (fig. V-13). Each of these, except portions of $\mathrm{fig} \cdot \mathrm{V}-12$, are constructed from calculated equilibria.

Figs. V-5, V-9, and V-11 identify permissible associations among the simple-salt components (with bicarbonate expressed as carbonate throughout) in normative salts for two alternative anions; the upper horizontal line is a linear array of simple-salt components of one anion and the lower horizontal Ine is the matching array of salts of the second anion. The diagram is to be read from left to right starting at the left end of the upper horizontal line and dropping to the lower horizontal line only after all of the anion common to the upper horizontal line has been assigned to the left-to-right sequence of salts. Thus, in fig. V-5, for example, if there is sufficient carbonate to form $\mathrm{MgCO}_{3}$ and $\mathrm{CaCO}_{3}$ (normative dolomite and either calcite or magnesite from fig. $\mathrm{V}-1$ ), the simple salt component $\mathrm{MgSO}_{4}$ (and any $\mathrm{Mg}$-bearing normative sulfate salt from fig. $\mathrm{V}-4 \mathrm{~A}$ ) is prohibited (table 6 ). If unassigned carbonate remains, the next simple salt in the sequence, $\mathrm{SrCO}_{3}$ (normative strontionite) forms, but if all carbonate had been assigned to $\mathrm{Mg}-\mathrm{Ca}, \mathrm{CaSO}_{4}$ (normative anhydrite/gypsum) forms and is followed by the succeeding left-to-right sequence of sulfate simple salts until sulfate is exhausted. This type of figure is most useful in illustrating permissible (and prohibited)

associations among minor cation salts or between minor cation and major cation salts.

\section{$\underline{\mathrm{Ca}-\mathrm{Mg}-\mathrm{K}-\mathrm{Na} \text { sulfate salts }}$}

Relationships among major-cation sulfate salts are complex. A number of equilibria (table V-l) fall within the water activity interval in which salt norms occur; thus, prohibited associations (table 6) may not be valid for all norms. Harvie and others (1982) have calculated water activities in 4 sulfate-salt associations coexisting with a single chloride salt (table V-2) and 3 sulfate-salt association with two chloride salts (table V-3) in the Ca$\mathrm{Mg}-\mathrm{K}-\mathrm{Na}-\mathrm{SO}_{4}-\mathrm{Cl}-\mathrm{H}_{2} \mathrm{O}$ system; all sulfate associations are stable within the 0.726-0.665 water activity interval between equilibria $K$ and $M$ (table V-1), and conform to sulfate salt phase relations in $f i g \cdot V-2$ and table 6 . In the 


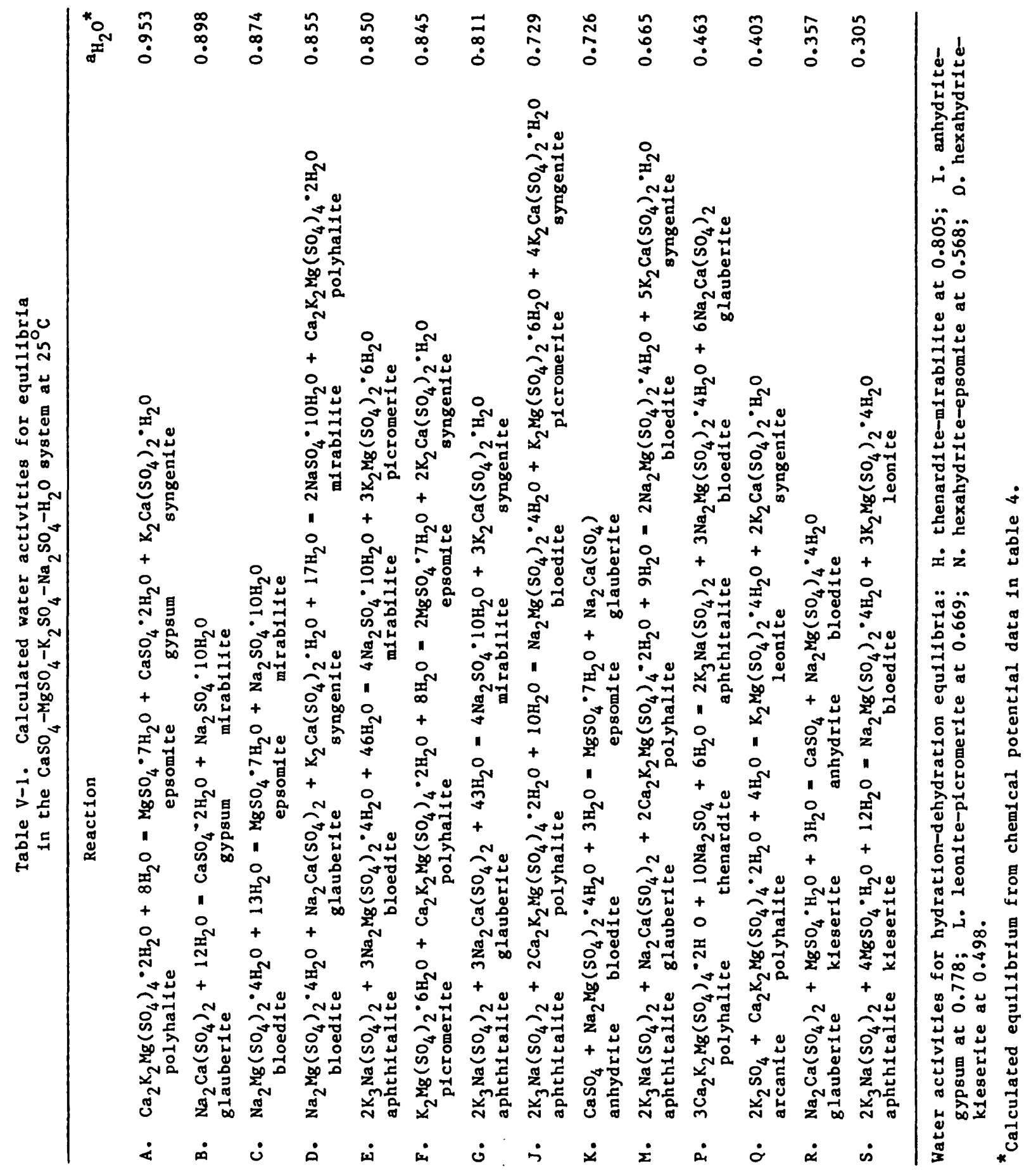




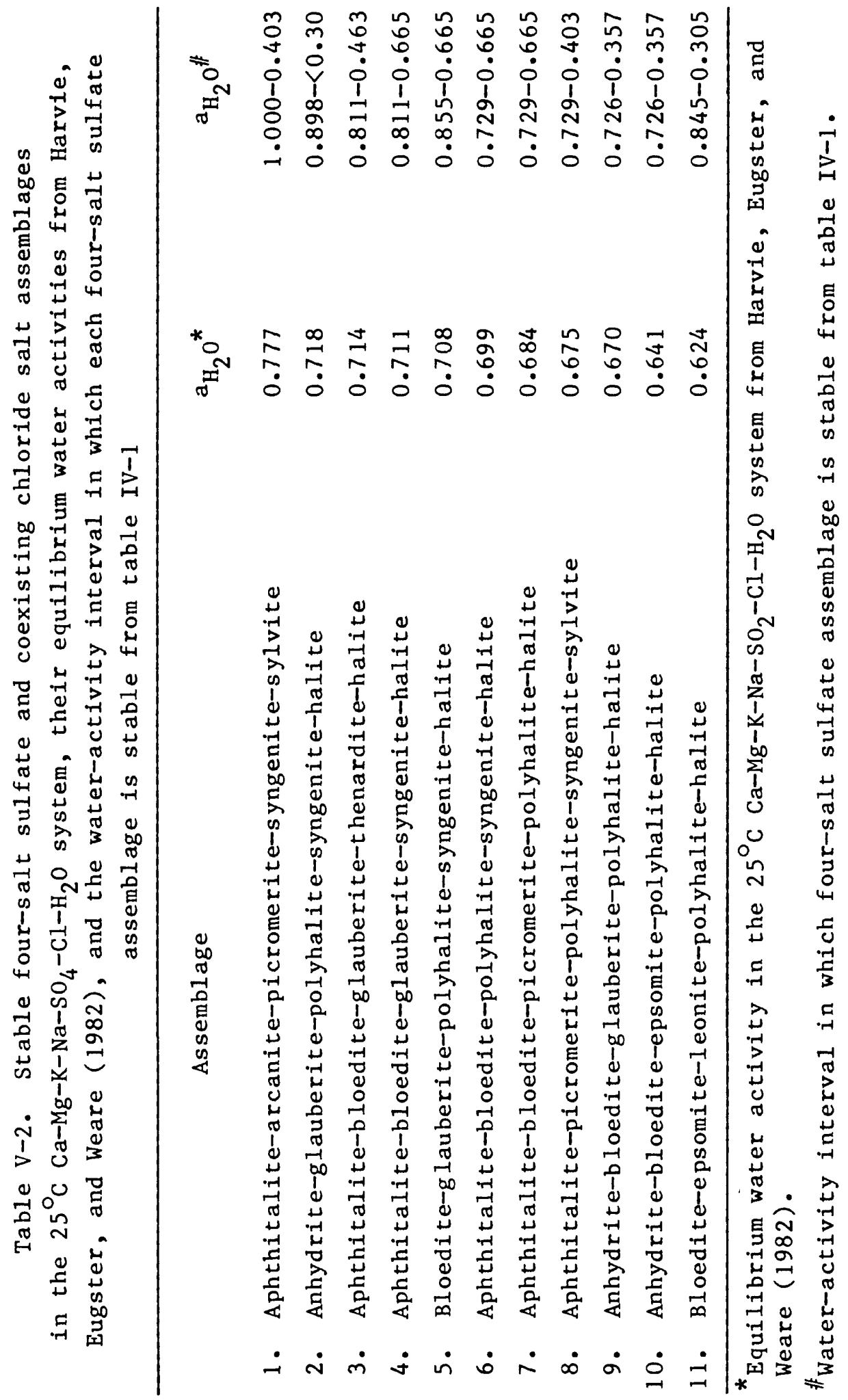




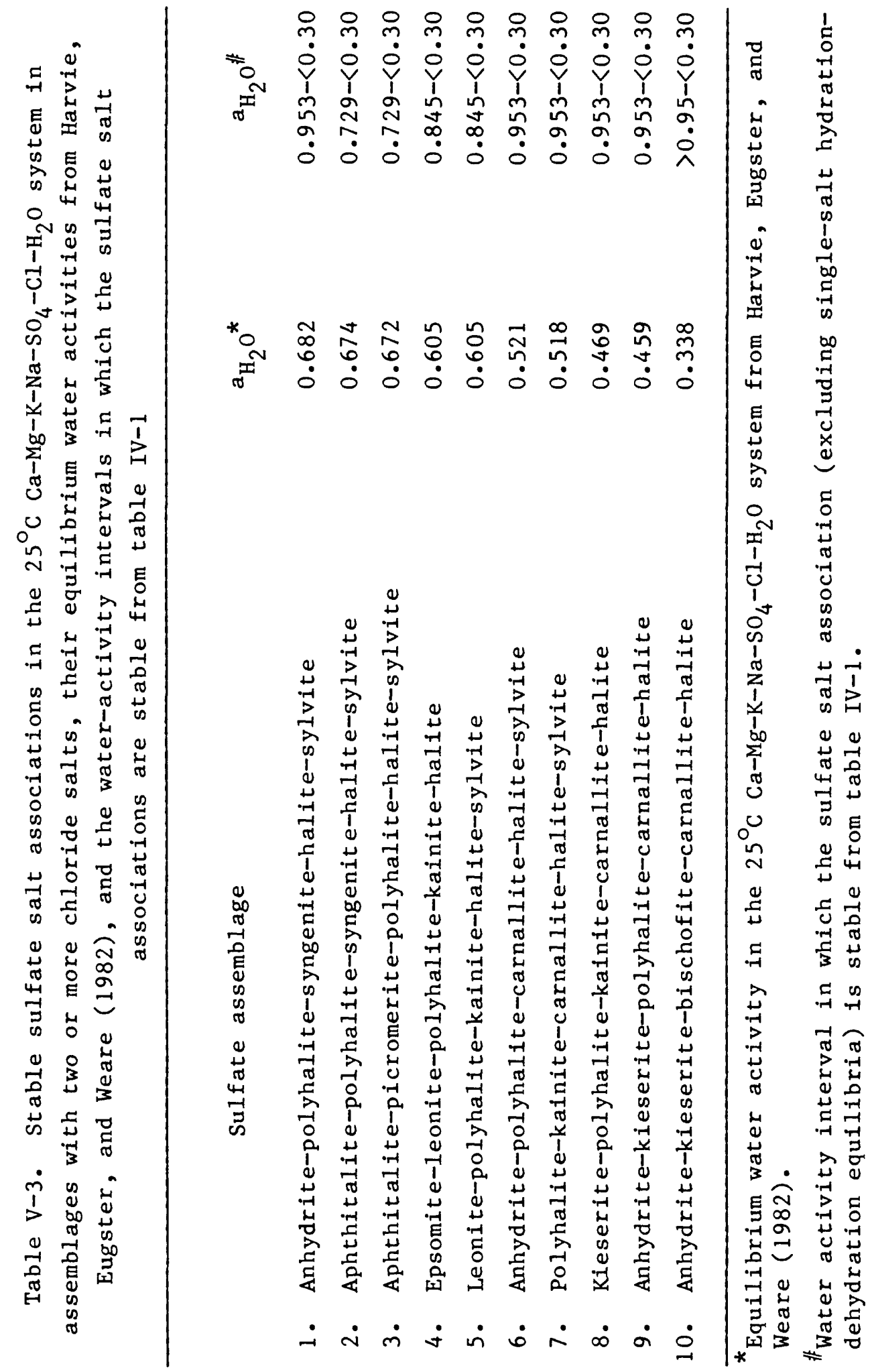




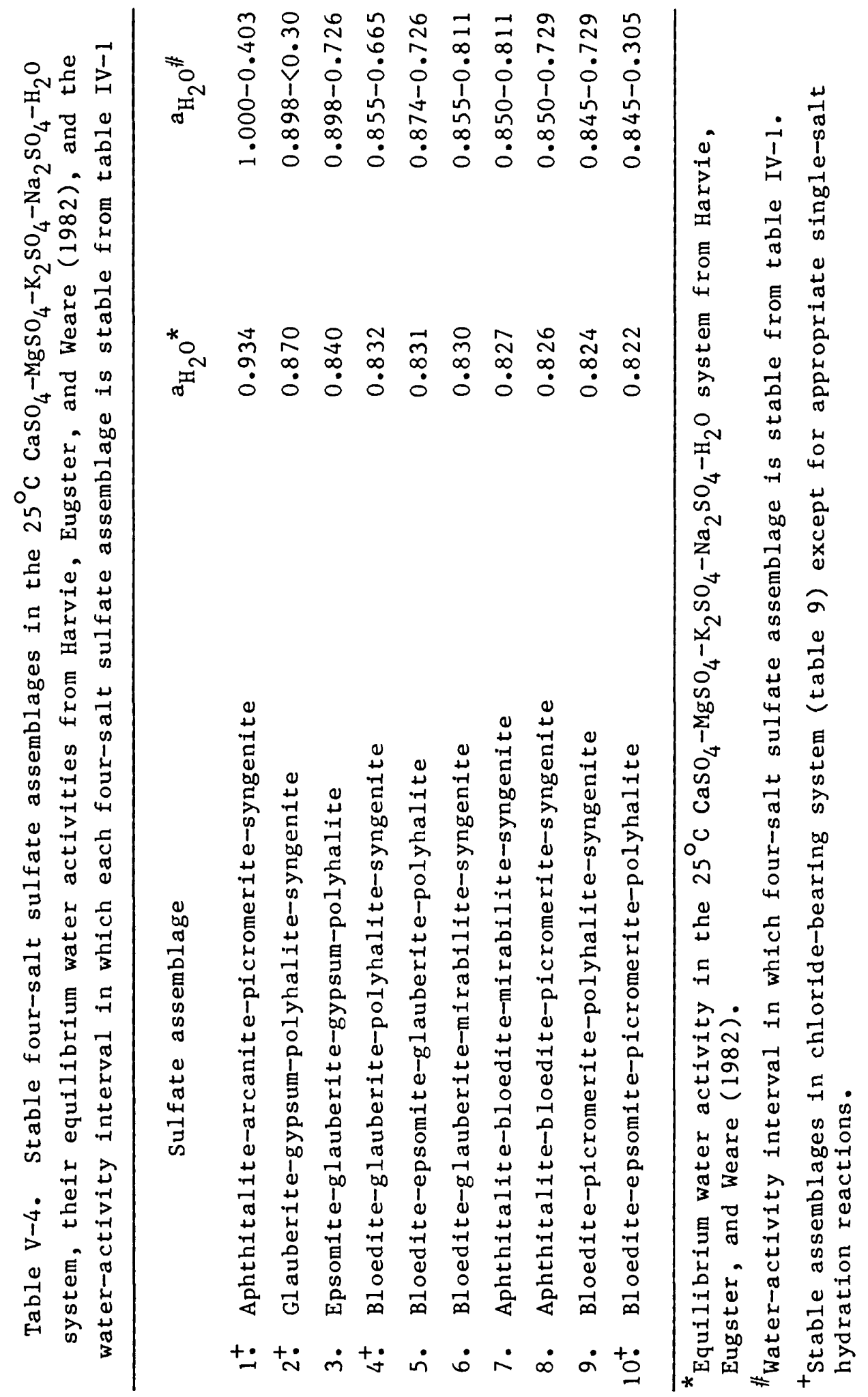



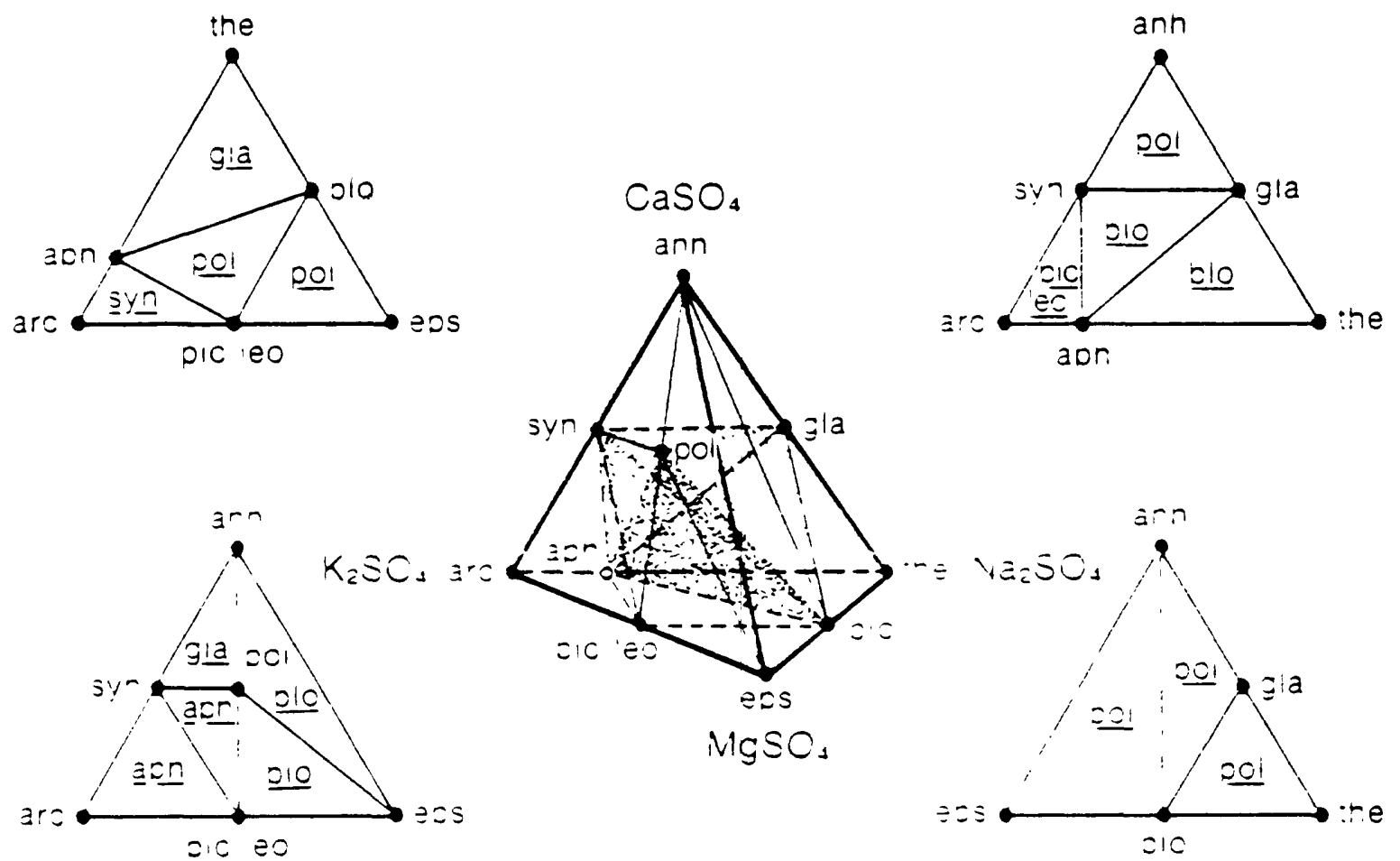

Figure V-2. Calculated phase relations in the $\mathrm{CaSO}_{4}-\mathrm{MgSO}_{4}-\mathrm{K}_{2} \mathrm{SO}_{4}-\mathrm{Na}_{2} \mathrm{SO}_{4}-$ $\mathrm{H}_{2} \mathrm{O}$ system at $25^{\circ} \mathrm{C}$ and 1 bar pressure within the water activity interval between 0.726 and 0.665 that represents normative salt relations in chloride or nitrate bearing waters; interval includes the picromerite-leonite transition $\left(\mathrm{a}_{\mathrm{H}_{2} \mathrm{O}}=0.669\right)$. Central tetrahedron is projection of the fivecomponent system into the quaternary sulfate salt tetrahedron; the four surrounding sulfate salt ternaries are faces of the tetrahedron. Mineral abbreviations from table 2; underlined abbreviation within each three-phase association on the ternary faces identify stable salt containing the fourth sulfate component. Solid joins on exposed faces of tetrahedron, dashed joins on hidden faces, and dotted joins penetrate tetrahedron; highlighted assemblages (aph-blo-pol-syn and blo-gla-pol-syn) do not form a three-phase assoctation on any ternary face. 

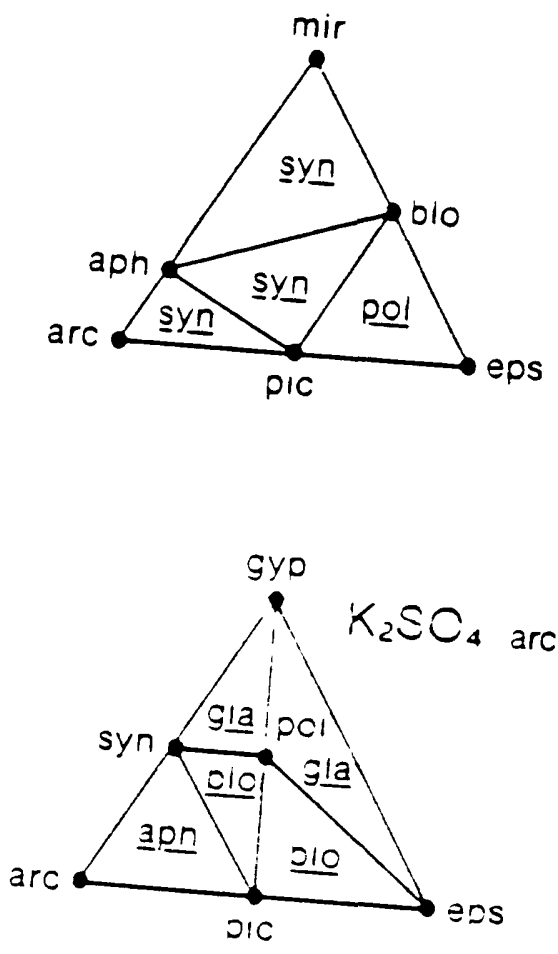
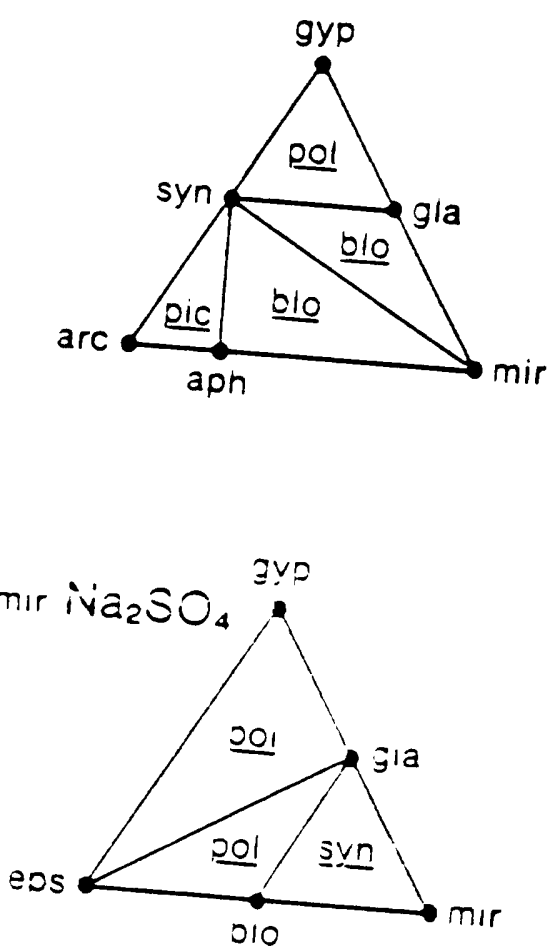

Figure V-3. Calculated phase relations in the $\mathrm{CaSO}_{4}-\mathrm{MgSO}_{4}-\mathrm{K}_{2} \mathrm{SO}_{4}-\mathrm{Na}_{2} \mathrm{SO}_{4}-$ $\mathrm{H}_{2} \mathrm{O}$ system at $25^{\circ} \mathrm{C}$ and 1 bar pressure within the water activity interval between 0.845 and 0.811 that represents normative salt relations in waters lacking chloride and nitrate. Central tetrahedron is projection of the fivecomponent system into the quaternary sulfate salt tetrahedron; the four surrounding sulfate salt ternaries are faces of the tetrahedron. Mineral abbreviations from table 2; underlined abbreviation within each three-phase association on the ternary faces identify stable salt containing the fourth sulfate component. Solid joins on exposed faces of tetrahedron, dashed jolns on hidden faces, and dotted jolns penetrate tetrahedron; highlighted assemblage (blo-gla-pol-syn) does not form a three-phase association on any ternary face. 

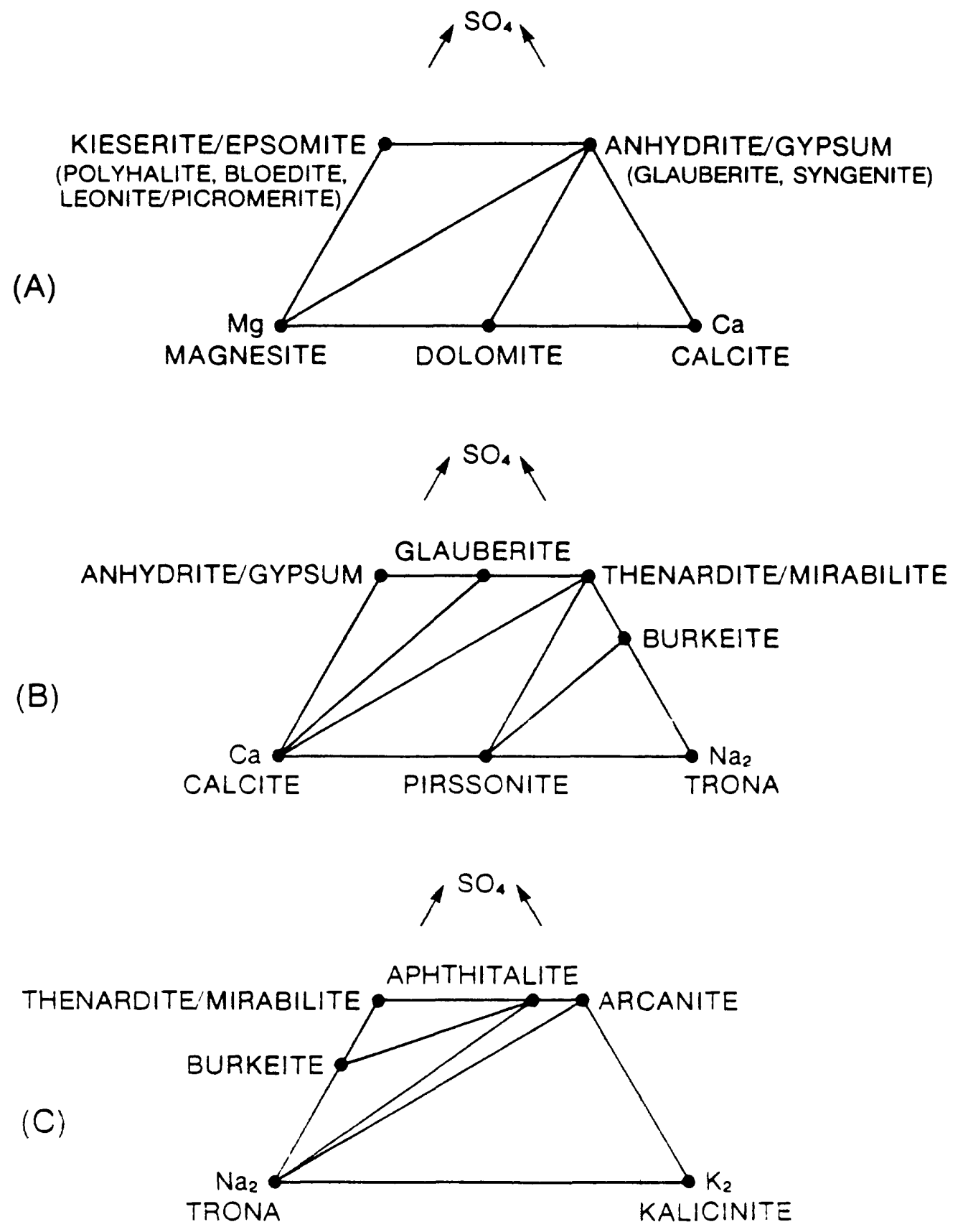

Figure V-4. Calculated phase relations among (bi)carbonate and sulfate normative salts at $25^{\circ} \mathrm{C}, 1$ bar pressure, and $10^{-3.5}$ bars partial pressure of $\mathrm{CO}_{2}$ in (bi)carbonate-saturated assemblages with sulfate and two cations: (A) $\mathrm{Mg}-\mathrm{Ca}-\mathrm{SO}_{4}-\mathrm{CO}_{3}-\mathrm{H}_{2} \mathrm{O}$ system with permissable alkali-bearing sulfates in parentheses; (B) $\mathrm{Ca}-\mathrm{Na}_{2}-\mathrm{SO}_{4}-\left(. \mathrm{OO}_{3}, 2 \mathrm{HCO}_{3}\right)-\mathrm{H}_{2} \mathrm{O}$ system; and (C) $\mathrm{Na}_{2}-\mathrm{K}_{2}-\mathrm{SO}_{4}-$ $\left(\mathrm{CO}_{3}, 2 \mathrm{HCO}_{3}\right)-\mathrm{H}_{2} \mathrm{O}$ system. 


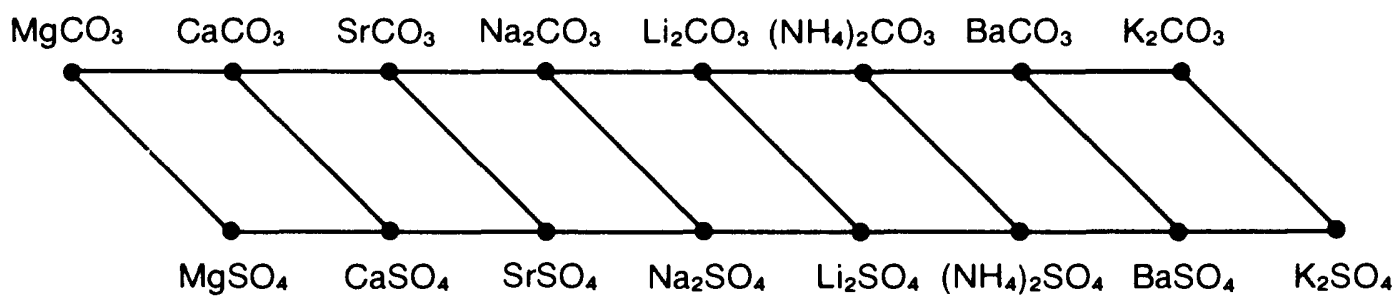

Figure V-5. Calculated relations at $25^{\circ} \mathrm{C}, 1$ bar pressure, and $10^{-3.5}$ bars $\mathrm{CO}_{2}$ partial pressure among carbonate and sulfate simple-salt components of normative salts with permissable associations forming a path that proceeds only from left to right on the diagram; bicarbonate components included with carbonate components.

absence of chloride and nitrate (unknown to our knowledge in natural waters), the stable 4 sulfate-salt assemblages and their water activities (Harvie and others, 1982) are stable in the 0.845-0.811 water activity interval (table $\mathrm{V}-4$ ) between equilibria $\mathrm{F}$ and $\mathrm{G}$ (table $\mathrm{V}-1$ ) and conform to phase relations in Fig. V-3. A hypothetical chloride-nitrate free water prompts SNORM to perform reactions $\mathrm{K}, \mathrm{J}$, and $\mathrm{G}$ (table $\mathrm{V}-1$ ) to form major-cation sulfate associations that are in accordance with table 6 and $\mathrm{fig} \cdot \mathrm{V}-2$, to yield the correct associations.

$\mathrm{Ca}-\mathrm{Mg}-\mathrm{Na}$ borate salts

Because free energy values for three of the four normative borate salts are lacking, the prohibited associations of borate salts in the salt norm are assigned to conform with general relations observed in natural assemblages and be consistent with relations in other salt groups.

We have restricted indirite's occurrence to $\mathrm{Mg}-$-rich norms in which magnesite is the sole carbonate; anhydrite, kieserite, leonite/picromerite, and polyhalite are the only permissible sulfates; bischofite and carnallite are the only permissible $\mathrm{Ca}$ and $\mathrm{Mg}$-bearing chlorides; and nitromagnesite is the only permitted $\mathrm{Ca}$ and $\mathrm{Mg}$-bearing nitrate. These relations were assigned based on the dominance, albeit secondary origin, of the magnesium borates boracite and ascherite in marine evaporites, the occurrence of indirite and kurnakovite in the Indir salt dome in Russia (Khn, 1968; Braitsch, 1971; Sonnenfeld, 1984), and the paucity and nearly exclusively secondary origin of indirite and other magnesium borates in continental playa deposits (Muessig, 1959, 1966; Bowser and Dickson, 1966). 


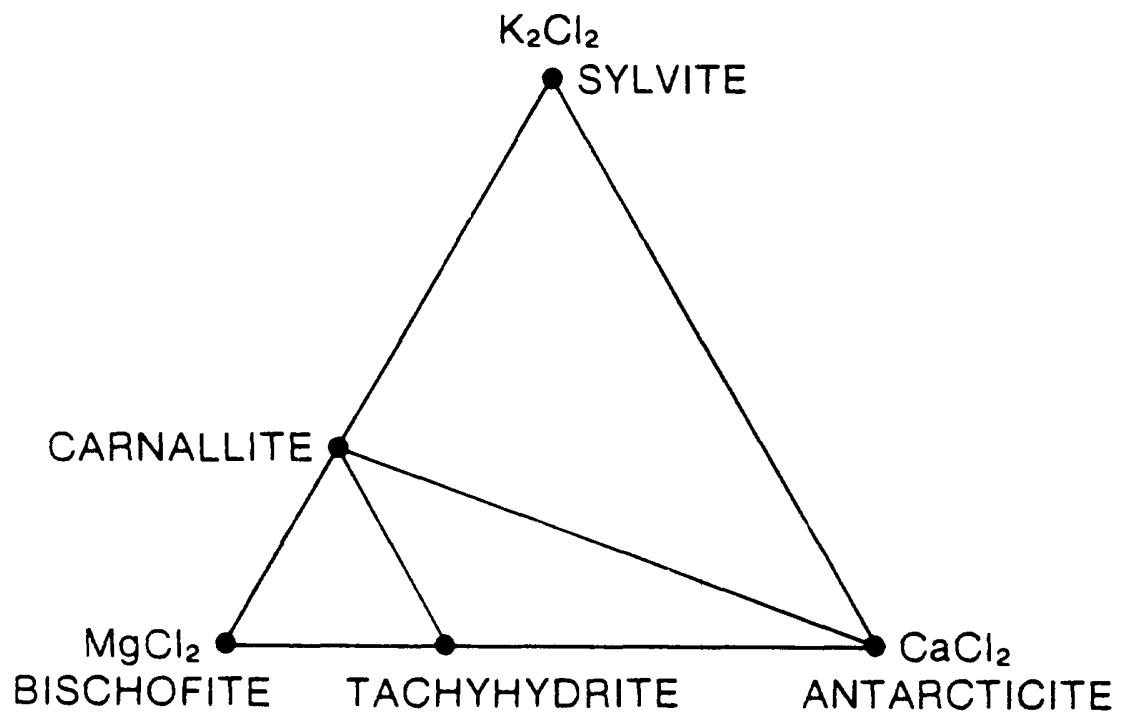

Figure V-6. Calculated phase relations among normative salts in the $\mathrm{CaCl}_{2}-\mathrm{MgCl}_{2}-\mathrm{K}_{2} \mathrm{Cl}_{2}-\mathrm{H}_{2} \mathrm{O}$ system at $25^{\circ} \mathrm{C}$ and 1 bar pressure; coexisting halite stable with all assemblages.

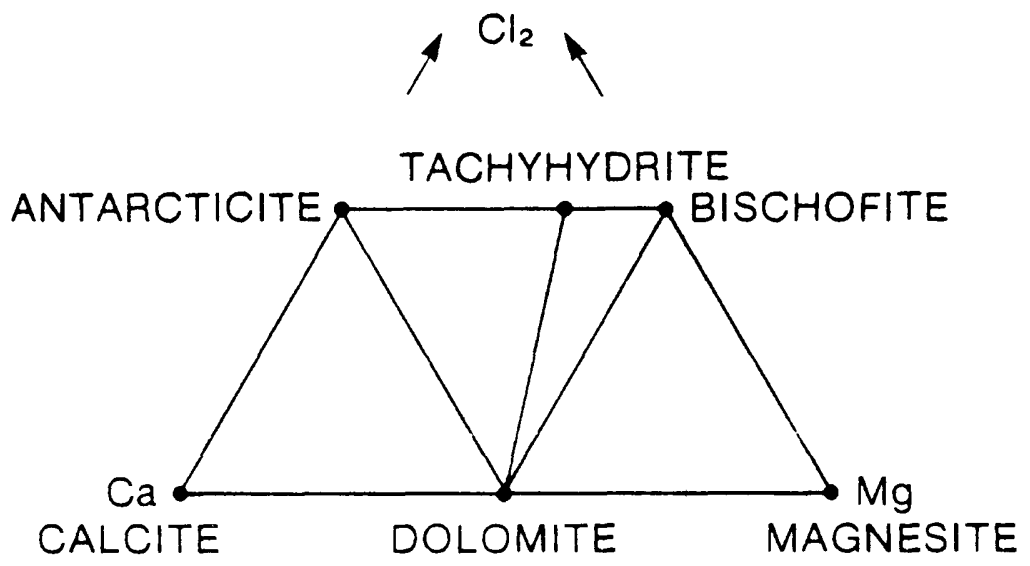

Figure $\mathrm{V}-7$. Calculated phase relations among normative salts in the $\mathrm{Ca}-\mathrm{Mg}-\mathrm{Cl}_{2}-\mathrm{CO}_{3}-\mathrm{H}_{2} \mathrm{O}$ system at $25^{\circ} \mathrm{C}, 1$ bar pressure, and $10^{-3.5}$ bars $\mathrm{CO}_{2}$ partial pressure with carnalite and halite permissable coexisting $K$ and $N a$ salts. 

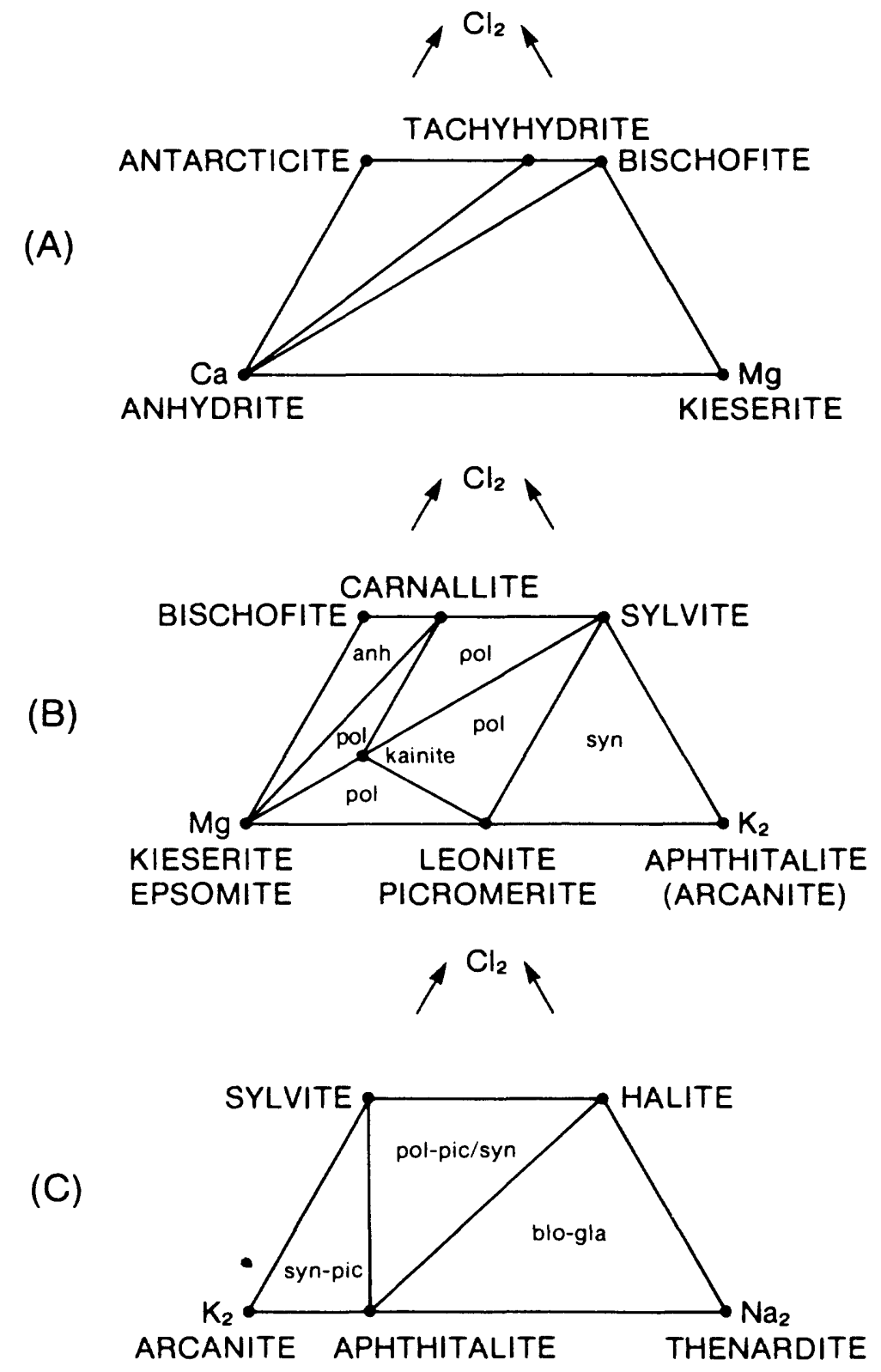

Figure V-8. Calculated phase relations among sulfate and chloride normative salts at $25^{\circ} \mathrm{C}$ and $\mathrm{I}$ bar pressure in sulfate-saturated assemblages with chloride and two cations; salt abbreviations from table 2: (A) $\mathrm{Ca}-\mathrm{Mg}-$ $\mathrm{Cl}_{2}-\mathrm{SO}_{4}-\mathrm{H}_{2} \mathrm{O}$ system with carnallite and halite as permissable coexisting $\mathrm{K}$ and $\mathrm{Na}$ salts; (B) $\mathrm{Mg}-\mathrm{K}_{2}-\mathrm{Cl}_{2}-\mathrm{SO}_{4}-\mathrm{H}_{2} \mathrm{O}$ system with sulfates labeled in three-phase triangles and halite permissable coexisting $\mathrm{Ca}$ and $\mathrm{Na}$ salts (if arcaniteaphthitalite present halite not permitted, see (C) below); and (C) $\mathrm{K}_{2}-\mathrm{N}_{2}-\mathrm{Cl}_{2}{ }^{-}$ $\mathrm{SO}_{4}-\mathrm{H}_{2} \mathrm{O}$ system with sulfates labeled in three-phase triangles permissable coexisting $\mathrm{Ca}$ and $\mathrm{Mg}$ salts. 

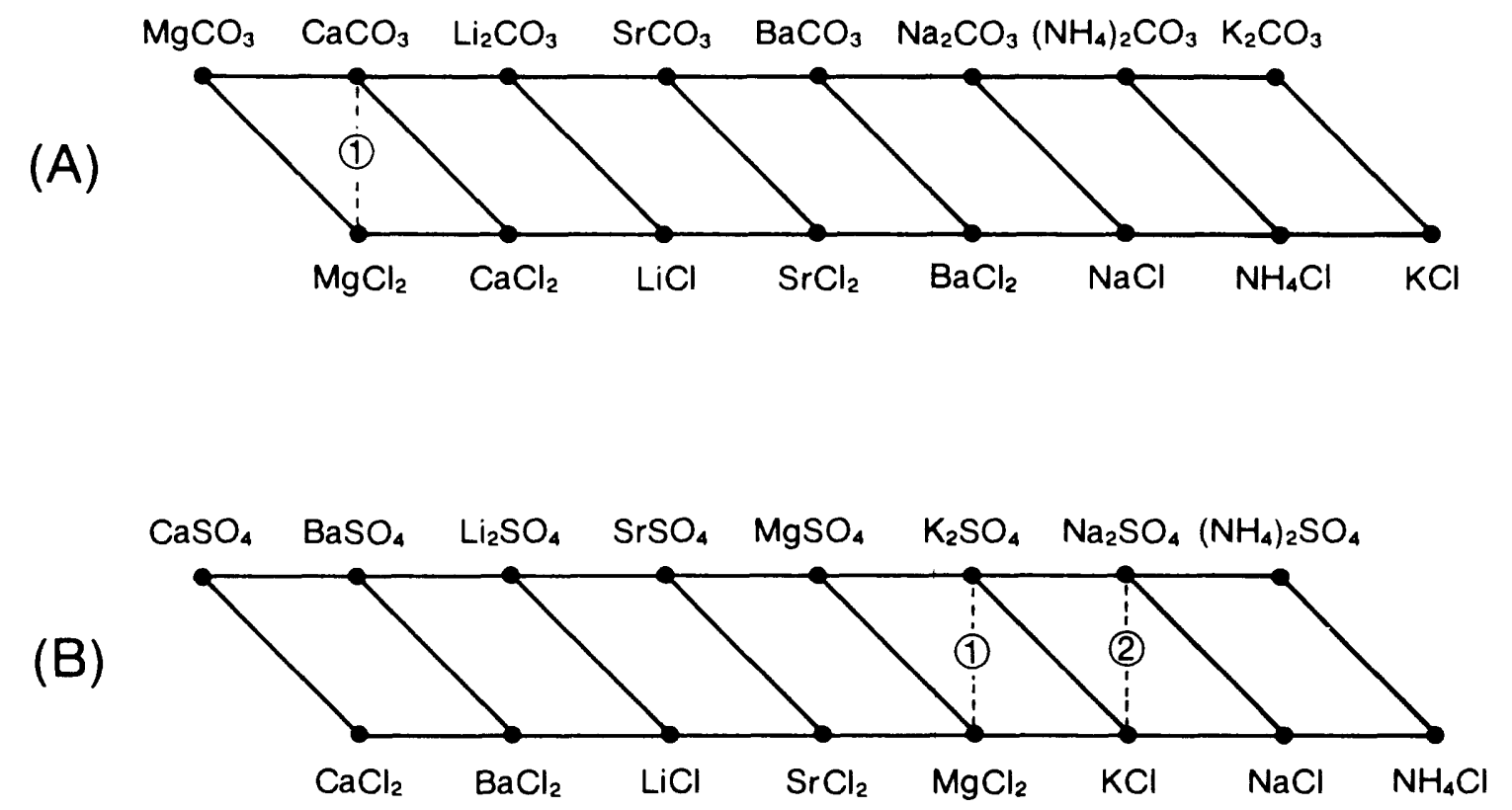

Figure V-9. Calculated relations among simple-salt components of normative salts with permissable associations at $25^{\circ} \mathrm{C}, 1$ bar pressure, and $10^{-3.5}$ bars $\mathrm{CO}_{2}$ partial pressure forming a path that proceeds only from left to right on each diagram: (A) (bi)carbonate and chloride salt components with bicarbonate components included with carbonate components and dashed segment 1 denoting stability of the dolomite-tachyhydrite pair; (B) sulfate and chloride salt components with dashed segment 1 denoting stability of the carnallitepolyhalite pair and dashed segment 2 denoting stability of the aphthitalitesylvite pair.

Normative inyoite is also similarly restricted but to Ca-rich norms; one or more of Ca-bearing chlorides and nitrates, and $\mathrm{Sr}$ and $\mathrm{Ba}$ chlorides and nitrates characteristically coexist with inyouite, and anhydrite is the only major-cation sulfate that is permitted in inyoite-bearing assemblages. Primary calcium borate mineraj.s are rare in continental evaporite deposits although colemanite and, to a lesser extent, inyoite and meyerhofferite are observed as secondary minerals in some lacustrine assemblages (Muessig, 1959; Bowser and Dickson, 1966); documented primary inyoite has only been described from a single continental deposit--Laguna Salinas, Peru (Muessig, 1958).

By far the dominant minerals in continental playa and thermal spring deposits are borax and ulexite; they are the normative borates that occur in norms of typical continental waters generally characterized by normative alkali-bearing sulfates and possibly (bi)carbonates. We have arbitrarily established the following criteria for their occurrence in normative 


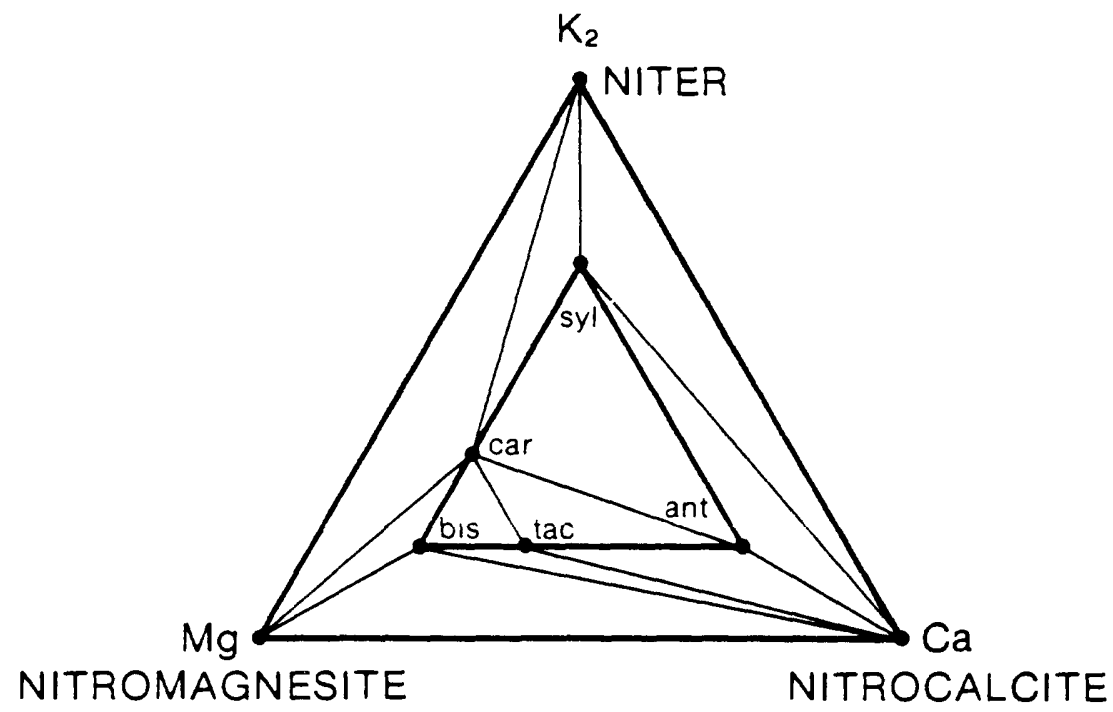

Figure V-10. Calculated phase relations among normative salts in the Ca$\mathrm{Mg}-\mathrm{K}-\mathrm{Cl}-\mathrm{NO}_{3}-\mathrm{H}_{2} \mathrm{O}$ system at $25^{\circ} \mathrm{C}$ and 1 bar pressure in nitrate-saturated assemblages looking down onto the $\mathrm{Cl}_{2}-\mathrm{K}_{2}-\mathrm{Ca}-\mathrm{Mg}$ tetrahedron with the $\mathrm{Cl}_{2}$ apex truncated along the $\mathrm{K}_{2} \mathrm{Cl}_{2}-\mathrm{CaCl}_{2}-\mathrm{MgCl}_{2}$ plane; salt abbreviations from table 2; halite occurs with all assemblages as the permissable sodium salt except for the prohibited niter-nitromagnesite-halite association that is replaced by the soda niter-carnalite pair.

assemblages: neither borax nor ulexite are permitted to coexist with any $\mathrm{Ca}$ and $\mathrm{Mg}$-bearing chloride and nitrate salts (inyoite and indirite occur in such assemblages); only borax coexists with any Na-bearing (bi)carbonate salt (pirssonite, trona, burkeite) or Na-bearing alkali sulfate salt (thenardite/mirabilite, aphthitalite); and only ulexite occurs with anhydrite, kieserite/epsomite, and the polyhalite-glauberite pair unless either inyoite or indirite is the proper borate salt (table 6 ).

These criteria for the occurrence of borax and ulexite appear, in general, to be compatable with borate mineral occurrences in Quaternary playa and thermal spring deposits. Other than searlesite (a sodium borosilicate), the only borate minerals in the Searles Lake evaporites are borax and its less hydrated analog, tincalconite associated with one or more of gaylussite, pirssonite, trona, nahcolite, thenardite, and mirabilite; Ca-bearing borates are not observed (Smith and Haines, 1964). In the numerous and extensive playa and thermal spring deposits in the high Andes of South America (Muessig, 1958, 1959, 1966; Rettig and others, 1980), on the other hand, ulexite is the dominant primary borate, borax is infrequently abundant, and primary inyoite 

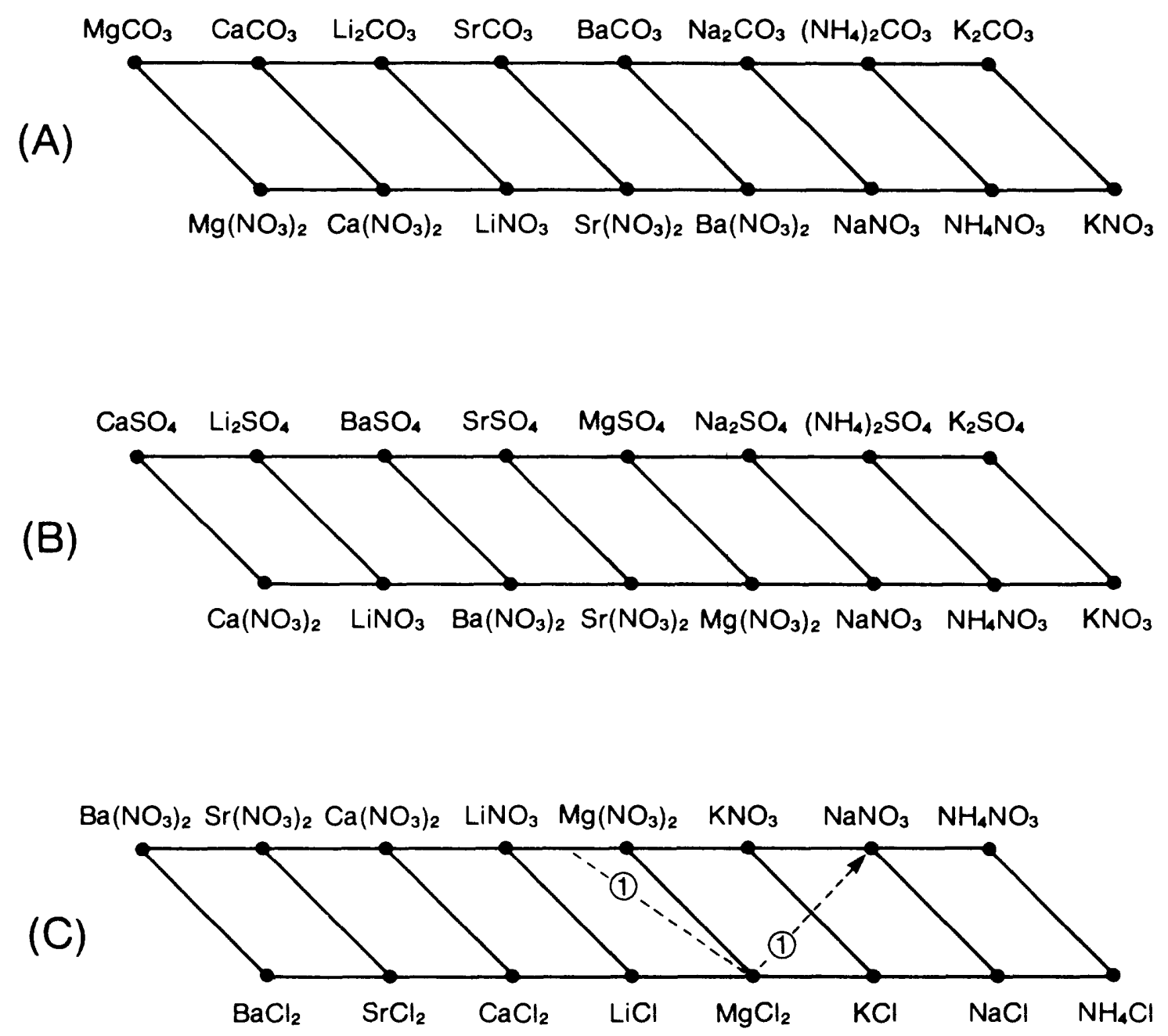

Figure V-11. Calculated relations among simple-salt components of normative salts at $25^{\circ} \mathrm{C}, 1$ bar pressure, and $10^{-3.5}$ bars $\mathrm{CO}_{2}$ partial pressure with permissable associations forming a path that proceeds only from left to right on the diagram: (A) (bi)carbonate and nitrate salt components with bicabonate components included with carbonate components; (B) sulfate-nitrate salt components; and (C) nitrate-chloride salt components with dashed segment 1 denoting stability of the soda niter-carnallite pair.

and indirite are rarely observed; a very common association in many of these deposits is the ulexite-gypsum pair.

We recognize that the mineral associations assigned to SNORM are far more rigorous and specific than those observed in natural associations; however, in order for SNORM to define a single normative assemblage for a boron-bearing water, comprehensive restrictions (table 6) must be imposed. We feel our 
assignments are not in conflict with relations in naturally occurring assemblages, but, at the same time, they are subject to modifications as more definitve observations become available or themodynamic data for additional borate mineral salts are determined.

Ca-Mg-Na phosphate and fluoride salts

Fig. V-12 is constructed with $\mathrm{Na}_{3} \mathrm{PO}_{4}$ and $\mathrm{Mg}_{3}\left(\mathrm{PO}_{4}\right)_{2}$ as nonmineral salts. We exclude the former from all assemblages that contain suffcient $\mathrm{Ca}$ and $\mathrm{Mg}$ to form their respective phosphates, and permit the latter only if insufficient fluoride exists to form wagnerite. Because the free energy of wagnerite is unknown, we have assumed stablitty of the fluorapatite-sellatte pair and prohibited the wagnerite-fluorite pair; sellaite is more widespread than wagnerite in marine evaporites and apparently coexists with fluorapatite (Kühn, 1968; Braitsch, 1971, Sonnenfeld, 1984). Fortunately standard free engergies of the $\mathrm{Ca}-\mathrm{Mg}-\mathrm{Na}$ fluorides are available (table 4) that allow determination of their equilibria ( $f i g \cdot V-13$ ), and the restriction of LiF and villiaumite to alkali-bearing (bi)carbonate associations with LiF-trona being stable with respect to villiaumite- $\mathrm{Li}_{2} \mathrm{CO}_{3}$. Phosphate and fluorphosphate normative mineral assignments are assumed to have restrictions that parallel

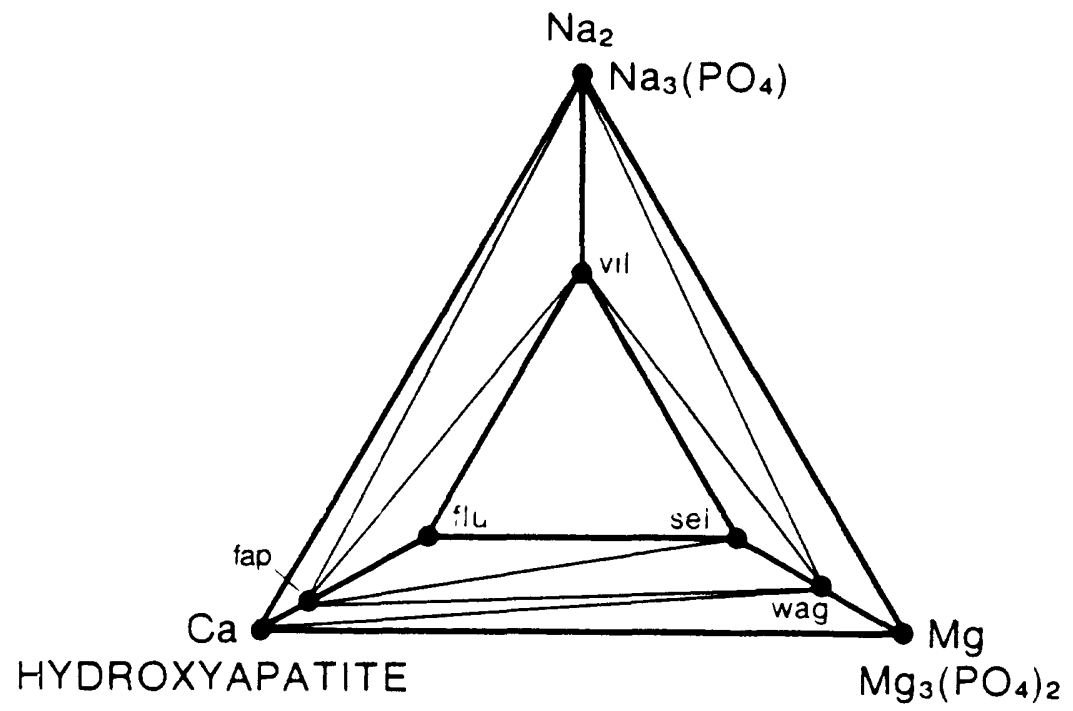

Figure V-12. Suggested phase relations among normative salts in the Ca$\mathrm{Mg}-\mathrm{Na}-\mathrm{PO}_{4}-\mathrm{F}-\mathrm{H}_{2} \mathrm{O}$ system at $25^{\circ} \mathrm{C}$ and 1 bar pressure projected into the phosphate and water saturated $\mathrm{F}_{2}-\mathrm{Na}{ }_{2}-\mathrm{Ca}-\mathrm{Mg}$ tetrahedron with the $\mathrm{F}_{2}$ apex truncated along the $\mathrm{Na}_{2} \mathrm{~F}_{2}-\mathrm{CaF}_{2}-\mathrm{MgF}_{2}$ plane. Salt mineral abbreviations from table 2; hydroxyapatite plotted as $\mathrm{Ca}_{3}\left(\mathrm{PO}_{4}\right)_{2}$. 
(A)

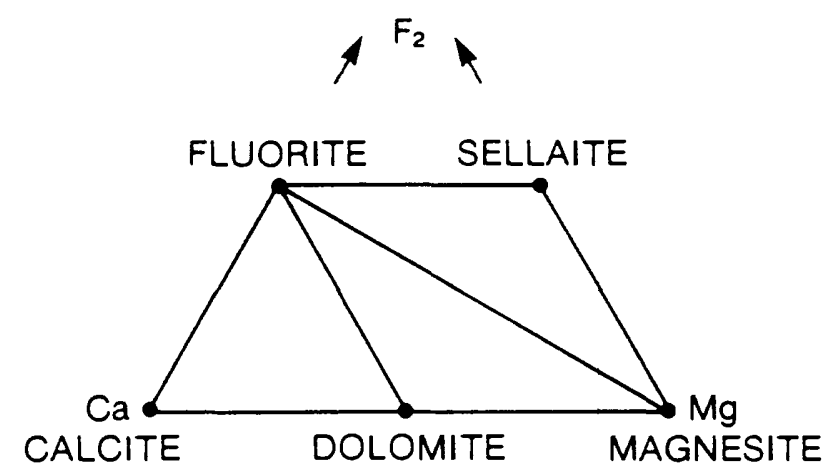

(B)
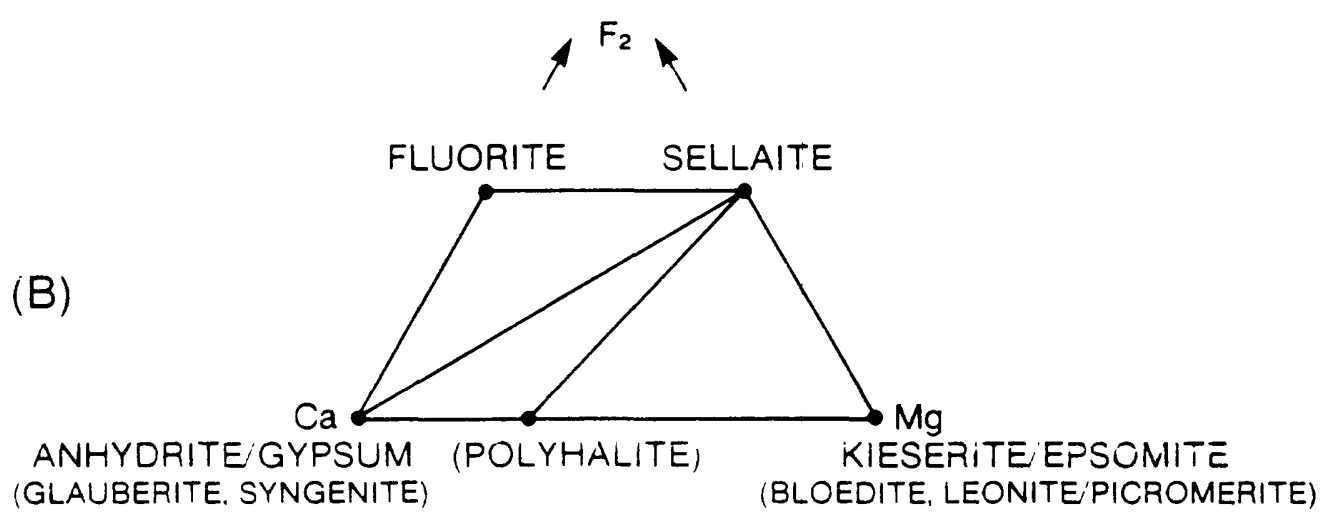

(C)

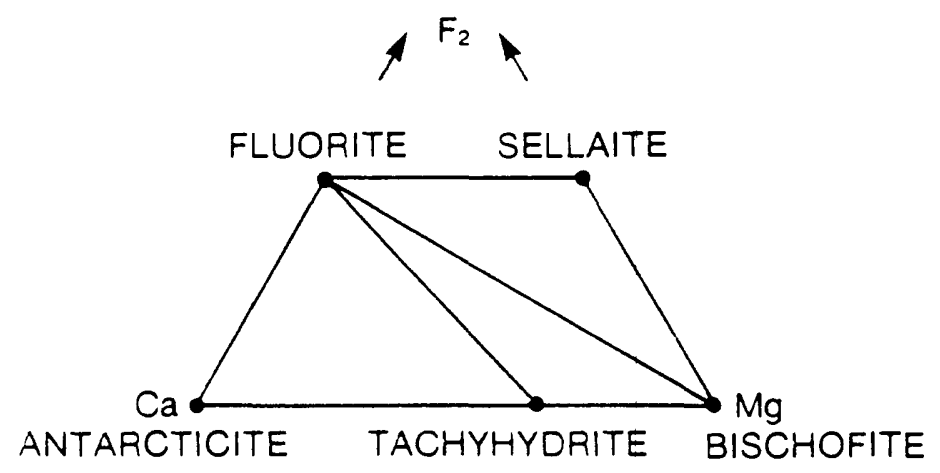

Figure V-13. Calculated phase relations among Ca-Mg fluoride salts and coexisting carbonate, sulfate, and chloride salts at $25^{\circ} \mathrm{C}$ and 1 bar pressure projected onto the $\mathrm{Ca}-\mathrm{Mg}-\mathrm{F}_{2}$ triangle and saturated with the major anion and water: (A) $\mathrm{Ca}-\mathrm{Mg}-\mathrm{CO}_{3}-\mathrm{F}_{2}-\mathrm{H}_{2} \mathrm{O}$ system at $\mathrm{CO}_{2}$ partial pressure of $10^{-3.5}$ bars; (B) $\mathrm{Ca}-\mathrm{Mg}-\mathrm{SO}_{4}-\mathrm{F}_{2}-\mathrm{H}_{2} \mathrm{O}$ system; and (C) $\mathrm{Ca}-\mathrm{Mg}-\mathrm{Cl}_{2}-\mathrm{F}_{2}-\mathrm{H}_{2} \mathrm{O}$ system. Mineral compositions in parentheses lie outside of the designated system; Ca-Mg phosphates and fluorphosphates suggested to have identical relations with major anion salts as the fluorides. 


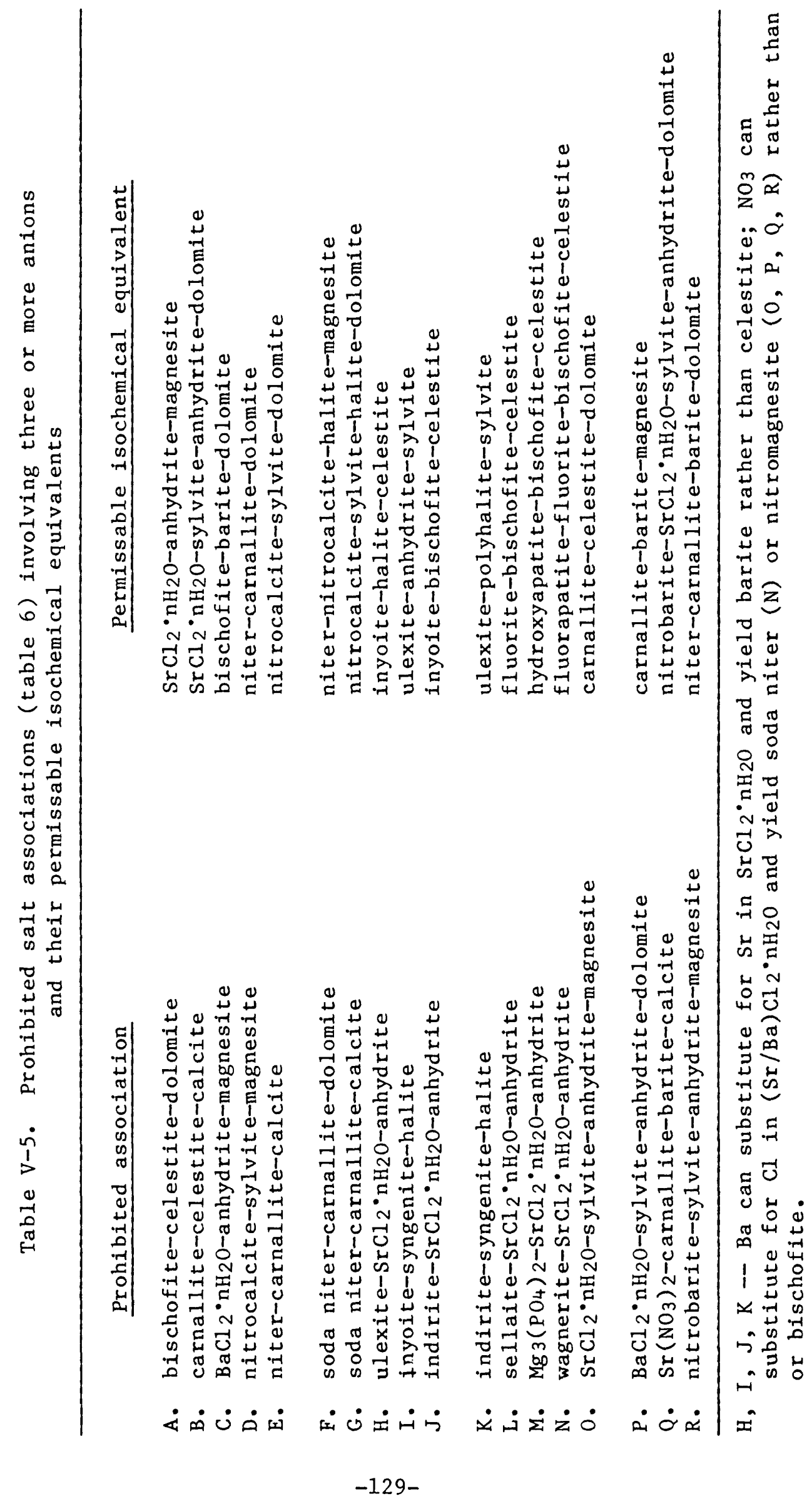


the fluorides, except, whenever possible, prohibiting $\mathrm{Na}_{3} \mathrm{PO}_{4}$ in favor of the apatite-trona and wagnerite-trona pairs.

\section{Equilibria involving three anions}

Many of the three and four salt assoclation in table 6 contain three or more anions; each is listed in table V-5 along with it isochemically equivalent permissible association. Each involves a minor solute and, to a large extent, each is an extension of a related two-anion association.

For example, the tachyhydrite-celestite association is prohibited (table 6) In favor of the stable bischofite-anhydrite- $\mathrm{SrCl}_{2} \cdot{ }^{\cdot} \mathrm{H}_{2} \mathrm{O}$ association (fig. $\mathrm{V}-9)$. If there is insufficient tachyhydrite to convert all celestite to $\mathrm{SrCl}_{2} \cdot 2 \mathrm{H}_{2} \mathrm{O}$, the bishofite and celestite can interact with dolomite (the stable carbonate with tachyhydrite) to convert more celestite to $\mathrm{SrCL}_{2} \cdot \mathrm{H}_{2} \mathrm{O}$ and yield anyhdrite and magnesite (A in table $\mathrm{V}-5$ ). However, the parallel sequence of associations with barfum salts rather than strontium, although again prohibiting the barite-tachyhydrite association (table 6 and fig. V-9), permits the bischofite-barite-dolomite association and prohibits the $\mathrm{BaCl}_{2} \cdot 2 \mathrm{H}_{2} \mathrm{O}$-anhydrite-magnesite association ( $\mathrm{C}$ in table $\mathrm{V}-5$ ). 
COMPOSITION OF SEAWATER

Riley \& Chester (1971); WedepohI (1971)

Sea water

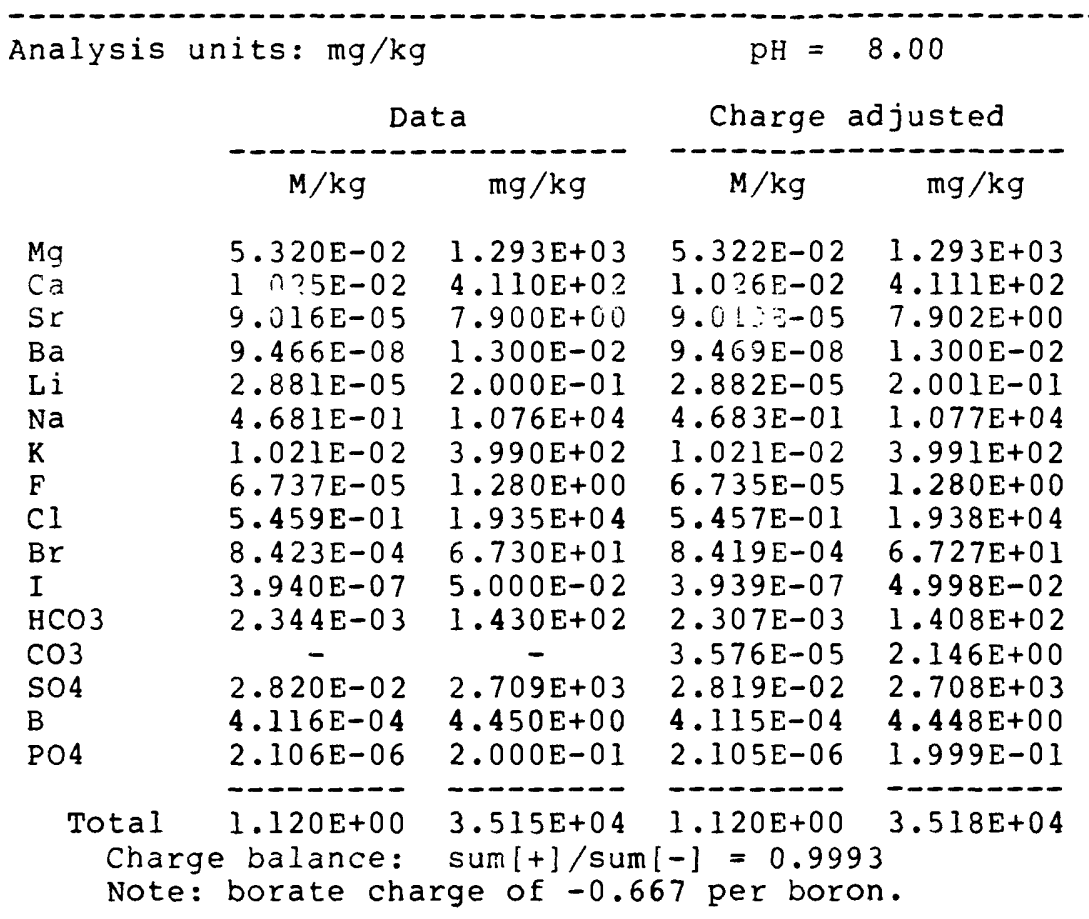

density $=1.030$

Mole ratio

$\mathrm{Ca} / \mathrm{Mg} 1.93 \mathrm{E}-0 \mathrm{I}$

$\mathrm{K} / \mathrm{Na} 2.18 \mathrm{E}-02$

$\mathrm{Mg}+\mathrm{Ca} / \mathrm{Na}+\mathrm{K} 1.33 \mathrm{E}-0 \mathrm{I}$

alk./hal. 8.75E-0I

$\mathrm{HCO} 3 / \mathrm{Cl} 4.29 \mathrm{E}-03$

$\mathrm{SO} 4 / \mathrm{Cl} 5.17 \mathrm{E}-02$

$\mathrm{E} / \mathrm{Cl} 1.23 \mathrm{E}-04$

$\mathrm{Br} / \mathrm{Cl} 1.54 \mathrm{E}-03$

$\mathrm{I} / \mathrm{Cl} 7.22 \mathrm{E}-07$

$\mathrm{PO} 4 / \mathrm{Cl} 3.86 \mathrm{E}-06$

$\mathrm{B} / \mathrm{Cl} 7.54 \mathrm{E}-04$

$\mathrm{Mg} / \mathrm{Cl} 9.75 \mathrm{E}-02$

$\mathrm{Ca} / \mathrm{Cl} 1.88 \mathrm{E}-02$

$\mathrm{Sr} / \mathrm{Cl} 1.65 \mathrm{E}-04$

$\mathrm{Ba} / \mathrm{Cl} 1.73 \mathrm{E}-07$

$\mathrm{Li} / \mathrm{Cl} 5.28 \mathrm{E}-05$

$\mathrm{Na} / \mathrm{Cl} 8.58 \mathrm{E}-01$

$\mathrm{K} / \mathrm{Cl} 1.87 \mathrm{E}-02$

Normative salt assemblage

\begin{tabular}{|c|c|c|c|c|c|}
\hline & & $\mathrm{mol} / \mathrm{kg}$ & $8(\operatorname{mol})$ & $q(w t)$ & $8(a n-w t)$ \\
\hline $\begin{array}{l}\text { Halite } \\
\text { Bischofite } \\
\text { Carnallite } \\
\text { Kieserite } \\
\text { Anhydrite } \\
\text { Magnesite } \\
\text { Indirite } \\
\text { Celestite } \\
\text { Sellaite } \\
\quad \text { - } \\
\text { Wagnerite } \\
\text { Barite }\end{array}$ & $\begin{array}{l}\mathrm{NaCl} \\
\mathrm{MgCl} 2.6 \mathrm{H} 2 \mathrm{O} \\
\mathrm{KMgCl} 3.6 \mathrm{H} 2 \mathrm{O} \\
\mathrm{MgSO} 4 \cdot \mathrm{H} 2 \mathrm{O} \\
\mathrm{CaSO} 4 \\
\mathrm{MgCO} 3 \\
\mathrm{Mg} 2 \mathrm{~B} 6 \mathrm{O} 11.15 \mathrm{H} 2 \mathrm{O} \\
\mathrm{SrSO} 4 \\
\mathrm{MgF2} \\
\mathrm{Li} 2 \mathrm{SO} 4 . \mathrm{H} 2 \mathrm{O} \\
\mathrm{Mg} 2\left(\mathrm{PO}_{4}\right) \mathrm{F} \\
\mathrm{BaSO} 4\end{array}$ & $\begin{array}{l}4.683 E-01 \\
2.381 E-02 \\
1.021 E-02 \\
1.783 E-02 \\
1.026 E-02 \\
1.189 E-03 \\
6.858 E-05 \\
9.019 E-05 \\
3.262 E-05 \\
1.441 E-05 \\
2.105 E-06 \\
9.469 E-08\end{array}$ & $\begin{array}{r}88.05749 \\
4.47838 \\
1.91966 \\
3.35278 \\
1.92896 \\
0.22364 \\
0.01290 \\
0.01696 \\
0.00613 \\
0.00271 \\
0.00040 \\
0.00002\end{array}$ & $\begin{array}{r}70.06436 \\
12.38930 \\
7.25858 \\
6.30902 \\
3.57101 \\
0.25641 \\
0.09815 \\
0.04236 \\
0.00520 \\
0.00472 \\
0.00088 \\
0.00006\end{array}$ & $\begin{array}{r}78.08681 \\
6.47149 \\
4.94495 \\
6.11600 \\
3.97990 \\
0.28577 \\
0.05658 \\
0.04721 \\
0.00579 \\
0.00452 \\
0.00098 \\
0.00006\end{array}$ \\
\hline & Total & $5.318 E-01$ & 100.00000 & 100.00001 & 100.00000 \\
\hline
\end{tabular}

Simple salts

\begin{tabular}{|c|c|c|}
\hline & \multicolumn{2}{|c|}{ percent } \\
\hline & mole & weight \\
\hline $\mathrm{Na} 2 \mathrm{Cl} 2$ & 77.39011 & 78.17679 \\
\hline $\mathrm{K} 2 \mathrm{Cl} 2$ & 1.68711 & 2.17345 \\
\hline $\mathrm{MgCl} 2$ & 11.24595 & 9.25615 \\
\hline CaSO 4 & 3.39056 & 3.98448 \\
\hline $\mathrm{MgSO} 4$ & 5.89323 & 6.12305 \\
\hline $\mathrm{MgCO} 3$ & 0.39310 & 0.28610 \\
\hline Total & 100.0 & 99.99997 \\
\hline
\end{tabular}

NOTES: 1. Solute mole ratios calculated from initial analytical data; alkali/halide ratio excludes lithium and fluoride.

2. $\mathrm{g} / \mathrm{kgW}=$ grams per kilogram water.

3. Mole percent $B r$ in $C l$ sites $=0.1541$; I in $C l$ sites $=0.000072$.

Sample 1 in file: ocean No simple-salt file created. 4-28-1986

\section{SUMMARY OF REQUIRED CALCULATIONS}

\section{COMPOSITION OF SEAWATER}

1. Sea water Salt-pair tests $=117667$
Riley \& Chester (1971); Wedepohl (1971) Assemblage tests $=1954 \quad$ Inversions $=851$ 

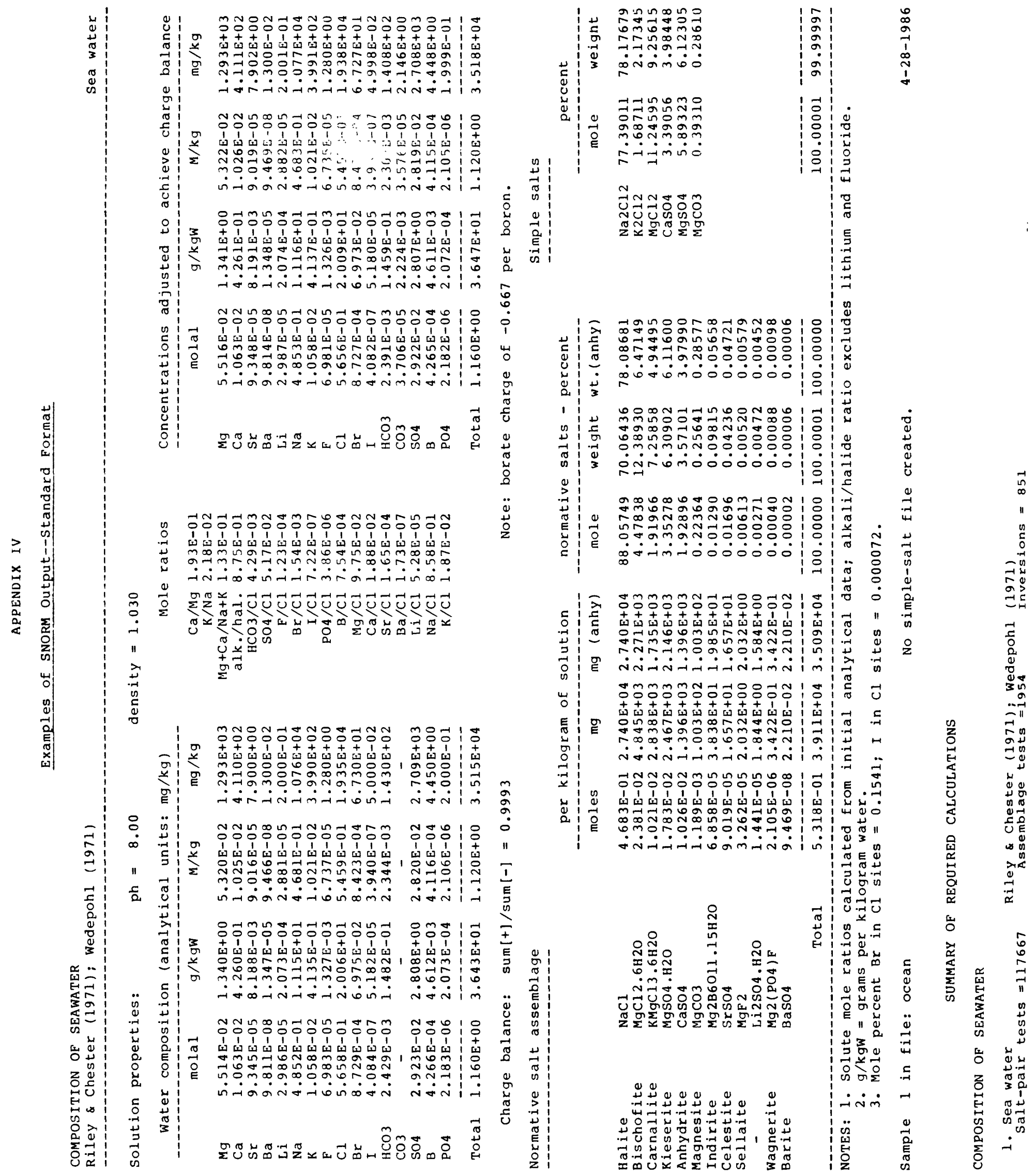


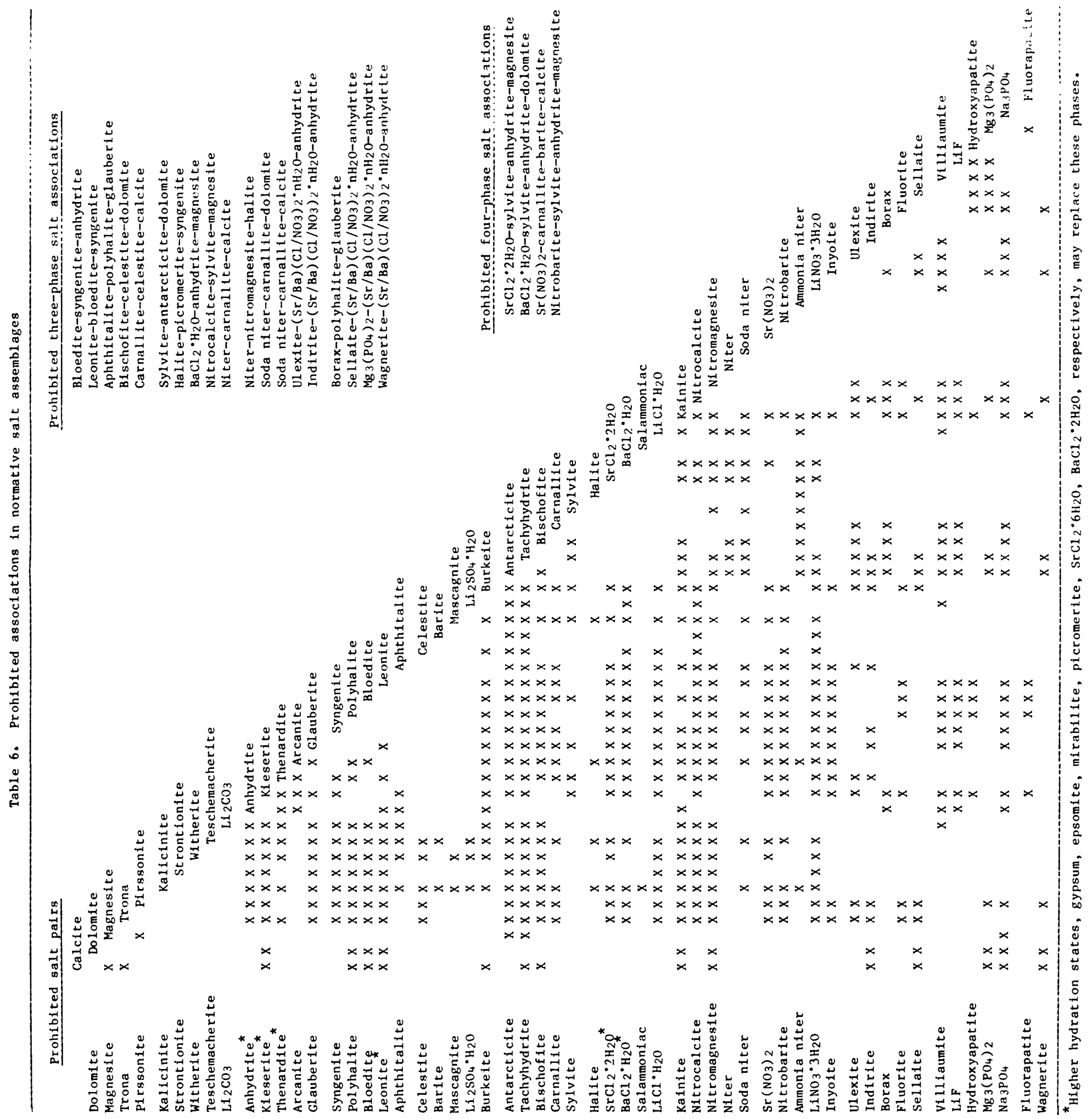




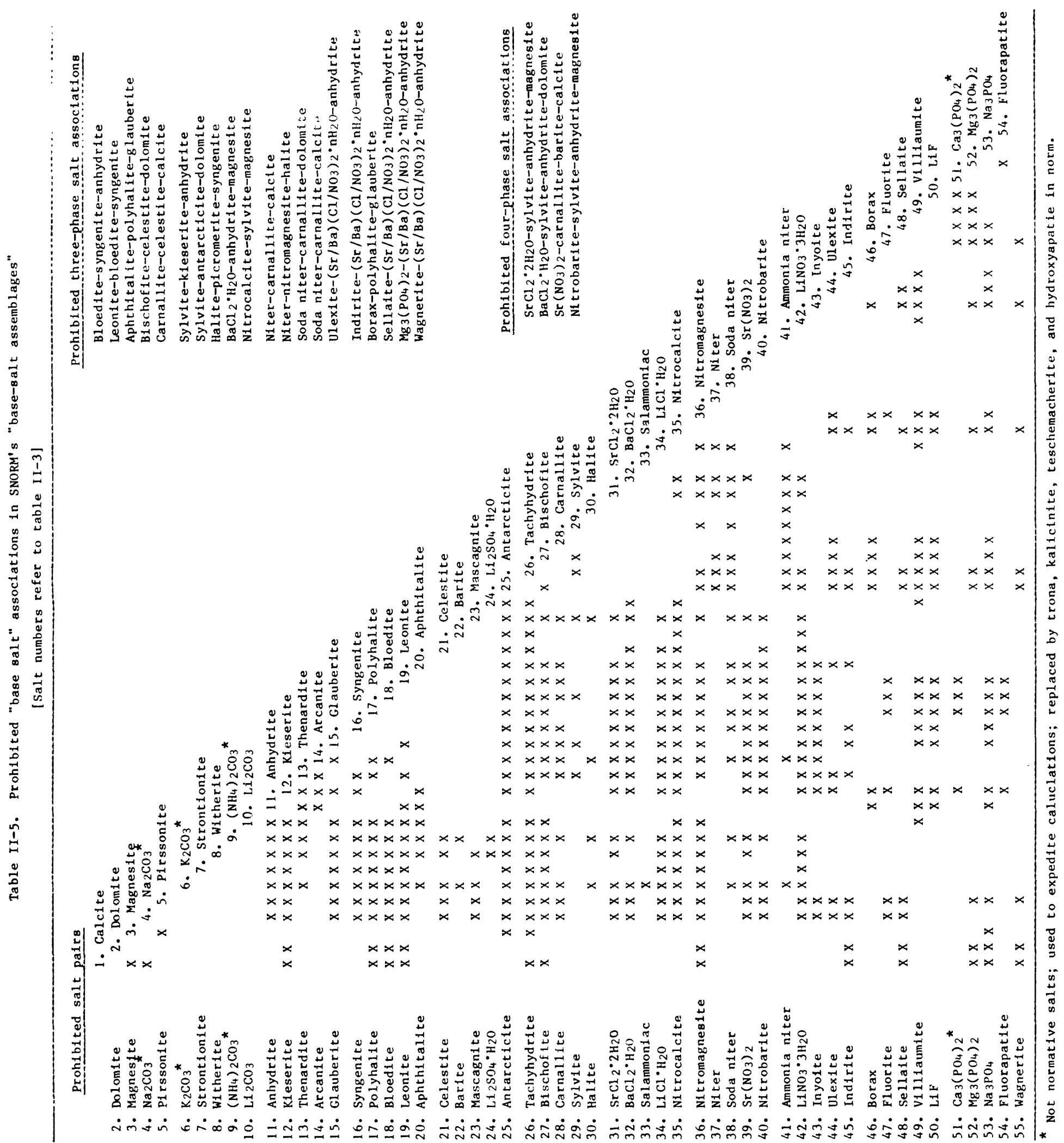

